Florida International University FIU Digital Commons

FIU Electronic Theses and Dissertations

University Graduate School

3-23-2011

\title{
A Quantitative Approach to the Organizational Design Problem
}

Jesus A. Mena

Florida International University, alonso.mena@itesm.mx

DOI: $10.25148 /$ etd.FI1 1050610

Follow this and additional works at: https://digitalcommons.fiu.edu/etd

\section{Recommended Citation}

Mena, Jesus A., "A Quantitative Approach to the Organizational Design Problem" (2011). FIU Electronic Theses and Dissertations. 413. https://digitalcommons.fiu.edu/etd/413

This work is brought to you for free and open access by the University Graduate School at FIU Digital Commons. It has been accepted for inclusion in FIU Electronic Theses and Dissertations by an authorized administrator of FIU Digital Commons. For more information, please contact dcc@fiu.edu. 


\section{FLORIDA INTERNATIONAL UNIVERSITY \\ Miami, Florida}

\section{A QUANTITATIVE APPROACH TO THE ORGANIZATIONAL DESIGN PROBLEM}

A dissertation submitted in partial fulfillment of the

requirements for the degree of

DOCTOR OF PHILOSOPHY

in

INDUSTRIAL AND SYSTEMS ENGINEERING

by

Jesús A. Mena

2011 
To: Dean Amir Mirmiran

College of Engineering and Computing

This dissertation, written by Jesús A. Mena, and entitled A Quantitative Approach to the Organizational Design Problem, having been approved in respect to style and intellectual content, is referred to you for judgment.

We have read this dissertation and recommend that it be approved.

Irtishad Ahmad

Ronald Giachetti

Shih-Ming Lee

Chin-Sheng Chen, Major Professor

Date of Defense: March 23, 2011

The dissertation of Jesús A. Mena is approved.

Dean Amir Mirmiran

College of Engineering and Computing

Interim Dean Kevin O'Shea

University Graduate School

Florida International University, 2011 


\section{DEDICATION}

This thesis is dedicated to my mother and sister. There is no doubt in my mind that without their love, patience, understating, and support, the completion of this work would not have been possible. 


\section{ACKNOWLEDGMENTS}

I wish to thank the members of my committee for their support and patience. I would like to thank my major professor, Dr. Chin-Sheng Chen, who from the beginning, has confidence in my abilities to not only complete a degree, but complete it with excellence.

I would like to thank Amira Diaz, from the Engineering Dean's office, because working on my dissertation as a student overseas was a challenge. Every time I had a problem I could always count on her for help. For the same reason, I would like to thank my friend, Dr. Desiree Tejada. 


\begin{abstract}
OF THE DISSERTATION
A QUANTITATIVE APPROACH TO THE ORGANIZATIONAL DESIGN PROBLEM
\end{abstract}

by

Jesús A. Mena

Florida International University, 2011

Miami, Florida

Professor Chin-Sheng Chen, Major Professor

The span of control is the most discussed single concept in classical and modern management theory. In specifying conditions for organizational effectiveness, the span of control has generally been regarded as a critical factor. Existing research work has focused mainly on qualitative methods to analyze this concept, for example heuristic rules based on experiences and/or intuition.

This research takes a quantitative approach to this problem and formulates it as a binary integer model, which is used as a tool to study the organizational design issue. This model considers a range of requirements affecting management and supervision of a given set of jobs in a company. These decision variables include allocation of jobs to workers, considering complexity and compatibility of each job with respect to workers, and the requirement of management for planning, execution, training, and control activities in a hierarchical organization. The objective of the model is minimal operations cost, which is the sum of supervision costs at each level of the hierarchy, and the costs of workers assigned to jobs. 
The model is intended for application in the make-to-order industries as a design tool. It could also be applied to make-to-stock companies as an evaluation tool, to assess the optimality of their current organizational structure.

Extensive experiments were conducted to validate the model, to study its behavior, and to evaluate the impact of changing parameters with practical problems. This research proposes a meta-heuristic approach to solving large-size problems, based on the concept of greedy algorithms and the Meta-RaPS algorithm. The proposed heuristic was evaluated with two measures of performance: solution quality and computational speed. The quality is assessed by comparing the obtained objective function value to the one achieved by the optimal solution. The computational efficiency is assessed by comparing the computer time used by the proposed heuristic to the time taken by a commercial software system. Test results show the proposed heuristic procedure generates good solutions in a time-efficient manner. 


\section{TABLE OF CONTENTS}

CHAPTER

PAGE

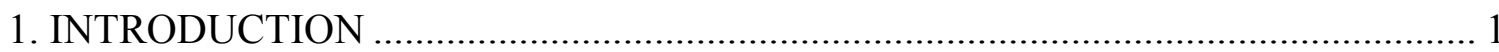

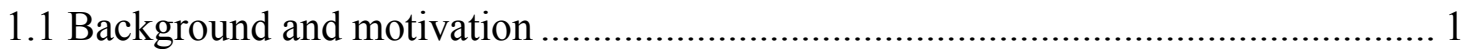

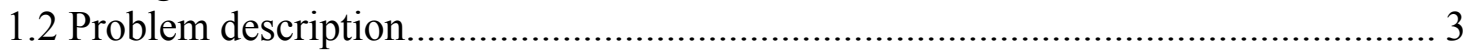

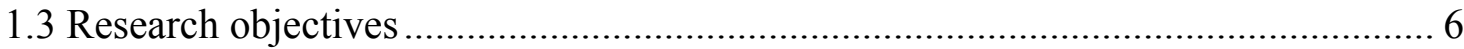

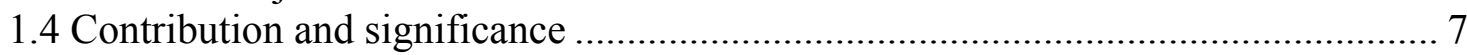

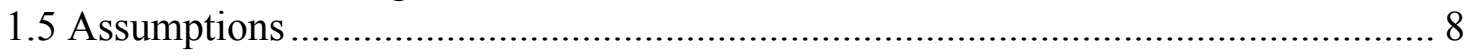

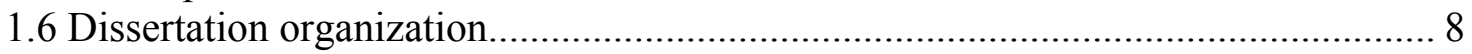

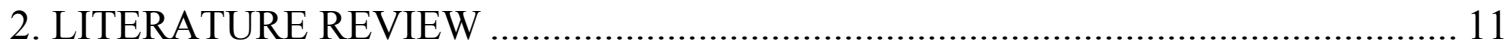

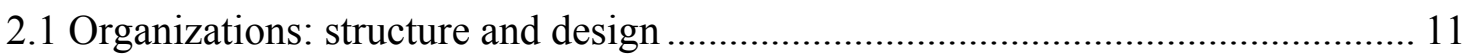

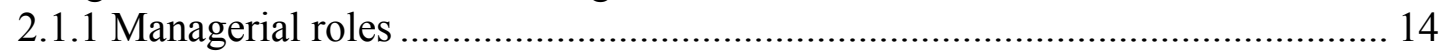

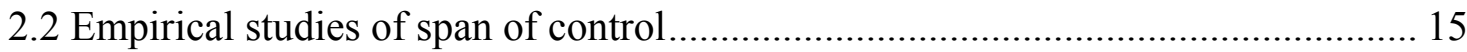

2.4 Heuristic and meta-heuristics methods ............................................................ 22

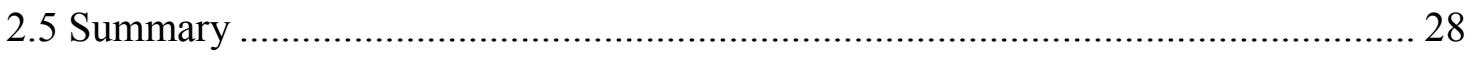

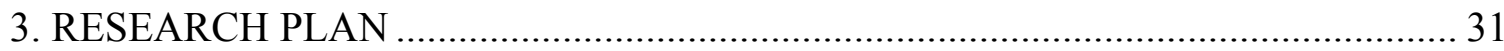

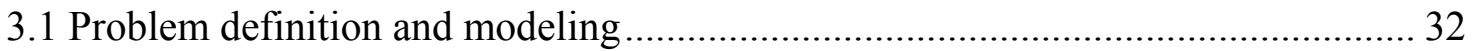

3.2 Valuation of coefficients affecting modeling factors ........................................... 35

3.3 Proposed solution approach ........................................................................... 37

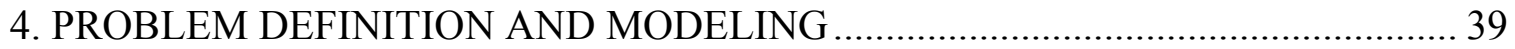

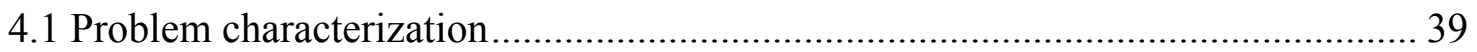

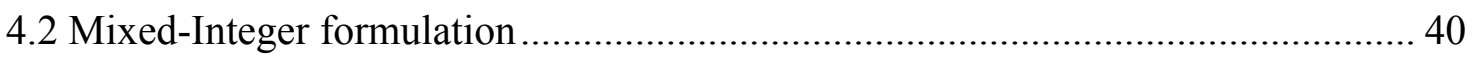

4.3 Computational experiments................................................................................. 42

4.3.1 Eight-job problem and four stations (Case one, Section one) ……………...... 43

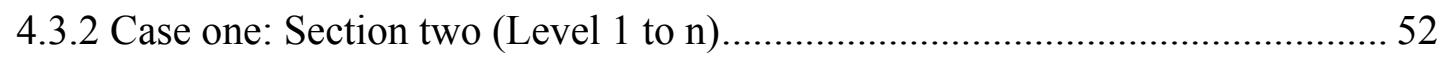

4.3.3 Limit size problem for a comercial solver (Case two) …………………......... 57

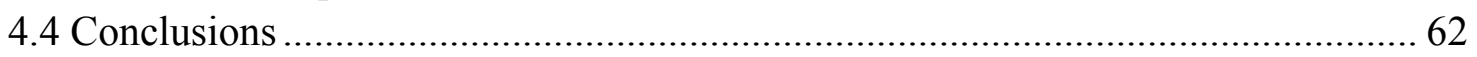

5. VALUATION OF COEFFICIENTS AFFECTING MODELING FACTORS.............63

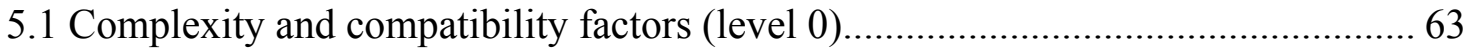

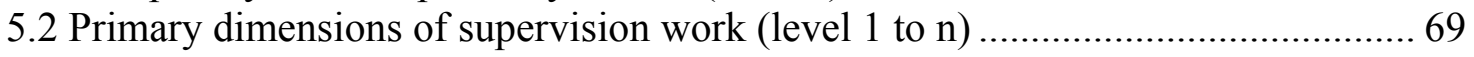

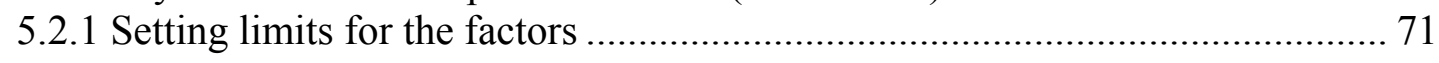

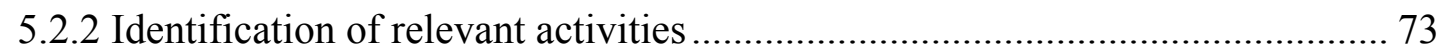

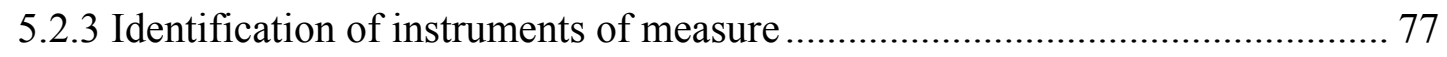

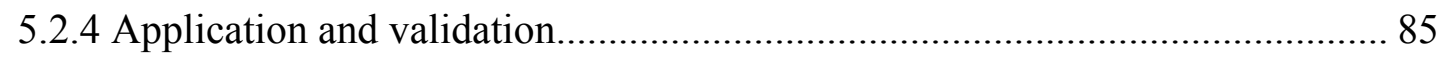

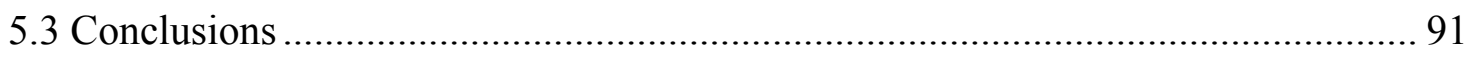

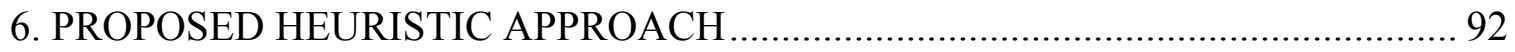

6.1 Introduction of the proposed heuristic approach.................................................. 92 


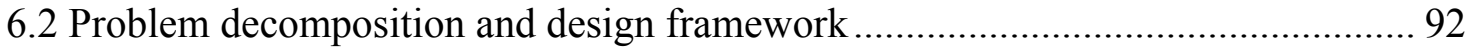

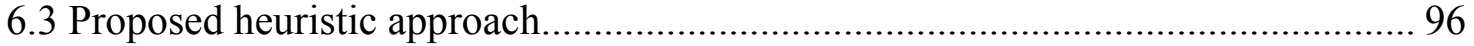

6.5 Solution improvement by a meta-heuristic (Meta-RaPS) ................................... 106

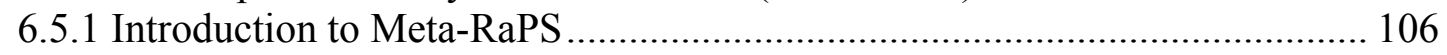

6.5.2. Modify priority rules using randomness.................................................... 107

6.5.2 Composition of the "next available task" ................................................. 110

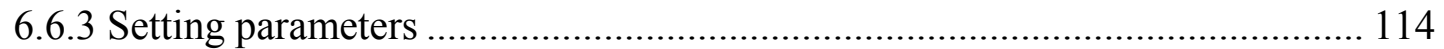

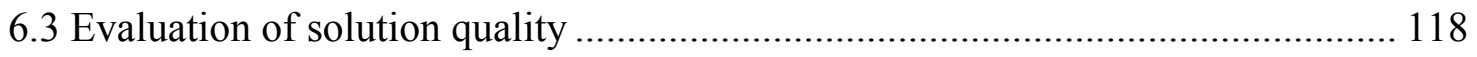

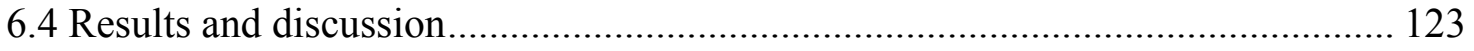

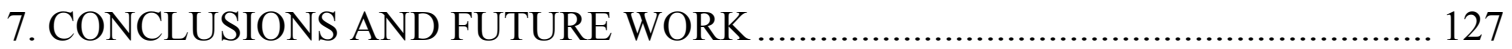

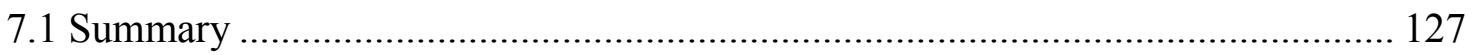

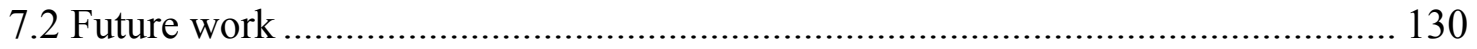

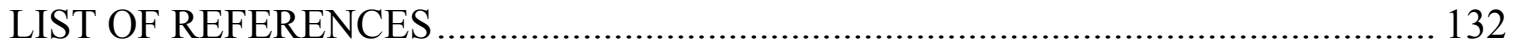

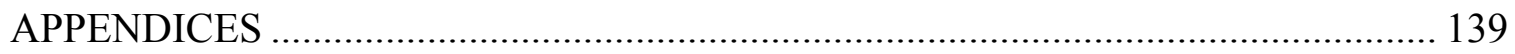

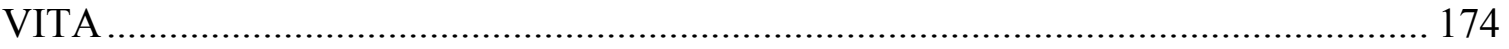




\section{LIST OF TABLES}

TABLE

PAGE

Table 1-1 Data for six-job problem and four stations ................................................ 6

Table 2-1 Summary of empirical studies of $\operatorname{span}$ of control......................................... 17

Table 2-2 Mathematical approaches of span of control............................................ 22

Table 2-3 Meta-heurisitics for solving combinatorial problems.................................. 27

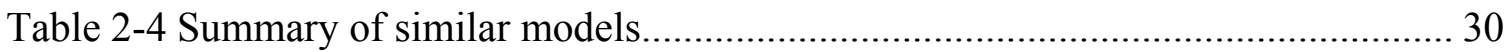

Table 4-1 Problem data of eight jobs and four stations ........................................... 44

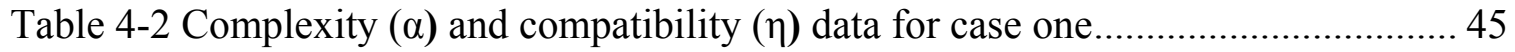

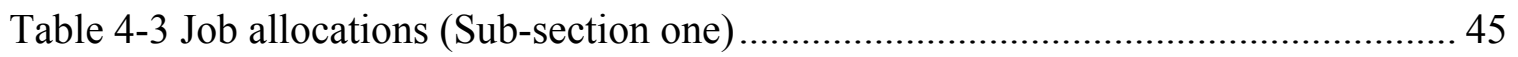

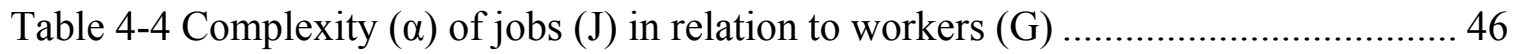

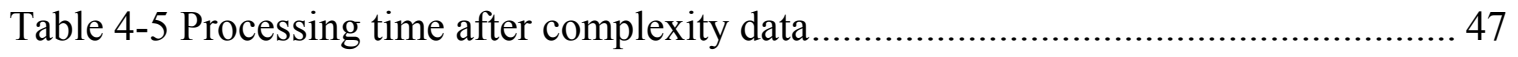

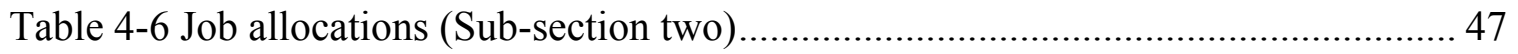

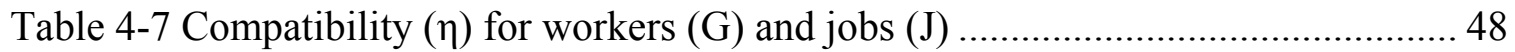

Table 4-8 Processing time after compatibility data .............................................. 49

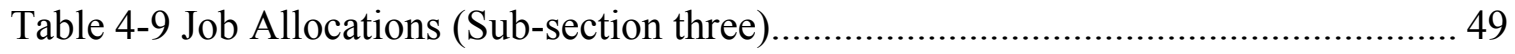

Table 4-10 Job Allocations (Sub-sections one, two and three) ................................... 51

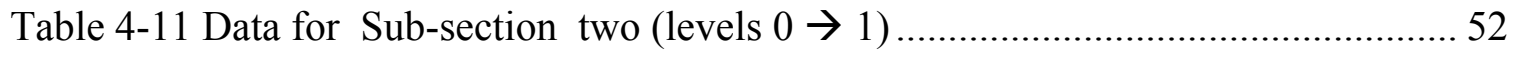

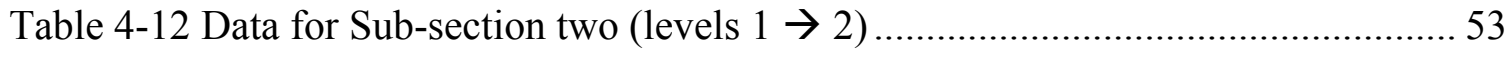

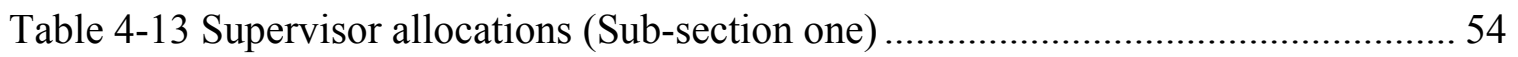

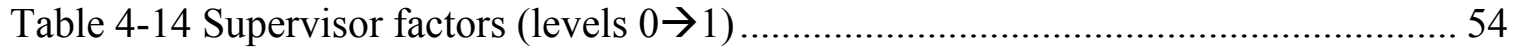

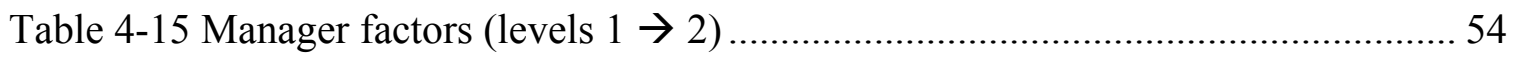

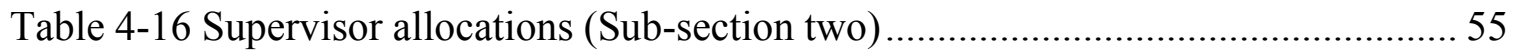




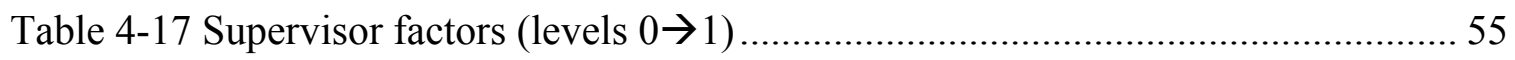

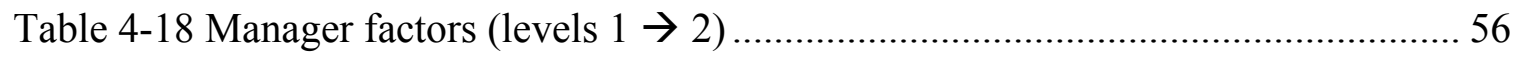

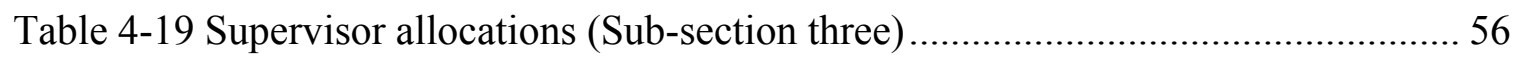

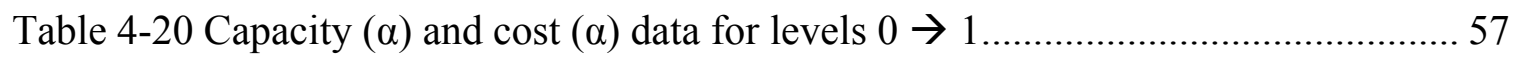

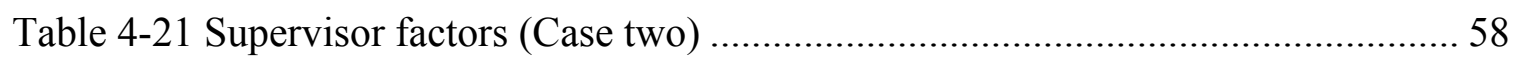

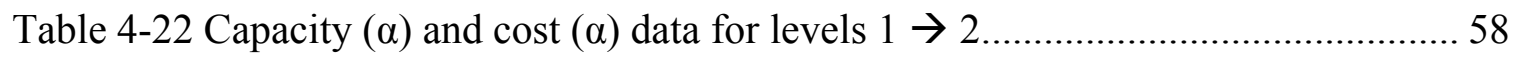

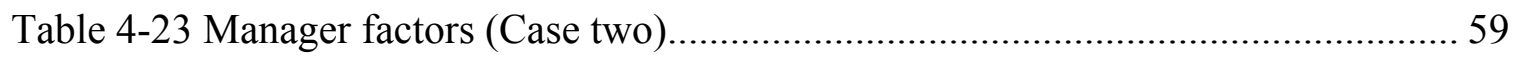

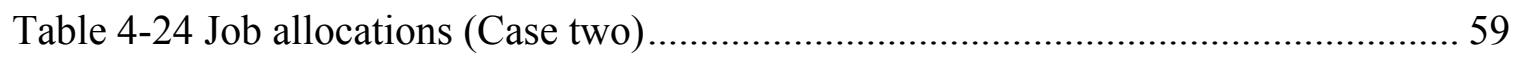

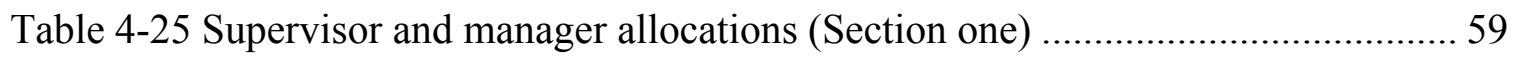

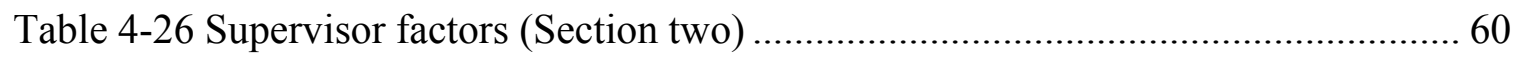

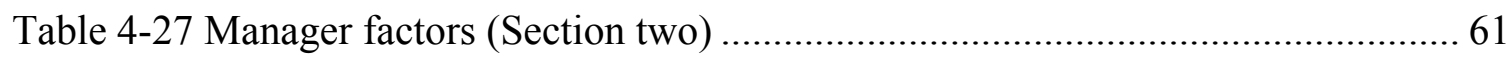

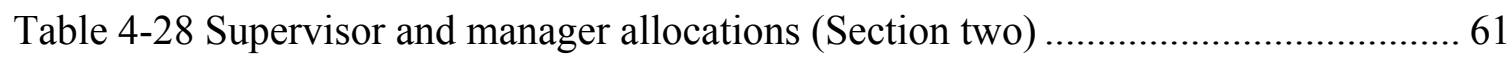

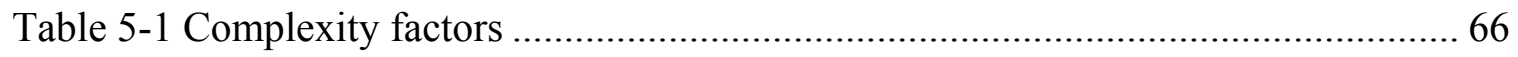

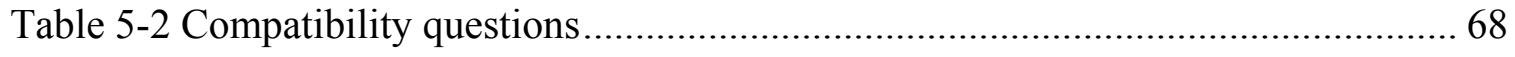

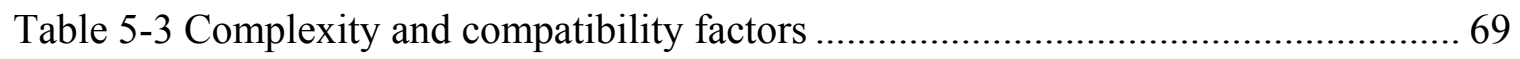

Tabla 5-4 Relevant activities in supervisor factors ............................................. 74

Table 5-5 Instruments for measure of each factor .............................................. 77

Table 5-6 Instruments used for the planning factor ............................................. 79

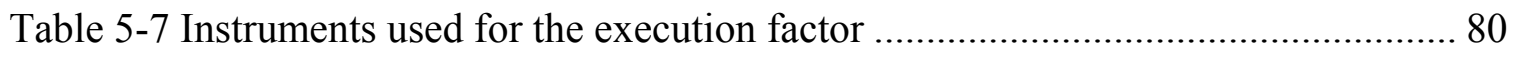

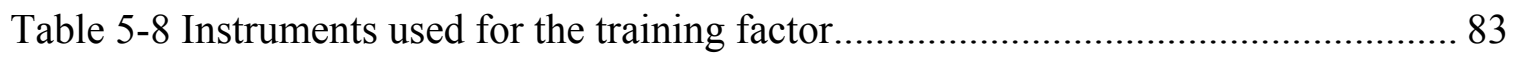

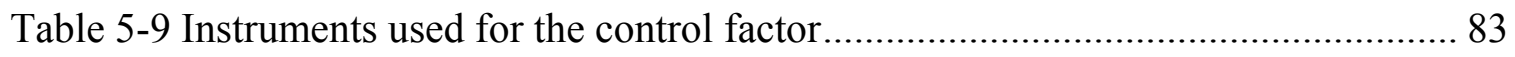

Table 5-10 Level of importance of primary dimensions of supervision work ............... 85

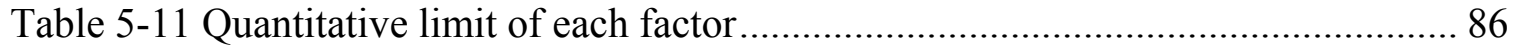


Table 5-12 Evaluation of primary dimensions of supervision work............................ 87

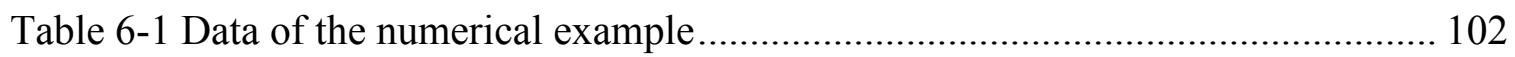

Table 6-2 Processing time with complexity and compatibility factors........................ 103

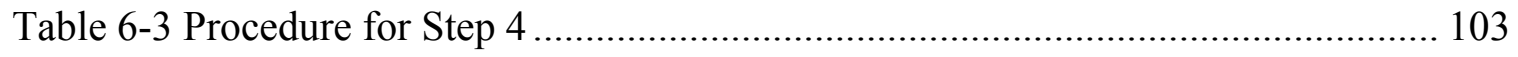

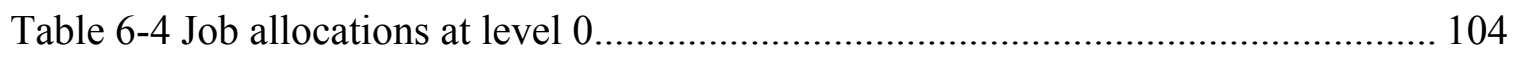

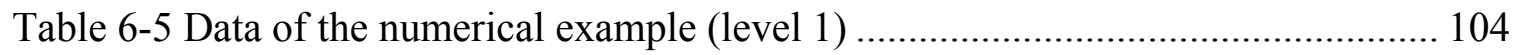

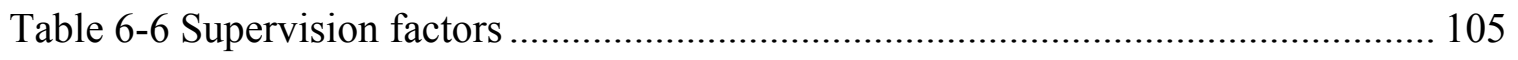

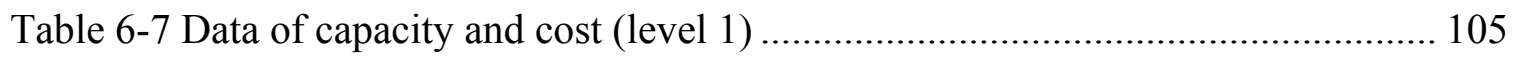

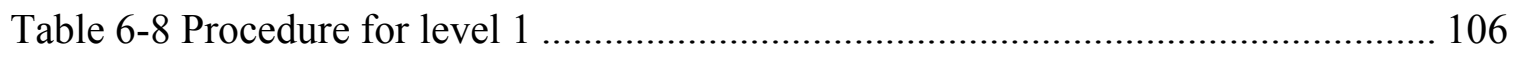

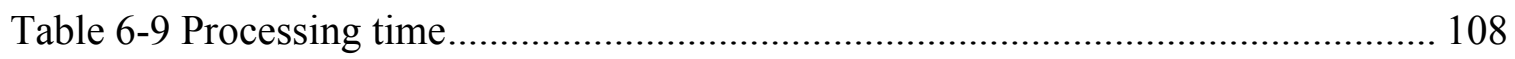

Table 6-10 Candidates for "next available activity"............................................... 108

Table 6-11 Size of problems used to evaluate the meta-heuristic ............................... 114

Table 6-12 Subset of problems selected for setting parameters ................................ 115

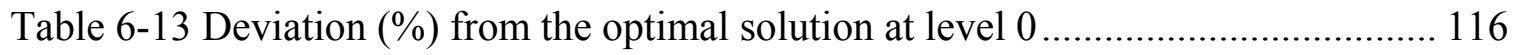

Table 6-14 Frequencies out of six problems getting a deviation of 5\% or less ............. 117

Table 6-15 Deviation (\%) from the optimal solution and the meta-heuristic ................ 118

Table 6-16 Preliminary Meta-Heuristic Results (Case A and B) ............................... 118

Table 6-17 Average, std dev and maximum \% difference from optimal..................... 119

Table 6-18 Comparision of the meta-heuristic versus greedy algorithm..................... 120

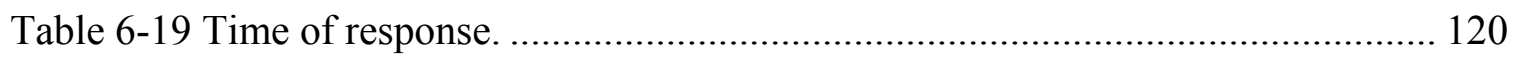

Table 6-20 Approximate running time for bigger problems.................................... 122

Table 6-21 Average, std dev and max dev (\%) between greedy and meta-heuristic...... 124 


\section{LIST OF FIGURES}

FIGURE

PAGE

Figure 1-1 Mapping Work Breakdowm Structure to Organizational Structure ................ 2

Figure 1-2 Assigning jobs to resources.................................................................. 4

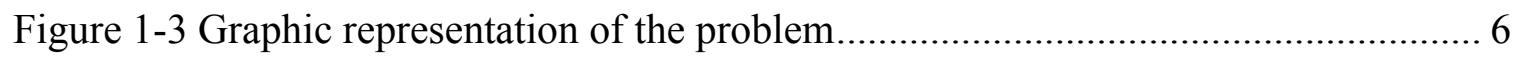

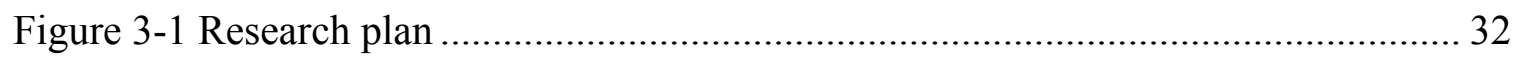

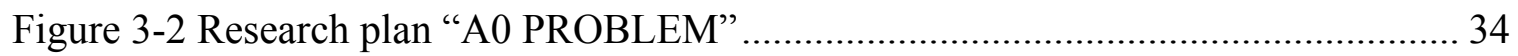

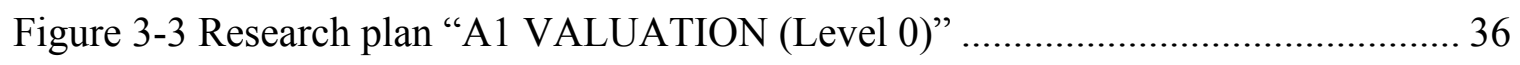

Figure 3-4 Research plan “A1 VALUATION (Levels 1 to n)" ...................................... 36

Figure 3-5 Research plan “A2 PROPOSED SOLUTION APPROACH”....................... 38

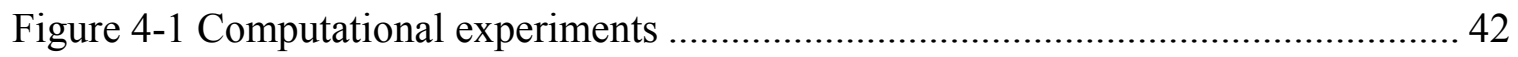

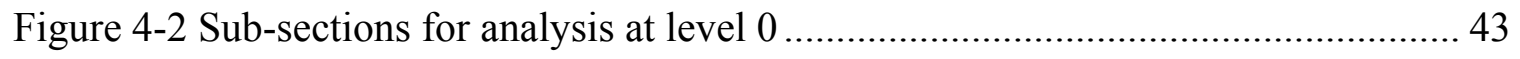

Figure 4-3 Graphical representation of Section one ............................................ 44

Figure 4-4 Graphical representation of results in Sub-section one .............................. 46

Figure 4-5 Graphical representation of results in Sub-section two............................. 48

Figure 4-6 Graphical representation of results in Sub-section three............................ 50

Figure 4-7 Utilization of each group en each Sub-section......................................... 51

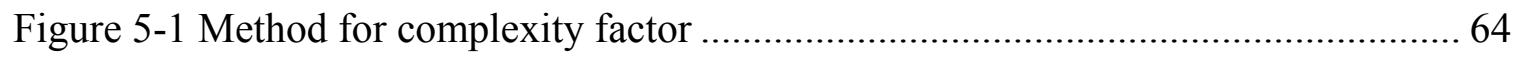

Figure 5-2 Example of skills and skill levels between workers and jobs ...................... 66

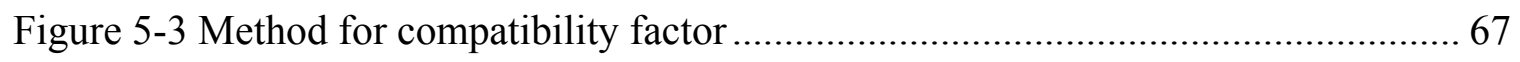

Figure 5-4 Method for supervisor factors ....................................................... 70

Figure 5-5 Impact of sum of factors in span of control ........................................ 71

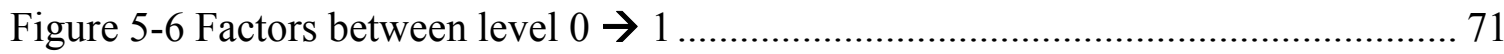




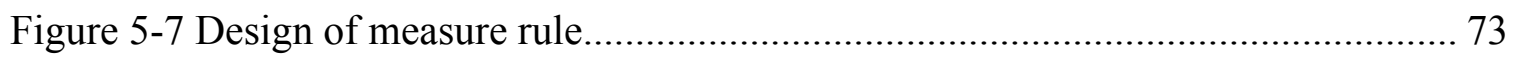

Figure 5-8 Activity implementation process.......................................................... 76

Figure 5-9 Evaluation of planning and training factor............................................ 88

Figure 5-10 Evaluation of training and control factor. ........................................... 89

Figure 5-11 Relationship between groups and supervisor factors .............................. 90

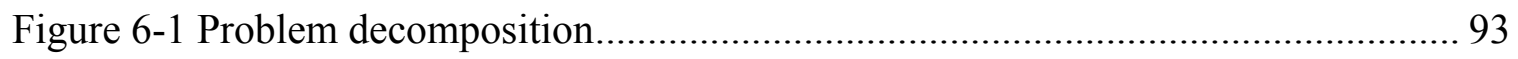

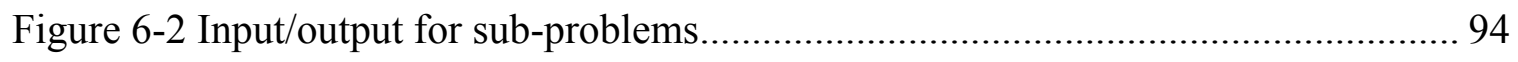

Figure 6-3 Meta-heuristic framework ................................................................ 95

Figure 6-4 Procedure of the proposed solution approach (level 0) .............................. 98

Figure 6-5 Procedure for the proposed heuristic approach ....................................... 99

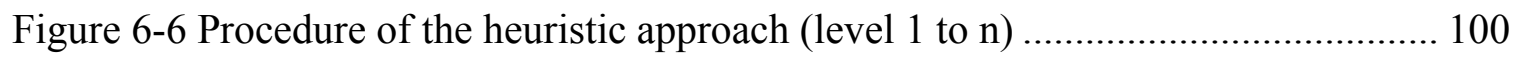

Figure 6-7 Procedure for the modified Lagoudakis greedy algorithm ........................ 101

Figure 6-8 Procedure of the meta-heuristic proposed at level 0 ............................... 111

Figure 6-9 Meta-RaPS procedure for the solution approach ................................... 112

Figure 6-10 Procedure of the meta-heuristic proposed at level 1 ............................... 113

Figure 6-11 Meta-RaPS procedure for the solution approach (level 1)....................... 113

Figure 6-12 Number of variables and constraints ............................................... 115

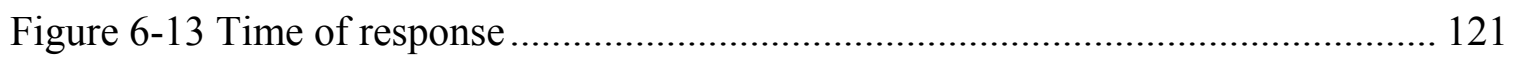

Figure 6-14 Interpolation of the number of variables......................................... 122

Figure 6-15 Average run times for meta-heuristic............................................. 125

Figure 6-16 Average, std dev and max percentage of solution................................ 126

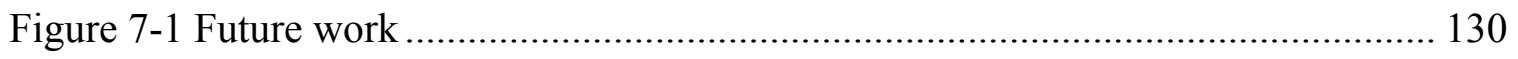




\section{INTRODUCTION}

\subsection{Background and motivation}

The span of management is the most discussed single concept in classical and modern management theory. Throughout the evolution of this concept, it has been referred to by various alternative terms, such as span of control, span of supervision, and span of authority [1]. Existing research work has focused mainly on qualitative methods to analyze this concept, for example heuristic rules based on experiences and/or intuition. Currently there are only a few reports that focus on a quantitative approach to an organizational structure design problem.

The challenge of mass customization (e.g., building cars to customer order), brings great value to both the customer and the company. For example, building cars to customer order eliminates the need for companies to hold billions of dollars worth of finished stock. Any company able to free this capital would improve their competitive position, and be able to reinvest in future product development. The question for many company executives is how efficient the organizational structure could be. The need for frequent adjustment to an organizational structure can be found in this type of make-to-order or project-based companies, where work contents and its organizational structure could vary dramatically over a short period of time. For companies that are going through their transitional stages (e.g., development and growth), an optimal design tool can help evaluate, justify, and optimize their organizational structure from time to time.

Meier and Bohte [2] have recently reinvigorated the debate on span of control and the optimal manager-subordinate relationship. They offer a theory concerning the impact and 
determining factors of span of control, and they test it using data from educational organizations. Theobald et al. [3] suggest that manager-subordinate ratios, along with other structural influences on production, deserve considerably more attention than they have received in modern administration research.

According to Van Fleet [1], the specific number of subordinates supervised by any given superior is not crucial in and of itself but rather functions as an intermediate variable between factors, such as "routine work", "trained subordinates", "personal assistant used", "stable operations", "supervision shared", and "need for control", among others. Because of these factors, the number of span of control is only an intermediate variable between the factors and the effectiveness of supervision.

Figure 1.1 represents a typical problem of allocation of work given a Work Breakdown Structure (WBS) and its corresponding Organization Breakdown Structure (OBS). Each job is assigned to a resource (worker and/or workstation), which in turn is integrated into layers of hierarchical managerial units of the company.

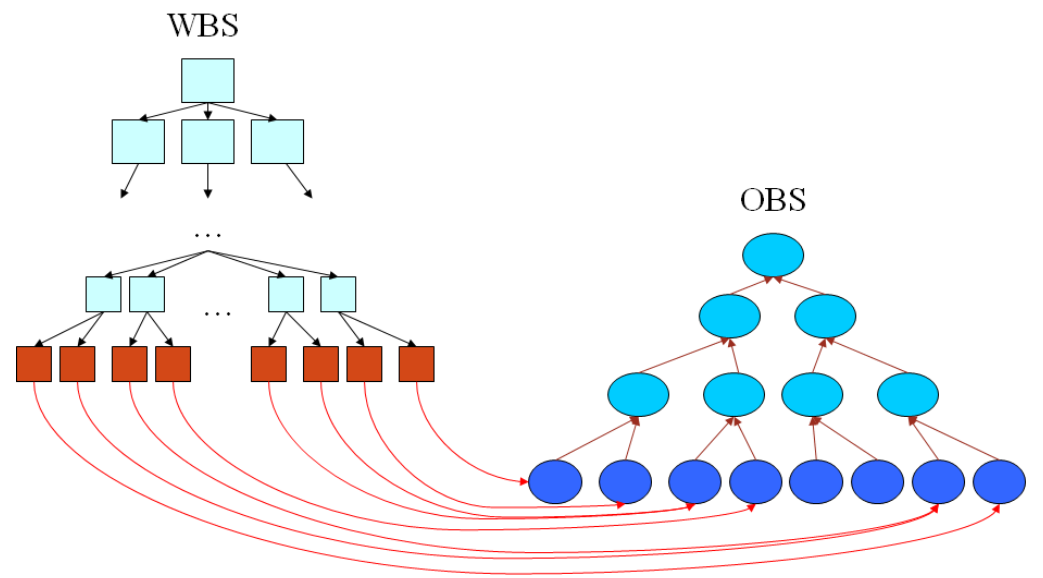

Figure 1-1 Mapping Work Breakdown Structure to Organizational Structure 
In specifying conditions for organizational effectiveness, the span of control has generally been regarded as a critical factor. It is apparent that certain variables affect the span of control and hence organizational effectiveness, but a clear expression of the concept has been slow to emerge.

The span of control is an old problem which has generated a lot of qualitative approaches, but there are only a few reports on quantitative treatments of this problem. It is imperative to work with this problem by identifying, not only the factors that may affect the span of control, but also the criteria upon which any value judgment is to be based.

\subsection{Problem description}

Formally, the problem can be described as follows: a set of jobs $(\mathrm{J})$ and a set of different processing workstations (G) are given. Each job in (J) is described by its processing time for the jobs to be completed, the skills needed for the job, the level of each skill (complexity factor), and compatibility according to the information given to the workstations. The objective is to find a set of workstations $(\mathrm{G})$ to schedule the jobs $(\mathrm{J})$ in such a way that the utilization of each workstation could be maximized, and to find the span of control needed for this Work Breakdown Structure (WBS). All of the above while maintaining the minimum cost of supervision. The number of "span of control" to be formed depends upon the number of workstations $(\mathrm{G})$ considered in an instance, and also depends on the factors identified for supervision: planning, control, execution, and training. The following figure summarizes the description of the problem, where a group of jobs must be assigned to a group of available resources. 


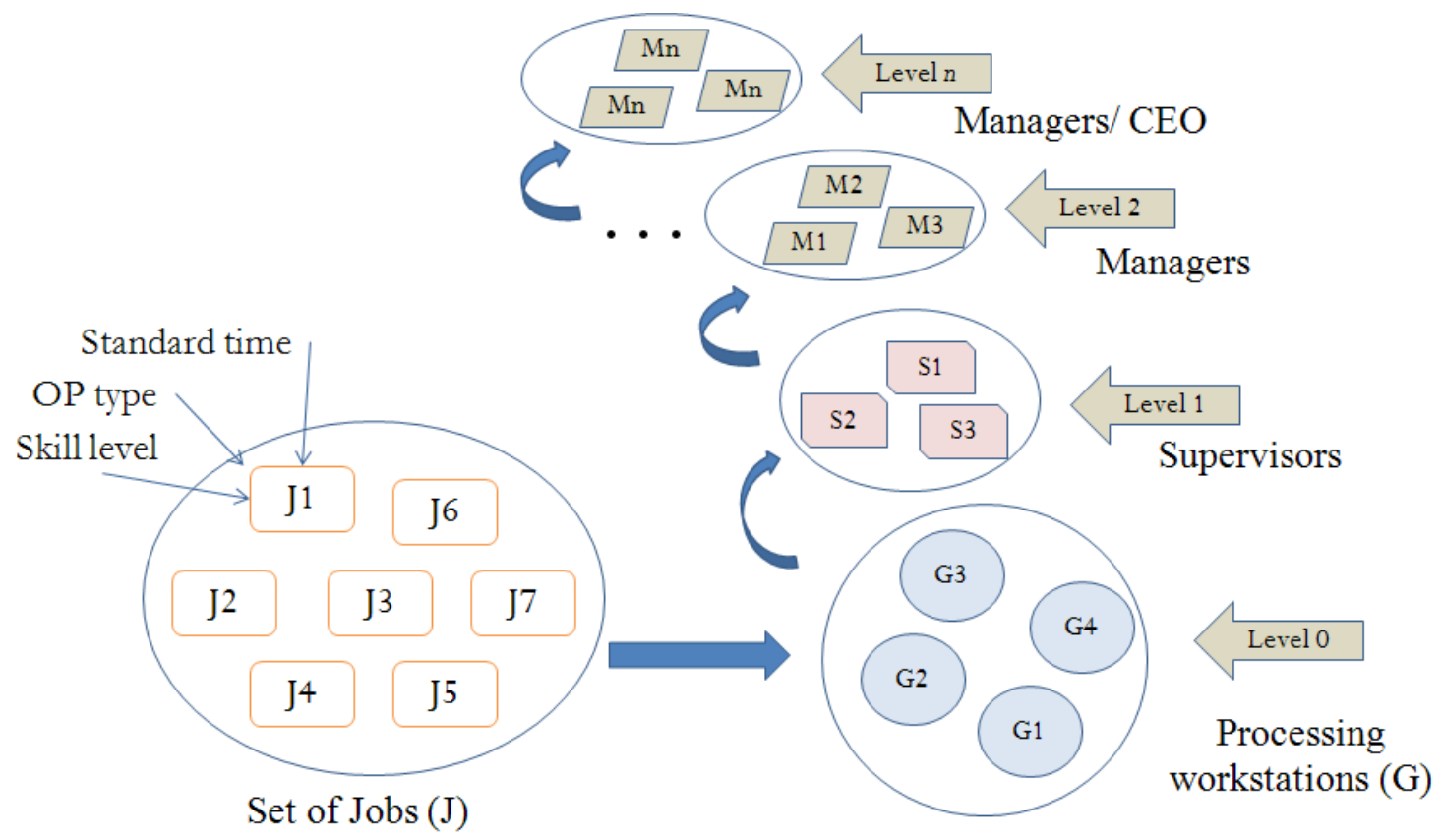

Figure 1-2 Assigning jobs to resources

Once the Work Breakdown Structure (WBS) has been established, it must be related to the Organization Breakdown Structure (OBS), as in Figure 1-1. In this process, the main assumptions made are: (1) job processing times and capacity of the workstations are deterministic and known in advance, (2) information about skills and skill level of each workstation and each job is available, (3) job splitting is not acceptable, (4) workstation is available according to the remaining capacity for the jobs, (5) it is feasible to eliminate or to add any workstations or supervisors as needed.

To exemplify and validate this description, Information Systems (IS) companies were contacted. The client determined the requirements for software development, which in turn established the WBS and indicated the tangible or intangible object produced as a result of the project (deliverables) that was assigned to accomplish this project. Inside the company, a set of programmers had to accomplish these deliverables. To assign the job 
(or number of jobs) for every programming station, the standard time that every job needed and the capacity of every station had to be established first, in such a way that the sum of jobs assigned to every station did not exceed the capacity of every workstation.

The skills of every workstation can change depending on the level of certification that exists in each one. For such an effect, it is necessary to correlate, across the parameter "complexity", the type of specialty that the job needs to be completed. What causes the "complexity" factor, depending on the level of specialty that exists at a station, is that the standard time stays constant, or that it increases or diminishes according to the skill vs the level of workmanship needed for every operation. The job is generally described in terms of the tasks to be completed, the skills needed for the task, and the level of each skill. Skills are different from one another, but not necessarily unique to their tasks, therefore the same skill could be required, whether at the same level or at a different level, for more than one task. Each job is assigned to exactly one worker (or station), while workers may be assigned multiple jobs provided the worker's capacity is not exceeded. The same information is used to define the possible incompatibility of jobs in regards to the workers.

Table 1-1 presents the data of a six-job problem instance, and figure 1-3 presents a graphic representation of the problem. Each rectangle represents a job and each circle represents a workstation; $\beta$ represents the standard time of each job and $r$ represents the capacity of each workstation. 
Table 1-1 Data for six job and four station problem

\begin{tabular}{|c|c|c|c|c|c|c|}
\hline $\mathrm{J}$ & 1 & 2 & 3 & 4 & 5 & 6 \\
\hline$\beta(\mathrm{hrs})$ & 1 & 0.5 & 0.5 & 1 & 1.5 & 1 \\
\hline
\end{tabular}

\begin{tabular}{|c|c|c|c|c|}
\hline $\mathrm{G}$ & 1 & 2 & 3 & 4 \\
\hline $\mathrm{r}(\mathrm{hrs})$ & 2 & 2 & 2 & 1 \\
\hline
\end{tabular}

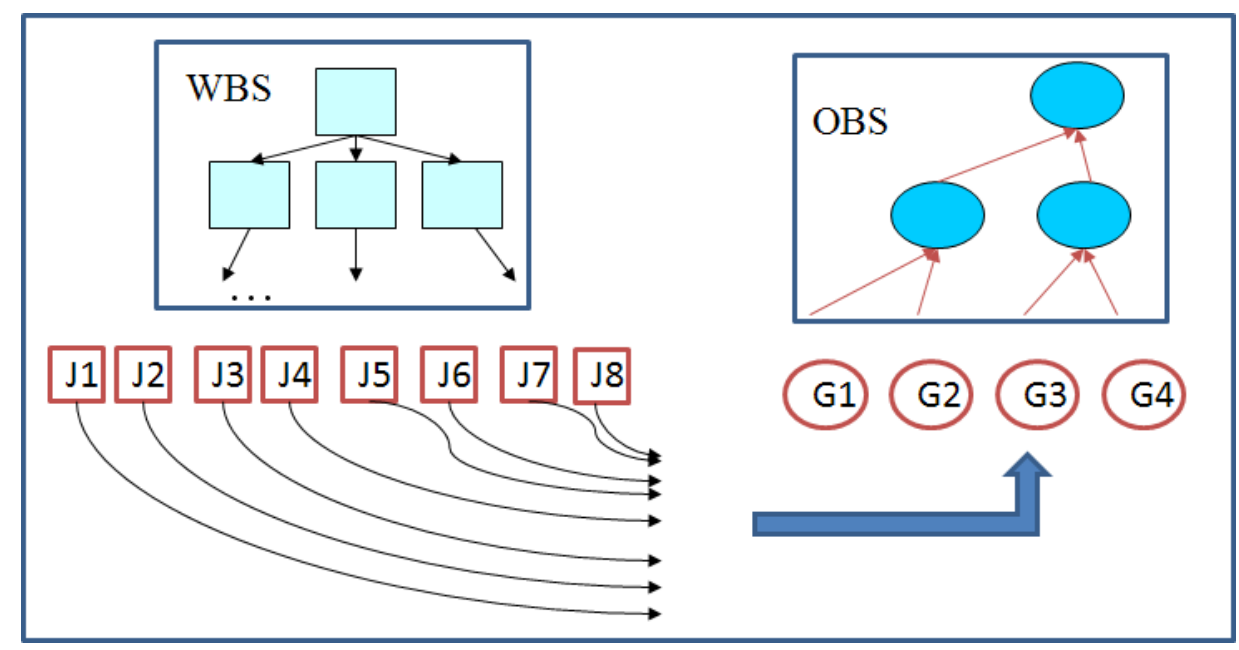

Figure 1-3 Graphic representation of the problem

\subsection{Research objectives}

The objectives of this research are to determine the feasibility of designing (or reorganizing) the organizational structure based on a quantitative model, and to determine the possible impact on organizational costs. From these objectives, one of the goals is to determine how flat an organizational structure should be. Another goal is to develop a method for the customization of the quantitative model proposed for some particular types of industries, and to develop instruments in order to measure up the parameters that affect the managerial role within the organizational structure. In order to accomplish these research objectives, the analytical modeling is a critical tool for the methodology that mathematically formulates the problem under study, and that leads to the 
development of practical solution approaches to effectively solve large-size problem instances.

Quantitative models for combinatorial problems have been demonstrated to be NP-hard class, in such a way that, to solve this type of problems, the run-time of an exact algorithm increases exponentially with the instance size, implying that usually, only small instances can be solved in practice. Therefore, in order to solve real (large) problems, a heuristic and meta-heuristic approach are proposed in this research. The performance of the approach is measured by the computational cost and the solution quality.

To accomplish these objectives, the deliverables of this research include: (1) the development of a quantitative model for optimal organizational structure design, (2) an evaluation of the parameters used in the model for an industry application, and (3) the development of a practical solution approach to the analytical model.

\subsection{Contribution and significance}

The principal contribution of this research is the development of a quantitative tool for study of the organizational design problem. This research makes a contribution to the analytical linkage between work contents and resource requirements, quantifying managerial task requirements, and relating management requirements quantitatively to the organizational hierarchy design. This quantitative model enables the user to analytically study the organization design problem, and prescribe an optimal design for real-life industrial applications. 
This study leads to a new (i.e. analytical) research approach to the organizational design problem, and lays a solid foundation for further academic research. This model and its solution approach will help companies to evaluate or optimally design their organizational structure. The proposed research takes an innovative approach to this organizational design problem, which hopefully can lay the basis for quantitative research approaches.

\subsection{Assumptions}

For the problem under consideration, assumptions were made that the job processing times and the capacity of the workstations are deterministic and known in advance. Another assumption for the model proposed is that in any new type of industry, the method for job and worker allocations must be customized, which could involve the development of additional models according to the type of business. Once the Work Breakdown Structure (WBS) has been established, job splitting is not acceptable. For constructing a solution, the model starts with an existing set of workers, supervisors, and managers. In order to run the model, it is feasible to eliminate or to add any workstation or supervisor as needed. The minimum overhead as the target function was set, and assuming that material and other costs are not affected by the change of number of managerial layers, these were not considered. The model in this research is intended for applications as a design tool in the make-to-order industries and can also be applied to make-to-stock companies as an evaluation tool.

\subsection{Dissertation organization}


Chapter 1 outlines the motivation behind this study, the objective, the scope, and a summary of the contents. Chapter 2 presents a review of the academic literature that addresses the organizational design problem, as well as the empirical and quantitative methods used to solve it. Also an extensive review of the academic literature regarding related research problems was conducted. Chapter 3 discusses the research plan that includes the problem definition and modeling, the plan for the valuation of the factors that affect the job allocation and supervision effort, and the proposed solution approach.

Chapter 4 introduces the problem description, formulation, and computational experiments, clearly specifying the problem object of this research, the mathematical formulation for the problem under study, and also the preliminary results using computational experiments. Chapter 5 develops the valuation of the factors affecting job allocation and supervision efforts. In order to validate the model, data was collected within the context of Information Systems (IS) companies based in the city of Chihuahua, Mexico. The objective was to construct an instrument for providing a measure of IS organizational factors (planning, execution, training, and control).

In Chapter 6, the heuristic approach was developed to solve the mathematical model, and includes the analysis of the computational experiments conducted. The proposed solution approach was based on the concept of greedy algorithms and the Meta-RaPS algorithm. It includes the computational experimentation results and experiments using a heuristic, and improving it with a meta-heuristic. Then the solution quality of the meta-heuristic algorithm was compared with the results obtained using commercial software, and 
finally, the response time for those bigger problems that cannot be solved by the commercial software was analyzed. Conclusions and future work are drawn in Chapter 7. 


\section{LITERATURE REVIEW}

There exists a large body of literature in the area of organizational design. This review focuses on the study of span of control and other aspects relevant to quantitative modeling and solution approaches. Section 2.1 is an overview of organizational structure design; section 2.2 is a review of empirical models of span of control; section 2.3 reviews mathematical models of span of control; and section 2.4 reviews heuristic solution approaches to solving large-size problems.

\subsection{Organizations: structure and design}

Organization Theory (OT) has embraced multiple perspectives because it draws inspiration from a wide variety of other fields of study, and because organizations are too complex and malleable to ever be summed up by any single theory, design or structure. In this review, the objective is to analyze those aspects of OT that are directly related to the organizational structure design and consequently to the span of control.

In order to design hierarchical organizations, Smith [4] believed in the practice of work decomposition, and proposed the concept of "division of labor", determining that division of labor represents a qualitative increase in productivity. Taylor [5] proposed the theory of "the scientific management", whose principal objectives were the development of science for each element of a man's work, the scientific selection, training and development of workers, and the division of work between workers and management in almost equal share. Based on the above, workers are to be supervised by a specialist foreman. Taylor [5] expected that the expertise of managerial workers could be maximized like the ones of specialists. However, vertical division of labor is conflicting 
with one design principle of management theory: unity of command. This principle requires that each worker be directed by one and only one supervisor. The scalar principle is introduced so that the managerial roles are organized as a pyramid hierarchy of authority.

Fayol [6] developed a general theory of management to add a managerial perspective to the problem of organizational governance. According to Scientific Management Theory, he laid down the following "principles of management": specialization, which is to encourage continuous improvement in skills and the development of improvements in methods; unity of command, where each employee has one and only one supervisor; line of authority, which implies formal chain of command running from top to bottom of the organization; and coordination by managers, including authority and unity of direction. In order to put this system to work, Taylor's functional foremanship has to be abandoned, and unity of command needs to be established.

Blau and Scott [7] argue that it is impossible to find the best way to structure the organization. They point out that the size of the organization, the technology level, and the environment all have strong impacts on the organizational structure. The number of layers, the number of departments, and the number of job titles of an organization increase with size, but the rate decreases as the size increases. In similar terms, Kulik et al. [8] suggested there isn't a single model for organizational structure design, and any proposed model should be based on the characteristics of the type of organization for which development is being done, taking into account the possible influences of the environment. Woodward [9] suggested that the organizational structure strongly depends 
on the work structure, which in turn is decided by the organization's primary system of production. He classified organizations into three different categories according to their primary production system: (1) project/order based company with unit production/small batch, (2) mass production/large batch, and (3) continuous production. Make-to-order companies, which produce one-of-a-kind customized or small volume products, may not need as many levels of hierarchy since the production line system is not stable. In this type of companies, human workers frequently have to change the processes in order to meet requirements for different projects or orders. Therefore, more coordination efforts are needed to handle the exceptions. Companies that produce large volumes of identical products, referred to as "mass production", are typically highly automatic, and machines dominate instead of people. They may have more layers of structure and at the bottom level, the number of workers is very large. The companies that belong to the continuous production category are using machines to do all the work, and there isn't much coordination and control work involved. These organizations have the highest hierarchical structure.

Choo [10], among others, outlined distinct forms of organizational structures: functional, divisional, and matrix structure. Functional structure applies when the organization is small, geographically centralized, and provides few goods and services. A divisional structure applies when the organization is large, geographically disperse and when it produces a wide range of goods. Matrix structure applies when the organization needs constant coordination of its functional activities, and the organization could modify many traditional management practices. In general, the same organizational structure has been 
proposed by different authors such as Price [11], who also included one variant of the divisional structure, and Armandi [57]. Burton [12] proposed practically the same classification as follows: functional, decentralized, and mixed functional. He included in the classification the environmental complexity (simple for functional and complex for the others), the environmental change (dynamic for functional and static for the others), and the environmental segmentation (present in decentralized and absent in the others). Lim et al. [13] used the same structure classification for their study on "Organizational Structure for the Twenty-first Century". They also proposed that the development of the organizational structure is dependent on the expression of the strategies and behavior of the management and the workers as limited by the distribution of power between them, and influenced by their environment. The main contribution of the authors is the identification of the characteristics of the organizations in order to establish the variables and their impact in organizational design.

\subsubsection{Managerial roles}

Fayol [6] described a manager as a person who plans, organizes, commands, coordinates, and controls. Mintzberg [14] suggested that managerial roles are classified into three broad categories: interpersonal roles (figurehead), informational roles (monitor, disseminator, and spokesman), and decisional roles (entrepreneur, disturbance handler, resource allocator, and negotiator). Pavett and Lau [15] pointed out the most important roles for managers are that of leader, resource allocator and disseminator. Davis [16] categorized the managerial work into physical work and mental work. Physical work includes coordinating, guiding, and discussing. Mental work includes scheduling, 
controlling, and planning. Katz [17] identified that administrators use three skills, in executing their work: technical, human, and conceptual.

Based on this literature review, managerial tasks are classified into four types: planning (such as initiation, preparation, resource allocation, and scheduling), control (such as monitoring, coordinating, decision making, dissemination, dispatching, and performance evaluation), training (such as lecturing, coaching, guiding and discussing), and execution (such as problem solving and implementation).

These definitions give a very clear context to define the organizational structure proposed through a mathematical model, and most of all, generates a context of the difficulties that can occur when wanting to model this type of organizational design.

\subsection{Empirical studies of span of control}

The span of control is defined, according to Van Fleet et al. [1], as "the number of subordinates who can be successfully directed by a superior". The authors consider the terms of "span of management", "span of control", "span of supervision", and "span of authority" as synonymous.

Empirical studies report that the ideal span of control is around five, but there are not conclusive tests that say this would be universally true. Entwisle and Walton [18] collected information on the importance of span of control and showed an average of five to seven in schools, and four to seven in small companies. In a study examining the span of control for manufacturing companies Udell [19], based on 67 personal interviews, reported spans of up to 30 . Udell found that formal job descriptions did not add to span of control, that non-supervisory roles such as planning, budgeting, or meeting with 
customers did not reduce span of control. Bell [20], based on a study of 33 departments in a community hospital, found correlations between the complexity of tasks realized by subordinates, and a limited span of control. His data indicated that the fewer the subordinates they regulate, the closer the supervision, and the more complex the supervisor's task. Blau [7] reported on a study of 250 government agencies confirming that organizations requiring higher qualifications of their personnel are more decentralized, exhibit narrow spans of control, and have large number of managerial levels in their hierarchy. Ouchi et al. [21] surveyed 78 department stores and reported that the typical supervisor handled 8.7 subordinates on average, and used about $50 \%$ of their time on supervision.

Woodward [9] conducted a study of over 200 British industrial firms and found that variations in spans of control were present across the different types of firms. He classified the investigated firms into three types: unit production firms (e.g., shipbuilding), mass production firms (e.g., food or mined minerals), and continuous production firms (e.g., chemical). Within each category, successful firms used similar spans. Meier and Bohte $[2,22]$ collected data on 678 Texas school districts and found that the optimal span of control is dependent upon three factors: diversity of functions performed by subordinates, tenure of subordinates, and the size of the organization. The more diverse group a supervisor oversees, the smaller the span of control. The more time subordinates have been doing the same job, the less supervision they require, and consequently, a large span of control is possible. Finally, the larger organizations tend to use specialists instead of generalists, which allows for wider spans. One conclusion that 
can be reached from this review is that in modern administration research, the managersubordinate ratios, along with other structural influences on production (as suggested by Theobald et al. [3]) deserve considerably more attention than they have received.

Table 2-1 Summary of empirical studies of span of control

\begin{tabular}{|l|l|l|}
\hline Authors & Study of Span of Control & SOC \\
\hline Van Fleet et al. (1977) [1] & History of span of control & $\sim 5$ \\
Entwisle and Walton (1961) [18] & Schools and small companies & $\sim 5-7$ \\
Udell (1967) [19] & 67 personal interviews & 30 \\
Bell (1967) [20] & 33 departments in a community hospital & $*$ \\
Blau (1968) [7] & 250 government agencies & $* *$ \\
Ouchi et al. (1974) [21] & 78 department stores & 8.7 \\
Woodward (1980) [9] & 200 British industrial firms & $* * *$ \\
Meier and Bohte (2003) [2] & 678 Texas school districts & $* * * *$ \\
\hline $\begin{array}{l}* \text { Complexity of tasks performed by subordinates and a limited supervisory SOC. } \\
* * \text { Higher qualifications of their personnel exhibit narrow spans of control, and have large number of } \\
\text { managerial levels in their hierarchy. } \\
* * * \text { Successful firms used similar spans. } \\
* * * * \text { Optimal SOC is dependent on: diversity of functions performed by subordinates, tenure of subordinates, } \\
\text { and the size of the organization }\end{array}$
\end{tabular}

\subsection{Mathematical approaches of span of control}

Graicunas [23] was among the first to propose a mathematical approach to the span of control. He defined three types of interactions, namely, single relationships, crossrelationships, and direct group relationships. Denote $n^{*}$ as the number of subordinates and $t^{*}$ as the unit of time a manager needs to spend for the interaction, and then the total managerial work (measured as time), $w^{*}$ for a supervisor is estimated as $\mathrm{w}^{*}=$ $\left.\mathrm{n}^{*}\left(\mathrm{n}^{*}-1\right)+\mathrm{n}^{*}\left(\frac{2^{\mathrm{n}^{*}}}{2}-1\right)\right] * \mathrm{t}^{*}$.

Graicunas' [23] formula shows that as each additional subordinate increases, the managerial work increases significantly. Thus, he established that a supervisor, who 
handles interactions with groups of subordinates in addition to direct interactions, leads to the exponential increase of the number of relationships and interactions that a supervisor must handle after a certain number of subordinates. His conclusions were that a number around four subordinates was right to avoid the exponential growth of relationships and interactions. With regards to this research, it is valid to conclude that the explanation of a span of control is far more complex for a precise specification using only one mathematical formula without valid constraints.

Urwick [24] imposed (in Graicunas' formula) a strict limit to the number of employees that an executive should have. Urwick's main contribution was to propose ten principles of management to avoid increasing the administrative or supervisory overhead cost. Urwick's principles are: objective (the overall purpose), specialization (one group, one function), coordination and definitions (jobs with duties and relationships), among others. Urwick [24] and Graicunas [23], rather than proposing a mathematical model that would identify an optimal number of span of control, sought to determine, through a mathematical formula, the effect of increasing the number of employees by direct and indirect relationships that are built with subordinates. This model serves as a reference of the first attempt to quantify the relationship between the number of subordinates and the supervisory work. However, this approach is only based on a formula that does not have a goal of optimizing, and neither places constraints on the formulation, assuming as input a number of existing subordinates, and the time required for interfacing with them, while the output is only the time required by the manager. 
Mackenzie [25] focused on the determinants of, and the calculation for the maximum span of control. In Mackenzie's model, $\mathrm{G}_{0}$ represents the person from which he is analyzing the maximum span of control. $\mathrm{G}_{0}$ has $n$ subordinates and $m$ colleagues or superiors. The main assumptions in the model are: (1) Person $\mathrm{G}_{0}$ must spend time because interactions and solving problems between interactions; (2) others interact with person $\mathrm{G}_{0}$ in order to satisfy their own needs; and (3) there is an upper bond for how much the group will allow person $\mathrm{G}_{0}$ to complete their activities. Then, the span of control is the available time divided by the communication time for each subject. Mackenzie based his model on interaction between supervisors and subordinates, assuming that the communication time could be specific to each contact and jobs. The model uses as constraint the time of coordination between superiors and subordinates, slack time, and internal calculation time. Thus, the principal difference from our model is that Mackenzie's model is leaving aside issues identified in the work of supervision, such as control and training.

Keren and Levhari [26] use an "internal computation time", which is proportional to the size and complexity of the task, in order to compute the span of control. They compute the span of control for each level in the hierarchy using the speed of completion, and the amount of the resources employed by a planning job as a decision variable. In this case, the "optimum span of control" is an increasing function of wages and fixed time costs, and the increment of the span of control from one level to the next is an increasing function of wage costs. In their model, the objective function has two elements: the direct cost of the members employed (C) in the hierarchy and the cost of profits (w) lost 
through slow planning $\left(\min \left[\mathrm{C}\left(y_{r}\right)+\mathrm{w} \sum_{t=1}^{T} x_{t}\right]\right)$. The constraints basically take into account the time of planning through the hierarchy without considering the factors of control, execution, and training as part of the model proposed in our research.

Nasrallah and Levitt [27] suggest that organizations of different sizes could have similar optimal structures, as long as they have similar normalized levels or interdependence between interactions. Their model establishes that the organization is at its most effective when it maximizes the interaction value (interaction that person $i$ initiates with person $j$, $\left.h_{i j}\right)$, proportion of interaction time per person $\left(p_{i j}\right)$, and the success probability (the probability that an attempt by $i$ to interact with $j$ will succeed); with a restriction assuming that $p_{i j}$ must be equal to one. Although the above mentioned research is not oriented to span of control, the authors pursue a pragmatic "organizational design" paradigm, which is useful to analyze and compare the proposed organizational design in this research.

Yassine et al. [28] developed an analytical model for describing hierarchical organizations, through the creation and use of models of organizational interaction to balance the communication time within and between organizational hierarchies. Their research concludes by proposing a hypothetical managerial framework for characterizing different types of organizations, but they only base their model on the communicationtime ratio (between and within hierarchies). The model of Yassine et al. [28] with the "size of the organization" (m) as objective, shows how it is affected by the span of control and the communication between different levels in the hierarchy (where $\mathrm{m}=$ 
$\left.\left.\exp [\mathrm{k} \operatorname{In~} \mathrm{k})^{2}\right]^{\frac{\mathrm{T} 1}{\mathrm{~T} 2}}\right)$. The model does not allow making an estimate of the optimal span of control that the organization must have.

DePuy et al. [29] proposed a mathematical model to match employees to tasks based on the logistics skills of the employee and the skills necessary for the task. They presented a mathematical model which assigns tasks to workers, in such a way that the total training costs are minimized. The objective function is based on minimizing the training required by an operator at the first level of the organization $\left(\min \sum \sum \sum G_{i j k_{1}}\right)$. This model is used as a reference in order to assign jobs to workers at level 0, but the DePuy model does not address the problem of span of control within the hierarchy of the organization.

LeBlanc et al. [30] developed and implemented an optimization model to minimize the total cost of the assignments, while maintaining a balanced workload for different managers assigned to construction projects ( $\min \sum \sum C_{i j} X_{i j}$, where $\mathrm{C}$ is the intensity of assigning manager $i$ to project $j$ and $X$ the decision variable). Their research focused only on one type of industry and for balancing the workload at supervision levels.

Awad et al. [31] developed a computer-based system to replace an existing manual method for assigning proctors (Carleton University in Canada, needs proctors during examination sessions to oversee the students as they write their final examinations), and as a result, freeing up valuable staff time in the overloaded scheduling office. They used "A Basic Genetic Algorithm for the Initial Assignment of Proctors" where the number of possible proctor assignments is extremely large. In a worst case scenario, there are $p$ proctors, $t$ examination time slots, and $a$ possible assignment in every time slot. This 
situation is similar to the assignment problem in our research al level 0 . The authors combined some problem-specific heuristics and genetic-algorithm framework. This research is relevant in order to evaluate their heuristics and genetic-algorithm for their assignment problem, but the application is too specific in order to use it for a more general organizational design. Below is a summary of the literature on empirical studies and mathematical models of span of control.

Table 2-2 Mathematical approaches of span of control

\begin{tabular}{|c|c|c|c|}
\hline & $\begin{array}{l}\text { Mathematical } \\
\text { Approaches }\end{array}$ & Objective Function & Constraints \\
\hline \multirow{5}{*}{ 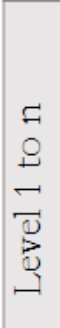 } & Graicunas (1937) [23] & Total managerial work (measured as time) & 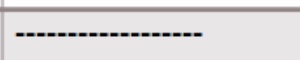 \\
\hline & Keren and Levhar (1979) [26] & Direct cost of subordinates & Planning time \\
\hline & Mackenzie (1974) [25] & Maximum SOC & Coordination tine \\
\hline & LeBlanc et al. (2000) [30] & Minimize cost of assignments & Workload(balanced) \\
\hline & Yassine et al. (2005) [28] & Size of the organization & Communication time \\
\hline \multirow{2}{*}{$\stackrel{\circ}{\stackrel{\varrho}{\leftrightarrow}}$} & Awad et al. (1998) [31] & Assigning proctors & Examination time \\
\hline & DePuy et al. (2006) [29] & Minimize training cost & Job complexity \\
\hline
\end{tabular}

2.4 Heuristic and meta-heuristics methods

Feasible solutions of mathematical models of this organizational design problem could not be found in a reasonable amount of time for large-size problems, therefore a heuristic solution methodology is developed. The solution quality of the heuristic is compared to optimal for small problems using commercial software.

Foulds [32] defined the term heuristic as a "method which, on the basis of experience or judgment, seems likely to yield a reasonable solution to a problem, but which cannot be 
guaranteed to produce the mathematically optimal solution". Greedy algorithms have been reported to give a good quality solution for combinatorial problems, as in the research of Il'ev et al. [33]. He used this solution approach for a maximization problem as an objective function, and a performance guarantee of the greedy algorithm is proven in terms of the parameters of a feasible set of problems. Mcgovern et al. [34] used a greedy algorithm for a combinatorial optimization analysis of the unary NP-complete disassembly line balancing problem. Other analysis on similar problems with greedy algorithms can be found in the research work of Agnihotri [35], Angelopoulos [36], among others [37, 38].

The term meta-heuristic refers to a master strategy that guides and modifies other heuristics to produce solutions beyond those that are normally generated in a quest for a local optimality [40]. Candidate solution methods for a problem of this type include Specific Heuristic Rules (SHR), Simulated Annealing (SA), Tabu Search (TS), Genetic Algorithms (GA), and Meta-heuristic for Randomized Priority Search (Meta-RaPS). The Meta-RaPS framework was chosen using results from recent research [44-49] that reports the following:

1. This method performs better than other meta-heuristics in problems such as the "Resource Allocation Problem (RAP)", "Traveling Salesman Problem (TSP)", and "Vehicle Routing Problem (VRP)" that have similar characteristics to the problem in this research.

2. The computation times are better than other meta-heuristics that have similar or the same quality solution. 
3. Run times are not dramatically affected by the size of the problem and generate feasible solution at each iteration.

4. The method is relatively easy to implement

The extensive work of the authors has been analyzed to propose a revision of this metaheuristic that allows to obtain a good solution in a reasonable computation time. Genetic Algorithms (GA), Tabu Search (TS), Simulated Annealing (SA) and Meta-RaPS are modern heuristics that succeed in leaving the local optimum by temporarily accepting moves that cause a worse value for the objecting function. As shown in Table 2-3, these meta-heuristics are the most common proposed in combinatorial problems.

Genetic Algorithms imitate some of the natural processes of evolution and selection. According to the literature on GA, this algorithm consists of the following components: Chromosomal Representation (each chromosome represents a legal solution to the problem, and is composed of a string of genes), Initial Population (serves as the starting point for the GA), Fitness Evaluation (defining an objective of fitness function), Selection (the selection procedure picks out two parent chromosomes), Crossover (cross over the parents to form a new offspring) and Mutation (mutate new offspring at each locus).

Simulated Annealing (SA) simulates the change in energy of the system when subjected to a cooling process, until it converges to a steady "frozen" state; in Tabu Search (TS) the idea is to derive and exploit a collection of principles of intelligent problem solving. This has adaptive memory using neighborhood search, and it moves from one current solution to the next after every iteration. 
As reported by DePuy [41], Meta-RaPS is the result of research on the application of a modified COMSOAL approach to solve several types of combinatorial problems. COMSOAL is a computer heuristic originally reported by Arcus [42] as a solution approach to the assembly line balancing problem. The philosophy behind Meta-RaPS consists of three basic ideas: (1) the incorporation of randomness in a particular heuristic may dramatically improve the solution quality, (2) random combinations of heuristics may lead to better results than each heuristic individually, (3) the recent and ongoing increase in computer speed and capacity encourages the use of practical although computer-intensive methods for solving combinatorial problems.

Meta-RaPS constructs feasible solutions through the utilization of a greedy algorithm in a randomized fashion. A greedy algorithm often constructs a solution by iteratively adding elements or activities to the solution based the activity's priority value. Meta-RaPS modifies the way a greedy construction heuristic chooses the next activity to add to the solution by occasionally choosing an activity that does not have the best priority value.

DePuy al. [41] reported that, for this category of problems, it is possible to find a good type of heuristics based on the concept of greedy algorithm that produces good solutions, such as the one proposed by Lagoudakis (2001) and Eilon et al. (1971).

Table 2-3 presented below analyzes different meta-heuristics for solving combinatorial problems. Applications discussed include well known problems in the industrial engineering field such as: Traveling Salesman Problem (TSP), Resource Constrained Project Scheduling Problem (RCPSP), Multidimensional Knapsack Problem (MKP), Quadratic Assignment Problem (QAP), Early/Tardy Single Machine Scheduling (E/T 
SMS), and Vehicle Routing Problem (VRP). These problems have a similar construction in objective function and constraints as the one proposed in this research.

DePuy et al. [43] developed and applied Meta-RaPS to solve three typical combinatorial problems: TSP, RCPSP, and MKP. The solution approach (Meta-RaPS) is applied to several heuristic algorithms showing that the solution quality significantly improved. They compared their method against other meta-heuristics (GA, SA, TS) also getting a better quality of solution when comparing the percentage of deviation from optimal and run times. Results indicate the Meta-RaPS heuristic performed as well or better than other, more complicated heuristics.

Hepdogan et al. [44] for the E/T SMS problem used an heuristic and an improvement with Meta-RaPS, then he compares the results vs the SA approach. Their results report that Meta-RaPS obtains a better quality solution and shorter run times. Mora et al. [45] develops a Meta-RaPS for the QAP. He uses a five-rule construction heuristics, and then combines the greedy heuristics in Meta-RaPS. His results show that the use of MetaRaPS significantly improves the solution quality of each of the five greedy algorithms. Hepdogan et al. [46] studied Meta-RaPS for 0-1 MKP. In their application, the priority rule selected uses the normalization of weights and then improvement with Meta-RaPS and GA, the latter having the best solution performance $(0.53 \%$ deviation of GA vs $0.73 \%$ of Meta-RaPS). However, the computation time for the GA ranges between six to 65 minutes comparing to Meta-RaPS with seven to 35 minutes per problem.

Keith et al. [47] studied Meta-RaPS for the TSP. Two fairly simple priority rules were tested by these authors, the nearest neighbor and cheapest insertion rules, and then 
improvement with Meta-RaPS showing that this method outperforms the priority rules with respect to percent difference from optimality. Song et al. [48] reports in the metaheuristics for the VRP good results in a reasonable amount of time using Meta-RaPS, when compared to optimal solutions of other heuristics like the GA and the TS.

Table 2-3 Meta-heuristics for solving combinatorial problems

\begin{tabular}{|c|c|c|c|c|c|c|}
\hline \multirow[b]{2}{*}{ Author } & \multirow[b]{2}{*}{ Problem } & \multicolumn{5}{|c|}{ METHOD } \\
\hline & & $\mathrm{GrH}$ & GA & SA & TS & MR \\
\hline Mora et al. [45] & QAP & $\bullet$ & & & & 0 \\
\hline Hepdogan et al. [44] & E/T MSP & - & & - & & 0 \\
\hline DePuy et al. [29] & $\begin{array}{l}\text { TSP } \\
\text { RCPSP } \\
\text { MKP }\end{array}$ & $\begin{array}{l}\bullet \\
\bullet \\
\bullet\end{array}$ & $\begin{array}{l}\cdot \\
\bullet \\
\bullet\end{array}$ & $\begin{array}{l}\cdot \\
\bullet \\
\bullet\end{array}$ & $\begin{array}{l}\bullet \\
\bullet \\
\bullet \\
\bullet\end{array}$ & $\begin{array}{l}0 \\
0 \\
0\end{array}$ \\
\hline Hepdogan et al. [46] & MKP & - & 0 & & & - \\
\hline Keith et al. [47] & TSP & - & & & & 0 \\
\hline Song et al. [48] & VRP & - & - & & - & Q \\
\hline Moraga et al. [49] & MKP & - & 0 & - & - & 0 \\
\hline \multicolumn{3}{|l|}{ Problem: } & \multicolumn{4}{|c|}{ Method: } \\
\hline $\begin{array}{l}\text { QAP: Quadratic Assis } \\
\text { E/T SMS: Early/T } \\
\text { Schedu } \\
\text { TSP: Traveling Salesı } \\
\text { RCPSP: Resource Co } \\
\text { Scheduling P } \\
\text { MKP: Multidimensio } \\
\text { Problem } \\
\text { VRP: Vehicle Routin }\end{array}$ & $\begin{array}{l}\text { ment Problem } \\
\text { ly Single } \\
\text { g } \\
\text { n Problem } \\
\text { rained Projec } \\
\text { blem } \\
\text { Knapsack } \\
\text { roblem }\end{array}$ & achine & \multicolumn{4}{|c|}{$\begin{array}{l}\text { GrH: Greedy Heuristic } \\
\text { GA: Genetic Algorithm } \\
\text { SA: Simulated Annealing } \\
\text { TS: Tabu Search } \\
\text { MR: Meta-RaPS } \\
\text { •: Heuristics methods } \\
\text { used by the author } \\
\text { ם: Best solution found }\end{array}$} \\
\hline
\end{tabular}


According to the authors, one of the improvements of Meta-RaPS is that the run times are not dramatically affected by the size of the problem, and generate feasible solution at each iteration. Moraga et al. [49] for the MKP report the same solution quality between Meta-RaPS and the GA. Although Meta-RaPS has practically the same average deviation from optimal than the GA, its performance is with a very short run time. The results shown here lead to the conclusion that this meta-heuristic is the best for the problem proposed in this research.

\subsection{Summary}

According to definitions and empirical studies of span of control discussed in the literature review, the following conclusions can be drawn: there isn't a generally applicable optimum span of control, the size of span of control is higher in the lower level, but smaller in the higher level, and the more complex the subordinates' tasks, the smaller the supervisor's span of control, and the more complex the supervisor's tasks, the narrower the span of control.

Regarding the mathematical models found in the literature review, conclusions lead to the fact that those models take into account a series of assumptions that are complex to use for a practical analysis. These models focus on a particular aspect of the work of a supervisor, and do not take into account the different parameters that affect this type of work.

The constraints of the models found in the literature focus only on one type of work performed by the supervisor (training or coordination). Therefore one of the main differences with the model presented in this research is that the constraints take into 
account the complexity (and compatibility) of the jobs in the first level, and the activities that involve the supervision work needed at the following levels of the organization (classified as planning, control, training, and execution time).

The first constraint (assigning jobs to groups) is virtually ignored by the models related with the span of control (they take into account a group of permanent workers at the first level), and those models that focus on the task allocation problem ignored the required span of control needed for these working groups.

The model presented in this research extends the works discussed in the literature review (mathematical models), particularly the one of DePuy et al. [29], extending their original formulation and exploring a broad range of decision-making organizational structures that take into account factors in deciding the minimum cost of supervision. These factors include planning, training, execution, and control at higher levels, while taking into account the skills of workers for specific jobs in the lower level. DePuy et al. [29] model used five constraints to determine training needs, ensuring that all jobs are assigned, and maintain the capacity of workstations. The latter two being similar constraints in our model at the first level $(\mathrm{n}=0)$. However the quoted model does not consider other relevant factors in the allocation of jobs to workers, such as the compatibility of each job with respect to each of the workers involved.

The model proposed in this research includes six constraints to ensure that all jobs are assigned (similar to that proposed by DePuy et al. [29]), to maintain the capacity of the workstation, including the factors of complexity and compatibility to ensure the correct 
allocation of jobs. In the following levels, the constraints seek to maintain the capacity of the supervisor including four relevant factors: planning, control, execution, and training.

The main difference from this research in regard to other models in the literature, takes into account only one of the factors, such as planning time [19], coordination and slack time [25] or training requirements [29]. The following restrictions on the model proposed in this research ensure that all working groups are assigned to a supervisor, and they in turn, are assigned to a manager whose capacity is affected also by the time spent on planning, control, execution, and training. The following table is a summary of the characteristics reported in models that analyze a similar problem to that outlined in this research.

Table 2-4 Summary of similar models

\begin{tabular}{|c|c|c|c|c|c|c|}
\hline Research & Level 0* & $\begin{array}{l}\text { Level } \\
1 \text { to } n^{*}\end{array}$ & $\begin{array}{l}\text { Planning } \\
* *\end{array}$ & $\begin{array}{l}\text { Training } \\
* *\end{array}$ & $\begin{array}{l}\text { Control } \\
* *\end{array}$ & $\begin{array}{l}\text { Execution } \\
* *\end{array}$ \\
\hline $\begin{array}{l}\text { Keren and } \\
\text { Levari }\end{array}$ & NO & YES & YES & $\mathrm{NO}$ & $\mathrm{NO}$ & NO \\
\hline Mackenzie & $\mathrm{NO}$ & YES & $\mathrm{NO}$ & NO & YES & NO \\
\hline DePuy et al & YES & $\mathrm{NO}$ & NO & YES & $\mathrm{NO}$ & $\mathrm{NO}$ \\
\hline $\begin{array}{l}\text { Proposed } \\
\text { research }\end{array}$ & YES & YES & YES & YES & YES & YES \\
\hline \multicolumn{7}{|c|}{$\begin{array}{l}\text { * The research includes assignment of jobs to workers (level } 0 \text { ) and/or assignment of } \\
\text { workers to supervisors (level } 1 \text { to } n \text { ) } \\
\text { ** The research includes in the mathematical model a planning, training, control or } \\
\text { execution factor. }\end{array}$} \\
\hline
\end{tabular}




\section{RESEARCH PLAN}

The main questions that concern this research are to determine, based on analysis of several cases, the feasibility of designing (or re-organizing) the organizational structure from a quantitative model, and to determine the possible impact in organization costs. Taking into account the above statement, one question arises: if an organizational structure is suggested to be flat, ¿how optimal should it be? The general solution approach to design or re-organize the organizational structure is through a quantitative modeling as integer-programming consisting of different levels of decision systems.

Authors from the existing Organization Theory establish a list of parameters and variables that affect the managerial role within the organizational structure. This research questions the possibility of developing instruments in order to measure up those variables in a quantitative method, and the customization of the model for some particular types of industries.

Quantitative models for combinatorial problems (TSP, MKP, VRP) have been demonstrated to be NP-hard class, in such a way that, in order to solve real (large) problems, it would require a heuristic solution approach. Therefore this research analyzes heuristic methods, and questions whether there is a particular one to obtain a good quality solution for the model proposed in a reasonable computation time. In order to answer these questions, the proposed research plan consists of: (1) problem definition and modeling, (2) valuation of the coefficients affecting modeling factors, and (3) proposed solution approach.

The following figure draws a map for the general research plan: 


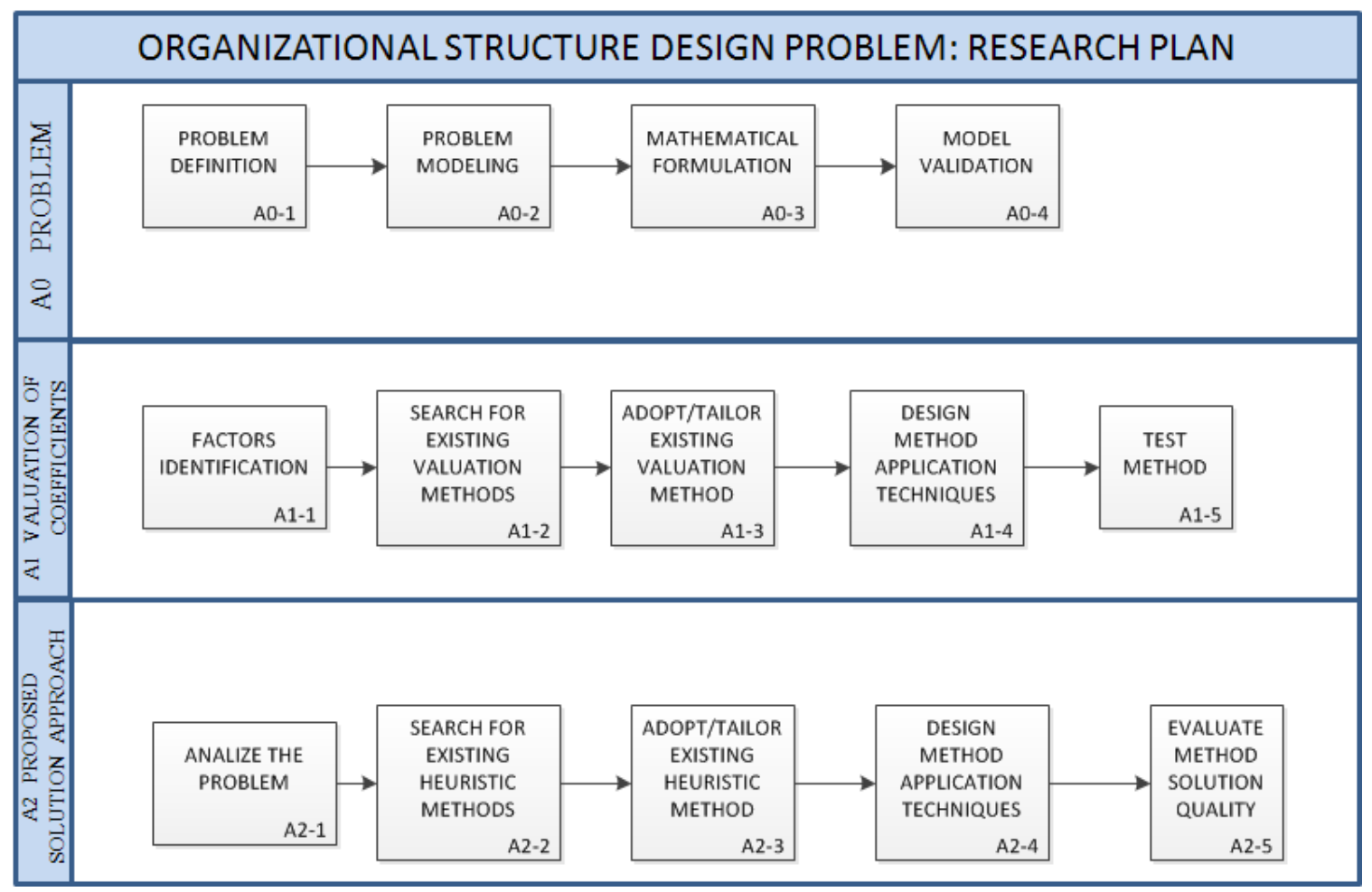

Figure 3-1 Research plan

\subsection{Problem definition and modeling}

In order to answer the first question regarding the feasibility of designing (or reorganizing) the organizational structure, it is necessary first to optimize the number of subordinates that report to each manager. The objective is to answer the question through a quantitative model design.

There are two main objectives for this modeling development: to provide an assignment of jobs to workers taking into account the skills of the workers in regards to the complexity and compatibility of the job, and to develop a more extensive model that assigns workers to supervisors and managers. The total cost required to achieve all the jobs and to assign all the workers has to be minimized. In this model, the minimum 
overhead is set as the objective function, mapping the work structure to the organizational structure through the relationship between the number of jobs and the number of workers for each job.

The literature review allows the identification of limitations found in current mathematically and organizational structure design models. The results of the reviews help in the creation of a detailed set of equations that describe in reasonable detail how Organization Theory (OT)-based quantitative analysis might be constructed. There are two goals that companies would like to reach when they are working on organizational structure redesigning: one is to keep the cost untouched, but improve the organization performance, for example the productivity and quality level of products is kept the same or higher. The other one is to maintain the performance level and to reduce the overhead. A typical organizational structure consists of a set of workstations that process a variety of jobs and relate to different levels of supervision. The assignment of jobs is dependent upon the complexity and compatibility of the jobs to be done. The allocation of jobs in different workstations must maximize the utilization of installed capacity, while minimizing the number of workstations required. Jobs that are successfully processed are assigned only to one workstation and workstations are assigned, in turn, to only one supervisor. These characteristics of organizational structure make them suitable for modeling as integer-programming consisting of different levels of decision systems. DePuy et al. [29] proposed an integer model for the problem under study, but only for the first level (0). The proposed model in this research is compared with the DePuy model with respect to the number of decision variables and linear constraints, and with the ones 
proposed by Keren and Levhari [26] and Yassine et al. [28], who also establish an objective function and constraints.

In this research a binary-integer programming model was first formulated and solved using a commercial solver (LINGO) to obtain an optimal solution. The proposed model intends to optimize the entire organizational structure by eliminating unnecessary work units, instead of optimizing local spans of control to improve the organizational structure. Because the model is NP-hard, an optimal solution can be obtained in reasonable time for only small problem instances.

The following figure establishes the design of this part of the research plan:

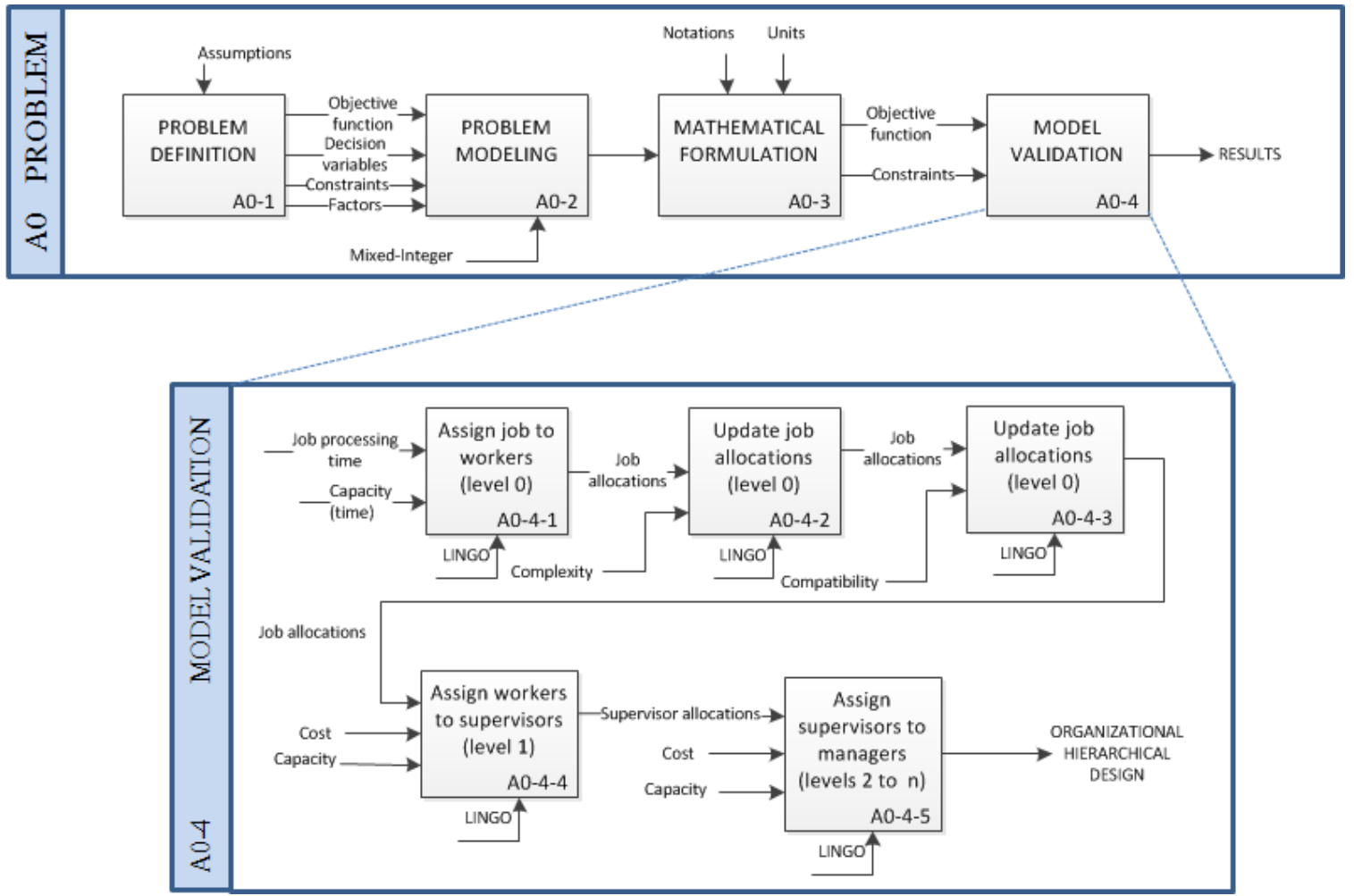

Figure 3-2 Research plan "A0 PROBLEM" 


\subsection{Valuation of coefficients affecting modeling factors}

In order to develop and customize efficient problem instances for an industrial application, the valuation of the factors affecting job allocation and supervision effort (complexity, compatibility, planning, execution, training, and control) into the mathematical model were analyzed. Within the model, factors are set at the first level of decision ( 0 ) and for the following levels ( 1 to $\mathrm{n}$ ). To quantify these factors, an instrument was developed, which gives us tools to determine the quantification of the factors in the model for decision making. On the first level (0), information of a job consists of the tasks (to be completed), the skills (needed for the task), and the level (required to complete each task). The objectives in estimating parameters at this level are: (1) determining their existing workers' skills and their levels, and (2) assigning the workers to their complexity and compatibility factors at an appropriate level regarding the jobs.

For the following levels ( 1 to $\mathrm{n}$ ) regarding supervision effort, an initial set of criteria for assessing organizational factors were formulated. These factors take into account the concept of managerial work [6], its different categories [14], their classification (physical and mental work) [16], the skills needed for administrators [17], the roles of managers [15], and the classification of the types of managerial tasks $[6,16]$. In order to be able to quantify and test the dimensions of supervision effort, data were collected on four Information System (IS) companies in the city of Chihuahua, México, with 30 supervisors and managers.

The following figures establish the design of this part of the research plan: 


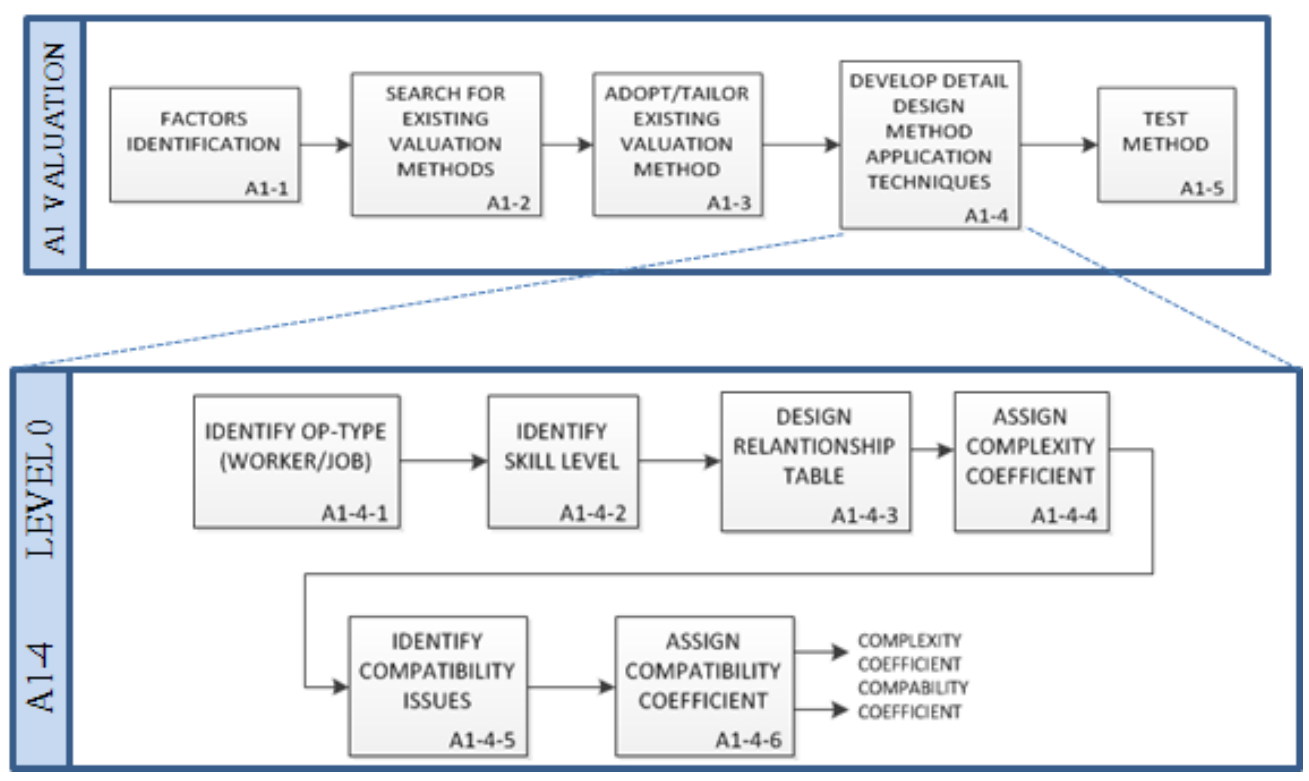

Figure 3-3 Research plan "A1 VALUATION (Level 0)"

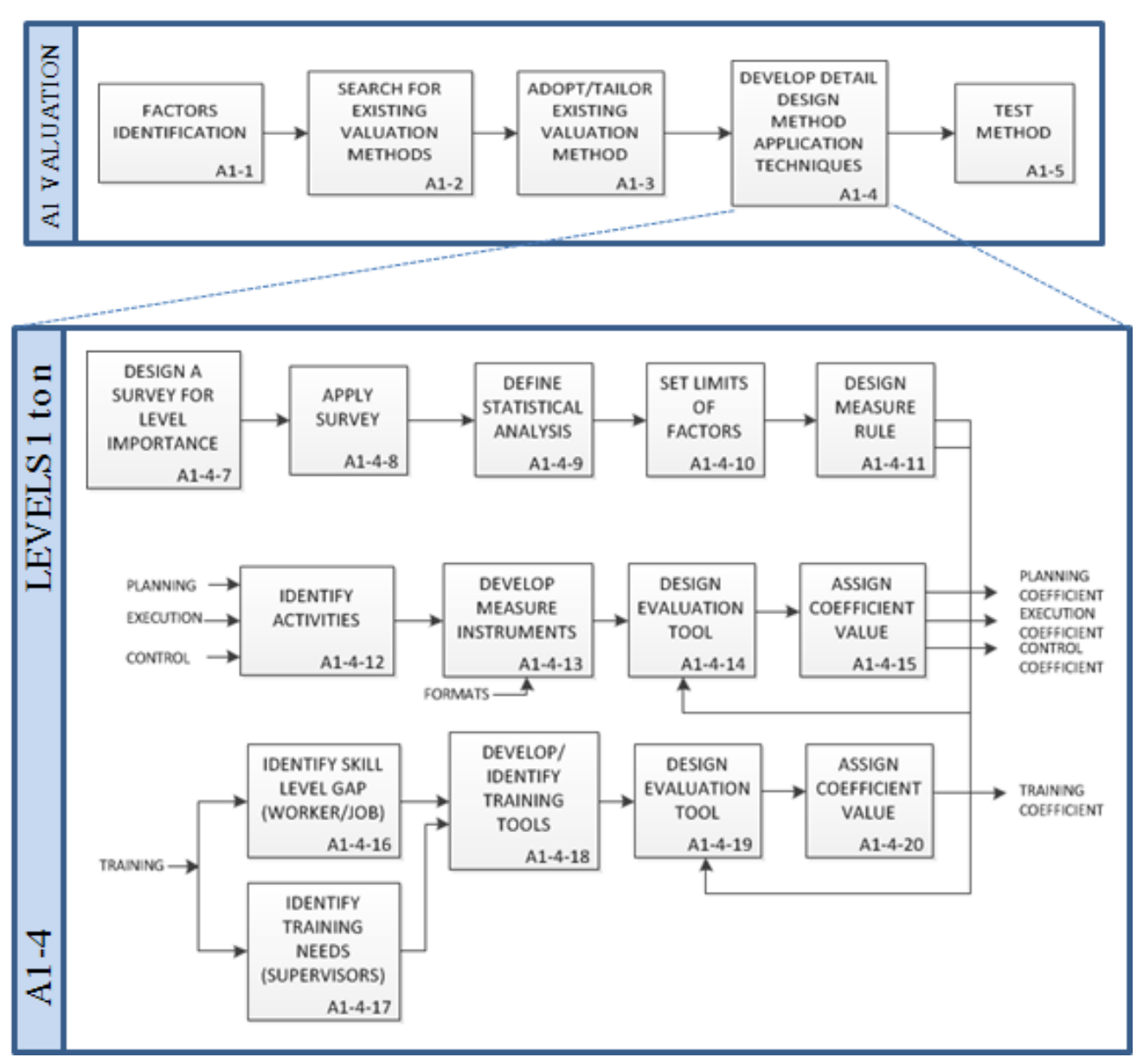

Figure 3-4 Research plan "A1 VALUATION (Levels 1 to n)" 


\subsection{Proposed solution approach}

The proposed formulation inherits properties which help to decompose the problem under study into smaller sub-problems. For the problem (NP-hard class), there isn't an exact algorithm that terminates within polynomial-bounded computational time (for large-size problems). In order to solve such problems, heuristic algorithms have to be used to find a good solution at a reasonable computational time.

The literature reviewed on heuristic approaches (Table 2-3) justifies the utilization of Meta-RaPS framework for the type of model proposed in this research. In order to develop this solution approach, the philosophy behind Meta-RaPS was used consisting of three basic ideas: (1) the incorporation of randomness in a particular heuristic may dramatically improve the solution quality, (2) random combinations of heuristics may lead to better results than each heuristic individually, and (3) the recent increase in computer speed and capacity encourages the use of practical computer-intensive methods for solving combinatorial problems.

The general framework for constructing the solution approach development in this research follows the following criteria: (1) the structure of the problem consists of $m$ constraints that will bound the construction of any feasible solution, when a job is chosen to be in the feasible solution, the addition of the new job cannot exceed the capacity constraints, (2) the framework begins with a simple rule called "greedy algorithm" proposed by Lagoudakis [41] in order to select the best job candidate with the best suitable worker at level 0 , and the best suitable supervisor at the following levels, (3) the greedy algorithm is modified by altering the composition of the "next available activity", 
adding randomness to the selection of jobs to workers, these to supervisors, and so on, (4) construct feasible solutions using priority rule and randomness, (5) pick the best answer for a number of iterations, and (6) evaluate the solution quality compared to optimal and computational requirements.

The following figure draws the design of the proposed solution approach:

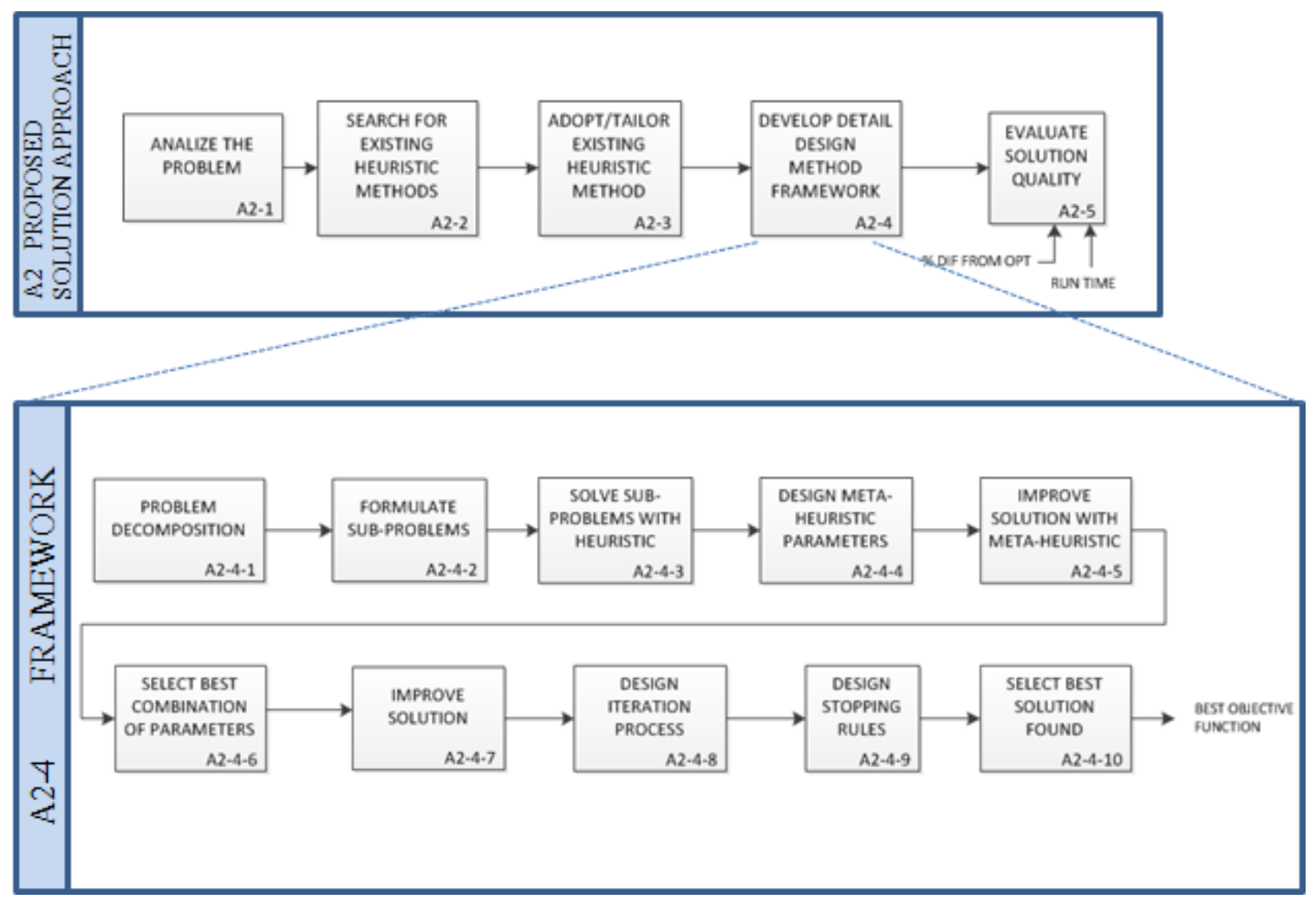

Figure 3-5 Research plan "A2 PROPOSED SOLUTION APPROACH” 


\section{PROBLEM DEFINITION AND MODELING}

\subsection{Problem characterization}

The design process begins with decomposition of each work into elemental work units (called OP), and assigning each OP to direct resources (machine and worker required), in relevance to work complexity, resource competency (skill and proficiency), and their compatibility. It then moves to organizing the required resources into groups, sections, and departments, forming a hierarchical management structure. It assumes work can be decomposed into a hierarchy of standard OPs, of which specifications, requirements and methods have been formalized for each OP type. It further assumes management effort for each managerial activity is measurable and is unique for each company, depending on the experience and expertise it has, and tools and techniques it uses to run the operation.

Work in this study is originated as customer orders, work orders, contracts, projects, and/or forecasts. Work content is applied as either an order-specific process plan, or a standardized process plan, defined through the use of the Group Technology (GT) concept. The modeling effort begins with the first level (0) problem, where there is a given set of structured tasks to be processed by workers at workstations (G). Each task is defined with an OP type and a proficiency level. Each worker (or workstation) possesses different skills. Complexity and compatibility are two factors used at this decision level (0), to ensure that each job is assigned to a proper workstation. Once all direct jobs are assigned and the requirement for each station is established at level 0 , the decision effort moves to managerial requirements at higher levels of the organizational hierarchy, (i.e. levels 1 to $n$ ). This prescriptive model seeks an optimal organizational structure, i.e. span 
of control and management layers, that minimizes the overall operation costs. Along with the modeling, an initial set of factors was identified and used in the constraints to assess organizational parameters pertaining to the nature of managerial effort, work type, and required skills.

\subsection{Mixed-Integer formulation}

The following notations were used to model the problem. The unit of time is the hour.

0 is the bottom level; $n$ is the top level, $n \in N$

Parameters:

- $w_{n j}$ : the unit cost coefficient for section $j$ at level $n$

- $\quad \beta_{\mathrm{i}}$ : the processing time for job $i, i \in I$

- $\quad r_{o j}$ : the capacity of the working group $j, j \in J$

- $\quad \alpha_{i j}$ : the complexity factor when job $i$ is assigned to group $j$

- $\quad p_{n j}$ : the planning factor for section $j$ at level $n$

- $c_{n j}$ : the control factor for section $j$ at level $n$

- $t_{n j}$ : the training factor for section $j$ at level $n$

- $e_{n j}$ : the execution factor for section $j$ at level $n$

- $\quad f_{n j}$ : the capacity of section $j$ at level $n$

- $\quad n_{i j}$ : the compatibility factor when job $i$ is assigned to group $j$

Decision variables:

- $\quad z_{i j}=\left\{\begin{array}{l}1 \text { if job is assigned to group } j \\ 0 \text { otherwise }\end{array}\right\}$ 
- $\quad y_{0 j p_{0}}=\left\{\begin{array}{l}1 \text { if group } j \text { with section } p_{0} \text { at bottom level is occupied } \\ 0 \text { otherwise }\end{array}\right\}$

- $y_{n j p_{n}}=\left\{\begin{array}{l}1 \text { if section } j \text { with section } p_{n} \text { at level } n \text { is occupied } \\ 0 \text { otherwise }\end{array}\right\}$

The mixed-integer formulation developed is as follows:

$\operatorname{Min} \sum_{n=1}^{N} \sum_{j=1}^{J} w_{n j} f_{n j} y_{n j p_{n}}+\sum_{j=1}^{N} y_{o j p_{0}} \quad(\forall j \in J),(\forall n \in N)$

Subject to:

$\sum_{j} z_{i j}=1$

$(\forall i=1 \ldots m)$

$\sum_{i} \beta_{i} \alpha_{i j} z_{i j} / n_{i j} \leq r_{0 j} y_{o j p_{0}}$

$(\forall j=1 \ldots n)$

$\sum_{j} r_{o j} y_{0 j p_{0}}\left(\rho_{i j}+c_{i j}+t_{i j}+e_{i j}\right) \leq \sum_{j} f_{i j} y_{i j p_{1}}$

$(\forall i=1 \ldots m)$

$y_{o j p_{0}} \leq \sum_{p 1} y_{1_{p 0 p 1}}$

$\sum_{j} f_{n-1, j} y_{n-1, j p_{n-1}}\left(\rho_{i j}+c_{i j}+t_{i j}+e_{i j}\right) \leq \sum_{j} f_{n j} y_{n j p_{n}} \quad(\forall i=1 \ldots m)$

$y_{n-1, j p_{n-1}} \leq \sum_{p n} y_{n p_{n-1}} p_{n}$

$\left(z_{i j}, y_{0 j p_{0}}, y_{n j p_{n}}\right.$ binary, $\left.(\forall j \in J),(\forall i \in I)\right)$.

In this formulation, the objective function (3.2.1) is to minimize the supervision cost. Constraint one (3.2.2) ensures each job (operation type) is assigned to only one direct labor group. Constraint two (3.2.3) ensures each direct labor group has a finite capacity, and all job assignments are limited by this capacity. The following two constraints (3.2.4 and 3.2.6) ensure that the total managerial work requirement of its child units cannot exceed the finite capacity imposed on the parent unit. Finally, the last two constraints (3.2.5 and 3.2.7) ensure that each child unit must have a parent unit. 


\subsection{Computational experiments}

LINGO, a commercial software system, is used to help validate the proposed $0-1$ integer program, study its behavior, and explore its limits. A preliminary computational experiment was conducted that validates the model with practical problems, and evaluates the impact of changing the complexity and compatibility parameters at level 0 . It also evaluates the impact in managerial-related parameters for planning, training, execution, and control at the higher levels. The proposed model was implemented on LINGO and run on a workstation computer (DELL PRECISION | M4400) equipped with processor Intel Core 2 Duo T9400 2.53 GHz. This experimentation demonstrates the use of the proposed model, and reveals that the software system is limited to solving small size problems. It cannot produce an optimal solution for large-size problems in a feasible computer (run) time.

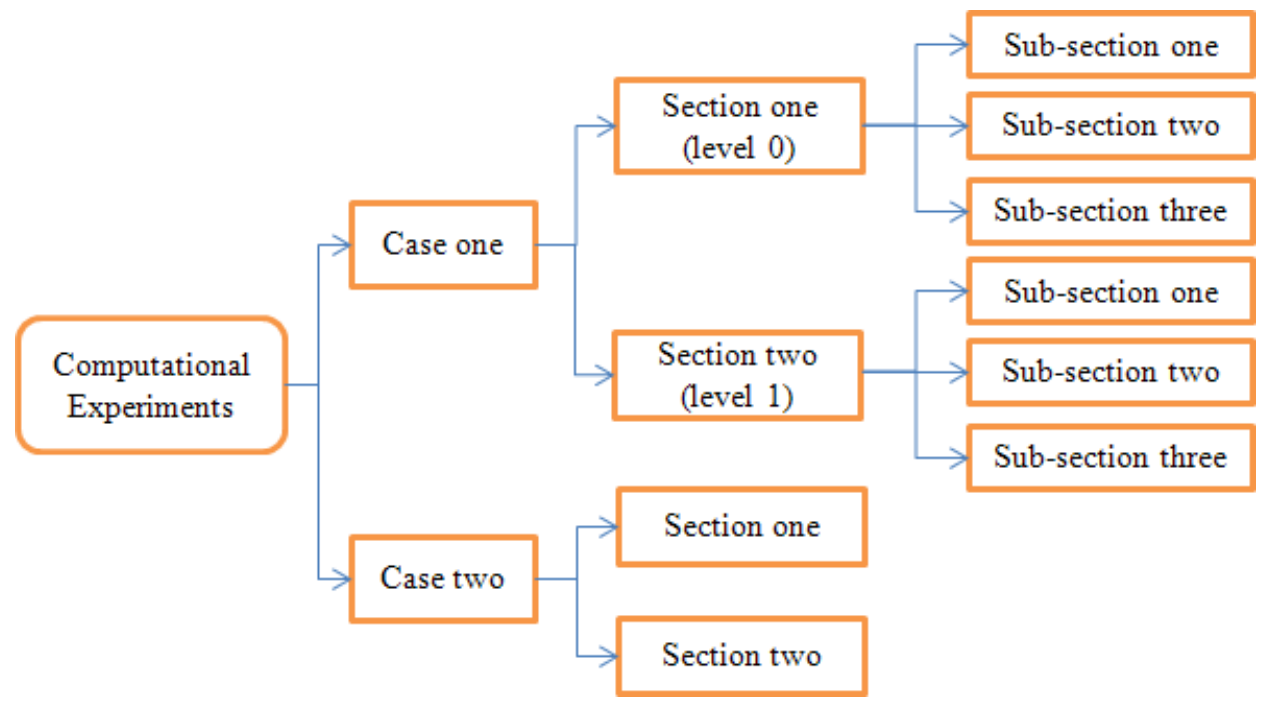

Figure 4-1 Computational experiments 
Figure 4-1 shows the design structure of cases performed for this study. The objective of the first case is to determine the impact on the variation of all the factors involved in the model at all levels $(0$ to $n)$. The aim of the second case is to investigate the size of problems that can be solved using LINGO.

\subsubsection{Eight-job problem and four stations (Case one, Section one)}

The following figure shows how the first case proposed was divided.

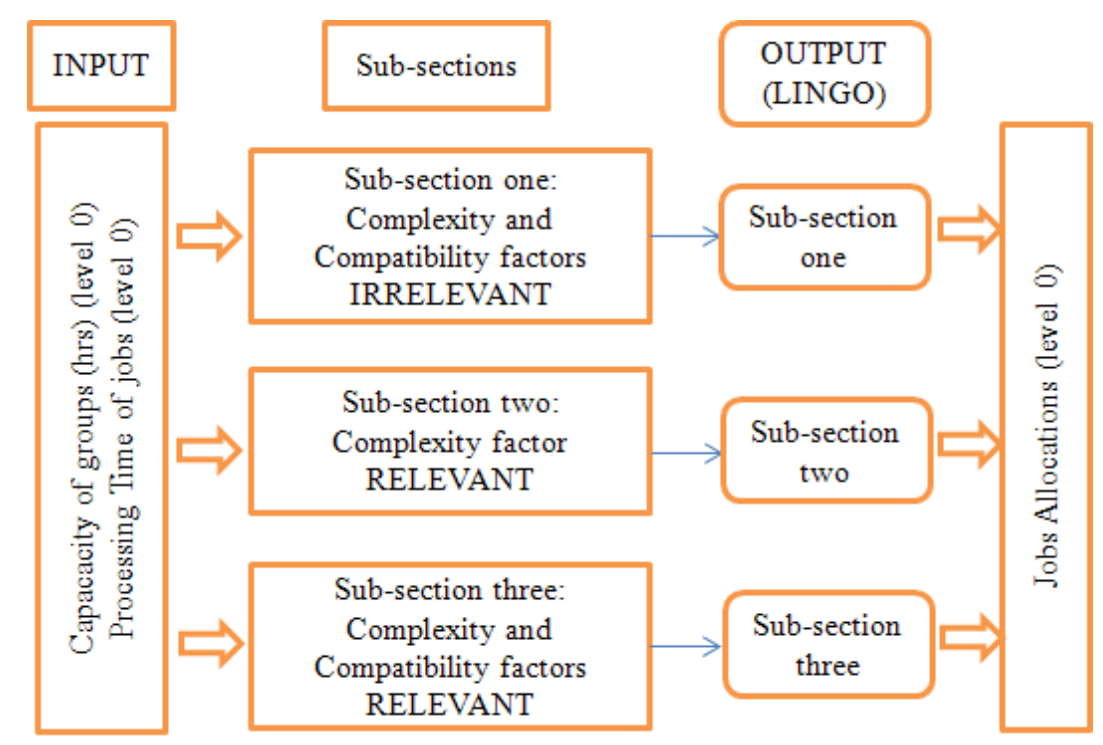

Figure 4-2 Sub-sections for analysis at level 0

It consists of two sections: the first one for allocation of jobs to workers (level 0), and section two for assignment of workers to supervisors (level 1 to $n$ ). In order to verify the allocation of jobs (from WBS) at level zero, section one was divided into three Subsections: (1) sub-section one where complexity and compatibility factors of jobs regarding the workers are irrelevant, (2) Sub-section two in order to explore the impact 
on the solution when complexity is relevant, and (3) Sub-section three in order to explore the impact of both factors in the solution.

The following figure shows, graphically, the structure of the first section of the case where there are eight jobs to be processed in four working groups.

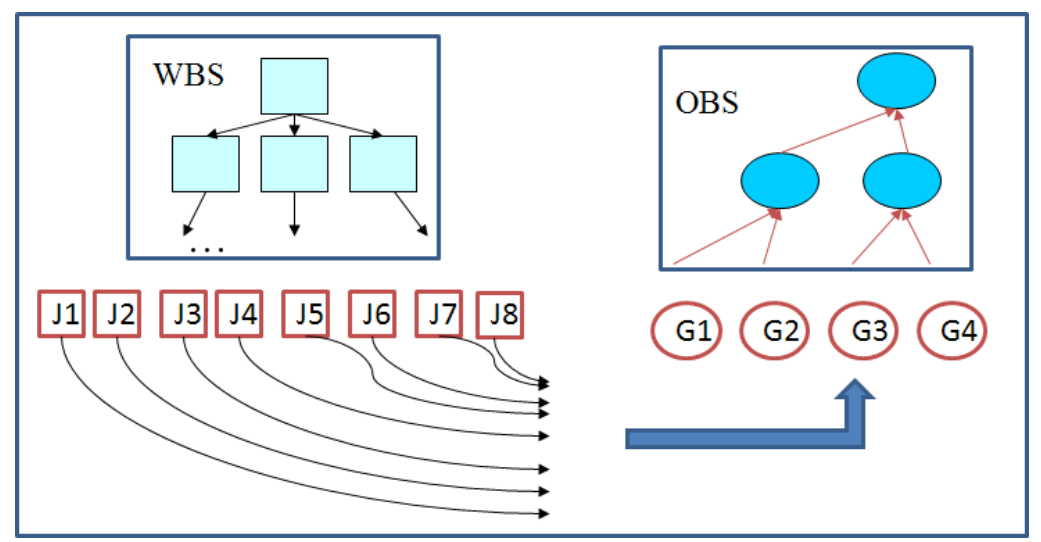

Figure 4-3 Graphical representation of Section one

The data for section one of this case consist of the capacity of each working group and the time required to accomplish each job (Table 4-1). In order to solve the model, data for level 1 and 2 need to be fed into the model (these tables are in Appendix A). All equations to run this case in LINGO are shown in Appendix A.

Table 4-1 Problem data of eight jobs and four stations

\begin{tabular}{|c|c|c|c|c|c|c|c|c|}
\hline GROUPS & \multicolumn{2}{|c|}{ G1 } & \multicolumn{2}{c|}{ G2 } & \multicolumn{2}{c|}{ G3 } & \multicolumn{2}{c|}{ G4 } \\
\hline CAPACITY (HRS) & \multicolumn{2}{|c|}{1} & \multicolumn{2}{|c|}{2} & \multicolumn{2}{c|}{1} & \multicolumn{2}{c|}{1} \\
\hline JOBS (i) & J1 & J2 & J3 & J4 & J5 & J6 & J7 & J8 \\
\hline TIME * & 0.2 & 0.3 & 0.5 & 1 & 0.8 & 0.75 & 0.1 & 0.15 \\
\hline
\end{tabular}

* Time required to accomplish the job ( $\beta$ in hours)

\subsubsection{Sub-section one}


Assuming the complexity and compatibility factors of the jobs are irrelevant to the groups, the value of the complexity and compatibility factors is equal to one, as reported in Table 4-2.

Table 4-2 Complexity $(\alpha)$ and compatibility $(\eta)$ data for case one

\begin{tabular}{|l|r|r|r|r|r|r|r|r|}
\hline \multicolumn{1}{|c|}{$\alpha=\eta$} & J1 & J2 & \multicolumn{1}{l|}{ J3 } & J4 & J5 & J6 & \multicolumn{1}{l|}{ J7 } & \multicolumn{1}{l|}{ J8 } \\
\hline G1 & 1.0 & 1.0 & 1.0 & 1.0 & 1.0 & 1.0 & 1.0 & 1.0 \\
\hline G2 & 1.0 & 1.0 & 1.0 & 1.0 & 1.0 & 1.0 & 1.0 & 1.0 \\
\hline G3 & 1.0 & 1.0 & 1.0 & 1.0 & 1.0 & 1.0 & 1.0 & 1.0 \\
\hline G4 & 1.0 & 1.0 & 1.0 & 1.0 & 1.0 & 1.0 & 1.0 & 1.0 \\
\hline
\end{tabular}

Once the model was run, the optimal solution found by the solver includes the allocation of the following jobs in working groups as shown in the table below:

Table 4-3 Job allocations (Sub-section one)

\begin{tabular}{|l|l|l|l|}
\hline \multirow{2}{*}{$\begin{array}{l}\text { GROUPS } \\
\text { (WORKERS })\end{array}$} & \multicolumn{3}{|c|}{ JOB ALLOCATIONS } \\
\cline { 2 - 4 } & Alloc \#1 & Alloc \#2 & Alloc \#3 \\
\hline G1 & ------- & ------- & ------ \\
\hline G2 & J1 & J4 & J5 \\
\hline G3 & J6 & J8 & \\
\hline G4 & J2 & J3 & J7 \\
\hline
\end{tabular}

The next figure identifies the use (in time) of each of the groups or workstations. The graph has identified the maximum capacity of each group (e.g., capacity of group 1 is less than or equal to $1, \mathrm{G} 1 \leq 1$ ). Group 2 has three job assignments with a total time of two hours, and the allocation for groups 3 and 4 has been identified in the same way. Group 1 
was not assigned, and therefore, this station can be eliminated from the design of the organizational structure.

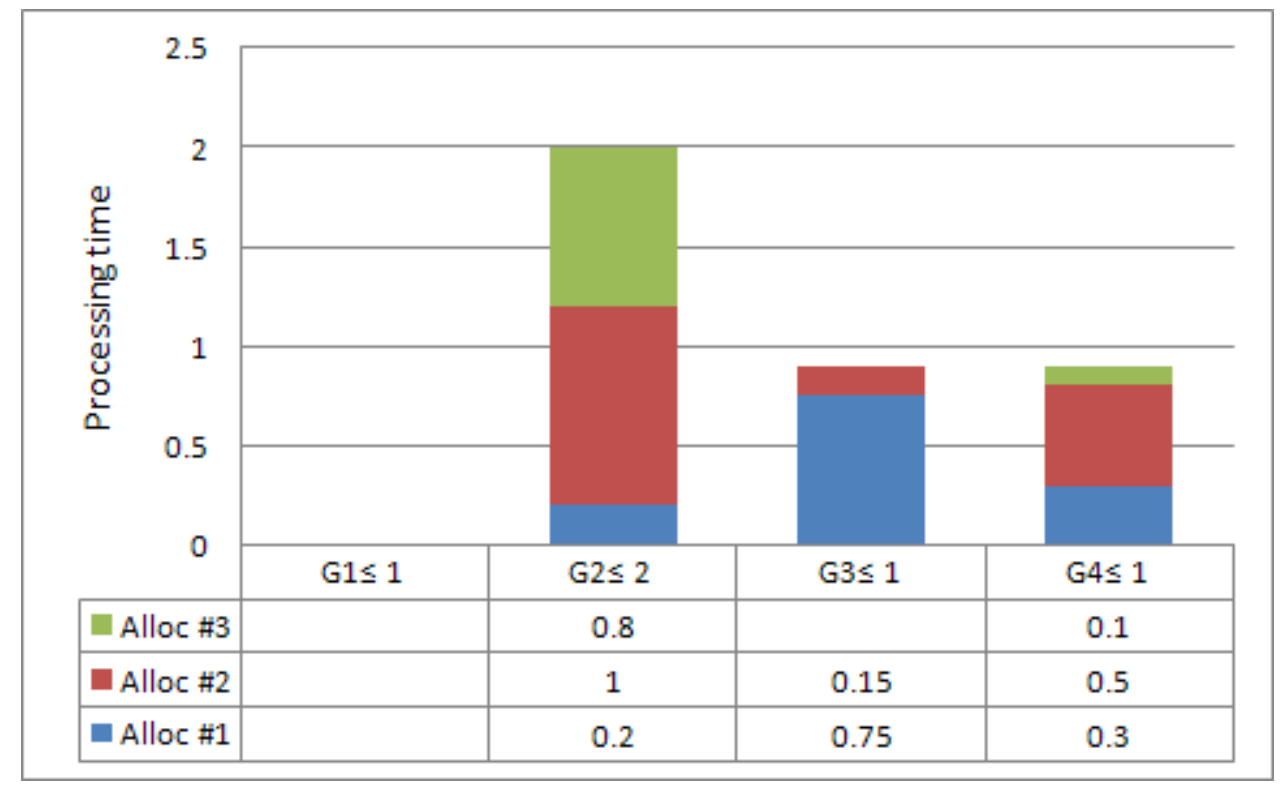

Figure 4-4 Graphical representation of results in Sub-section one

\subsubsection{Sub-section two}

This sub-section discusses the solution when the factor of complexity between jobs and workers was incorporated. To validate the model, the data for the factor shown on Table 4-4 were randomly assigned between jobs and groups. If the complexity of the jobs with regards to the groups was not irrelevant, then the problem changes according to the following data (the remaining data stay the same):

Table 4-4 Complexity $(\alpha)$ of jobs $(J)$ in relation to workers $(G)$

\begin{tabular}{|c|c|c|c|c|c|c|c|c|}
\hline \multirow{2}{*}{$\begin{array}{c}\text { GROUPS } \\
\text { (workers) }\end{array}$} & \multicolumn{10}{|c|}{ JOBS } \\
\cline { 2 - 9 } & $\mathrm{J} 1$ & $\mathrm{~J} 2$ & $\mathrm{~J} 3$ & $\mathrm{~J} 4$ & $\mathrm{~J} 5$ & $\mathrm{~J} 6$ & $\mathrm{~J} 7$ & $\mathrm{~J} 8$ \\
\hline G1 & 0.60 & 1.20 & 0.80 & 1.30 & 0.60 & 1.10 & 1.30 & 1.50 \\
\hline
\end{tabular}




\begin{tabular}{|l|l|l|l|l|l|l|l|l|} 
G2 & 0.70 & 1.30 & 0.90 & 1.20 & 0.70 & 1.40 & 1.50 & 1.60 \\
\hline G3 & 0.80 & 1.50 & 1.00 & 1.40 & 0.80 & 1.60 & 1.40 & 1.10 \\
\hline G4 & 1.00 & 1.70 & 1.50 & 1.00 & 1.00 & 1.70 & 1.30 & 1.00 \\
\hline
\end{tabular}

The previous table causes a change in the processing time required for each job with respect to each worker, updating the values according to the table below using the formula $\mathrm{a}_{\mathrm{ij}}=\beta_{\mathrm{i}} * \alpha_{\mathrm{ij}} / \eta_{\mathrm{ij}}$.

Table 4-5 Processing time after complexity data

\begin{tabular}{|c|c|c|c|c|c|c|c|c|}
\hline \multirow{2}{*}{ GROUPS } & \multicolumn{7}{|c|}{ JOBS } \\
\cline { 2 - 9 } & J1 & J2 & J3 & J4 & J5 & J6 & J7 & J8 \\
\hline G1 & 0.12 & 0.36 & 0.4 & 1.3 & 0.48 & 0.825 & 0.13 & 0.225 \\
\hline G2 & 0.14 & 0.39 & 0.45 & 1.2 & 0.56 & 1.05 & 0.15 & 0.24 \\
\hline G3 & 0.16 & 0.45 & 0.5 & 1.4 & 0.64 & 1.2 & 0.14 & 0.165 \\
\hline G4 & 0.2 & 0.51 & 0.75 & 1 & 0.8 & 1.275 & 0.13 & 0.15 \\
\hline
\end{tabular}

The optimal solution obtained by the solver gave as a result the allocation of jobs to workers according to the next table.

Table 4-6 Job allocations (Sub-section two)

\begin{tabular}{|l|l|l|l|l|}
\hline \multirow{2}{*}{$\begin{array}{l}\text { GROUPS } \\
\text { (WORKERS })\end{array}$} & \multicolumn{4}{|c|}{ JOB ALLOCATIONS } \\
\cline { 2 - 5 } & Alloc \#1 & Alloc \#2 & Alloc \#3 & Alloc \#4 \\
\hline G1 & J1 & J3 & J5 & \\
\hline G2 & J2 & J6 & J7 & J8 \\
\hline G3 & ------- & ------- & ------- & -------- \\
\hline G4 & J1 & & & \\
\hline
\end{tabular}

The chart below shows how the allocation of jobs at the workstations changed according to the complexity data. In this solution, group 1 has the assignment of three jobs, while 
all assignments of group 3 were eliminated. As the data are analyzed, job one (J1), which was assigned in the previous results to group 2, has now changed its allocation to group 1. In the complexity table, job one has the lowest value with respect to that group.

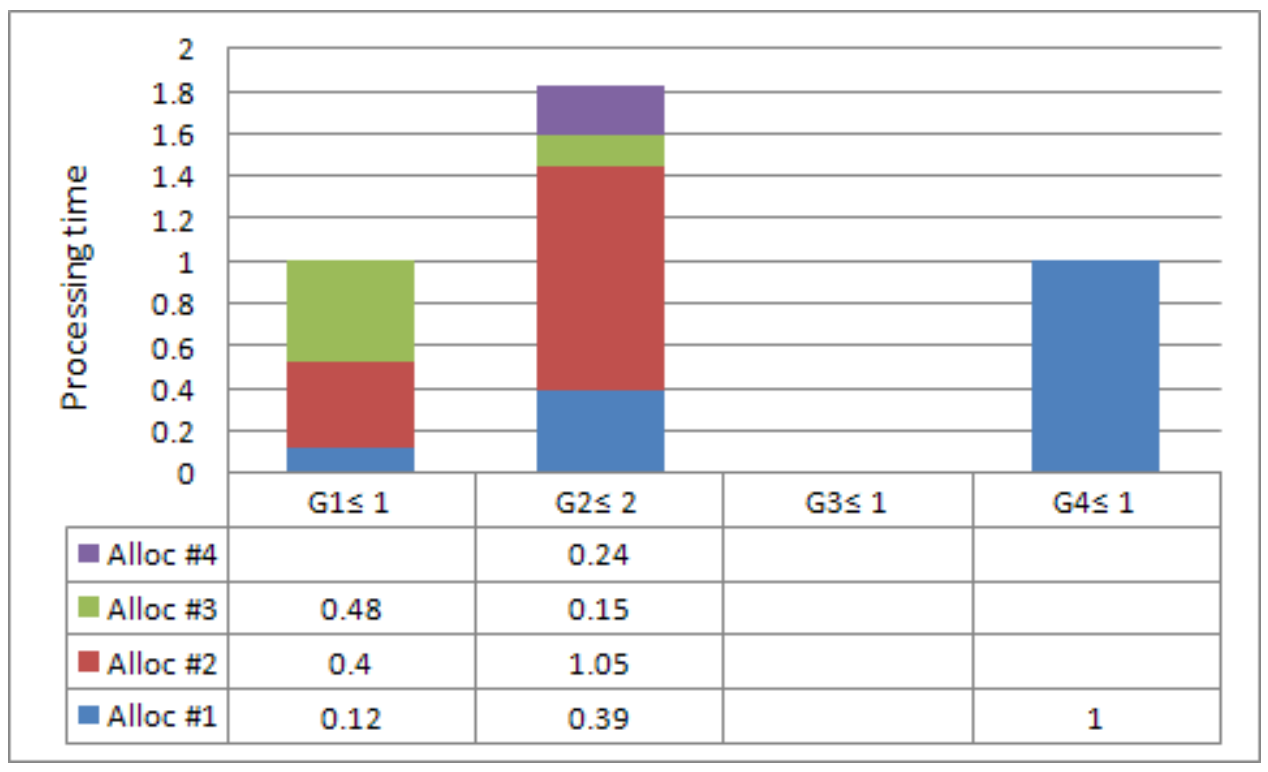

Figure 4-5 Graphical representation of results in Sub-section two

\subsubsection{Sub-section three}

This sub-section discusses the solution when the complexity and compatibility factors between jobs and workers were incorporated. To validate the model, the data for the compatibility factor were randomly assigned between jobs and groups (while complexity factor remains constant). If the complexity and the compatibility of the jobs with regards to the groups are not irrelevant, then the problem changes according to the following table (the remaining data stay the same):

Table 4-7 Compatibility $(\eta)$ for workers $(\mathrm{G})$ and jobs $(\mathrm{J})$

\begin{tabular}{l|l} 
GROUPS & JOBS
\end{tabular}




\begin{tabular}{|c|c|c|c|c|c|c|c|c|}
\cline { 2 - 8 } (workers) & $\mathrm{J} 1$ & $\mathrm{~J} 2$ & $\mathrm{~J} 3$ & $\mathrm{~J} 4$ & $\mathrm{~J} 5$ & $\mathrm{~J} 6$ & $\mathrm{~J} 7$ & $\mathrm{~J} 8$ \\
\hline $\mathrm{G} 1$ & 0.01 & 1.00 & 1.00 & 1.00 & 1.00 & 1.00 & 0.01 & 1.00 \\
\hline $\mathrm{G} 2$ & 1.00 & 0.01 & 1.00 & 1.00 & 1.00 & 0.01 & 1.00 & 0.01 \\
\hline $\mathrm{G} 3$ & 1.00 & 1.00 & 0.01 & 1.00 & 0.01 & 1.00 & 1.00 & 1.00 \\
\hline $\mathrm{G} 4$ & 1.00 & 1.00 & 1.00 & 0.01 & 1.00 & 1.00 & 1.00 & 1.00 \\
\hline
\end{tabular}

The previous table causes a change in the processing time required for each job with respect to each worker, updating the values according to the table below using the formula $\mathrm{a}_{\mathrm{ij}}=\beta_{\mathrm{i}} * \alpha_{\mathrm{ij}} / \eta_{\mathrm{ij}}$.

Table 4-8 Processing time after compatibility data

\begin{tabular}{|c|c|c|c|c|c|c|c|c|}
\hline \multirow{2}{*}{ GROUPS } & \multicolumn{7}{|c|}{ JOBS } \\
\cline { 2 - 9 } & J1 & J2 & J3 & J4 & J5 & J6 & J7 & J8 \\
\hline G1 & 12 & 0.36 & 0.4 & 1.3 & 0.48 & 0.825 & 13 & 0.225 \\
\hline G2 & 0.14 & 39 & 0.45 & 1.2 & 0.56 & 105 & 0.15 & 24 \\
\hline G3 & 0.16 & 0.45 & 50 & 1.4 & 64 & 1.2 & 0.14 & 0.165 \\
\hline G4 & 0.2 & 0.51 & 0.75 & 100 & 0.8 & 1.275 & 0.13 & 0.15 \\
\hline
\end{tabular}

The optimal solution obtained by the solver gave as a result the allocation of jobs to workers according to the following table:

Table 4-9 Job Allocations (Sub-section three)

\begin{tabular}{|l|l|l|l|l|}
\hline \multirow{2}{*}{$\begin{array}{l}\text { GROUPS } \\
\text { (WORKERS) }\end{array}$} & \multicolumn{4}{|c|}{ JOB ALLOCATIONS } \\
\cline { 2 - 5 } & Alloc \#1 & Alloc \#2 & Alloc \#3 & Alloc \#4 \\
\hline G1 & J6 & & & \\
\hline
\end{tabular}




\begin{tabular}{|l|l|l|l|l|}
\hline G2 & J3 & J4 & & \\
\hline G3 & J1 & J2 & J7 & J8 \\
\hline G4 & J5 & & & \\
\hline
\end{tabular}

The figure below shows how the allocation of jobs at the workstations changed according to the complexity and the compatibility data. In this case, the model does not make any allocation of those jobs that don't have compatibility with the groups. For example, group 1 doesn't have jobs 1 and 7 assigned; group 2 doesn't have jobs 2, 6 and 8 assigned; group 3 doesn't have jobs 3 and 5 assigned; and group 4 doesn't have job 4 assigned due to the fact that they are not compatible. These constraints force the model to consider a longer processing time of jobs, and therefore, the solution to this problem involves 4 groups instead of 3 .

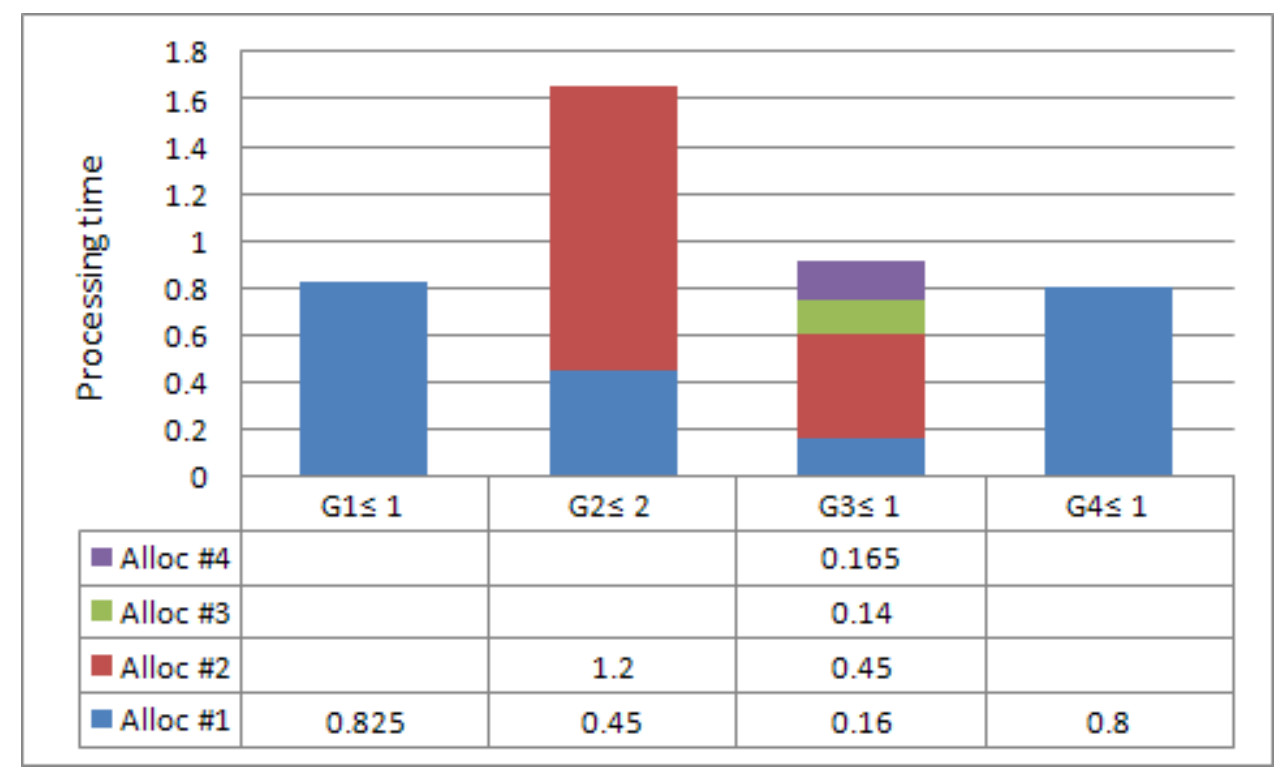

Figure 4-6 Graphical representation of results in Sub-section three 
The conclusion in this section one shows that the model minimizes the number of workstations looking for jobs that have the best processing time, avoiding the selection of jobs without compatibility to the assigned station. The following table shows how the job allocations were being re-organized in the different groups according to the complexity and compatibility factors within the model. Also, the chart below shows how the utilization (processing time) of each of group is changing according to the conditions of each Sub-section. Capacity constraint of each group was maintained in all Sub-sections.

Table 4-10 Job Allocations (Sub-sections one, two and three)

\begin{tabular}{|c|l|l|l|l|}
\hline \multirow{2}{*}{$\begin{array}{c}\text { Sub- } \\
\text { sections }\end{array}$} & \multicolumn{4}{|c|}{ GROUPS (WORKERS) } \\
\cline { 2 - 5 } & G1 & \multicolumn{1}{|c|}{ G2 } & G3 & G4 \\
\hline 1 & & J1-J4-J5 & J6-J8 & J2-J3-J7 \\
\hline 2 & J1-J3-J5 & J2-J6-J7-J8 & & J1 \\
\hline 3 & J1-J7 & J2-J6-J8 & J3-J5 & J4 \\
\hline
\end{tabular}

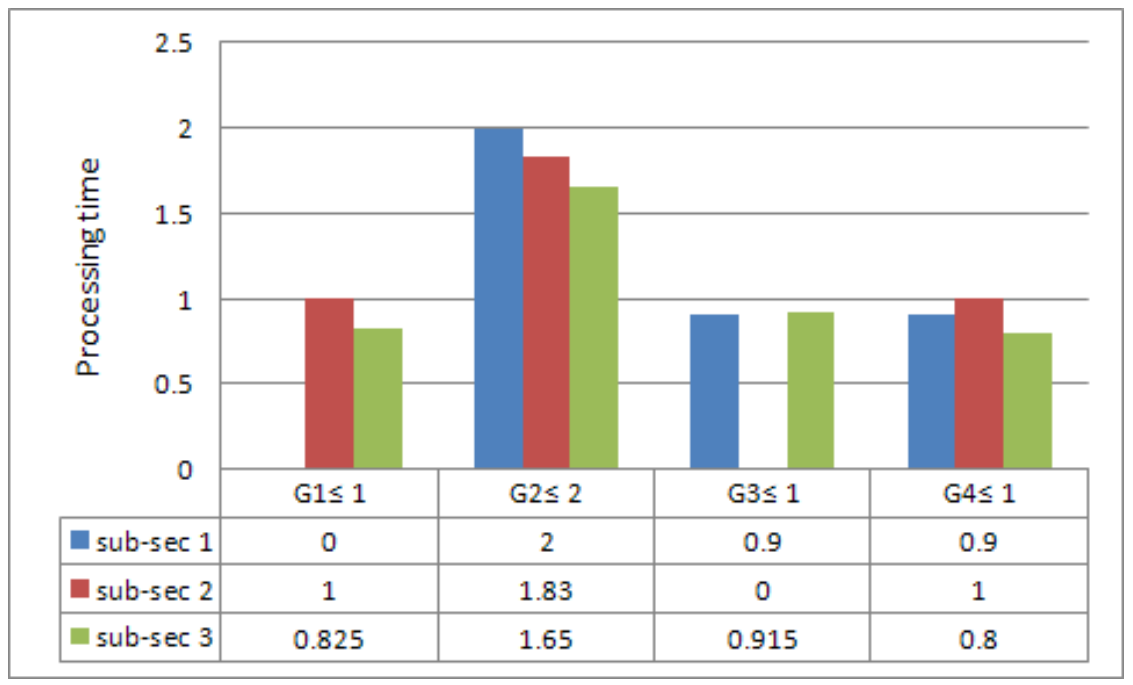

Figure 4-7 Utilization of each group en each Sub-section 


\subsubsection{Case one: Section two (Level 1 to $n$ )}

Once the validation of the model for level 0 (job allocations) was implemented, section two analyzes the impact of the factors involved in the supervision effort. This section analyzes the effect of changing the values of the different parameters for supervising. Taking the data and results of Sub-section two (from Section one), the results of level 0 were used to analyze the variation in the following levels of decision.

\subsubsection{Sub-section one}

The following table shows the capacity and cost of supervisors (level 1). This sub-section has been assigned a minimum value to the factors of supervision (close to zero).

Table 4-11 Data for Sub-section two (levels $0 \rightarrow 1$ )

\begin{tabular}{|c|c|c|c|c|}
\hline \multirow{2}{*}{$\begin{array}{l}\text { DATA OF SUPERVISORS } \\
\text { LEVEL } 0 \rightarrow 1\end{array}$} & & \multicolumn{3}{|c|}{ SUPERVISORS } \\
\hline & & S1 & S2 & S3 \\
\hline \multicolumn{2}{|l|}{ CAPACITY (Hrs) } & 3 & 2 & 1 \\
\hline \multicolumn{2}{|l|}{$\operatorname{COST}(\mathrm{w})$} & $\$ 200$ & $\$ 150$ & $\$ 100$ \\
\hline FACTORS OF & \multicolumn{4}{|c|}{ WORKERS (GROUPS) } \\
\hline SUPERVISOR EFFORT & G1 & $\mathrm{G} 2$ & G3 & G4 \\
\hline PLANNING $(\rho)$ & 0.01 & 0.05 & 0.1 & 0.2 \\
\hline CONTROL (c) & 0.01 & 0.05 & 0.1 & 0.2 \\
\hline TRAINING $(\mathrm{t})$ & 0.01 & 0.05 & 0.1 & 0.2 \\
\hline EXECUTION (e) & 0.01 & 0.05 & 0.1 & 0.2 \\
\hline
\end{tabular}


The following table shows the capacity and cost of managers (level 2). This Sub-section has been assigned a minimum value to the manager factors (close to zero).

Table 4-12 Data for Sub-section two (levels $1 \rightarrow 2$ )

\begin{tabular}{|c|c|c|c|}
\hline \multirow{2}{*}{$\begin{array}{l}\text { DATA OF MANAGERS } \\
\text { LEVEL } 1 \rightarrow 2\end{array}$} & & \multicolumn{2}{|c|}{ MANAGERS } \\
\hline & & M1 & M2 \\
\hline CAPACITY (Hrs) & & 3 & 3 \\
\hline $\operatorname{cosT}(\mathrm{w})$ & & $\$ 450$ & $\$ 500$ \\
\hline FACTORS OF & & PERVIS & $\mathrm{RS}$ \\
\hline MANAGER EFFORT & S1 & S2 & S3 \\
\hline PLANNING $(\rho)$ & 0.01 & 0.05 & 0.1 \\
\hline CONTROL (c) & 0.01 & 0.05 & 0.1 \\
\hline TRAINING (t) & 0.01 & 0.05 & 0.1 \\
\hline EXECUTION (e) & 0.01 & 0.05 & 0.1 \\
\hline
\end{tabular}

Once the allocation of jobs to working groups has been done (from Sub-section two of Section 1), supervisors and managers are selected taking into account the cost and capacity, as well as the planning, control, training, and execution factors of each.

Results of this Sub-section show that the values given for the supervisor factors, only requires the supervisor 3 with a minimum cost of $\$ 100$; for level 2 the solution requires only the manager 2 with a minimum cost of $\$ 1350$, giving a total minimum cost of $\$ 1453$. 
Table 4-13 Supervisor allocations (Sub-section one)

\begin{tabular}{|l|l|l|l|l|l|}
\hline $\begin{array}{l}\text { SUPERVISORS } \\
\text { (LEVEL 1) }\end{array}$ & GROUPS & COST & $\begin{array}{l}\text { MANAGERS } \\
\text { (LEVEL 2) }\end{array}$ & SUPERVISORS & COST \\
\hline S1 & ------ & ----- & M1 & S3 & $\$ 1350$ \\
\hline S2 & ------ & ----- & M2 & ----- & \\
\hline S3 & G1-G2-G4 & $\$ 100$ & TOTAL COSTS & $\$ 1453$ \\
\hline
\end{tabular}

\subsubsection{Sub-section two}

This Sub-section analyzes the behavior of the results of the model increasing (randomly) the requirements for each of the factors involved, as shown in the following table:

Table 4-14 Supervisor factors (levels $0 \rightarrow 1$ )

\begin{tabular}{|c|c|c|c|c|}
\hline \multirow{2}{*}{$\begin{array}{c}\text { GROUPS } \\
\text { (workers) }\end{array}$} & \multicolumn{4}{|c|}{ SUPERVISOR FACTORS } \\
\cline { 2 - 5 } & PLANNING $(\rho)$ & CONTROL (c) & TRAINING (t) & EXECUTION(e) \\
\hline G1 & 0.1 & 0.1 & 0.1 & 0.1 \\
\hline G2 & 0.12 & 0.12 & 0.12 & 0.12 \\
\hline G3 & 0.15 & 0.15 & 0.15 & 0.15 \\
\hline G4 & 0.2 & 0.2 & 0.2 & 0.2 \\
\hline
\end{tabular}

For the following level two, the values of the factors are also increased according to the table below:

Table 4-15 Manager factors (levels $1 \rightarrow 2$ )

\begin{tabular}{|c|c|c|c|c|}
\hline SUPER- & \multicolumn{4}{|c|}{ MANAGER FACTORS } \\
\cline { 2 - 5 } VISORS & PLANNING $(\rho)$ & CONTROL $(\mathrm{c})$ & TRAINING $(\mathrm{t})$ & EXECUTION (e) \\
\hline S1 & 0.1 & 0.1 & 0.1 & 0.1 \\
\hline
\end{tabular}




\begin{tabular}{|l|l|l|l|l|} 
S2 & 0.12 & 0.12 & 0.12 & 0.12 \\
\hline S3 & 0.15 & 0.15 & 0.15 & 0.15 \\
\hline
\end{tabular}

Results of this Sub-section show that increasing the values of supervisor factors also increases the requirements of supervision hours. Therefore the decision changes to supervisor 2, who has a higher capacity, while also increasing the cost of this level (1). The result for level two remains the same and the total cost increases, as shown in the following table:

Table 4-16 Supervisor allocations (Sub-section two)

\begin{tabular}{|l|l|l|l|l|l|}
\hline $\begin{array}{l}\text { SUPERVISORS } \\
\text { (LEVEL 1) }\end{array}$ & GROUPS & COST & $\begin{array}{l}\text { MANAGERS } \\
\text { (LEVEL 2) }\end{array}$ & SUPERVISORS & COST \\
\hline S1 & ------ & ----- & M1 & S3 & $\$ 1350$ \\
\hline S2 & G1-G2-G4 & $\$ 300$ & M2 & ------ & \\
\hline S3 & ------ & ----- & \multicolumn{2}{|l|}{ TOTAL COSTS } & $\$ 1653$ \\
\hline
\end{tabular}

\subsubsection{Sub-section three}

Sub-section three explores the impact of assigning the maximum value of the supervisor factors. The maximum value assigned to each of the factors is 0.25 , which implies that the sum of the factors is equal to one, and therefore, one hour of supervision is required for each hour assigned to the worker. The values of the factors for this sub-section appear in the following tables:

Table 4-17 Supervisor factors (levels $0 \rightarrow 1$ )

\begin{tabular}{|c|c|c|c|c|}
\hline $\begin{array}{c}\text { GROUPS } \\
\text { (workers) }\end{array}$ & \multicolumn{5}{|c|}{ SUPERVISOR FACTORS } \\
\cline { 2 - 5 } & PLANNING $(\rho)$ & CONTROL $(\mathrm{c})$ & TRAINING (t) & EXECUTION(e) \\
\hline
\end{tabular}




\begin{tabular}{|l|l|l|l|l|} 
G1 & 0.25 & 0.25 & 0.25 & 0.25 \\
\hline G2 & 0.25 & 0.25 & 0.25 & 0.25 \\
\hline G3 & 0.25 & 0.25 & 0.25 & 0.25 \\
\hline G4 & 0.25 & 0.25 & 0.25 & 0.25 \\
\hline
\end{tabular}

For the following level two, the value or factors was also assigned in such a way that one hour of supervision requires one hour from the manager at the next hierarchical level, as shown in the table below:

Table 4-18 Manager factors (levels $1 \rightarrow 2$ )

\begin{tabular}{|c|c|c|c|c|}
\hline \multirow{2}{*}{$\begin{array}{c}\text { SUPER- } \\
\text { VISORS }\end{array}$} & \multicolumn{4}{|c|}{ MANAGERS FACTORS } \\
\cline { 2 - 5 } & PLANNING $(\rho)$ & CONTROL $(\mathrm{c})$ & TRAINING $(\mathrm{t})$ & EXECUTION (e) \\
\hline S1 & 0.25 & 0.25 & 0.25 & 0.25 \\
\hline S2 & 0.25 & 0.25 & 0.25 & 0.25 \\
\hline S3 & 0.25 & 0.25 & 0.25 & 0.25 \\
\hline
\end{tabular}

Results of this Sub-section show that increasing the values of supervisor factors (sum equals to one), also increases the requirements of supervision hours. Therefore the decision changes to supervisor 2 and 3 increasing the cost of this level (1). The result for level two includes both managers and the total cost increases, as shown in the following table:

Table 4-19 Supervisor allocations (Sub-section three)

\begin{tabular}{|l|l|l|l|l|l|}
\hline $\begin{array}{l}\text { SUPERVISORS } \\
\text { (LEVEL 1) }\end{array}$ & GROUPS & COST & $\begin{array}{l}\text { MANAGERS } \\
\text { (LEVEL 2) }\end{array}$ & SUPERVISORS & COST \\
\hline S1 & ------ & ----- & M1 & S2 & $\$ 1350$ \\
\hline S2 & G2-G4 & $\$ 300$ & M2 & S3 & $\$ 550$ \\
\hline
\end{tabular}




\begin{tabular}{|l|l|l|l|l|}
\hline S3 & G1 & $\$ 100$ & TOTAL COST & $\$ 2303$ \\
\hline
\end{tabular}

In this Section two, increasing the planning, execution, control, or training requirements, also increases the time required for each supervisor, increasing as a result, the total cost. The data of cost (w) and capacities (f) of supervisors and managers have remained constant in order to know how they influence the values of the factors mentioned before.

\subsubsection{Limit size problem for a commercial solver (Case two)}

For this research, it is important to know the size of the problem that the commercial solver could handle, in order to know what size of problems is feasible to get an optimal solution. For bigger problems, a heuristic method that is able to get a good quality solution is required. Therefore, the main objective in this Case two is to determine the number of constraints and variables that the commercial solver can handle. After several experiments with LINGO, it is concluded that the software can handle problems with up to 30 jobs and 10 groups. In this case, supervising parameters were selected close to zero and then close to one to review how the allocation of supervisory requirements was affected. Data of capacity, time, complexity, and compatibility factors for a problem instance of 30 jobs and 10 groups at level 0 is found in Appendix A (this data is the same for both Sections).

\subsubsection{Case two, Section one}

The following table shows the capacity and cost of supervisors (level 1):

Table 4-20 Capacity $(\alpha)$ and cost $(\alpha)$ data for levels $0 \rightarrow 1$

DATA OF SUPERVISORS
SUPERVISORS 


\begin{tabular}{|l|l|l|l|l|l|}
\hline LEVEL $0 \rightarrow 1$ & S1 & S2 & S3 & S4 & S5 \\
\hline CAPACITY (f) (Hrs) & 4 & 4 & 4 & 8 & 8 \\
\hline COST $(\mathrm{w})$ & $\$ 50$ & $\$ 100$ & $\$ 150$ & $\$ 200$ & $\$ 250$ \\
\hline
\end{tabular}

This sub-section has been assigned a minimum value to the factors of supervision (close to zero) as in the following table:

Table 4-21 Supervisor factors (Case two)

\begin{tabular}{|c|c|c|c|c|}
\hline \multirow{2}{*}{ GROUPS } & \multicolumn{4}{|c|}{ SUPERVISOR FACTORS } \\
\cline { 2 - 5 } & $\begin{array}{c}\text { PLANNING } \\
(\rho)\end{array}$ & $\begin{array}{c}\text { CONTROL } \\
(\mathrm{c})\end{array}$ & $\begin{array}{c}\text { TRAINING } \\
(\mathrm{t})\end{array}$ & $\begin{array}{c}\text { EXECUTION } \\
(\mathrm{e})\end{array}$ \\
\hline G1 & 0.01 & 0.01 & 0.02 & 0.03 \\
\hline G2 & 0.001 & 0.004 & 0.003 & 0.02 \\
\hline G3 & 0.01 & 0.01 & 0.02 & 0.03 \\
\hline G4 & 0.005 & 0.06 & 0.02 & 0.01 \\
\hline G5 & 0.01 & 0.01 & 0.02 & 0.03 \\
\hline G6 & 0.001 & 0.004 & 0.003 & 0.02 \\
\hline G7 & 0.01 & 0.01 & 0.02 & 0.03 \\
\hline G8 & 0.001 & 0.004 & 0.003 & 0.02 \\
\hline G9 & 0.01 & 0.01 & 0.02 & 0.03 \\
\hline G10 & 0.001 & 0.004 & 0.003 & 0.02 \\
\hline
\end{tabular}

The following table shows the capacity and cost of managers (level 2):

Table 4-22 Capacity $(\alpha)$ and $\operatorname{cost}(\alpha)$ data for levels $1 \rightarrow 2$

\begin{tabular}{|l|l|l|l|}
\hline DATA OF MANAGERS & \multicolumn{3}{|c|}{ MANAGERS } \\
\cline { 2 - 4 } LEVEL $1 \rightarrow 2$ & M1 & M2 & M3 \\
\hline CAPACITY (f) (Hrs) & 4 & 8 & 8 \\
\hline
\end{tabular}




\begin{tabular}{|l|l|l|l|}
\hline $\operatorname{COST}(\mathrm{w})$ & $\$ 100$ & $\$ 200$ & $\$ 30$ \\
\hline
\end{tabular}

For the following level two, the values of the factors are according to the table below:

Table 4-23 Manager factors (Case two)

\begin{tabular}{|c|c|c|c|c|}
\hline \multirow[b]{2}{*}{$\begin{array}{l}\text { SUPE- } \\
\text { VISORS }\end{array}$} & \multicolumn{4}{|c|}{ MANAGER FACTORS } \\
\hline & $\begin{array}{c}\text { PLANNING } \\
\text { (р) }\end{array}$ & $\begin{array}{l}\text { CONTROL } \\
\text { (c) }\end{array}$ & $\begin{array}{c}\text { TRAINING } \\
\text { (t) }\end{array}$ & $\begin{array}{l}\text { EXECUTION } \\
\text { (e) }\end{array}$ \\
\hline S1 & 0.002 & 0.003 & 0.01 & 0.02 \\
\hline $\mathrm{S} 2$ & 0.002 & 0.003 & 0.01 & 0.02 \\
\hline S3 & 0.002 & 0.003 & 0.01 & 0.02 \\
\hline S4 & 0.002 & 0.003 & 0.01 & 0.02 \\
\hline S5 & 0.002 & 0.003 & 0.01 & 0.02 \\
\hline
\end{tabular}

Results for job allocations for this case are shown in table below:

Table 4-24 Job allocations (Case two)

\begin{tabular}{|l|l|l|l|}
\hline GROUPS & G1 & G3 & G4 \\
\hline JOBS & $\begin{array}{l}\text { J3-J4-J5-J6-J8-J10-J13- } \\
\text { J16-J18-J24-J25-J28 }\end{array}$ & $\begin{array}{l}\text { J1-J2-J9-J12-J20- } \\
\text { J22-J27-J17 }\end{array}$ & $\begin{array}{l}\text { J7-J11-J14-J15-J19- } \\
\text { J21-J23-J26-J29-J30 }\end{array}$ \\
\hline
\end{tabular}

Results for level 1 and 2, regarding the assignment of groups to supervisors and supervisors to managers are in the following table. This sub-section only requires one supervisor (S1) and one manager (M1) with a total cost of $\$ 603$.

Table 4-25 Supervisor and manager allocations (Section one)

\begin{tabular}{|l|l|l|l|l|l|}
\hline $\begin{array}{l}\text { SUPERVISORS } \\
\text { (LEVEL 1) }\end{array}$ & GROUPS & COST & $\begin{array}{l}\text { MANAGERS } \\
\text { (LEVEL 2) }\end{array}$ & SUPERVISORS & COST \\
\hline S1 & G1-G2-G3 & $\$ 200$ & M1 & S1 & $\$ 400$ \\
\hline
\end{tabular}




\begin{tabular}{|l|l|l|l|l|l|}
\hline S2 & ------ & ---- & M2 & ---- & ------- \\
\hline S3 & ------ & ----- & M3 & ---- & ------- \\
\hline S4 & ------ & ------ & TOTAL COST & $\$$ \\
\cline { 1 - 3 } S5 & -------- & ------ & & \\
\hline
\end{tabular}

\subsubsection{Case two, Section two}

This section two explores the impact of assigning the maximum value of the supervisor factors. The maximum value assigned to each of the factors is 0.25 , which implies that the sum of the factors is equal to one, and therefore, one hour of supervision is required for each hour assigned to the worker. The values of the supervisor factors for this Section appear in the following table:

Table 4-26 Supervisor factors (Section two)

\begin{tabular}{|c|c|c|c|c|}
\hline \multirow{2}{*}{ GROUPS } & \multicolumn{4}{|c|}{ SUPERVISOR FACTORS } \\
\cline { 2 - 5 } & $\begin{array}{c}\text { PLANNING } \\
(\rho)\end{array}$ & $\begin{array}{c}\text { CONTROL } \\
(\mathrm{c})\end{array}$ & $\begin{array}{c}\text { TRAINING } \\
(\mathrm{t})\end{array}$ & $\begin{array}{c}\text { EXECUTION } \\
(\mathrm{e})\end{array}$ \\
\hline G1 & 0.1 & 0.2 & 0.2 & 0.1 \\
\hline G2 & 0.2 & 0.2 & 0.3 & 0.1 \\
\hline G3 & 0.1 & 0.2 & 0.2 & 0.1 \\
\hline G4 & 0.2 & 0.2 & 0.3 & 0.1 \\
\hline G5 & 0.1 & 0.2 & 0.2 & 0.1 \\
\hline G6 & 0.2 & 0.2 & 0.3 & 0.1 \\
\hline G7 & 0.1 & 0.2 & 0.2 & 0.1 \\
\hline G8 & 0.2 & 0.2 & 0.3 & 0.1 \\
\hline G9 & 0.1 & 0.2 & 0.2 & 0.1 \\
\hline G10 & 0.2 & 0.2 & 0.3 & 0.1 \\
\hline
\end{tabular}

The values of the manager factors for this Section appear in the following table: 
Table 4-27 Manager factors (Section two)

\begin{tabular}{|c|c|c|c|c|}
\hline \multirow{2}{*}{$\begin{array}{c}\text { SUPER- } \\
\text { VISORS }\end{array}$} & \multicolumn{4}{|c|}{ MANAGER FACTORS } \\
\cline { 2 - 5 } & PLANNING & CONTROL & TRAINING & EXECUTION \\
$(\mathrm{c})$ & 0.2 & 0.2 & 0.1 \\
\hline S1 & 0.1 & 0.2 & 0.3 & 0.1 \\
\hline S2 & 0.2 & 0.2 & 0.2 & 0.1 \\
\hline S3 & 0.1 & 0.2 & 0.3 & 0.1 \\
\hline S4 & 0.2 & 0.2 & 0.3 & 0.1 \\
\hline S5 & 0.2 & & & \\
\hline
\end{tabular}

The number of groups remains constant since there were no changes in the complexity and compatibility of jobs with respect to workers (groups). Increases in the requirements of planning, control, execution, and training resulted in an increase in the number of supervisors (1 to 2$)$ and for the next level in the selection of a manager with higher capacity. Results for level 1 and 2, regarding the assignment of workers to supervisors and supervisors to managers are in the following table. This Section requires two supervisors (S1 and S2) and one manager (M2) with a total cost of \$2203, increasing the total cost by $230 \%$.

Table 4-28 Supervisor and manager allocations (Section two)

\begin{tabular}{|l|l|l|l|l|l|}
\hline $\begin{array}{l}\text { SUPERVISORS } \\
(\text { LEVEL 1 })\end{array}$ & GROUPS & COST & $\begin{array}{l}\text { MANAGERS } \\
(\text { LEVEL })\end{array}$ & SUPERVISORS & COST \\
\hline S1 & G1 & $\$ 200$ & M1 & ----- & \\
\hline S2 & G2-G3 & $\$ 400$ & M2 & S1,S2 & $\$ 1600$ \\
\hline S3 & ------ & ----- & M3 & ---- & \\
\hline S4 & ------- & ------ & TOTAL COST & $\$ 2203$ \\
\hline
\end{tabular}




\begin{tabular}{|l|l|l|l|l|}
\hline S5 & -------- & ----- & & \\
\hline
\end{tabular}

4.4 Conclusions

Analysis has been carried out at least in 40 separate cases in order to ensure that allocations occur in a logical way as the data were fed into the system. The number of jobs, groups, supervisors, and managers had a significant impact on the computational cost because the number of variables had an exponential growth. In this case, the combination of jobs with groups had the highest impact. Increasing the number of jobs and groups after 30 jobs and 10 groups dramatically increases computational requirements.

The allocations made by the model with LINGO indicate that it works by making the correct allocation of activities taking into account the complexity and compatibility of the jobs with respect to each group for level 0 . For levels 1 and 2, supervisors and managers were selected in order to have the capacity to monitor and manage all the working groups, and it is also optimal for carrying out such activities considering factors of planning, control, training, and execution. In these cases, the model makes the assignment based on capacity and cost of supervision and management.

Conclusions regarding the cases report that the size of span is greater in the lower level, but smaller in the higher level. The more complex the subordinates' tasks (associated with complexity factors), the smaller the supervisor's span of control. The more complex the supervisor's tasks (associated with supervisor factors), the narrower the span of control. Solving these cases concludes that the model is functional and takes into account all the constraints that were designed for the model. 


\section{VALUATION OF COEFFICIENTS AFFECTING MODELING FACTORS}

The objective of this chapter is to determine a method to quantify the factors that determine the allocation of jobs to workers (level 0 ), and those related with supervising time, divided into the following factors: planning, control, execution, and training. In order to do this, the level of importance between the factors has to be determined, and a quantitative range has to be identified with which it is possible to make an objective measurement that can be incorporated in solving the mathematical model proposed. This part of the research is conducted through the study of the activities of people who have supervisory duties. For this purpose, data were collected from four different Information System (IS) companies in the city of Chihuahua, Mexico.

\subsection{Complexity and compatibility factors (level 0$)$}

The objectives pursued with the following method are based in two points: (1) determining their existing workers' OP-types and skill levels, and (2) assigning the workers to their complexity and compatibility factors at an appropriate level regarding the jobs. The method for assessment of the complexity and compatibility factors at level zero is based on the information of a job proposed to the company which consists of the jobs to be completed, the OP-Type, and the level of skill (required to complete each job). The theoretical foundation for this method is based on the analysis of workers' skills, and makes a comparison with respect to the skills required for a particular job. The following figures show the steps needed for this process. The proposed model is partially built on the one developed by Depuy et al. [29]. 


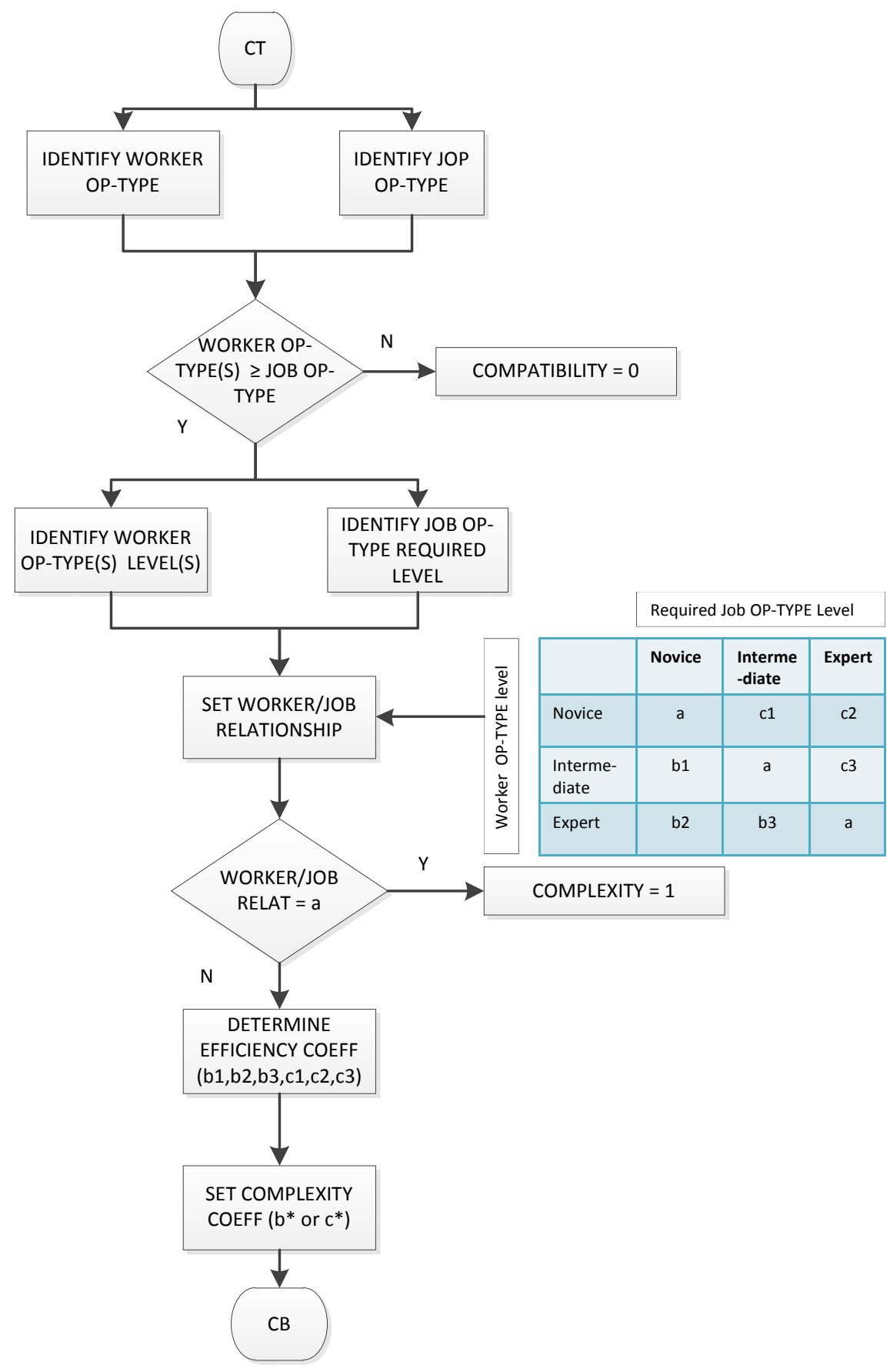

Figure 5-1 Method for complexity factor

On the left side (worker), the first step is to identify the skills (OP-Types) of the worker.

Once the different skills of each worker have been established, the next step is to determine, based on technical tests, the level of each skill. On the right side (job), the OP- 
Type and required skills of each job are defined. Next step is to determine the required skill level of each job. In order to assign a skill relationship between jobs and workers, it is necessary to design a skill relationship table. For this table, the first step is to determine how many levels are required (e.g., novice, intermediate, expert), and the numerical relationship between the different combinations (e.g., novice-novice, noviceintermediate, novice-expert).

As an example, consider a project with a total number of three jobs with three required skills identified, and each skill is further defined by a skill level ranging from 1- novice, 2- intermediate, and 3- expert. Some jobs can require the same skill, but at different levels. Multiple jobs can be assigned to the same employee, subject to a capacity constraint. The figure below shows the following situation: worker 1 (group G1) has the skills 1 and 3, with skill levels of 1 and 2, such that, if assigned to job 1, there would be the same skills relationship, and therefore, the complexity factor would be 1 . If however, that same employee were assigned to job 2, there would be a skills relationship of "intermediate-expert", and therefore, according to Table 4-1, the complexity factor would be 1.5. If worker 1 were assigned to job 3 , there would not be a skills relationship, and therefore, the compatibility factor would be close to zero.

Once the relationship between workers and jobs has been established, the complexity factor is determined based on Table 5-1. 


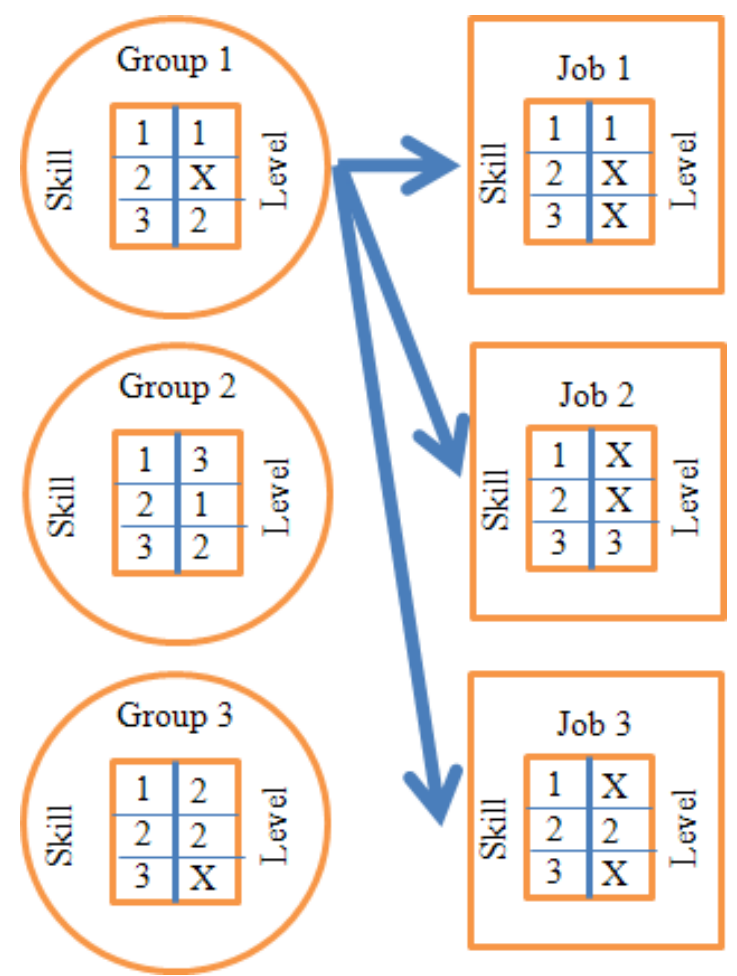

Figure 5-2 Example of skills and skill levels between workers and jobs Table 5-1 Complexity factors

\begin{tabular}{|c|c|c|c|c|}
\hline & & \multicolumn{2}{|c|}{ Req Job Skill } & \\
\hline \multirow{4}{*}{ 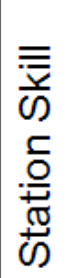 } & Station/Job & Novice (1) & Inter (2) & Expert (3) \\
\hline & Novice (1) & 1 & 1.5 & 2 \\
\hline & Inter (2) & 0.8 & 1 & 1.5 \\
\hline & Expert (3) & 0.6 & 0.8 & 1 \\
\hline
\end{tabular}

The previous table is based on the relationship found by analyzing 20 individual events in the companies selected for this study. This general format can be applied to any industry, as long as the values assigned to each of the relationships (e.g., novice-intermediate equals 1.5) are reviewed. It is clear that the weights that are equal to one are the same for 
any situation, where the same worker skill level against the same job skill level required is compared. For the rest of the relationships, there must be an adjustment made depending on the situations in which this format will be used. Therefore, a relationship of a worker skill level "expert" for a job skill level requirement of "novice" is set for the worker to require only a $60 \%$ of standard time to do such work. In a different situation, this percentage may be lower (30-50\%) or higher (70-90\%).

The compatibility factor, as shown in the following figure, verifies the compatibility and then assigns a value to this factor updating the relationship between a job and a worker.

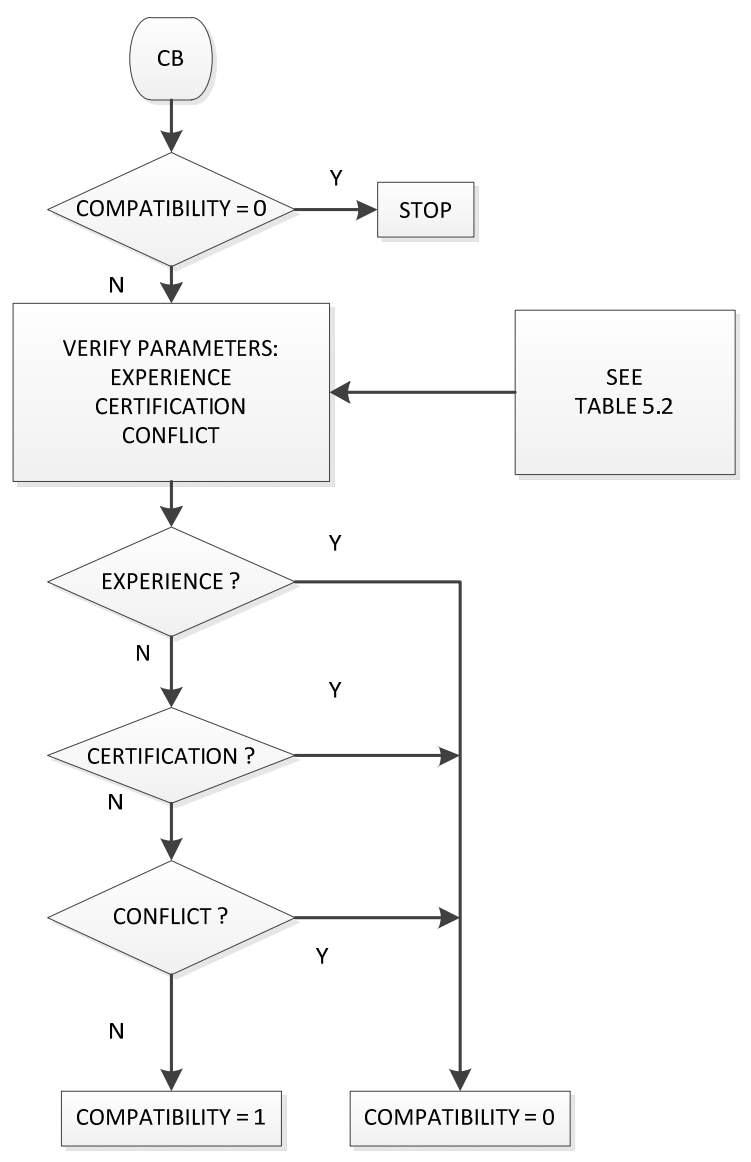

Figure 5-3 Method for compatibility factor 
In the table below are some questions that must be made regarding the compatibility factor between worker and job assignments.

Table 5-2 Compatibility questions

\begin{tabular}{|l|l|l|}
\hline Compatibility & Questions & Worker/Job \\
\hline Experience & $\begin{array}{l}\text { Are there any issues regarding the experience of the } \\
\text { worker related with a particular job? } \\
\text { Is there any requirement in relation to the experience that } \\
\text { the worker must have to perform a particular job? }\end{array}$ & YES/NO \\
\hline Certification & $\begin{array}{l}\text { Is there any certification process that the worker must } \\
\text { meet in order to be able to execute any particular job? } \\
\text { Is there any academic degree that the worker must meet } \\
\text { in order to execute any particular job? } \\
\text { Is there a specific license (e.g., from government) in } \\
\text { order to execute a particular job? }\end{array}$ & YES/NO \\
\hline Conflicts & $\begin{array}{l}\text { Are there any conflicts that the worker has with the } \\
\text { company/supervisor in order to assign jobs? } \\
\text { Does the worker have any kind of conflict in order to } \\
\text { execute a particular job? }\end{array}$ & YES/NO \\
\hline
\end{tabular}

Compatibility values, in this case, consider only close to 0 and 1 , in such a way that the model assigns jobs to workers only when compatibility is equal to one. When compatibility is close to zero, the model assigns a very large number for the processing time of that activity and does not assign that activity to that individual worker.

The no-compatibility factor is used when a worker does not have the appropriate level to perform a job. For example, assume that it is not appropriate to assign a worker with a 
skill level "novice", who requires double time for a job with an expert level requirement (200\% according to Table 4-1), to that job. This "novice-expert" relationship could be eliminated through the compatibility factor. In some scenarios it may also be forbidden to assign jobs that require minimum skill level to expert workers; in such case the use of compatibility factor ensures the type of assignment needed for the job. At other times, even when an operator can perform the required work changing their standard time, they may not have a proper certification to do the job or they may not have the necessary tools at their workplace. Therefore a value of non-compliance with respect to that job must be assigned. If the solution of the model, with the compatibility values that were assigned, is not feasible, then it is possible to analyze the causes of worker compatibility in order to have higher flexibility in finding a workable solution. The result of this method is the development of a model that provides an assignment of workers to jobs, such that the total skills gap is minimized. The complexity and compatibility factors between the three groups and jobs (of Figure 4-1) are found in table below:

Table 5-3 Complexity and compatibility factors

\begin{tabular}{|c|c|c|c|}
\multicolumn{5}{c|}{ Complexity } \\
\hline$\alpha$ & J1 & J2 & J3 \\
\hline G1 & 1 & 1.5 & $\mathrm{X}$ \\
\hline G2 & 0.6 & 1.5 & 1.5 \\
\hline G3 & 0.8 & $\mathrm{X}$ & 1 \\
\hline
\end{tabular}

\begin{tabular}{|c|c|c|c|}
\multicolumn{5}{c|}{ Compatibility } \\
\hline n & J1 & J2 & J3 \\
\hline G1 & 1 & 1 & 0.01 \\
\hline G2 & 1 & 1 & 1 \\
\hline G3 & 1 & 0.01 & 1 \\
\hline
\end{tabular}

5.2 Primary dimensions of supervision work (level 1 to $n$ )

In this section, the objective is to construct an instrument for providing a measure of organizational factors (planning, execution, training, and control). This develops a more extensive model that assigns workers to supervisors, in such a way that the total cost 
required achieving all the jobs is minimized. From examination of the literature on Organization Theory, four primary dimensions of supervision work were defined: (1) planning, which is concerned with process, product standardization in the organization, initiation, preparation, resource allocation, and scheduling; (2) control, which is concerned with the extent to which good project management control is employed, such as monitoring, coordinating, decision making, dissemination, dispatching, and performance evaluation; (3) training, which is concerned with effective training tools such as lecturing, coaching, guiding, and discussing in the organization; and (4) execution, which is concerned mainly with the alignment of organization objectives, problem solving and implementation. These definitions are going to be translated into operational definitions, and developing the methods and results of scaling the supervisor work variables.

The theoretical foundation for this method is based on the analysis of the relevant activities related to each factor, and the identification of instruments for measure. This method is partially based on the work of Khaled et al. [58] for measuring organizational maturity. The following figure shows the general steps:

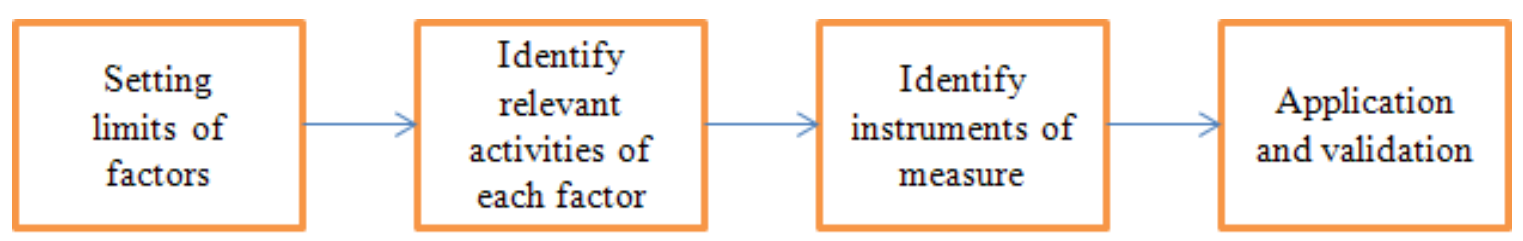

Figure 5-4 Method for supervisor factors 


\subsubsection{Setting limits for the factors}

In the model, if the sum of the factors (constraints 3.2.4, 3.2.6) is equal to one, then that implies that supervision at level 1 requires the same quantity of time than the worker at level 0 . On the other hand, if the sum is less than one, this implies that the supervision time required is less than the operating time of the group; therefore, a supervisor can have more than one subordinate as shown in the following figure.

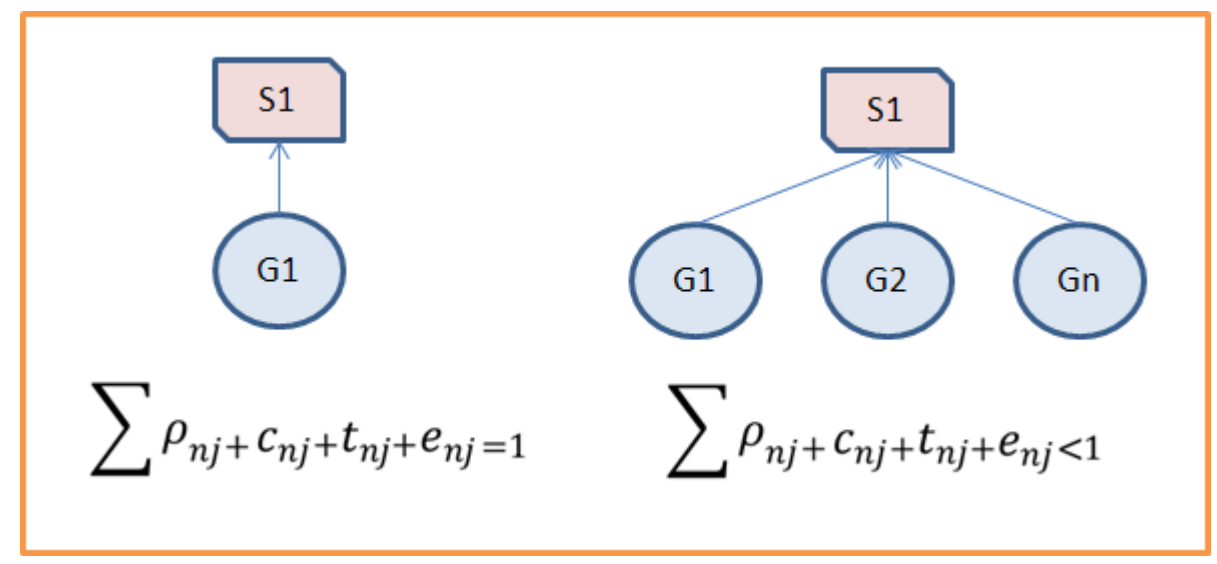

Figure 5-5 Impact of sum of factors in span of control

As shown in Figure 5-6, a method was developed to identify the boundary of each of the factors within the constraints indicated.

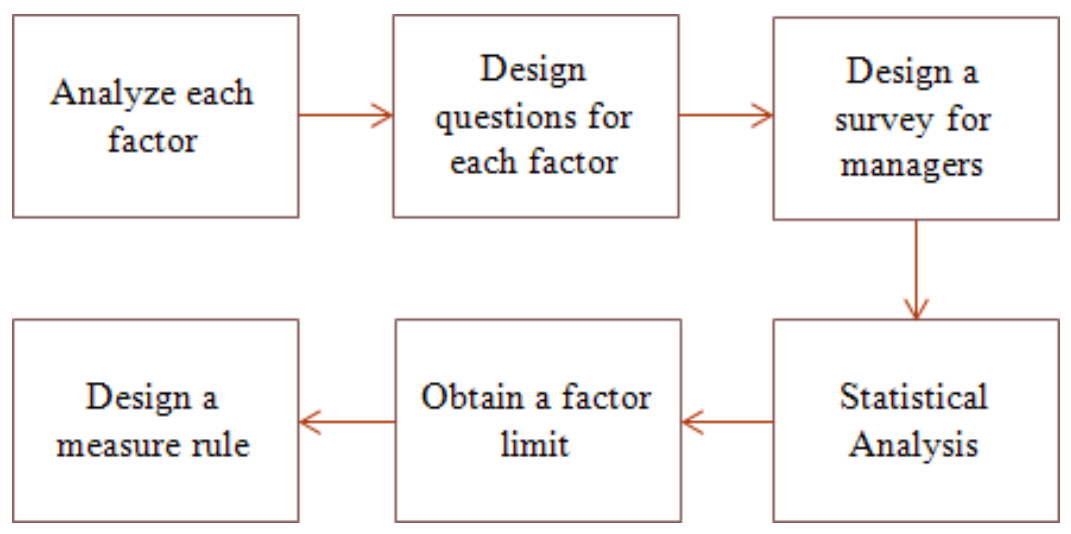

Figure 5-6 Factors between level $0 \rightarrow 1$ 
The first step in the previous model includes the analysis of each factor according to the type of industry. Planning, control, execution, and training could have different meaning in different types of industries. In order to know the importance level of each factor within the company, a survey with different questions regarding each factor was designed. The survey was applied to all supervisors and managers in the company and the results were analyzed using statistical software (in order to obtain mean, standard deviation, and relevant parameters). If for a particular type of business, the importance of each factor was the same, then the limit would be 0.25 for each (in such a way that the sum of the four factors equals one: $0.25+0.25+0.25+0.25$ ). Otherwise, applying linearity to the results, a factor limit is obtained. Once the factor limit is known, a measure rule could be designed adjusting the minimum and maximum number of subordinates, in such a way that the rule is according to the span of control for each particular industry. In order to show how this process works, data were collected in four IS companies and 30 supervisors (within these companies) in the city of Chihuahua, Mexico. The results are discussed in section 5.2.4.

The next figure shows how to design a measure rule: once the survey that establishes the level of importance of each of the supervisor factors has been designed and applied, the next step is to get the mean (a1, a2, a3, a4) and standard deviation of each factor. The next step is to get the sum of the means values (at), and assuming that the sum of the coefficients must be less or equals to one, applying linearity the coefficients limits could be obtained (equals a*/at). Each of the instruments, in order to valuate supervision effort, used in this process, has an evaluation from one (expert), two (intermediate), and three 
(novice). The coefficient limit at level three (novice) will be the mean value of each factor. In order to get the measure rule, the number of steps must be established and from there the measure rule could be designed dividing the coefficient limit by the number of steps with regular increments (as shown in figure).

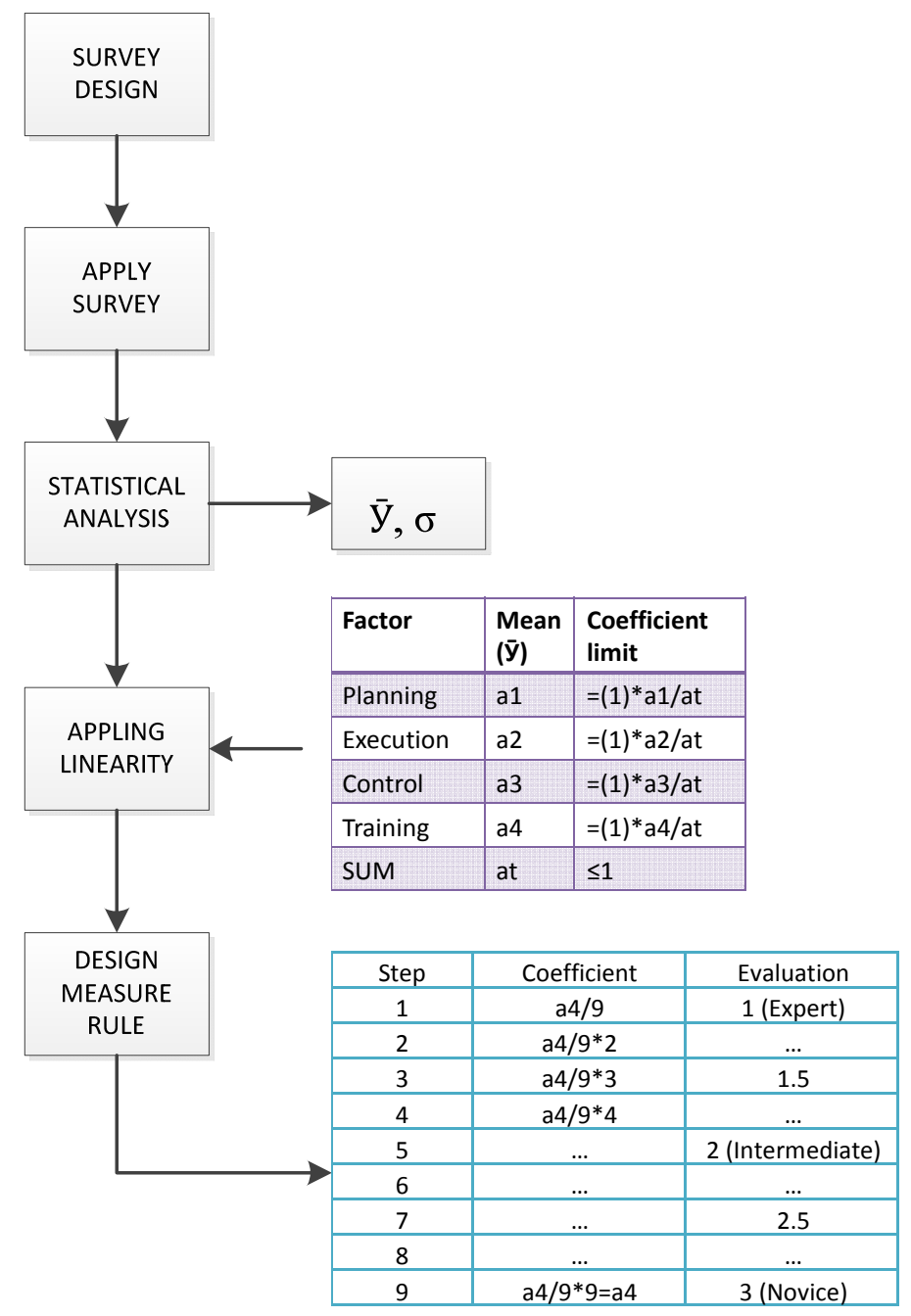

Figure 5-7 Design of measure rule

5.2.2 Identification of relevant activities 
Once the coefficients limits of each factor have been identified, it is necessary to establish the relevant activities for each factor in order to identify possible instruments to measure the required time of supervision effort. From definitions found on the work of Iyigün [50], Raishi [51], Annand et al. [52], and Hales [55] the principal activities for the planning, control, training, and execution factors were defined. The following table shows these activities:

Tabla 5-4 Relevant activities in supervisor factors

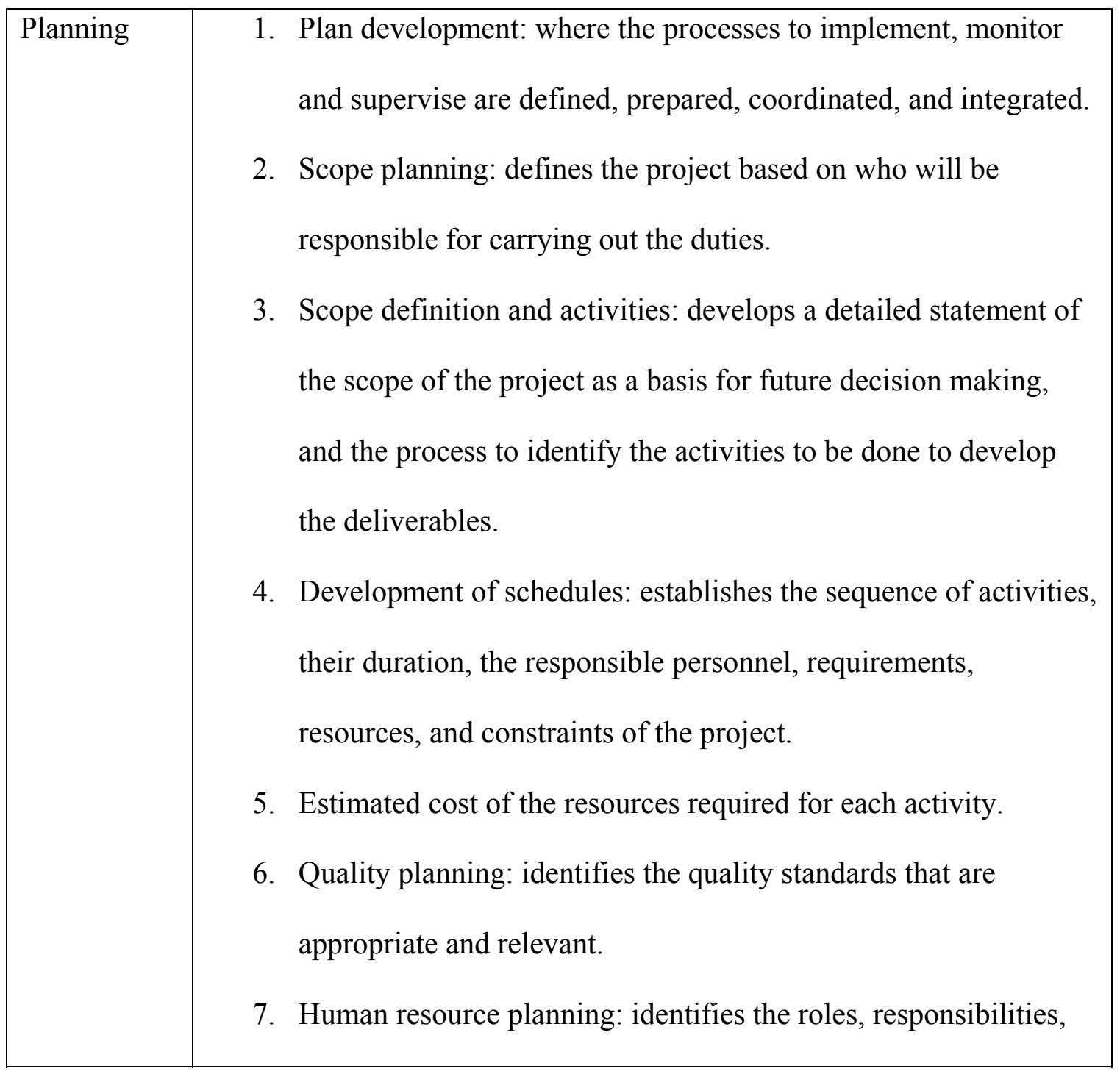




\begin{tabular}{|c|c|c|}
\hline & & and reporting relationships based on the information obtained. \\
\hline Control & 7. & $\begin{array}{l}\text { Perform activities to meet project objectives. } \\
\text { Make efforts and invest funds to meet project objectives. } \\
\text { Obtain, manage, and use resources including materials, tools, } \\
\text { equipment, and facilities. } \\
\text { Implement the planned methods and standards. } \\
\text { Create, monitor, verify, and validate project deliverables. } \\
\text { Define the risks and implement risk response activities. } \\
\text { Adapt approved changes to the scope, plans, and project } \\
\text { environment. } \\
\text { Establish project communication channels, both external and } \\
\text { internal to the team. } \\
\text { Collect data and report on project cost, schedule, quality, and } \\
\text { technical progress and status information to facilitate } \\
\text { projections. }\end{array}$ \\
\hline Training & 2. & $\begin{array}{l}\text { To improve the performance of a job using new technologies, } \\
\text { policies or procedures carried out in the organization. } \\
\text { To facilitate (or teach) courses, workshops, conferences or any } \\
\text { activities that facilitate new knowledge, techniques or } \\
\text { procedures. } \\
\text { To identify skills of workers related to the skills needed in the } \\
\text { company. }\end{array}$ \\
\hline
\end{tabular}




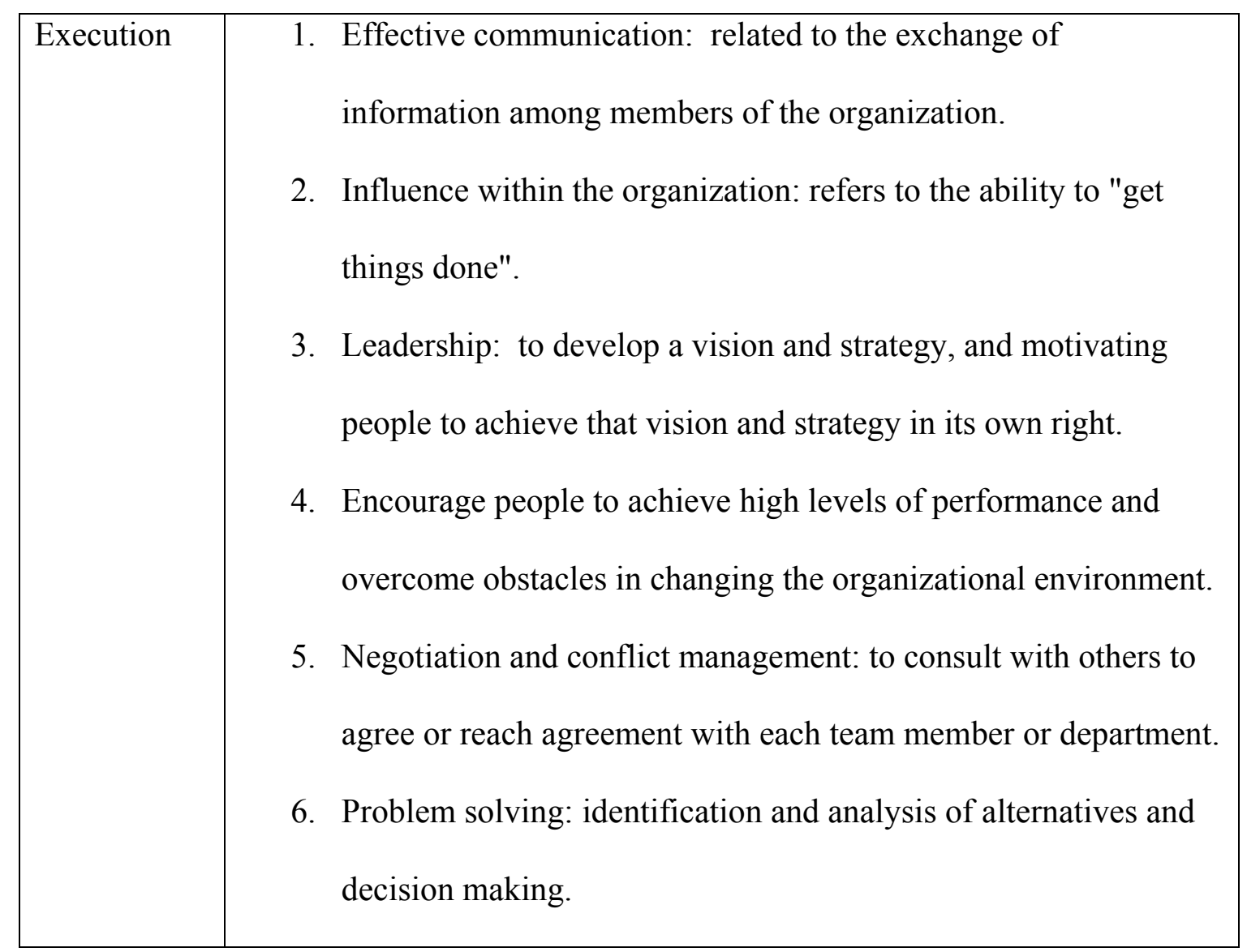

The next steps in this process, after the activities were identified for each factor, are focused on the following processes:

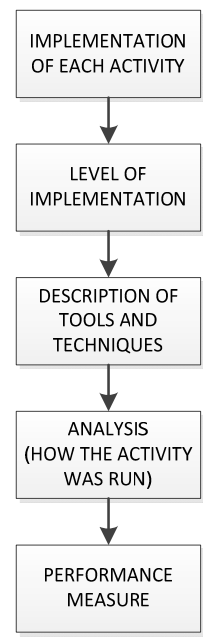

Figure 5-8 Activity implementation process 


\subsubsection{Identification of instruments of measure}

This section provides the procedure of the field test used, and a brief description of how variables were measured, the data analysis procedures, and discussion of the results of the study. The applications were validated with data collected within the context of four different Information Systems (IS) companies based in the city of Chihuahua, México. Supervisors, who might be a work manager, an area superintendent, or some other administrator, were first contacted by a letter addressed to the general manager of each IS company. Field work began with interviewing them at length, and interviews were conducted with standard schedules listing the data desired. This instrument is used as part of the software process diagnosis and improvement services that the IS companies provided.

The study was specifically conducted to confirm the patterns found in the literature with the organizational practice and to collect data that are useful for measuring the factors of planning, control, training, and execution. The thirty people (from four IS companies) who participated in this first process were selected based on the functions they perform in the workplace in supervising activities. The following table summarizes the instruments for measure in each of the factors:

Table 5-5 Instruments for measure of each factor

\begin{tabular}{|l|l|}
\hline Factor & Instruments \\
\hline Planning & $\begin{array}{l}\text { SWOT Matrix (Strengths, Weaknesses, Opportunities, } \\
\text { Threats) (see Appendix B) } \\
\text { Standardization }\end{array}$ \\
\hline
\end{tabular}




\begin{tabular}{|c|c|}
\hline & $\begin{array}{l}\text { Project action plan (see Appendix B) } \\
\text { Description or job profile (see Appendix B) }\end{array}$ \\
\hline Control & $\begin{array}{l}\text { Meeting report } \\
\text { Support tools: } \\
\text { 1. Charts } \\
\text { 2. Schedules } \\
\text { 3. Time Reports } \\
\text { 4. Efficiency Reports }\end{array}$ \\
\hline Execution & $\begin{array}{l}\text { Performance (see Appendix B) } \\
\text { Interviews and tests } \\
\text { MBO (Analysis of job performance) (see Appendix B) } \\
\text { Checklist } \\
\text { Performance in relation to work (see Appendix B) } \\
\text { Checklist }\end{array}$ \\
\hline Training & $\begin{array}{l}\text { Evaluation center } \\
\text { Practice tests }\end{array}$ \\
\hline
\end{tabular}

The formats specified are a compilation of the tools most commonly used in IS companies. The hypothesis at this point assumes that a supervisor properly using the tools necessary for the activities identified in each factor, requires less time to monitor these activities. The basic idea is to identify the tools that a supervisor knows and uses to carry out their work more efficiently. To the extent that a supervisor knows and uses the tools, 
the time required for each one of the activities identified in supervising factors will be lower. The following instruments were identified to evaluate the planning factor:

Table 5-6 Instruments used for the planning factor

\begin{tabular}{|c|c|}
\hline Instrument \#1: & SWOT Matrix \\
\hline Objective & $\begin{array}{l}\text { Analyze the situation where the enterprise is found, stay on top of } \\
\text { events, and anticipate situations in order to reduce threats and seize } \\
\text { opportunities }\end{array}$ \\
\hline Instructions & $\begin{array}{l}\text { 1. Make a list of external opportunities } \\
\text { 2. List the external threats } \\
\text { 3. List the internal strengths } \\
\text { 4. Make a list of internal weaknesses } \\
\text { 5. Compare the strengths with the opportunities and plan strategies } \\
\text { 6. Compare the weaknesses with the opportunities and plan strategies } \\
\text { 7. Compare the strengths of threats and propose strategies } \\
\text { 8. Compare the weaknesses with threats and propose strategies }\end{array}$ \\
\hline Measure & $\begin{array}{l}\text { 1. Tool is known and used } \\
\text { 2. Tool is known but not used } \\
\text { 3. Tool is not used or known }\end{array}$ \\
\hline Instrument \#2 & Standardization \\
\hline Objective & $\begin{array}{l}\text { Establish criteria and rules based on business requirements to } \\
\text { determine if there is progress or setbacks in the organization }\end{array}$ \\
\hline Instructions & 1. Check if there is a ISO format applicable to the company \\
\hline
\end{tabular}




\begin{tabular}{|c|c|}
\hline & $\begin{array}{l}\text { processes } \\
\text { 2. Study and analyze the format (i.e. ISO 9000) } \\
\text { 3. Implement formats } \\
\text { 4. Audit process }\end{array}$ \\
\hline Measure & $\begin{array}{l}\text { 1. Tool is known and used } \\
\text { 2. Tool is known but not used } \\
\text { 3. Tool is not used or known }\end{array}$ \\
\hline Instrument \#3 & Description of job profile \\
\hline Objective & $\begin{array}{l}\text { Integrating the elements necessary to know the true and proven } \\
\text { ability of an employee to carry out an activity or task correctly }\end{array}$ \\
\hline Instructions & $\begin{array}{l}\text { 1. Build a list indicating where the actions will be performed with by } \\
\text { persons assigned to the post } \\
\text { 2. Establish requirements that employees must follow } \\
\text { 3. Conduct a competency analysis } \\
\text { 4. Specify performance criteria }\end{array}$ \\
\hline Measure & $\begin{array}{l}\text { 1. Use all instruments to measure the experience } \\
\text { 2. Use only one instrument } \\
\text { 3. There are no instruments to measure the experience }\end{array}$ \\
\hline Format & See Appendix B \\
\hline
\end{tabular}

The following instruments were identified to evaluate the execution factor: 
Table 5-7 Instruments used for the execution factor

\begin{tabular}{|c|c|}
\hline Instrument \#1 & Interviews and tests \\
\hline Objective & $\begin{array}{l}\text { Measure the profile of leadership, abilities and skills of employees } \\
\text { regarding work performance in relation to the work required }\end{array}$ \\
\hline Instructions & $\begin{array}{l}\text { 1. Depth interviews are carried out by the head of the area. } \\
\text { 2. Diagnosis of personal skills }\end{array}$ \\
\hline Measure & $\begin{array}{l}\text { 1. Tool is known and used } \\
\text { 2. Tool is known but not used } \\
\text { 3. Tool is not used or known }\end{array}$ \\
\hline Instrument \#2 & Performance \\
\hline Objective & Evaluate and compare the performance of each employee \\
\hline Instructions & $\begin{array}{l}\text { 1. Comparative method } \\
\text { It consists of making a list of personnel to evaluate and compare } \\
\text { each employee with each member of the group and determine } \\
\text { who has better performance } \\
\text { 2. Scales method } \\
\text { The worker is assessed on a scale that is determined in advance } \\
\text { to evaluate each factor based on maximum and minimum levels }\end{array}$ \\
\hline Measure & $\begin{array}{l}\text { 1. Tool is known and used } \\
\text { 2. Tool is known but not used } \\
\text { 3. Tool is not used or known }\end{array}$ \\
\hline
\end{tabular}




\begin{tabular}{|c|c|}
\hline Format & See Appendix B \\
\hline Instrument \#3 & MBO (Management by Objectives) \\
\hline Objective: & Analysis of job performance \\
\hline Instructions & $\begin{array}{l}\text { 1. Set the job's responsibilities, project or assignment } \\
\text { 2. Set a time period to implement the actions set } \\
\text { 3. Conduct the assessment } \\
\text { 4. Establish new goals }\end{array}$ \\
\hline Measure & $\begin{array}{l}\text { 1. Tool is known and used } \\
\text { 2. Tool is known but not used } \\
\text { 3. Tool is not used or known }\end{array}$ \\
\hline Format & See Appendix B \\
\hline Instrument \#4 & Checklist \\
\hline Objective & Measure performance in relation to work performed \\
\hline Instructions & $\begin{array}{l}\text { Assign a range between } 25 \text { to } 100 \text { with a different value, then the } \\
\text { points are added, scored, and compared with other employees to } \\
\text { determine the effectiveness of each }\end{array}$ \\
\hline Measure & $\begin{array}{l}\text { 1. Tool is known and used } \\
\text { 2. Tool is known but not used } \\
\text { 3. Tool is not used or known }\end{array}$ \\
\hline
\end{tabular}

The following instruments were identified to evaluate the training factor: 
Table 5-8 Instruments used for the training factor

\begin{tabular}{|c|c|}
\hline Instrument \#1 & Ability \\
\hline Objective & $\begin{array}{l}\text { Measure abilities and skills of employees regarding work } \\
\text { performance in relation to the work required }\end{array}$ \\
\hline Instructions & $\begin{array}{l}\text { 1. Evaluation center } \\
\text { This tool shows the behavior of candidates in various } \\
\text { exercises designed for a particular purpose } \\
\text { 2. Practice tests } \\
\text { They are used for technical or specialized positions in } \\
\text { which they perform a specific task sample as close to } \\
\text { the reality to be resolved }\end{array}$ \\
\hline Measure & $\begin{array}{l}\text { 1. Tool is known and used } \\
\text { 2. Tool is known but not used } \\
\text { 3. Tool is not used or known }\end{array}$ \\
\hline
\end{tabular}

The following instruments were identified to evaluate the control factor:

Table 5-9 Instruments used for the control factor

\begin{tabular}{|l|l|}
\hline Instrument \#1 & Meeting report \\
\hline Objective & Document the information of department meetings \\
\hline Instructions & $\begin{array}{l}\text { 1. Must contain the date of meeting } \\
\text { 2. The topic }\end{array}$ \\
\hline
\end{tabular}




\begin{tabular}{|c|c|}
\hline & $\begin{array}{l}\text { 3. It should include people who attended the meeting } \\
\text { 4. Highlight the agreements or points that remained outstanding }\end{array}$ \\
\hline Measure: & $\begin{array}{l}\text { 1. Tool is known and used } \\
\text { 2. Tool is known but not used } \\
\text { 3. Tool is not used or known }\end{array}$ \\
\hline Instrument $\# 2$ & Support tools \\
\hline Objective & $\begin{array}{l}\text { Assess performance in relation to work performed and exercise } \\
\text { corrective action }\end{array}$ \\
\hline Instructions & $\begin{array}{l}\text { Support tools: } \\
\text { 1. Charts } \\
\text { 2. Schedules } \\
\text { 3. Time Reports } \\
\text { 4. Efficiency Reports }\end{array}$ \\
\hline Measure: & $\begin{array}{l}\text { 1. Tool is known and used } \\
\text { 2. Tool is known but not used } \\
\text { 3. Tool is not used or known }\end{array}$ \\
\hline Format*: & See Appendix B \\
\hline
\end{tabular}

*Formats used for the evaluation of these instruments are shown in Appendix B. 


\subsubsection{Application and validation}

In order to apply and validate this method, a sample of 30 supervisors and managers of the Information Systems (IS) companies were given a survey to determine the importance assigned to each of the factors within that particular organization type. The use of a semantic differential scale [53] for all the items in the survey was proposed.

The first part of the validation consists in setting the limit for the factors involved, and an analysis of the survey instrument employed was made using the statistical software SPSS version 17 for Windows Vista. The interview consisted of twenty questions (see Appendix B), five of them related to each factor in random order and on a scale of 1 to 5 (1. Strongly disagree, 2. Disagree, 3. Neither agree nor disagree, 4. Agree, 5. Strongly agree) that the supervisor has with respect to each question. The survey gave the following results:

Table 5-10 Level of importance of primary dimensions of supervision work

\begin{tabular}{|l|rr|c|c|}
\hline Factor & \multicolumn{1}{|l|}{ Mean } & \multicolumn{1}{l|}{$\begin{array}{l}\text { Std } \\
\text { Dev }\end{array}$} & Var \\
\hline Planning & 3.7 & 1.2 & 1.26 \\
Question 1 & 4.33 & 1.093 & 1.195 \\
Question 5 & 3.8 & 0.961 & 0.929 \\
Question 12 & 3.9 & 1.213 & 1.472 \\
Question 13 & 3.2 & 1.183 & 1.407 \\
Question 18 & 3.26 & 1.41 & 1.306 \\
\hline Control & 3.54 & 1.22 & 1.5 \\
Question 2 & & 3.4 & 1.27 & 1.628 \\
Question 3 & & 4.06 & 1.015 & 1.030 \\
Question 6 & & 3.06 & 1.311 & 1.72 \\
Question 10 & & 3.53 & 1.332 & 1.775 \\
Question 14 & & 3.63 & 1.159 & 1.344 \\
\hline Execution & 3.62 & 1.17 & 1.40 \\
Question 4 & 4.066 & 1.172 & 1.375 \\
\hline
\end{tabular}




\begin{tabular}{|l|r|r|c|}
\hline Question 8 & 3.3 & 1.512 & 2.286 \\
Question 9 & 3.1 & 1.062 & 1.128 \\
Question 16 & 3.66 & 0.994 & 0.989 \\
Question 20 & 3.96 & 1.098 & 1.206 \\
\hline Training & 3.24 & 1.17 & 1.37 \\
Question 7 & 3.93 & 1.093 & 1.195 \\
Question 11 & 3.66 & 0.961 & 0.929 \\
Question 15 & 3.86 & 1.213 & 1.472 \\
Question 17 & 1.9 & 1.183 & 1.407 \\
Question 19 & 2.83 & 1.41 & 1.306 \\
\hline Scale 1-5 (1.Strongly disagree, 2. Disagree, 3. \\
Neither agree nor disagree, 4. Agree, 5. Strongly \\
agree) Question's 1-20: see Appendix B \\
Quil \\
\hline
\end{tabular}

Applying linearity to the value found for average for each of the factors and assuming that the sum of the limits must be less than or equal to 1 , the limit for each of the factors identified were obtained. The previous quantification shows that the factors have different hierarchy between each of them, where the planning and execution were of significant importance of 0.26 , the control factor limit was 0.25 and a training factor of 0.23. The following table shows the values obtained for each factor:

Table 5-11 Quantitative limit of each factor

\begin{tabular}{|l|l|l|l|}
\hline Factor & mean & $\%$ & limit \\
\hline Planning & 3.7 & 26.24 & 0.26 \\
\hline Control & 3.54 & 25.11 & 0.25 \\
\hline Training & 3.24 & 22.98 & 0.23 \\
\hline Execution & 3.62 & 25.67 & 0.26 \\
\hline Sum & 14.10 & 100 & 1 \\
\hline
\end{tabular}


The next step for validation purposes was to measure the utilization of each of the instuments identified in Table 5-4. To validate this information, a study with 20 randomly selected supervisors was conducted. The analysis was carried out to identify how activities are performed for each factor using the formats identified for the same (tables $5-5,5-6,5-7,5-8)$. A standard measurement of 1 to 3 for all the instruments was used, where 1 is the full utilization of the instrument, and 3 when the instrument is not known. As noted in the factors for the level 0 , the analysis of the supervisor factors must be made by the next person higher in command to avoid, at least to the level $n$ - 1 , a self-assessment process.

The objective is to assess the number of subordinates that should be expected (on average). The study consisted of an interview with each supervisor where the evaluator collected data regarding the use and knowledge that each supervisor has in each of the formats identified before. Scales were constructed to define the variables operationally. These measured the degree of a particular factor present by linking together a number of items that could be used to measure that factor. The results obtained in these 20 evaluations are shown in the following table:

Table 5-12 Evaluation of primary dimensions of supervision work

\begin{tabular}{|l|r|r|r|}
\hline Factor & \multicolumn{1}{|l|}{ Mean } & Std Dev & \multicolumn{1}{l|}{ Var } \\
\hline Planning & \multicolumn{1}{|l|}{1.2} & & \\
SWOT Matrix & 1.47 & 0.640 & .410 \\
Project letter & 1.13 & 0.352 & .124 \\
Action plan & 1.07 & 0.258 & .067 \\
Job description & 1.13 & 0.352 & .124 \\
\hline Control & 1.36 & & \\
Meeting report & 1.27 & .704 & .495 \\
Scale method & 1.00 & 0 & 0 \\
Execution analysis & 1.00 & 0 & 0 \\
\hline
\end{tabular}




\begin{tabular}{|l|r|r|r|}
\hline Performance & 1.27 & .458 & .210 \\
Support tools & 2.27 & .884 & .781 \\
\hline Execution & 1.28 & & \\
Interview & 1.53 & 0.834 & .695 \\
Tech int & 1.40 & 0.737 & .543 \\
Eval center & 1.00 & 0 & 0 \\
Pract test & 1.00 & 0 & 0 \\
Scale method & 1.00 & 0 & 0 \\
Work exec & 1.33 & .617 & .381 \\
Perform analysis & 1.67 & .816 & .667 \\
\hline Training & 1.40 & & .834 \\
Interview & 1.53 & .695 \\
Tec Int & 1.40 & .737 & .543 \\
Eval center & 1 & 0 & 0 \\
Prac test & 2.07 & .704 & .495 \\
\hline Scale 1-3 (1. Tool is known but not used, 2. Tool is \\
known and used, 3. Tool is not used or known) \\
\multicolumn{3}{|l|}{} \\
\hline
\end{tabular}

Once the limit of the factors and the evaluation of each supervisor have been established, the next step was to determine the value of each factor that can be assigned to the supervisor. Applying linearity and using the following rule the value of the coefficient for each factor was calculated.
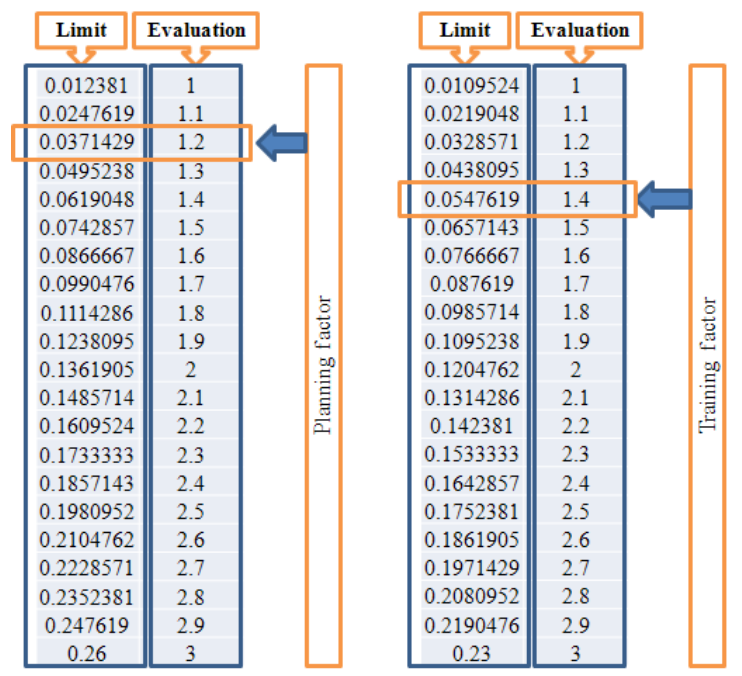

Figure 5-9 Evaluation of planning and training factor 


\begin{tabular}{|c|c|c|c|c|c|}
\hline Limit & Evaluation & & Limit & Evaluation & \\
\hline & $3 \longdiv { 5 }$ & & 35 & 35 & \\
\hline 0.012381 & 1 & & 0.0119048 & 1 & \\
\hline 0.0247619 & 1.1 & & 0.0238095 & 1.1 & \\
\hline 0.0371429 & 1.2 & & 0.0357143 & 1.2 & \\
\hline 0.0495238 & 1.3 & & 0047619 & 13 & \\
\hline 0.0619048 & 1.4 & & 0.0595238 & 1.4 & \\
\hline 0.0742857 & 1.5 & & 0.0714286 & 1.5 & \\
\hline 0.0866667 & 1.6 & & 0.0833333 & 1.6 & \\
\hline 0.0990476 & 1.7 & & 0.0952381 & 1.7 & \\
\hline 0.1114286 & 1.8 & $\stackrel{\circ}{0}$ & 0.1071429 & 1.8 & t \\
\hline 0.1238095 & 1.9 & $\stackrel{\pi}{=}$ & 0.1190476 & 1.9 & $\stackrel{\square}{d}$ \\
\hline 0.1361905 & 2 &. & 0.1309524 & 2 & $\bar{\circ}$ \\
\hline 0.1485714 & 2.1 & $\vec{J}$ & 0.1428571 & 2.1 & 咅 \\
\hline 0.1609524 & 2.2 & 鹿 & 0.1547619 & 2.2 & $\dot{0}$ \\
\hline 0.1733333 & 2.3 & & 0.1666667 & 2.3 & \\
\hline 0.1857143 & 2.4 & & 0.1785714 & 2.4 & \\
\hline 0.1980952 & 2.5 & & 0.1904762 & 2.5 & \\
\hline 0.2104762 & 2.6 & & 0.202381 & 2.6 & \\
\hline 0.2228571 & 2.7 & & 0.2142857 & 2.7 & \\
\hline 0.2352381 & 2.8 & & 0.2261905 & 2.8 & \\
\hline 0.247619 & 2.9 & & 0.2380952 & 2.9 & \\
\hline 0.26 & 3 & & 0.25 & 3 & \\
\hline
\end{tabular}

Figure 5-10 Evaluation of training and control factor.

With the data found on figures 4-3 and 4-4, and replaced in the following constraint:

$$
\sum_{j} r_{o j} y_{0 j p_{0}}\left(\rho_{i j}+c_{i j}+t_{i j}+e_{i j}\right) \leq \sum_{j} f_{i j} y_{i j p_{1}}
$$

for an 8-hour workday, the constraint results in the following equation:

$$
8 \mathrm{hrs} *(.037+.059+.054+.049)=8 \mathrm{hrs} *(0.199)=1.592 \mathrm{hrs} .
$$

This relationship indicates that the working group only requires 1.59 hours of supervision. Supervisor factors that affect each level must be calculated for each working group independently. If the working groups were homogeneous (same factor value for each group), then in the previous constraint the number of groups directed by each supervisor can be calculated with the following equation:

$$
\begin{gathered}
\mathrm{n}_{\text {groups }}(8)(0.199) \leq 8(1)_{\text {supervisor }} \\
\mathrm{n}_{\text {groups }} \leq \frac{8(1) \text { supervisor }}{(8)(0.199)} \sim 5 \text { groups }
\end{gathered}
$$


Under these conditions, one supervisor could manage up to five working groups (workers). In the extreme case, where a supervisor obtains an assessment of one (perfect score) in all measuring instruments, it involves the following equation:

$$
\begin{gathered}
\mathrm{n}_{\text {groups }}(8)(.045) \leq 8(1)_{\text {supervisor }} \\
\mathrm{n}_{\text {groups }} \leq \frac{8(1) \text { supervisor }}{(8)(0.045)} \sim 20 \text { groups }
\end{gathered}
$$

It is important to note that these results and tables of weights are relative to a particular type of organization and cannot be taken as the basis for any company. In any new design, the method must begin with the evaluation of the limit that the factors could take in order of the relevance of each factor related to the company and also the assessment made in measuring instruments.

The following figure shows the effect of the evaluation of the supervisor factors (planning, training, execution, and control) with respect to the number of subordinates who could be under each supervisor. The following figure shows that the minimum number of subordinates would be 1 and maximum 21:

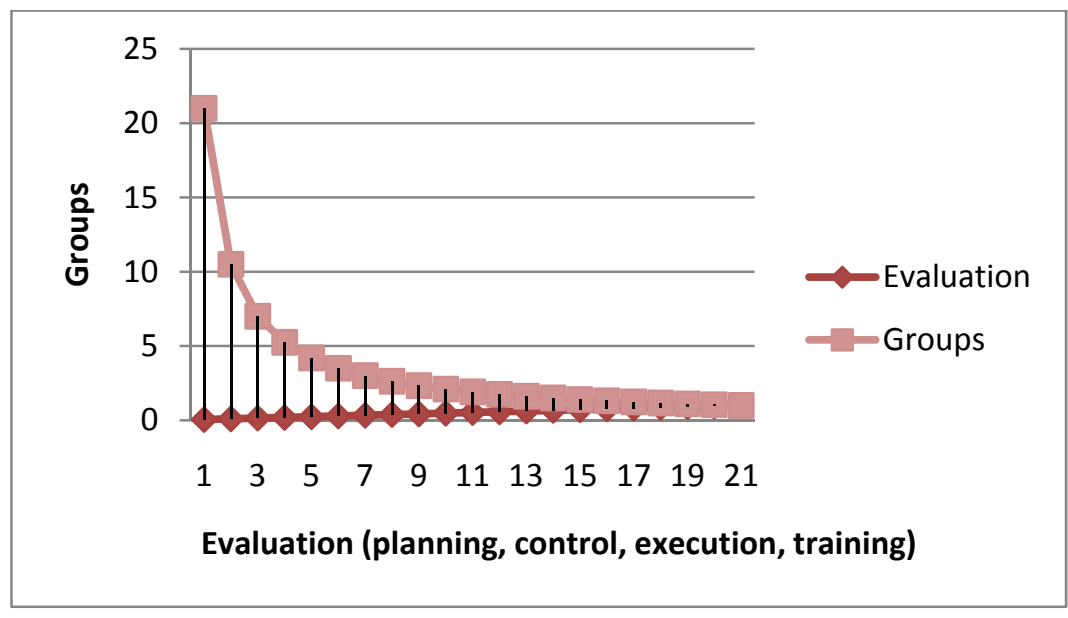

Figure 5-11 Relationship between groups and supervisor factors 


\subsection{Conclusions}

From an examination of the literature of Organization Theory, four primary dimensions of supervision work were defined: planning, control, execution, and training. These concepts were then operated by generating 14 instruments measuring various aspects of the primary dimensions.

The results found in this chapter, regarding the span of control within the Information Systems (IS) companies, were consistent with the practice that those companies currently have between four and eight operators in charge for each supervisor and also the span of control found in the literature review. This method can give some guidelines to determine how a supervisor may be responsible for more working groups. The evaluation of each factor must be analyzed, and from this assessment, it must be determined how it can improve the performance for each factor involved. The span of control can also identify managers who need further training by measuring their performance. One of the main contributions of this quantification of factors was to determine an appropriate method to increase the number of subordinates (and minimize the span of control) considering the analysis and study of the factors involved.

Regarding the results about of the span of control in the literature review, they are consistent with the number of subordinates founded in the work of Van Fleet et al. [1] with an average SOC of five and also Entwisle and Walton [18] (average between 5 and 7). The only author that mentions a maximum SOC is Udell [19] with 30 subordinates. For this particular application case, the SOC suggested is (around) five with a maximum SOC of 21. 


\section{PROPOSED HEURISTIC APPROACH}

The model under study is NP-hard, which means that the computational effort required to solve this problem increases exponentially with the problem size. When a commercial solver (such as LINGO) was used to solve the mathematical formulations presented in Chapter 4-1, it requires prohibitively a long run (or CPU) time. Consequently, a heuristic approach is presented in this chapter. Although this approach does not guarantee an optimal solution, it may require lesser computational time to find good solutions. In order to construct a feasible solution for the problem under study, two interdependent decisions must be made: (1) assign jobs to workers (level 0), and (2) assign the span of control for levels 1 to $\mathrm{n}$. For each of the decisions, a two phase approach is proposed, one that first assigns jobs to workers (and workers to supervisors and so on) with a heuristic, and then optimizes the results with a meta-heuristic.

\subsection{Introduction of the proposed heuristic approach}

Basically the characteristics that the model has in order to consider for constructing the heuristic are: (1) the ability to divide the model into two sub-problems, (2) the formulation is a combinatorial integer programming (binary) model in which an optimal solution is sought over a discrete search-space, and (3) the possibility of constructing a "greedy algorithm" based on previous algorithms that have been successfully tested.

\subsection{Problem decomposition and design framework}

Once the actual problem is identified (see Chapter 4 for problem description), the next step was to decompose the problem into smaller distinct elements. The intent is to gain additional insights into the problem, and subsequently, a better understanding of the 
solution approach. The proposed approach decomposes the binary integer model into two sub-problems: one assigns jobs to working groups, while the other focuses on the higher levels of managerial hierarchy. Using a hierarchical decomposition approach, the goal here is to divide the problem into independent smaller sub-problems: sub-problem one assigning jobs to workers at level 0 , and sub-problem two assigning workers to supervisors at the next level ( 1 to $n)$. Even though sub-problem two needs a feasible solution from sub-problem one, from this feasible solution at level 0 , sub-problem two becomes independent in order to find a feasible solution for the whole problem.

Decomposition consists of groups of data: input and output. For level 0, input data required by the model consist of processing times according to complexity and compatibility data of jobs with workers, and capacity of workers. Output data for this problem consist of the assignment of jobs to workers. For the next level ( 1 to $n)$ input data required by the model consist of number of workers selected in level 0 , capacity, and the cost of supervisors.

Decomposition for this problem is described in following figure:

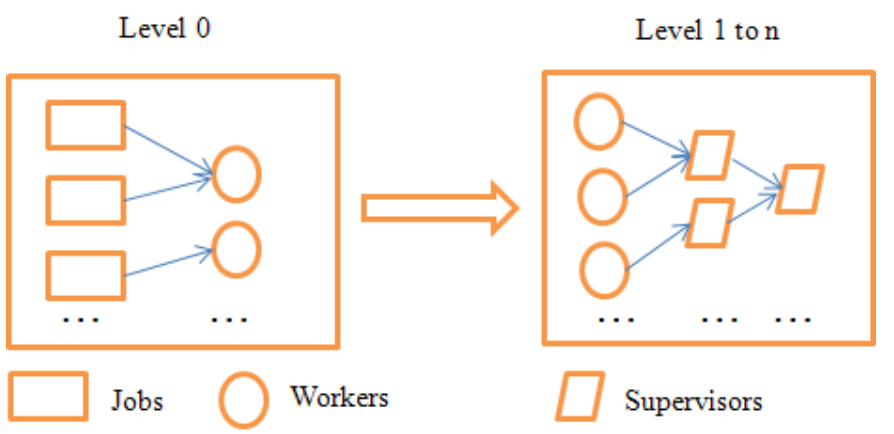

Figure 6-1 Problem decomposition 
In this decomposition process, sub-problem 1 requires input 1 and 2, and sub-problem 2 requires output 1 (as input 3 ) as in the following figure:

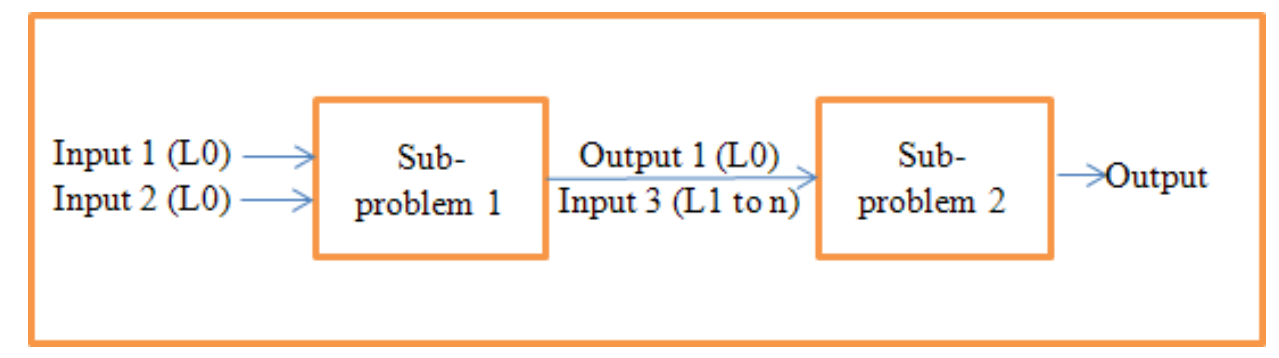

Figure 6-2 Input/output for sub-problems

Inputs and outputs required and obtained in this decomposition process are described as follows:

Sub-problem 1): a set of jobs (J) (input 1) and a set of different processing workstations (G) (input 2) are given. Each job (J) is described by its processing time for the jobs to be completed, the skills needed for the job, and the level of each skill (factor complexity) and compatibility according to the information given to the workstations. The objective is to find a set of workstations $(\mathrm{G})$ to schedule the jobs $(\mathrm{J})$ in such a way that the number of workstations can be minimized (output 1/input 3).

Sub-problem 2: Find the span of control needed for the Work Breakdown Structure (WBS), while maintaining the minimum cost of supervision. The number of span of control formed depends upon the number of workstations $(\mathrm{G})$ considered in an instance, and also depends on the factors identified for supervision effort: planning, control, execution, and training (output). 
The design framework for the proposed solution approach can be described in the following figure:

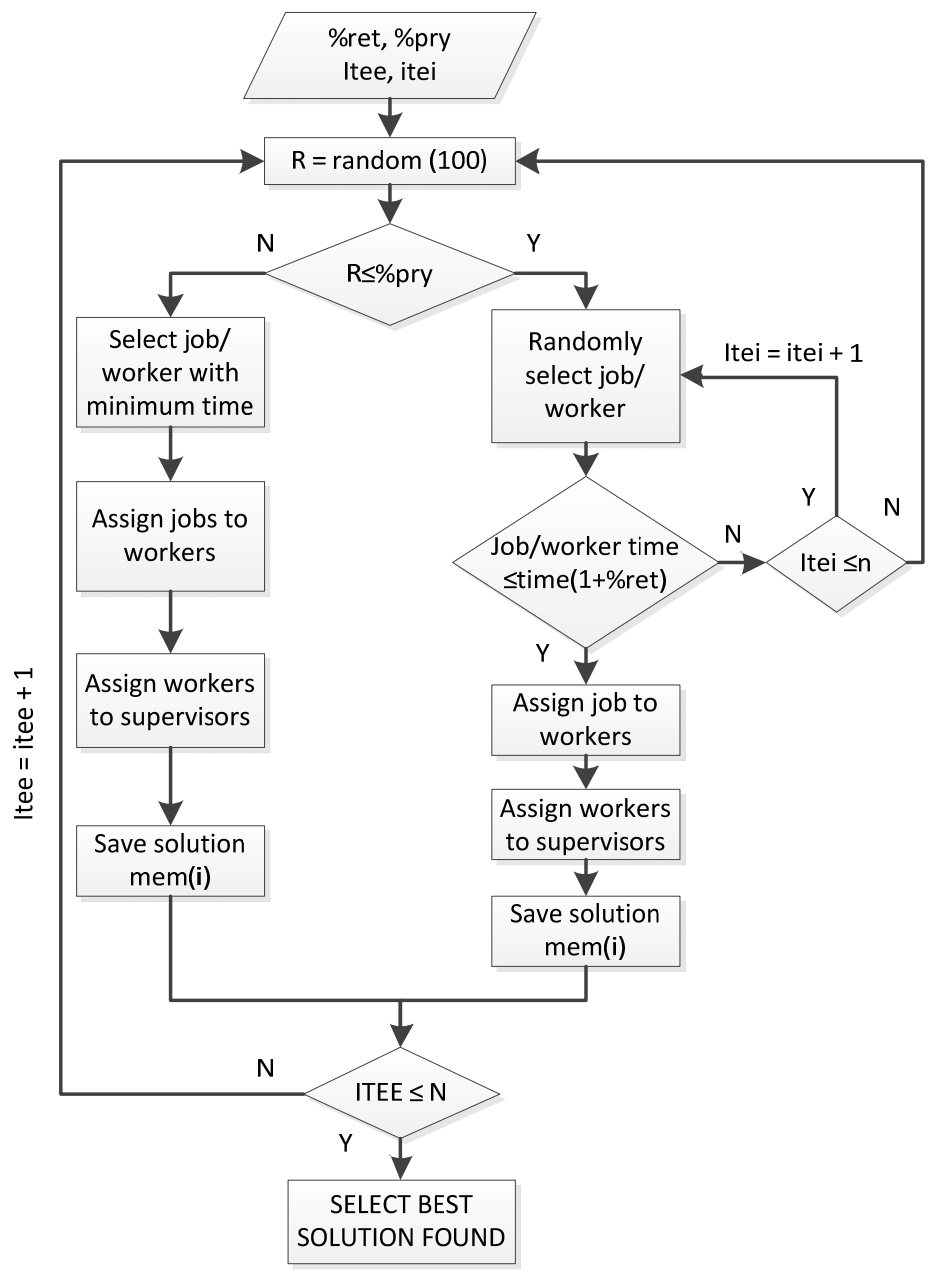

Figure 6-3 Meta-heuristic framework

The design framework is described below:

Step 1: Select initial set of parameters (\%ret, \%pry, itee, itei)

Step 2: Select random number $\mathrm{R}(1 \leq \mathrm{R} \leq 100)$

Step 3: If $\mathrm{R} \leq \%$ pry, select job/worker with minimum processing time

Step 4: Assign jobs to workers

Step 5: Assign workers to supervisors 
Step 6: Save solution in memory

Step 7: Repeat the process

Step 8: Randomly select jobs/workers

Step 9: If selection is between \%ret, assign jobs and workers

Step 10: If selection is out of \%ret, repeat the process until itei reaches $n$ value

Step 11: Save solution in memory

Step 12: Select best solution found

\subsection{Proposed heuristic approach}

The structure of the problem consists of $m$ constraints that will bound the construction of any feasible solution. When a job is chosen to be in the feasible solution, the addition of the new job cannot exceed the capacity constraints, e.g., for the first sub-problem:

$\operatorname{Min} \sum_{j=1}^{N} Y_{0 j}(\forall j \in J)$

Subject to:

$\sum_{j} Z_{i j}=1(\forall i=1 \ldots m)$

and

$\sum_{i} \beta_{i} \alpha_{i j} z_{i j} / n_{i j} \leq r_{0 j} y_{o j p_{0}}(\forall j=1 \ldots n)$

The theme of greedy algorithm is to make the choices in sequence, such that each individual choice is the best according to some short-term or local criterion. Any choice can be made that seems best at the moment and then solve the sub-problems that arise later. The choice made by a greedy algorithm may depend on choices made so far, but not on future choices or all the solutions to the sub-problem. It iteratively makes one greedy choice after another, reducing each given problem into a smaller one. 
Lagoudakis (L) (2001) [41] proposed, for a problem:

$\operatorname{Min} \sum_{j=1}^{N} c_{i} x_{i}(\forall j \in J)$,

Subject to:

$\sum_{i=1} a_{i j} x_{i} \leq b_{j}(\forall j=1 \ldots m)$

and $x$ binary

The following algorithm:

1) Order the items so that

$\mathrm{C}_{\mathrm{i}} / \mathrm{a}_{\mathrm{i}} \geq \mathrm{c}_{\mathrm{i}+1} / \mathrm{a}_{\mathrm{i}+1}$ for $\mathrm{i}=\mathrm{a} \ldots . . . \mathrm{n}-1$

2) $\mathrm{CW}=0$

3) If $\mathrm{CW}+\mathrm{a}_{\mathrm{i}} \leq \mathrm{b}_{\mathrm{j}}, \mathrm{j}=1$

Then $\mathrm{CW}=\mathrm{CW}+\mathrm{a}_{\mathrm{i}} ; \mathrm{x}_{\mathrm{i}}=1$

Else $x_{i}=0$

The modified version of the Lagoudakis (ML) algorithm [41] that is proposed for the subproblem one encompasses the following steps at level 0 :

5.3.1 Sub-problem 1: Level 0

Min

$\sum_{j=1}^{N} Y_{0 j}$

Subject to:

$\sum_{j} Z_{i j}=1$

$\sum_{\mathrm{i}} \beta_{\mathrm{i}} \alpha_{\mathrm{ij}} \mathrm{z}_{\mathrm{ij}} / \mathrm{n}_{\mathrm{ij}} \leq \mathrm{r}_{0 \mathrm{j}} \mathrm{y}_{\mathrm{oj}} \mathrm{p}_{0}$

- Step 1) Initialization

$b_{j}=r o_{j}$ and $Y o_{j}=$ decision variable 
- Step 2) Order the workers (workstations) in descending according to the capacity of each station

- Step 3) Compute for all processing time $a_{i j}$ the ratio $a_{i j}=\beta_{i} \alpha_{i j} z_{i j} / n_{i j}$

- Step 4) Find minimum $a_{i j}(\mathrm{j}=\mathrm{n})$; If the task does not exceeds the capacity of $b_{j}$, select the task for the workstation $b_{j}$ then assign to $a_{i j}$ a maximum value ( $>$ any $\left.a_{i j}\right)$ for all $\mathrm{j}$. If the next (minimum) $a_{i j}\left(\mathrm{j}=\mathrm{n}\right.$ ) exceeds the capacity of $b_{j}$, move to $\mathrm{j}=\mathrm{n}+1$.

- Step 5) Repeat step 3 until all the tasks have been assigned to a workstation

The procedure of the greedy algorithm at level 0 is shown in the following figure:

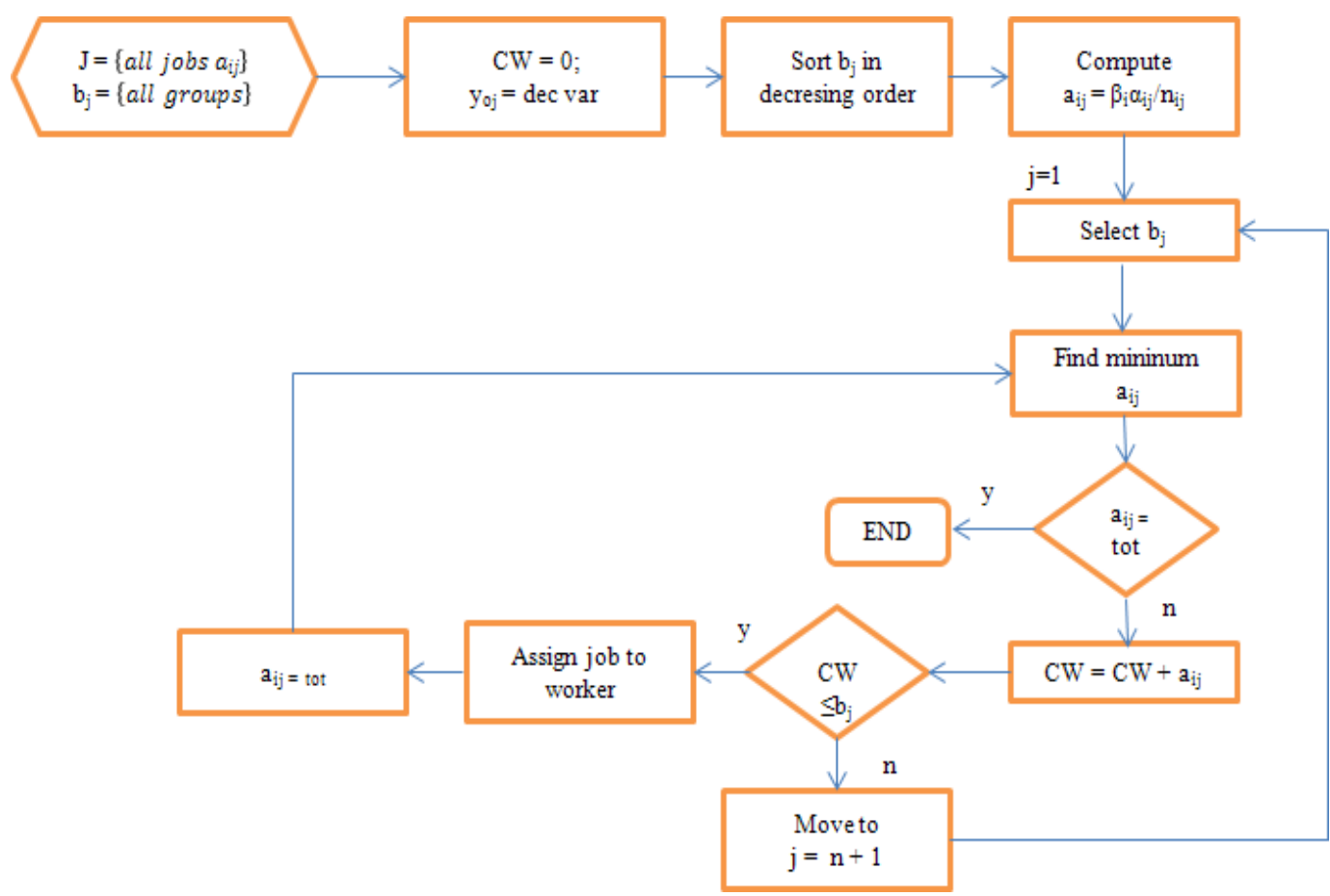

Figure 6-4 Procedure of the proposed solution approach (level 0)

The pseudo code for the modified Lagoudakis heuristic [41], at level 0 , is illustrated in figure below. 


\section{Begin with}

Let $J$ be the set of workstations, and let $a_{i j}$ be the modified processing time of task $i$ with respect to workstation $j$ (including complexity and compatibility factors).

Let $n, m$ be the number of tasks and the number of workstations.

Let tot be the maximum processing time for $a_{i j}$ once the task is assigned to a workstation and $b(j)$ the time capacity of workstation $\mathrm{j}$.

\section{Initialization}

Compute matrix a(i,j)

Set $n, m$, tot

Reset cw

Rank workstation in descending order b(j)

\section{For all workstations b(j) \\ For all activities a(i,j) \\ Find minimum a(i,j) \\ $\mathrm{cw}=\mathrm{cw}+\mathrm{a}(\mathrm{i}, \mathrm{j})$}

If capacity of workstation b(j) is not exceeded

Assign activity $a(i, j)$ to workstation $b(j)$

Assign to activity a(i,j) a maximum value for all

workstations

Else

\section{End if}

\section{Endfor}

Endfor

Return matrix y(i,j) with the allocation of the activities to workstations (workers)

Figure 6-5 Procedure for the proposed heuristic approach

6.3.2 Sub-problem 2: Level 1 to $\mathrm{n}$

$\operatorname{Min} \sum_{n=1}^{N} \quad \sum_{j=1}^{J} w_{n j} f_{n j} y_{n j p_{n}}$

Subject to:

$\sum_{j} r_{o j} y_{0 j p_{0}}\left(\rho_{i j}+c_{i j}+t_{i j}+e_{i j}\right) \leq \sum_{j} f_{i j} y_{i j p_{1}}$ 
$y_{o j p_{0}} \leq \sum_{p 1} y_{1_{p 0 p 1}}$

$\sum_{j} f_{n-1, j} y_{n-1, j p_{n-1}}\left(\rho_{i j}+c_{i j}+t_{i j}+e_{i j}\right) \leq \sum_{j} f_{n j} y_{n j p_{n}}$

$y_{n-1, j p_{n-1}} \leq \sum_{p n} y_{n p_{n-1}} p_{n}$

The procedure of the greedy algorithm at level 1 to $n$ is shown in Figure 6-6

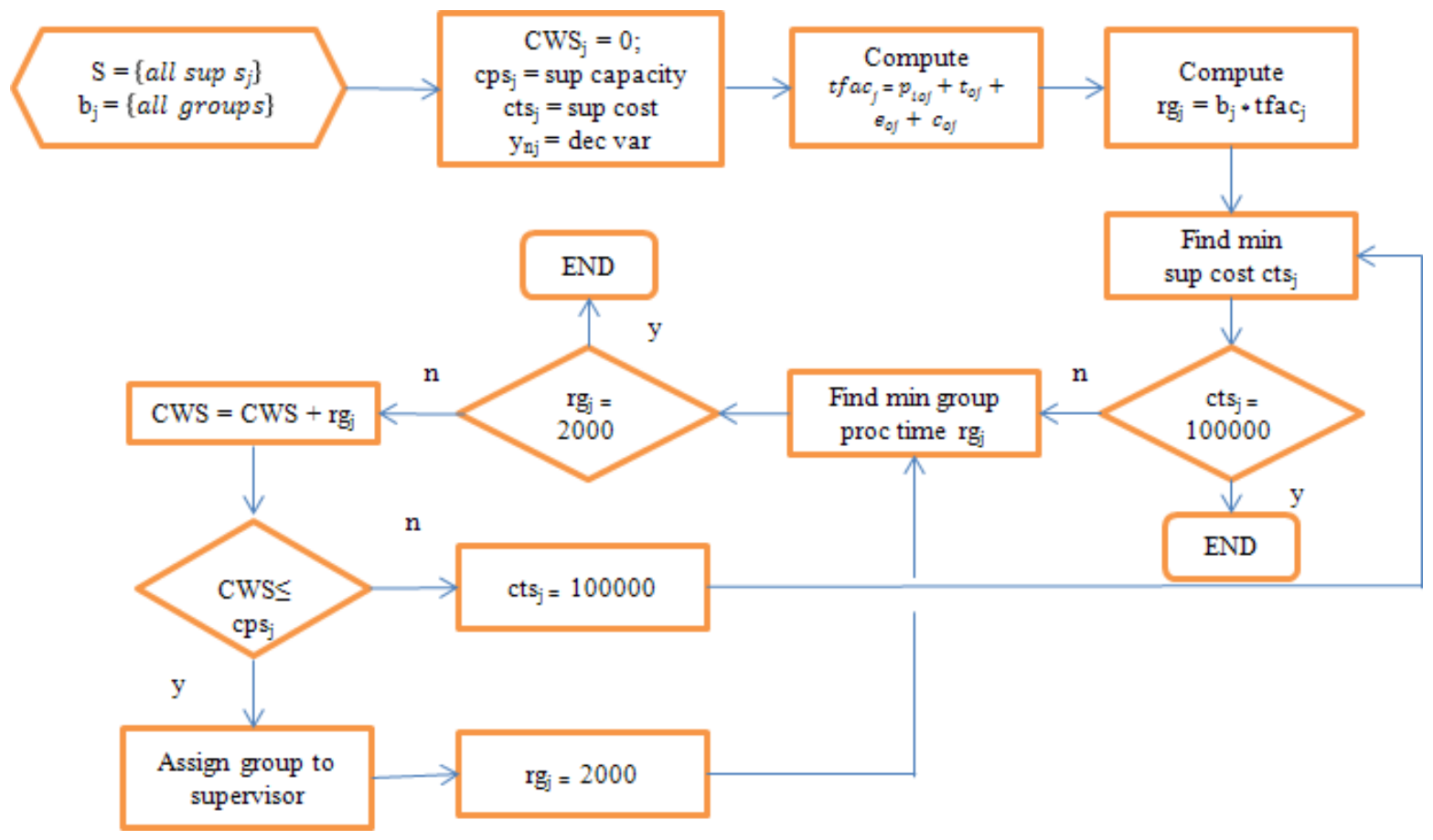

Figure 6-6 Procedure of the heuristic approach (level 1 to $n$ )

The modified version of the Lagoudakis (ML) [41] algorithm that is proposed for the subproblem two encompasses the following steps at level 1 to $\mathrm{n}$ :

- Step 1) Initialization

$\mathrm{Y}_{\mathrm{nj}}=$ decision variable

- Step 2) Compute for all workers $t f a c_{j}=p_{i o j}+t_{o j}+e_{o j}+c_{o j}$

- Step 3) Compute value $\operatorname{rg}(\mathrm{j})=\mathrm{b}(\mathrm{j}) * \operatorname{tfac}(\mathrm{j})$ for all workers assigned at level 0 .

- Step 4) Find supervisor with minimum cost 
- Step 5) Find worker with minimum processing time $r g_{j}$; if the worker does not exceed the capacity of supervisor $\mathrm{j}$, select the worker for the supervisor, then assign to worker a constant value (2000). If the next (minimum) processing time exceeds the capacity of supervisor, move to $j=n+1$.

- Step 6) Repeat step 3 until all the tasks has been assigned to a workstation.

The pseudo code for the modified Lagoudakis [41] heuristic is illustrated in Figure 6-7

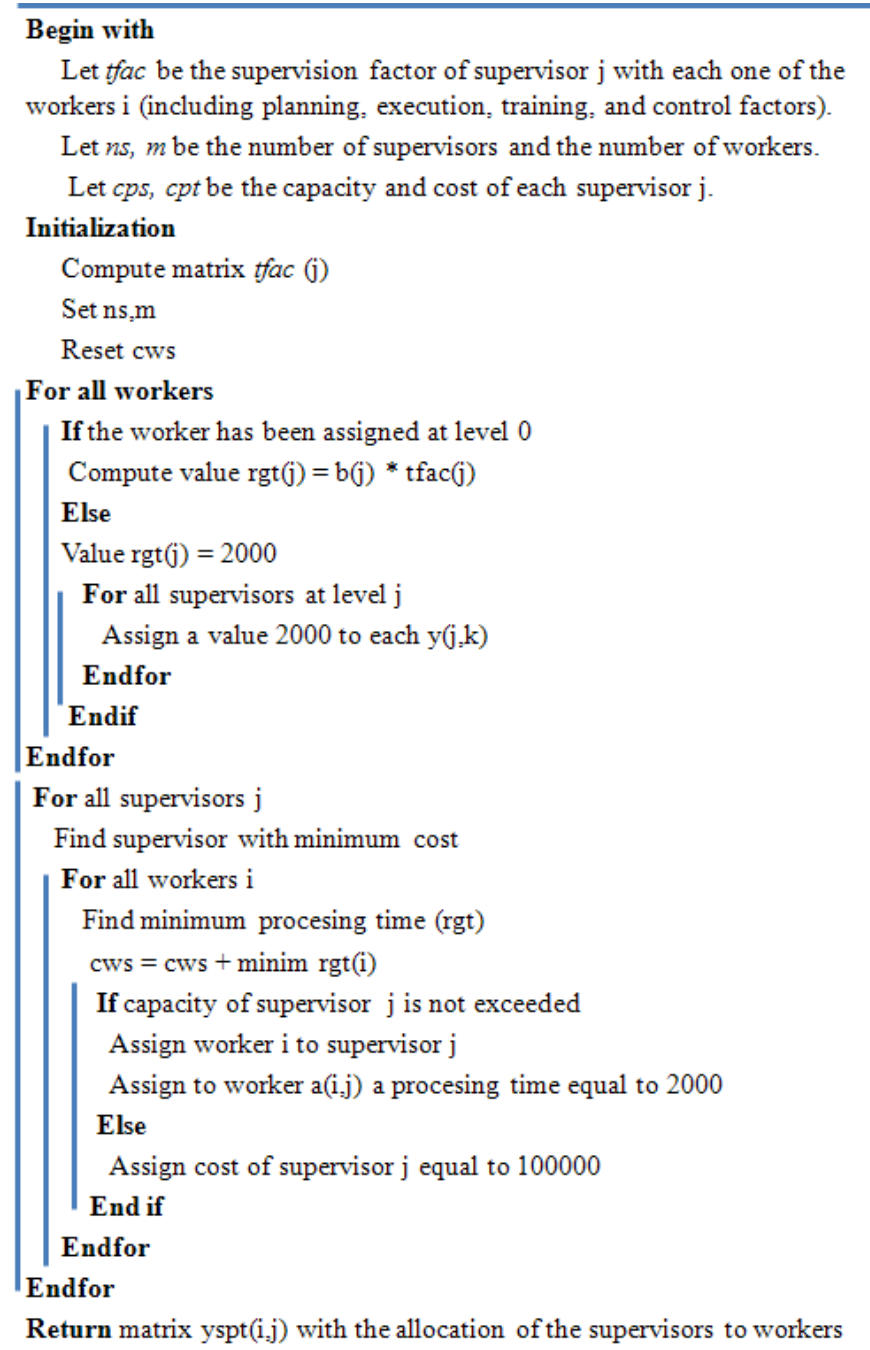

Figure 6-7 Procedure for the modified Lagoudakis greedy algorithm 


\subsection{A numerical example}

The modified Lagoudakis heuristic [41] is illustrated through the following problem instance that includes four workstations, eight jobs, three supervisors, and two managers.

\subsubsection{Sub-problem 1: Level 0}

Table 6-1 Data of the numerical example

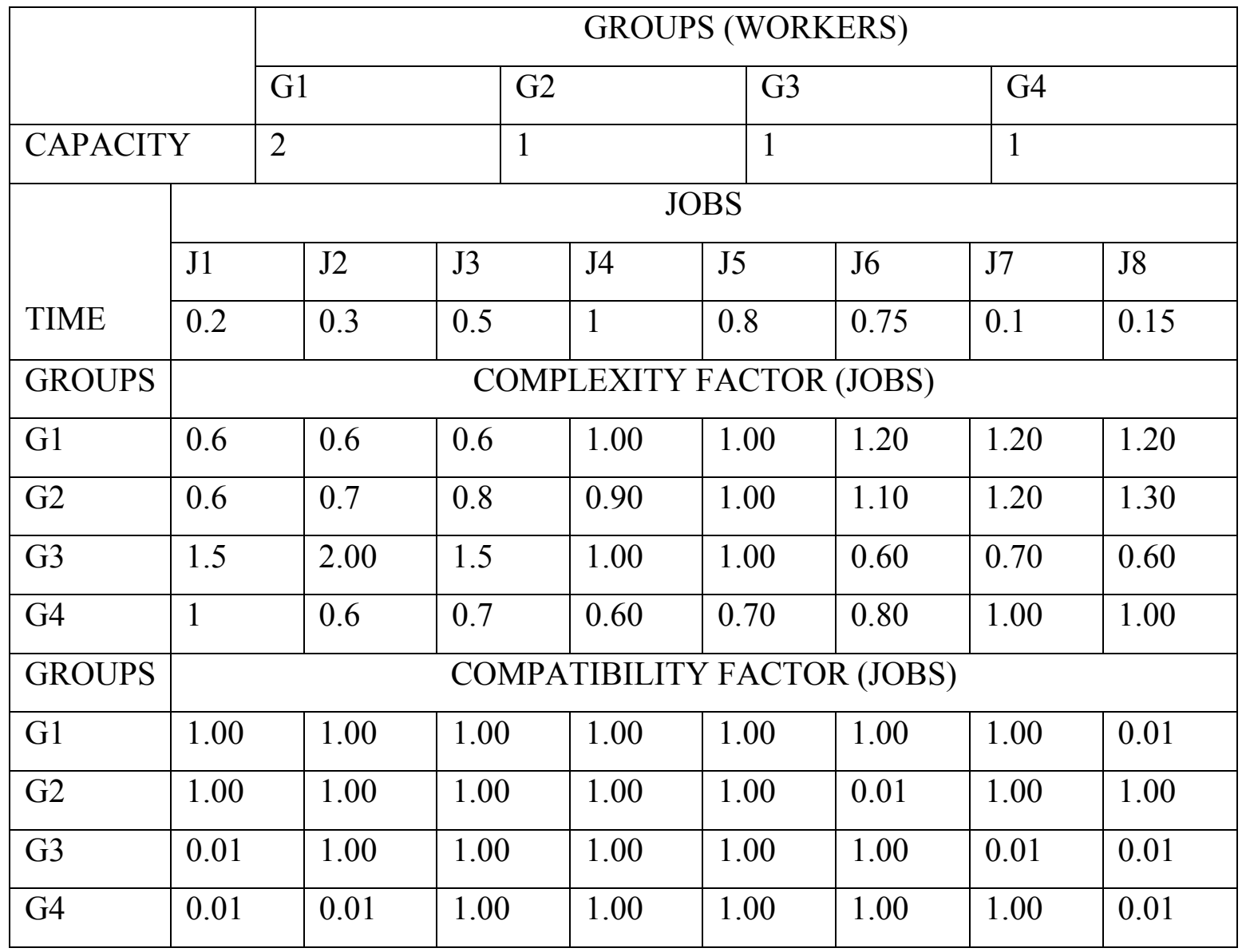

- Step 1) Enter the capacity available in hours for the workstations, the time required to accomplish each job, and the complexity and compatibility factors for each job with respect to each workstation, according to previous table 
- Step 2) Sort the capacity of the workstations in descending order $[b(j)=2,1,1,1]$

- Step 3) Compute for all jobs the ratio $a_{\mathrm{ij}}=\beta_{\mathrm{i}} * \alpha_{\mathrm{ij}} / \eta_{\mathrm{ij}}$

Table 6-2 Processing time with complexity and compatibility factors

\begin{tabular}{|c|c|c|c|c|c|c|c|c|}
\hline \multirow{2}{*}{ GROUPS } & \multicolumn{9}{|c|}{ JOBS } \\
\cline { 2 - 9 } & J1 & J2 & J3 & J4 & J5 & J6 & J7 & J8 \\
\hline G1 & 0.12 & 0.18 & 0.3 & 1 & 0.8 & 0.9 & 0.12 & 18 \\
\hline G2 & 0.12 & 0.21 & 0.4 & 0.9 & 0.8 & 82.5 & 0.12 & 0.195 \\
\hline G3 & 30 & 0.6 & 0.75 & 1 & 0.8 & 0.45 & 7 & 0.9 \\
\hline G4 & 20 & 18 & 0.35 & 0.6 & 0.56 & 0.6 & 0.1 & 15 \\
\hline
\end{tabular}

- Step 4) Find minimum $a_{\mathrm{ij}}(\mathrm{j}=\mathrm{n})$; if the job does not exceed the capacity of $b_{j}$, select the job for the workstation $b_{j}$, then assign to $\mathrm{a}_{\mathrm{ij}}$ a maximum value ( $>$ any $\left.\mathrm{a}_{\mathrm{ij}}\right)$ for all $\mathrm{j}$. If the next (minimum) $\mathrm{a}_{\mathrm{ij}}(\mathrm{j}=\mathrm{n})$ exceeds the capacity of $b_{j}$, move to $\mathrm{j}=$ $\mathrm{n}+1$.

Table 6-3 Procedure for Step 4

\begin{tabular}{|l|l|l|l|l|l|l|l|l|l|l|l|l|}
\hline Sp & Wk & J1 & J2 & J3 & J4 & J5 & J6 & J7 & J8 & $\mathrm{a}_{\mathrm{ij}}$ & $\mathrm{CW}_{\mathrm{i}}$ & $\mathrm{b}_{\mathrm{j}}$ \\
\hline 1 & $\mathrm{G} 1$ & .12 & .18 & .3 & 1 & .8 & .9 & .12 & 18 & $(1,1)$ & $\mathrm{CW}_{1}=0.12$ & $\mathrm{~b}_{1}=2$ \\
\hline 2 & $\mathrm{G} 1$ & $\mathrm{M}$ & .18 & .3 & 1 & .8 & .9 & .12 & 18 & $(1,7)$ & 0.24 & $\mathrm{~b}_{1}=2$ \\
\hline 3 & $\mathrm{G} 1$ & $\mathrm{M}$ & .18 & .3 & 1 & .8 & .9 & $\mathrm{M}$ & 18 & $(1,2)$ & 0.32 & $\mathrm{~b}_{1}=2$ \\
\hline 4 & $\mathrm{G} 1$ & $\mathrm{M}$ & $\mathrm{M}$ & .3 & 1 & .8 & .9 & $\mathrm{M}$ & 18 & $(1,3)$ & 0.62 & $\mathrm{~b}_{1}=2$ \\
\hline 5 & $\mathrm{G} 1$ & $\mathrm{M}$ & $\mathrm{M}$ & $\mathrm{M}$ & 1 & .8 & .9 & $\mathrm{M}$ & 18 & $(1,5)$ & 1.42 & $\mathrm{~b}_{1}=2$ \\
\hline 6 & $\mathrm{G} 1$ & $\mathrm{M}$ & $\mathrm{M}$ & $\mathrm{M}$ & 1 & $\mathrm{M}$ & .9 & $\mathrm{M}$ & 18 & $(1,6)$ & $2.32>2$ & $\mathrm{~b}_{1}=2$ \\
\hline 7 & $\mathrm{G} 2$ & $\mathrm{M}$ & $\mathrm{M}$ & $\mathrm{M}$ & 0.9 & $\mathrm{M}$ & 82.5 & $\mathrm{M}$ & .195 & $(2,8)$ & $\mathrm{CW}_{2}=0.195$ & $\mathrm{~b}_{2}=1$ \\
\hline
\end{tabular}




\begin{tabular}{|l|l|l|l|l|l|l|l|l|l|l|l|l|}
\hline 8 & $\mathrm{G} 2$ & $\mathrm{M}$ & $\mathrm{M}$ & $\mathrm{M}$ & 0.9 & $\mathrm{M}$ & 82.5 & $\mathrm{M}$ & $\mathrm{M}$ & $(2,4)$ & $1.195>1$ & $\mathrm{~b}_{2}=1$ \\
\hline 9 & $\mathrm{G} 3$ & $\mathrm{M}$ & $\mathrm{M}$ & $\mathrm{M}$ & 1 & $\mathrm{M}$ & .45 & $\mathrm{M}$ & $\mathrm{M}$ & $(3,6)$ & $\mathrm{CW}_{3}=0.45$ & $\mathrm{~b}_{3}=1$ \\
\hline 10 & $\mathrm{G} 3$ & $\mathrm{M}$ & $\mathrm{M}$ & $\mathrm{M}$ & 1 & $\mathrm{M}$ & $\mathrm{M}$ & $\mathrm{M}$ & $\mathrm{M}$ & $(3,4)$ & $1.45>1$ & $\mathrm{~b}_{3}=1$ \\
\hline 11 & $\mathrm{G} 4$ & $\mathrm{M}$ & $\mathrm{M}$ & $\mathrm{M}$ & 0.6 & $\mathrm{M}$ & $\mathrm{M}$ & $\mathrm{M}$ & $\mathrm{M}$ & $(4,4)$ & $\mathrm{CW}_{4}=0.6$ & $\mathrm{~b}_{4}=1$ \\
\hline 12 & $\mathrm{G} 4$ & $\mathrm{M}$ & $\mathrm{M}$ & $\mathrm{M}$ & $\mathrm{M}$ & $\mathrm{M}$ & $\mathrm{M}$ & $\mathrm{M}$ & $\mathrm{M}$ & & $\mathrm{STOP}$ & \\
\hline
\end{tabular}

The following table shows the results of the assigning problem at level 0

Table 6-4 Job allocations at level 0

\begin{tabular}{|l|l|l|l|l|}
\hline $\begin{array}{l}\text { GROUPS } \\
\text { (workers) }\end{array}$ & G1 & G2 & G3 & G4 \\
\hline Capacity $\left(\mathrm{b}_{\mathrm{j}}\right)$ & 2 & 1 & 1 & 2 \\
\hline Jobs & J1-J2-J3-J5-J7 & J8 & J6 & J4 \\
\hline
\end{tabular}

6.4.2 Sub-problem 2: Level 1 to $n$

Table 6-5 Data of the numerical example (level 1)

\begin{tabular}{|c|c|c|c|c|}
\hline \multirow{2}{*}{$\begin{array}{l}\text { DATA OF SUPERVISORS } \\
\text { LEVEL } 0 \rightarrow 1\end{array}$} & & \multicolumn{3}{|c|}{ SUPERVISORS } \\
\hline & & S1 & S2 & S3 \\
\hline CAPACITY (Hrs) & & 3 & 2 & 1 \\
\hline $\operatorname{COST}(w)$ & & $\$ 200$ & $\$ 150$ & $\$ 100$ \\
\hline FACTORS OF & \multicolumn{4}{|c|}{ WORKERS (GROUPS) } \\
\hline SUPERVISION EFFORT & G1 & $\mathrm{G} 2$ & G3 & G4 \\
\hline PLANNING $(\rho)$ & 0.02 & 0.015 & 0.01 & 0.02 \\
\hline
\end{tabular}




\begin{tabular}{|l|c|c|c|c|}
\hline CONTROL (c) & 0.03 & 0.1 & 0.14 & 0.11 \\
\hline TRAINING $(\mathrm{t})$ & 0.1 & 0.2 & 0.01 & 0.02 \\
\hline EXECUTION (e) & 0.11 & 0.12 & 0.01 & 0.05 \\
\hline
\end{tabular}

- Step 1) Initialization

$\mathrm{Y}_{0 \mathrm{j}}=$ decision variable

- Step 2) Compute for all group $p_{j}$ the ratio $r_{o j}=p_{0 j}+c_{0 j}+t_{0 j}+e_{0 j}$

Table 6-6 Supervision factors

\begin{tabular}{|c|c|c|c|c|}
\hline & G1 & G2 & G3 & G4 \\
\hline$r_{0 j}=p_{o j}+c_{o j}+t_{o j}+e_{o j}$ & 0.13 & 0.38 & 0.33 & 0.29 \\
\hline
\end{tabular}

- Step 3) Find supervisor with minimum cost $\mathrm{s}_{\mathrm{j}}(\mathrm{j}=\mathrm{n})$;

Table 6-7 Data of capacity and cost (level 1)

\begin{tabular}{|l|l|l|}
\hline Supervisor & Capacity (hrs) & Cost \\
\hline S1 & 3 & 200 \\
\hline S2 & 2 & 150 \\
\hline S3 & 1 & 100 \\
\hline
\end{tabular}

- Step 4) Find group with minimum time; if the group does not exceed the capacity of supervisor $f_{j}$, select the group for the supervisor $b_{j}$ then assign to $a_{i j}$ a maximum value ( $>$ any $\left.a_{i j}\right)$ for all $\mathrm{j}$. If the next (minimum) $a_{i j}(\mathrm{j}=\mathrm{n})$ exceeds the capacity of $b_{j}$, move to $\mathrm{j}=\mathrm{n}+1$. If group $\mathrm{j}$ was not selected in level 0 , assign a value of 2000 . 
Table 6-8 Procedure for level 1

\begin{tabular}{|l|l|l|l|l|l|l|l|l|l|}
\hline Sp & Sup $_{\mathrm{j}}$ & $\mathrm{r}_{\mathrm{ojG} 1}$ & $\mathrm{r}_{\mathrm{ojG} 2}$ & $\mathrm{r}_{\mathrm{ojG} 3}$ & $\mathrm{r}_{\mathrm{ojG} 4}$ & Select & CWsup & Cap $_{\mathrm{sj}}$ & Cost $_{\mathrm{j}}$ \\
\hline 1 & $\mathrm{~S} 3$ & .13 & .38 & .33 & .29 & $(3,1)$ & 0.13 & 1 & 100 \\
\hline 2 & $\mathrm{~S} 3$ & $\mathrm{M}$ & .38 & .33 & .29 & $(3,4)$ & 0.42 & 1 & 100 \\
\hline 3 & $\mathrm{~S} 3$ & $\mathrm{M}$ & .38 & .33 & $\mathrm{M}$ & $(3,3)$ & 0.77 & 1 & 100 \\
\hline 4 & $\mathrm{~S} 3$ & $\mathrm{M}$ & .38 & $\mathrm{M}$ & $\mathrm{M}$ & $(3,2)$ & $1.15>1$ & 1 & $\mathrm{M}$ \\
\hline 5 & $\mathrm{~S} 2$ & $\mathrm{M}$ & .38 & $\mathrm{M}$ & $\mathrm{M}$ & $(2,2)$ & .38 & 2 & 150 \\
\hline 6 & $\mathrm{~S} 2$ & $\mathrm{M}$ & $\mathrm{M}$ & $\mathrm{M}$ & $\mathrm{M}$ & ------ & & $\mathrm{STOP}$ & \\
\hline
\end{tabular}

- Step 5) If group exceeds the capacity of supervisor $\mathrm{j}$, assign a value of $\mathrm{M}$ to the supervisor cost $\mathrm{j}$.

- Step 6) Repeat all steps for level 2 to $\mathrm{n}$ (until all the supervisors have been assigned to a manager).

6.5 Solution improvement by a meta-heuristic (Meta-RaPS)

A natural extension to the constructive heuristic presented in Chapter 6.1 is to develop an improve heuristic that can draw better results for the solutions found. A meta-heuristic for the Organizational Design Problem is presented in this chapter to solve the problem under study.

\subsubsection{Introduction to Meta-RaPS}

The application of Meta-RaPS to any combinatorial problem, according to Moraga et al. [41], as a general methodology considers the following steps: 
1. Study the structure of the problem to be solved

2. Find good priority rules that construct feasible solutions

3. Modify priority rules using randomness

4. Construct feasible solutions using priority rule and randomness

5. Pick the best answer for a number of iterations

6. Improve solutions

According to DePuy [29] and Moraga et al. [54] Meta-RaPS modifies the way a greedy construction heuristic chooses the next activity to add to the solution, by occasionally choosing an activity that does not have the best priority value. Sometimes the next activity is chosen randomly from those feasible activities with good, but not the best, priority values. The heuristic approach begins with a well-defined mathematical representation of a problem. There is an objective or evaluation function that provides the value of any specific solution (values of the set of decision variables), and there are specified constraints that define the region of feasible solutions. Ideally, one would like to select the so-called optimal solution that achieves the minimum (in this case) value.

\subsubsection{Modify priority rules using randomness}

Once there is a priority rule that constructs feasible solutions (6.1 proposed solution approach), the next step is to use the framework of Meta-RaPS for improving the heuristic method. The greedy algorithm can be randomized altering the composition of the "next available activity" using a restriction range (r) so $\mathrm{R}={ }^{c} / a_{i j}[(1-\mathrm{r} / 100), 1]$. The next variable will be picked randomly from the list of items. 
Instead of selecting at each iteration the smallest $a_{i j}$, a wider list is chosen that contains more than one item available as the next item added to the solution. If the restriction percentage (\%r) is $35 \%$, that means the "next available activity" list is comprised of those not chosen variables whose ratios are within a distance $\mathrm{R}={ }^{c_{i}} / a_{i j}[0.65,1]$. Using the same data as the previous problem, the processing time is changed according to $a_{i j}=$ $\beta_{i} \alpha_{i j} z_{i j} / n_{i j}$ as shown in table below.

Table 6-9 Processing time

\begin{tabular}{|c|c|c|c|c|c|c|c|c|}
\hline \multirow{2}{*}{ GROUPS } & \multicolumn{9}{|c|}{ JOBS } \\
\cline { 2 - 9 } & J1 & J2 & J3 & J4 & J5 & J6 & J7 & J8 \\
\hline G1 & 0.12 & 0.18 & 0.3 & 1 & 0.8 & 0.9 & 0.12 & 18 \\
\hline G2 & 0.12 & 0.21 & 0.4 & 0.9 & 0.8 & 82.5 & 0.12 & 0.195 \\
\hline G3 & 30 & 0.6 & 0.75 & 1 & 0.8 & 0.45 & 7 & 0.9 \\
\hline G4 & 20 & 18 & 0.35 & 0.6 & 0.56 & 0.6 & 0.1 & 15 \\
\hline
\end{tabular}

Table below shows an example of the use of the percentage restriction (\%r):

Table 6-10 Candidates for "next available activity"

\begin{tabular}{|l|l|l|}
\hline For $\mathrm{j}=$ & $\begin{array}{l}\mathrm{R}={ }^{c} / a_{i j}[(1-\mathrm{r} / 100), 1] \\
\% \mathrm{ret}=35 \%\end{array}$ & $\begin{array}{l}\text { The available list contains } \\
\text { values }[x, y] \text { to choose randomly }\end{array}$ \\
\hline 1 & $\mathrm{R}^{\prime}=a_{i j}[0.12,0.15]$ & {$[0.12,0.12]$} \\
\hline 2 & $\mathrm{R}^{\prime}=a_{i j}[0.12,0.15]$ & {$[0.12,0.12]$} \\
\hline 3 & $\mathrm{R}^{\prime}=a_{i j}[0.45,0.6]$ & {$[0.45,0.6]$} \\
\hline 4 & $\mathrm{R}^{\prime}=a_{i j}[.1,0.13]$ & {$[0.1]$} \\
\hline
\end{tabular}


The modified version of the algorithm (with a percentage restriction \%ret) encompasses the following steps at level 0 .

- Step 1) Initialization

Set $b_{j}=\mathrm{ro}_{\mathrm{j}}$ and $\mathrm{Yo}_{\mathrm{j}}=$ decision variable

- Step 2) Compute for all $\mathrm{a}_{\mathrm{ij}}$ the ratio $\mathrm{a}_{\mathrm{ij}}=\beta_{\mathrm{i}} \alpha_{\mathrm{ij}} \mathrm{z}_{\mathrm{ij}} / \mathrm{n}_{\mathrm{ij}}$

- Step 3) Use a percentage restriction (\%ret) in order to find the list of "next available supervisor" with the minimum cost:

$\circ$ Find minimum $\mathrm{a}_{\mathrm{ij}}$

○ Pick randomly $\mathrm{a}_{\mathrm{ij}}$ for $\mathrm{j}=\mathrm{n}$; if the task $\mathrm{a}_{\mathrm{ij}} \leq$ minimum $\mathrm{a}_{\mathrm{ij}} *(1+\% \mathrm{r})$ and does not exceed the capacity of $b_{j}$, select the task for the workstation $b_{j}$, assign to $\mathrm{a}_{\mathrm{ij}}$ a maximum value ( $>$ any $\mathrm{a}_{\mathrm{ij}}$ ) for all $\mathrm{j}$. If the next task $\mathrm{a}_{\mathrm{ij}} \leq$ minimum $a_{i j} *(1+\% r)$ exceeds the capacity of $b_{j}$, move to $j=n+1$.If task $\mathrm{a}_{\mathrm{ij}} \geq \operatorname{minimum} \mathrm{a}_{\mathrm{ij}} *(1+\%$ ret $)$, choose another $\mathrm{a}_{\mathrm{ij}}$ until task $\mathrm{a}_{\mathrm{ij}} \leq$ minimum $\mathrm{a}_{\mathrm{ij}} *(1+\%$ ret $)$ or stop at $\mathrm{n}$ iterations according to variable "itei”

- Step 4) Repeat Step 3 until the entire tasks has been assigned to a workstation or the algorithm determines that the problem is unfeasible after $\mathrm{n}$ iterations according to variable "itee".

The modified version of the algorithm (with a percentage restriction \%ret) encompasses the following steps at level 1 to $\mathrm{n}$.

- Step 1) Initialization: Level 1 to $\mathrm{n}$ 
- Set $_{b_{j}}=\mathrm{ro}_{\mathrm{j}}$ and $\mathrm{Yo}_{\mathrm{j}}=$ decision variable

- Step 2) Compute for all workers $t f a c_{j}=p_{o j}+t_{o j}+e_{o j}+c_{o j}$

- Step 3) Use a percentage restriction (\%ret1) in order to find the list of "next available supervisor" with the minimum cost (cts).

○ Find supervisor with minimum cost (cts)

○ Pick randomly any supervisor for $\mathrm{j}=\mathrm{n}$; if the supervisor cost cts $\leq$ minimum cts $*(1+\%$ ret 1$)$ and does not exceeds the capacity of $\mathrm{cps}_{\mathrm{j}}$, select worker with minimum processing time, assign worker to supervisor j. Assign to $r g t_{j}$ a maximum value for all j. If the next supervisor cost cts $\leq$ minimum $\operatorname{cts}_{\mathrm{j}} *(1+\%$ ret 1$)$ exceeds the capacity of $\mathrm{cps}_{\mathrm{j}}$, move to $\mathrm{j}=\mathrm{n}+1$.

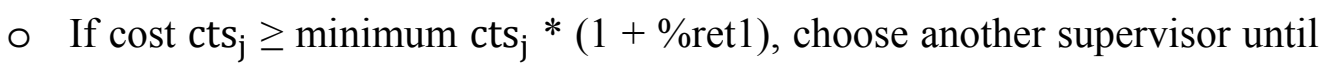
cost $c t s_{\mathrm{j}} \leq$ minimum $\mathrm{cts}_{\mathrm{j}} *(1+\%$ ret 1$)$ or stop at $\mathrm{n}$ iterations according to variable "itei"

- Step 4) Repeat Step 3 until all the workers have been assigned to a supervisor or the algorithm determines that the problem is unfeasible, after $\mathrm{n}$ iterations according to variable "itee".

- Step 5) Repeat Steps 1 to 4 until the entire span of control has been assigned.

\subsubsection{Composition of the "next available task"}

The greedy algorithm is modified by altering the composition of the "next available task". In this step, a priority percentage (\%p) is used (as suggested by Moraga et al. [41]) in order to set a percentage of the time the greedy algorithm, and the percentage of time 
the modified algorithm will be used to select the next task. If the $\% p=20$, that means $20 \%$ of the time the greedy algorithm will be used, and $80 \%$ of the time the modified algorithm will be used to select the next task.

This procedure is run for a user-defined number of replications and iterations in the metaheuristic, and the overall best solution in each replication can be reported which, can also be used to testify the robustness of the heuristic.

The procedure of meta-heuristic at level 0 is shown in the following figure:

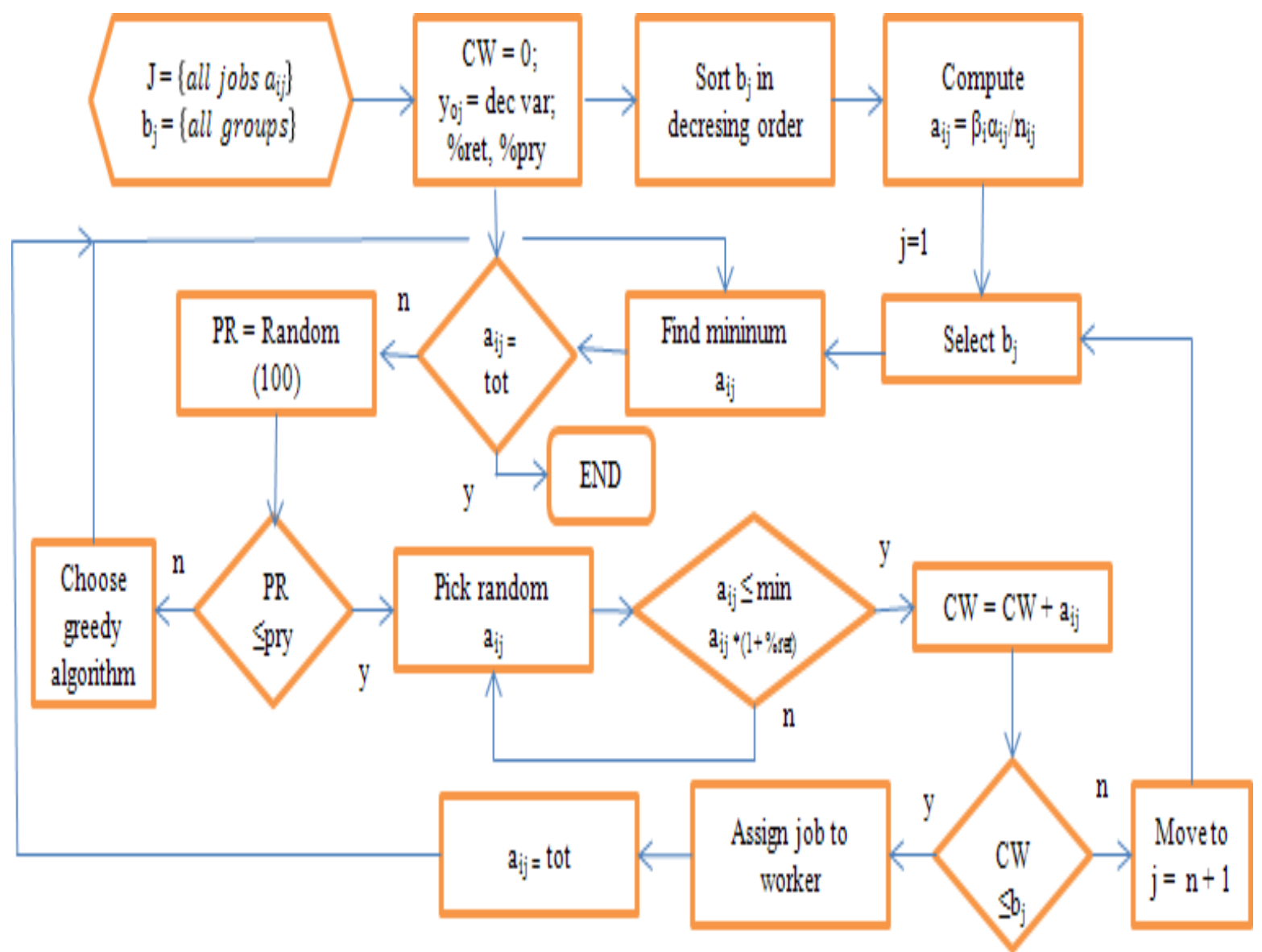

Figure 6-8 Procedure of the meta-heuristic proposed at level 0

The pseudo code for the meta-heuristic for level 0 can be illustrated in figure below: 


\section{Begin with}

Let $J$ be the set of workstations, and let $a_{i j}$ be the modified processing time of task $i$ with respect to workstation $j$ (including complexity and compatibility factors).

Let $n, m$ be the number of tasks and the number of workstations.

Let tot be the maximum processing time for $a_{i j}$ once the task is assigned to a workstation and $b(j)$ the time capacity of workstation $j$.

\section{Initialization}

Compute matrix a(i.j)

Set parameters \%ret, \%pry, itee, itei.

Set $\mathrm{n}, \mathrm{m}$, tot

Rank capacity of workers in decreasing order b(j)

For a fixed number of iterations DO (itee)

For all workstations b(j)

For all activities a(i,j)

Find minimum a(i.j)

Generate a random number PR (1-100)

If $\mathrm{PR}<=\%$ pry

Choose the greedy algorithm from the available list of activities

and assign to the worker

Else

For a fixed number of iterations DO (itei)

Generate a random number c(n)

Select one activity randomly

If the procesing time of the activity is within the minimum

processing time and $\%$ rest

Assign the activity to the worker

Assign to activity a(i,j) a maximum value for all workstations

End if

Endfor

Endif

Endfor

Endfor

Endfor

Return matrix $y(i, j)$ with the allocation of the activities to workstations (workers)

Figure 6-9 Meta-RaPS procedure for the solution approach 
The procedure of meta-heuristic at level 1 to $n$ is shown in the figure below:

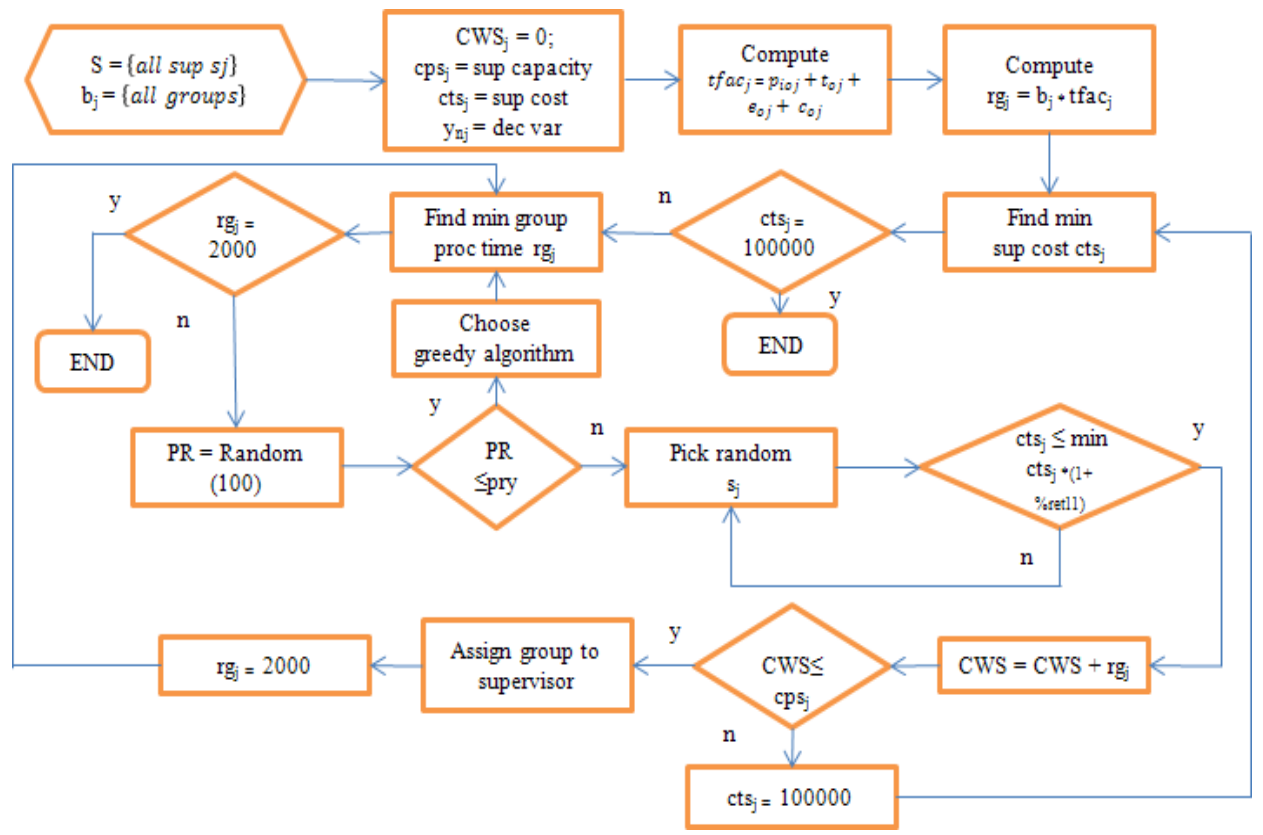

Figure 6-10 Procedure of the meta-heuristic proposed at level 1

The pseudo code for the meta-heuristic for level 1 to $\mathrm{n}$ can be illustrated as in figure 6-11:

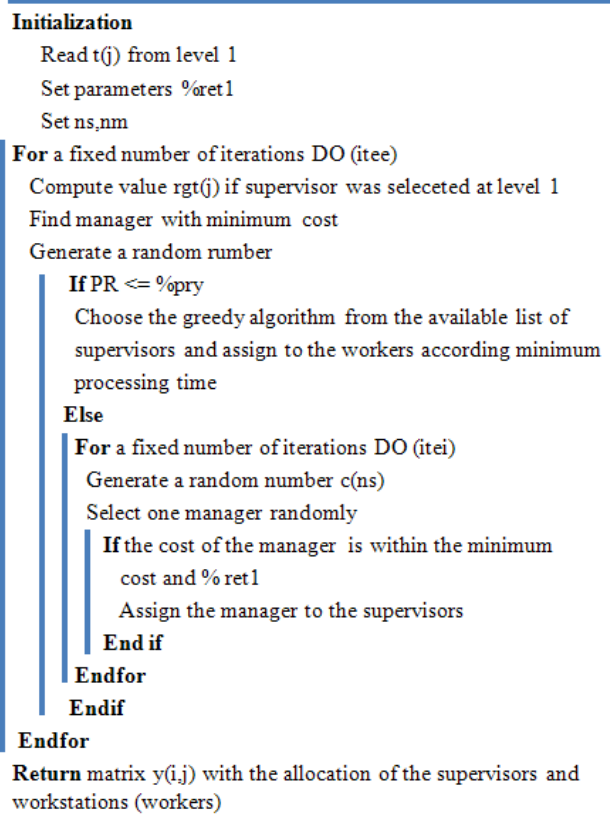

Figure 6-11 Meta-RaPS procedure for the solution approach (level 1) 
All procedures programmed in Matlab are shown in Appendix C.

\subsubsection{Setting parameters}

Almost all known meta-heuristic available have a number of parameters that need to be set. Combine the settings obtained in the "modify priority rules" in order to run the entire collection of restriction range. In order to construct a feasible solution, the following parameters: \%ret (restriction percentage), \%p (priority percentage), and the number of iterations need to be set. In order to set these parameters, this model uses some ideas reported by DePuy et al. [41] which consists in the following steps: 1) select a representative subset of problems to analyze, 2) select the appropriate parameter domain, 3) select good parameter settings for each problem, and 4) run the entire subset of problems.

The methodology to evaluate the heuristic design consists of comparing results obtained by the algorithm on test problems already solved with LINGO (with optimal values). This heuristic design is a refinement of the Meta-RaPS. The customization of the metaheuristic is in the construction of the greedy algorithm for this particular application and adjustments made to find the optimal values of mentioned parameters. The following table shows the size of problems used to evaluate the meta-heuristic.

Table 6-11 Size of problems used to evaluate the meta-heuristic

\begin{tabular}{|c|c|c|c|c|c|c|}
\hline $\begin{array}{c}\text { Case } \\
(\text { size })\end{array}$ & $\begin{array}{c}\mathrm{m} \\
(\text { jobs})\end{array}$ & $\begin{array}{c}\mathrm{n} \\
\text { (groups) }\end{array}$ & $\begin{array}{c}\mathrm{ns} \\
(\mathrm{sup})\end{array}$ & $\begin{array}{c}\mathrm{nm} \\
(\mathrm{man})\end{array}$ & Constraints & Variables \\
\hline $\mathrm{A}$ & 8 & 4 & 3 & 2 & 41 & 22 \\
\hline $\mathrm{B}$ & 30 & 10 & 5 & 3 & 58 & 318 \\
\hline $\mathrm{C}$ & 40 & 10 & 5 & 3 & 68 & 418 \\
\hline
\end{tabular}




\begin{tabular}{|c|c|c|c|c|c|c|}
$\mathrm{D}$ & 60 & 20 & 5 & 3 & 108 & 1228 \\
\hline $\mathrm{E}$ & 100 & 40 & 5 & 3 & 188 & 4048 \\
\hline $\mathrm{F}$ & 200 & 40 & 10 & 5 & 293 & 8055 \\
\hline $\mathrm{G}$ & 300 & 40 & 10 & 5 & 393 & 12055 \\
\hline
\end{tabular}

The following figure shows the number of variables and constraints for each problem size:

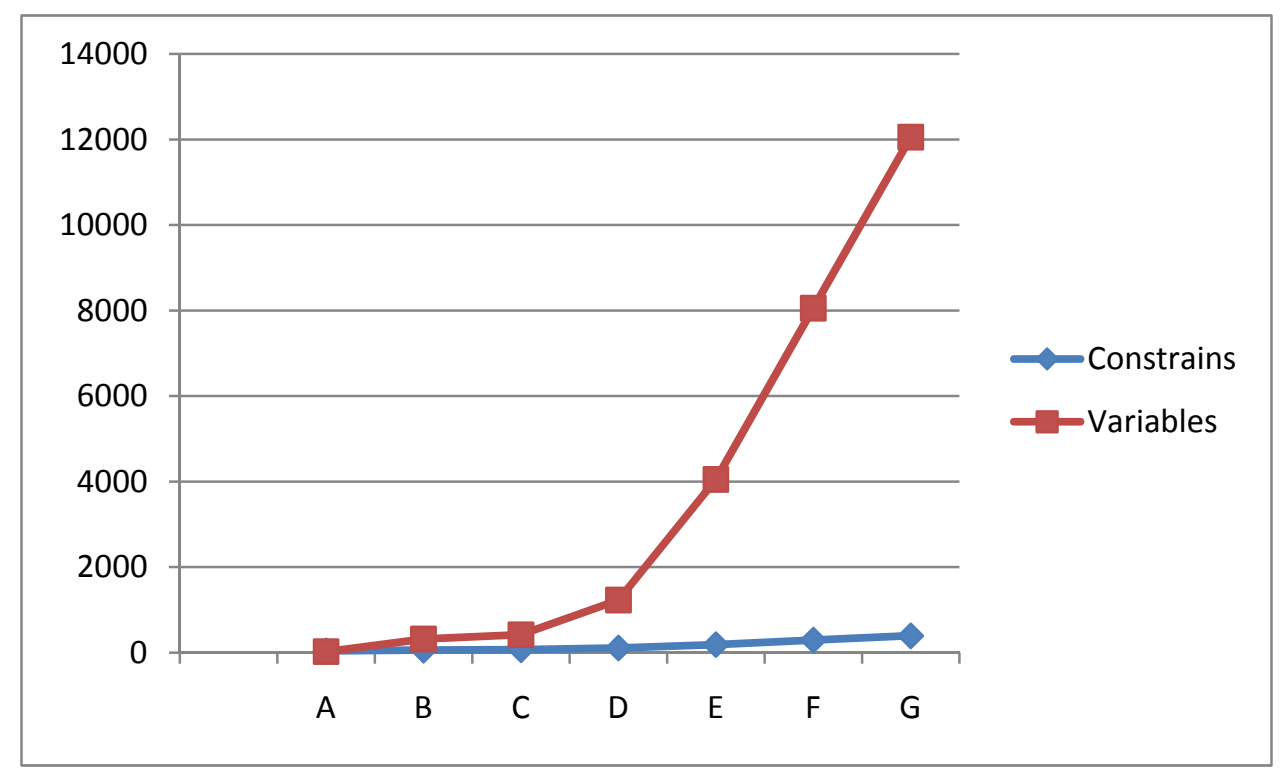

Figure 6-12 Number of variables and constraints

In order to implement the meta-heuristic, six representative problems in terms of the number of variables and constraints were selected. Table 6-12 shows the subset of problems chosen:

Table 6-12 Subset of problems selected for setting parameters

\begin{tabular}{|c|c|c|c|c|c|}
\hline $\begin{array}{c}\text { Problem } \\
\text { (B) }\end{array}$ & $\begin{array}{c}\mathrm{m} \\
\text { (jobs) }\end{array}$ & $\begin{array}{c}\mathrm{n} \\
\text { (groups) }\end{array}$ & $\begin{array}{c}\mathrm{ns} \\
\text { (sup) }\end{array}$ & $\begin{array}{c}\mathrm{nm} \\
\text { (man) }\end{array}$ & value \\
\hline CAS\#1 & 30 & 10 & 5 & 3 & 4205 \\
\hline
\end{tabular}




\begin{tabular}{|l|l|l|l|l|r|} 
CAS\#2 & 30 & 10 & 5 & 3 & 9524 \\
\hline CAS\#3 & 30 & 10 & 5 & 3 & 1103 \\
\hline CAS\#4 & 30 & 10 & 5 & 3 & 2103 \\
\hline CAS\#5 & 30 & 10 & 5 & 3 & 1003 \\
\hline CAS\#6 & 30 & 10 & 5 & 3 & 456 \\
\hline
\end{tabular}

Using parameters of 200 iterations (itee), 20 iterations (itei) and range values of $(0.1,4)$, and $(10,60)$ arbitrarily chosen for $\% \mathrm{r}$ and $\%$ p respectively, the subset is solved by metaheuristic and the best combination of parameters is selected. The criterion used for level 0 is to select a good combination of pairs (\%ret, \%p) that produces the less deviation from optimal values. Table 6-13 shows the deviation (\%) of the average six problems, i.e. with $\%$ ret $=0.1$ and $\% p=20$, the value of 116 means that the average of the deviation from optimal value of the six problems were $116 \%$. It is observed that the minimum deviation is with $\%$ ret $=4$ and $\% p=50$.

Table 6-13 Deviation (\%) from the optimal solution at level 0

\begin{tabular}{|c|l|r|r|r|r|r|}
\hline & $\% \mathrm{p}=10$ & 20 & 30 & 40 & 50 & 60 \\
\hline $\begin{array}{c}\text { \%ret }= \\
0.1\end{array}$ & $\begin{array}{l}\text { No } \\
\text { Feasible }\end{array}$ & 116 & 108 & 64 & 54 & 54 \\
\hline 0.3 & 116 & 92 & 76 & 54 & 40 & 35 \\
\hline 0.5 & 93 & 82 & 66 & 42 & 49 & 35 \\
\hline 1 & 60 & 56 & 42 & 42 & 25 & 29 \\
\hline 1.5 & 49 & 54 & 35 & 37 & 35 & 25 \\
\hline 2 & 67 & 51 & 42 & 35 & 35 & 29 \\
\hline 2.5 & 54 & 42 & 35 & 39 & 25 & 29 \\
\hline 3 & 42 & 42 & 35 & 42 & 29 & 31 \\
\hline 3.5 & 58 & 33 & 42 & 29 & 29 & 29 \\
\hline
\end{tabular}




\begin{tabular}{|l|l|l|l|l|l|l|}
4 & 35 & 31 & 25 & 31 & $\mathbf{2 1}$ & 25 \\
\hline 5 & 42 & 35 & 29 & 35 & 29 & 25 \\
\hline
\end{tabular}

Using the above results $(\% \mathrm{ret}=4, \% \mathrm{p}=50)$ for level 0 , Table $6-14$ shows pairs (\%ret1, $\% \mathrm{p} 1)$ that got highest frequencies out of six problems for a deviation less or equal than $5 \%$ throughout the subset (level 2 ). With values of $\%$ ret $1=1.5$ or above the frequencies are 6 , therefore the combination of parameters selected are $\%$ ret $0=4, \%$ ret $1=1.5$ and $\% \mathrm{p} 0=\% \mathrm{p} 1=50($ In level 1 and 2 , the \%p is irrelevant between values 10-60). Table 615 shows that with the parameters selected the (average) deviation from optimal values is $1.04 \%$.

Table 6-14 Frequencies out of six problems getting a deviation of 5\% or less

Level 1 to $n$

\begin{tabular}{|c|r|r|r|r|r|r|}
\hline & \%p1=10 & 20 & 30 & 40 & 50 & 60 \\
\hline$\% \mathrm{r} 1=0.1$ & 3 & 3 & 3 & 3 & 3 & 3 \\
\hline 0.3 & 3 & 3 & 3 & 3 & 3 & 3 \\
\hline 0.5 & 4 & 4 & 4 & 4 & 4 & 4 \\
\hline 1 & 4 & 4 & 4 & 4 & 4 & 4 \\
\hline $\mathbf{1 . 5}$ & $\mathbf{6}$ & $\mathbf{6}$ & $\mathbf{6}$ & $\mathbf{6}$ & $\mathbf{6}$ & $\mathbf{6}$ \\
\hline 2 & 6 & 6 & 6 & 6 & 6 & 6 \\
\hline 2.5 & 6 & 6 & 6 & 6 & 6 & 6 \\
\hline 3 & 6 & 6 & 6 & 6 & 6 & 6 \\
\hline 3.5 & 6 & 6 & 6 & 6 & 6 & 6 \\
\hline 4 & 6 & 6 & 6 & 6 & 6 & 6 \\
\hline 5 & 6 & 6 & 6 & 6 & 6 & 6 \\
\hline
\end{tabular}


Table 6-15 Deviation (\%) from the optimal solution and the meta-heuristic

Level 1 to $\mathrm{n}$

\begin{tabular}{|c|r|r|r|r|r|r|}
\hline & $\% \mathrm{p}=10$ & 20 & 30 & 40 & 50 & 60 \\
\hline $\mathrm{r}=0.1$ & 23 & 23 & 23 & 23 & 23 & 23 \\
\hline 0.3 & 23 & 23 & 23 & 23 & 23 & 23 \\
\hline 0.5 & 4.29 & 4.29 & 4.29 & 4.29 & 4.29 & 4.29 \\
\hline 1 & 2.7 & 2.7 & 2.7 & 2.7 & 2.7 & 2.7 \\
\hline $\mathbf{1 . 5}$ & $\mathbf{1 . 0 4}$ & $\mathbf{1 . 0 4}$ & $\mathbf{1 . 0 4}$ & $\mathbf{1 . 0 4}$ & $\mathbf{1 . 0 4}$ & $\mathbf{1 . 0 4}$ \\
\hline 2 & 1.04 & 1.04 & 1.04 & 1.04 & 1.04 & 1.04 \\
\hline 2.5 & 1.04 & 1.04 & 1.04 & 1.04 & 1.04 & 1.04 \\
\hline 3 & 1.04 & 1.04 & 1.04 & 1.04 & 1.04 & 1.04 \\
\hline 3.5 & 1.04 & 1.04 & 1.04 & 1.04 & 1.04 & 1.04 \\
\hline 4 & 1.04 & 1.04 & 1.04 & 1.04 & 1.04 & 1.04 \\
\hline 5 & 1.04 & 1.04 & 1.04 & 1.04 & 1.04 & 1.04 \\
\hline
\end{tabular}

6.3 Evaluation of solution quality

In table 6-17, preliminary results are shown of the meta-heuristic solving 30 cases of size A and B (commercial solver LINGO could not solve problems of size equal or larger than C).

Table 6-16 Preliminary Meta-Heuristic Results (Case A and B)

\begin{tabular}{|r|l|l|r|r|r|r|r|c|}
\hline Case & Name & itee & itei & \%p & \%ret0 & \%ret1 & value & $\begin{array}{l}\text { \%dev } \\
\text { From optimal }\end{array}$ \\
\hline 1 & CAS1-A & 200 & 40 & 50 & 4 & 1.5 & 2553 & 0 \\
\hline 2 & CAS2-A & 200 & 40 & 50 & 4 & 1.5 & 4603 & 0 \\
\hline 3 & CAS3-A & 200 & 40 & 50 & 4 & 1.5 & 2404 & 0 \\
\hline 4 & CAS4-A & 200 & 40 & 50 & 4 & 1.5 & 1603 & 10.39 \\
\hline 5 & CAS5-A & 200 & 40 & 50 & 4 & 1.5 & 1453 & 0 \\
\hline 6 & CAS6-A & 200 & 40 & 50 & 4 & 1.5 & 2704 & 0 \\
\hline 7 & CAS7-A & 200 & 40 & 50 & 4 & 1.5 & 2364 & 6.77 \\
\hline 8 & CAS8-A & 200 & 40 & 50 & 4 & 1.5 & 354 & 0.28 \\
\hline 9 & CAS9-A & 200 & 40 & 50 & 4 & 1.5 & 5603 & 0 \\
\hline
\end{tabular}




\begin{tabular}{|r|l|r|r|r|r|r|r|c|}
\hline 10 & CAS10-A & 200 & 40 & 50 & 4 & 1.5 & 603 & 0 \\
\hline 11 & CAS11-A & 200 & 40 & 50 & 4 & 1.5 & 2603 & 0 \\
\hline 12 & CAS12-A & 200 & 40 & 50 & 4 & 1.5 & 402 & 0 \\
\hline 13 & CAS13-A & 200 & 40 & 50 & 4 & 1.5 & 503 & 0.19 \\
\hline 14 & CAS14-A & 200 & 40 & 50 & 4 & 1.5 & 2652 & 1.92 \\
\hline 15 & CAS15-A & 200 & 40 & 50 & 4 & 1.5 & 1704 & 0.05 \\
\hline 16 & CAS16-A & 200 & 40 & 50 & 4 & 1.5 & 2003 & 0 \\
\hline 17 & CAS17-A & 200 & 40 & 50 & 4 & 1.5 & 2753 & 0 \\
\hline 18 & CAS18-A & 200 & 40 & 50 & 4 & 1.5 & 6402 & 0 \\
\hline 19 & CAS19-A & 200 & 40 & 50 & 4 & 1.5 & 823 & 0 \\
\hline 20 & CAS20-A & 200 & 40 & 50 & 4 & 1.5 & 2303 & 0 \\
\hline 21 & CAS1-B & 200 & 40 & 50 & 4 & 1.5 & 4206 & 0.02 \\
\hline 22 & CAS2-B & 200 & 40 & 50 & 4 & 1.5 & 9605 & 0.85 \\
\hline 23 & CAS3-B & 200 & 40 & 50 & 4 & 1.5 & 1104 & 0.09 \\
\hline 24 & CAS4-B & 200 & 40 & 50 & 4 & 1.5 & 2204 & 4.8 \\
\hline 25 & CAS5-B & 200 & 40 & 50 & 4 & 1.5 & 605 & 0.33 \\
\hline 26 & CAS6-B & 200 & 40 & 50 & 4 & 1.5 & 704 & 0.1422 \\
\hline 27 & CAS7-B & 200 & 40 & 50 & 4 & 1.5 & 1004 & 0.09 \\
\hline 28 & CAS8-B & 200 & 40 & 50 & 4 & 1.5 & 3404 & 0.029 \\
\hline 29 & CAS9-B & 200 & 40 & 50 & 4 & 1.5 & 458 & 0.43 \\
\hline 30 & CAS10-B & 200 & 40 & 50 & 4 & 1.5 & 504 & 0.19 \\
\hline
\end{tabular}

Table 6-17 Average, std dev and maximum \% difference from optimal

\begin{tabular}{|l|l|l|l|}
\hline Method & $\begin{array}{l}\text { Average } \\
\text { \% Difference from } \\
\text { optimal }\end{array}$ & $\begin{array}{l}\text { Std Dev } \\
\text { \% Difference from } \\
\text { optimal }\end{array}$ & $\begin{array}{l}\text { Maximum } \\
\text { \% Difference } \\
\text { from optimal }\end{array}$ \\
\hline Meta-heuristic & 0.8809667 & 2.3372189 & 10.39 \\
\hline
\end{tabular}

The method used to evaluate the meta-heuristic consists of comparing results obtained by the meta-heuristic on test problems with their optimal values; also the meta-heuristic was compared to the pure greedy algorithm results. Table 6-18 shows results of applying the meta-heuristic and the modified greedy approach (originally suggested by Lagoudakis [41]). 
Table 6-18 Comparison of the meta-heuristic versus greedy algorithm

\begin{tabular}{|c|c|c|c|c|c|c|c|c|c|c|}
\hline Case & Name & $\mathrm{m}$ & $\mathrm{n}$ & ns & $\mathrm{nm}$ & $\begin{array}{l}\text { Opt } \\
\text { Value } \\
\text { LINGO }\end{array}$ & $\begin{array}{l}\text { Greedy } \\
\text { algorithm }\end{array}$ & $\begin{array}{l}\text { Meta- } \\
\text { heuristic }\end{array}$ & $\begin{array}{l}\text { \%d1 } \\
\text { (ga) } \\
\text { from } \\
\text { optimal }\end{array}$ & $\begin{array}{l}\% \mathrm{~d} 2 \\
(\mathrm{mh}) \\
\text { from } \\
\text { optimal }\end{array}$ \\
\hline 1 & $\begin{array}{l}\text { CAS1- } \\
\text { TA }\end{array}$ & 8 & 4 & 3 & 2 & 2553 & 2653 & 2553 & 3.91696 & 0 \\
\hline 2 & $\begin{array}{l}\text { CAS2- } \\
\text { TA }\end{array}$ & 8 & 4 & 3 & 2 & 4603 & 9404 & 4603 & 104.302 & 0 \\
\hline 5 & $\begin{array}{l}\text { CAS5- } \\
\text { TA } \\
\end{array}$ & 8 & 4 & 3 & 2 & 1453 & 1604 & 1453 & 10.3923 & 0 \\
\hline 10 & $\begin{array}{l}\text { CAS10- } \\
\text { TA }\end{array}$ & 8 & 4 & 3 & 2 & 603 & 754 & 603 & 25.0415 & 0 \\
\hline 11 & $\begin{array}{l}\text { CAS11- } \\
\text { TA }\end{array}$ & 8 & 4 & 3 & 2 & 2603 & 5804 & 2603 & 122.973 & 0 \\
\hline 14 & $\begin{array}{l}\text { CAS19- } \\
\text { TA }\end{array}$ & 8 & 4 & 3 & 2 & 823 & 824 & 823 & 0.12151 & 0 \\
\hline 21 & $\begin{array}{l}\text { CAS1- } \\
\text { TB }\end{array}$ & 30 & 10 & 5 & 3 & 4205 & 4206 & 4206 & 0.02378 & 0.02378 \\
\hline 24 & $\begin{array}{l}\text { CAS4- } \\
\text { TB }\end{array}$ & 30 & 10 & 5 & 3 & 2103 & 2404 & 2204 & 14.3129 & 4.80266 \\
\hline 27 & $\begin{array}{l}\text { CAS7- } \\
\text { TB }\end{array}$ & 30 & 10 & 5 & 3 & 1003 & 1104 & 1004 & 10.0698 & 0.0997 \\
\hline 29 & $\begin{array}{l}\text { CAS9- } \\
\text { TB }\end{array}$ & 30 & 10 & 5 & 3 & 456 & 958 & 458 & 110.088 & 0.4386 \\
\hline
\end{tabular}

Another useful evaluation of the performance of the meta-heuristic is the time of response. Even though a commercial solver (LINGO) outperforms the meta-heuristic in the speed of the process, this solver can only handle problems of size (jobs $\mathrm{x}$ groups) until 30 jobs and 10 groups, while the meta-heuristic could solve bigger problems in a reasonable amount of time. Table 6-19 and Figure 6-11 show the performance of the meta-heuristic in each of the problems used for this evaluation.

Table 6-19 Time of response.

\begin{tabular}{|c|c|c|}
\hline $\begin{array}{l}\text { Case size } \\
\text { (jobs } \mathrm{x} \text { groups) }\end{array}$ & $\begin{array}{l}\text { LINGO } \\
\text { (seconds average) }\end{array}$ & $\begin{array}{l}\text { META-HEURISTIC } \\
\text { (seconds average) }\end{array}$ \\
\hline $8 \times 4$ & 00 & 0.46 \\
\hline
\end{tabular}




\begin{tabular}{|c|c|c|}
\hline $16 \times 6$ & 01 & 5.56 \\
\hline $30 \times 10$ & 01 & 7.76 \\
\hline $40 \times 10$ & $* *$ & 8.97 \\
\hline $60 \times 20$ & $* *$ & 25.33 \\
\hline $100 \times 40$ & $* *$ & 71.33 \\
\hline $200 \times 40$ & $* *$ & 125.4 \\
\hline $300 \times 40$ & $* *$ & 406 \\
\hline
\end{tabular}

Note: ** means that LINGO cannot solve problems of this size

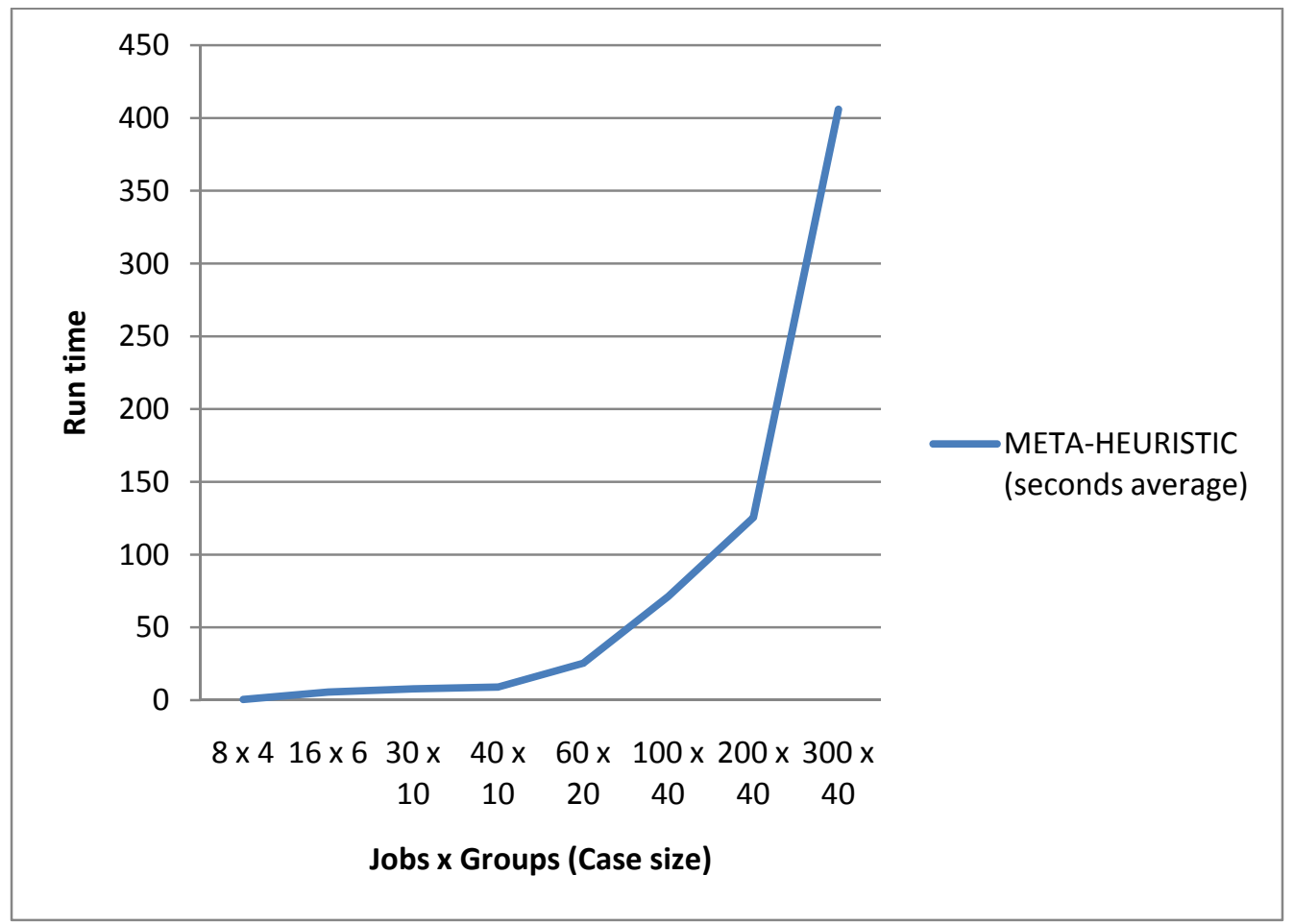

Figure 6-13 Time of response

Using these data, the computation time required by the algorithm for larger problems can be approximated. Using the number of variables (of the seven cases) a polynomial equation of degree 3 with a correlation of 0.9993 was obtained, as shown in the following figure: 


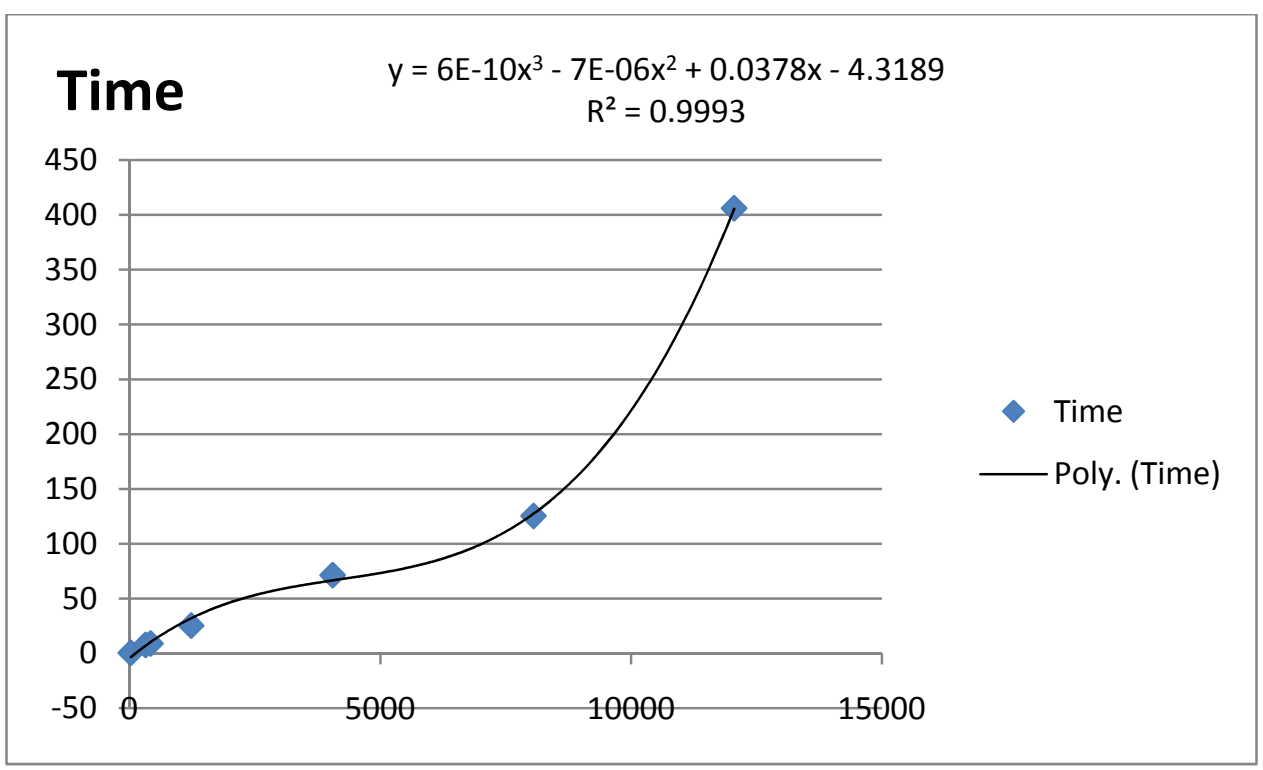

Figure 6-14 Interpolation of the number of variables

The number of variables used for each problem can be obtained with the formula:

$$
\operatorname{Vars}=(g * j)+g+s+m
$$

Where:

- $\quad$ Vars $=$ Number of variables

- $\mathrm{g}=$ number of workers (groups)

- $\mathrm{j}=$ number of jobs (activities)

- $\mathrm{s}=$ number or supervisors

- $\mathrm{m}=$ number of managers

Table 6-20 Approximate running time for bigger problems

\begin{tabular}{|l|l|l|l|l|l|l|l|l|}
\hline Case & jobs & workers & sup & man & \# of & $\begin{array}{l}\text { Aprox } \\
\text { time in }\end{array}$ & $\begin{array}{l}\text { Aprox } \\
\text { time in }\end{array}$ & $\begin{array}{l}\text { Aprox } \\
\text { time in }\end{array}$ \\
$($ size $)$ & $(\mathrm{j})$ & $(\mathrm{g})$ & $(\mathrm{s})$ & $(\mathrm{m})$ & vars & seconds & min & hrs \\
\hline
\end{tabular}




\begin{tabular}{|l|r|r|r|r|r|r|r|l|}
$\mathrm{H}$ & 500 & 40 & 10 & 5 & 20055 & 2778.048 & 46.3008 & 0.77168 \\
\hline $\mathrm{I}$ & 600 & 40 & 10 & 5 & 24055 & 5206.014 & 86.7669 & 1.446115 \\
\hline $\mathrm{J}$ & 700 & 40 & 20 & 5 & 28065 & 8806.17 & 146.7695 & 2.446158 \\
\hline $\mathrm{K}$ & 1000 & 50 & 20 & 5 & 50075 & 59673.98 & 994.5664 & 16.57611 \\
\hline
\end{tabular}

\subsection{Results and discussion}

The topic of Chapter 6 was to apply a simple and effective meta-heuristic into the Organizational Design problem. In this research, an effective heuristic to solve the set of covering problems was designed based on the meta-heuristic called Meta-RaPS, and extensive experiments were conducted. The following conclusions can be drawn: all of the results in the meta-heuristic were obtained for each test problems using parameter values of $\% p=50, \%$ ret $=4, \%$ ret $1=1.5$, itee $=200$, itei $=20$. The construction heuristic is efficient and solves problems with 343 constraints and 12055 variables in 406 seconds on a Dell M4400 workstation computer by using MatLab R2009b. Table 6-17 compares the average, standard deviation and maximum deviation from optimal value. These results are consistent with those reported by Song et al. [48] in the "Meta-Heuristic for the vehicle problem" based, also, on the Meta-RaPS procedure. Flexible and reconfigurable software has been implemented for this heuristic. Users can change the default values for some parameters such as \%priority, \%restriction (level 0 and 1 to $\mathrm{n}$ ) and also the number of iterations (itee and itei). Users can either speed up the execution of the program for an 
estimated solution, or slow down to obtain a good result, whereas the number of iterations can affect the quality of the solution obtained in this subset of problems.

In order to test the effectiveness of the meta-heuristic, 30 problems of different sizes (A and B) were solved. One of the main advantages of this meta-heuristics (as reported by Moraga et al. [41]) is the limited number of parameters compared with others, in this case five parameters (\%ret, \% ret $1, \% \mathrm{p}$, itee and itei) were used.

Table 6-21 compares the average and standard deviation from optimal values between the greedy algorithm and the meta-heuristic (based on results of 10 problems of Table 6-18). Introducing randomness into the construction heuristic greatly improves the solution quality; instead of choosing the best element as in the greedy heuristic, meta-heuristic selects the best element only during certain percentage of time, while in the remaining time, it chooses a good element from a list of candidates. For this problem, the improvement of solution quality via the randomized construction heuristic is around 80$90 \%$.

Table 6-21 Average, STD dev and max dev. (\%) between greedy and meta-heuristic

\begin{tabular}{|l|l|l|l|}
\hline Method & Average & Standard Dev. & Maximum \\
\hline $\begin{array}{l}\text { Difference from } \\
\text { optimal }\end{array}$ & $\begin{array}{l}\text { Difference from } \\
\text { optimal }\end{array}$ & $\begin{array}{l}\% \text { Difference from } \\
\text { optimal }\end{array}$ \\
\hline Greedy heuristic & 40.1241 & 50.638 & 122.973 \\
\hline Meta-heuristic & 0.536 & 1.505 & 4.80266 \\
\hline
\end{tabular}


Table 6-20 shows an approximation in the computation time required for problems with a thousand operations, fifty workers, twenty supervisors and five managers in approximately 16 hours, however the meta-heuristic can be stopped before this time and also get a feasible solution. With the number of variables generated by the model, the average run times for the meta-heuristic can be estimated. As shown in the following figure, when the problem size reaches 1000 jobs with 50 groups, the computational time required increases dramatically.

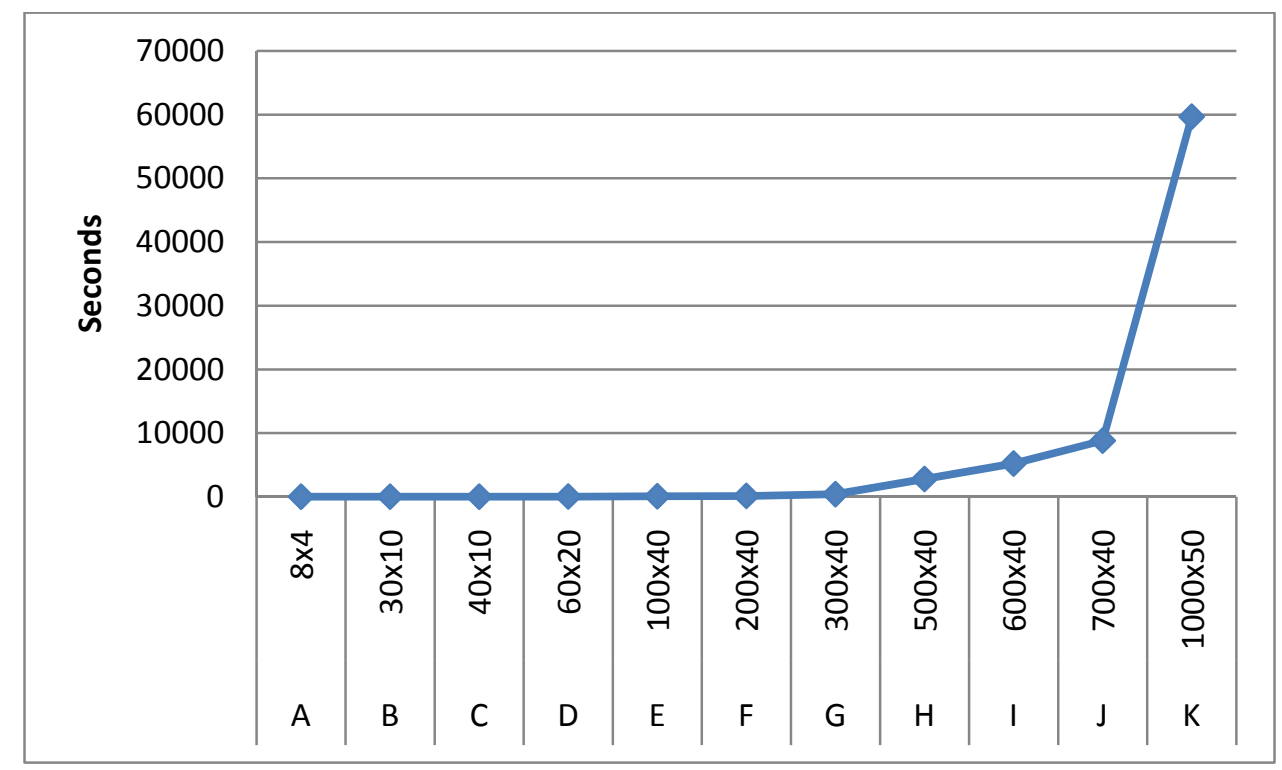

Figure 6-15 Average run times for meta-heuristic

For problems instances of size one (PS1), the meta-heuristic practically produces the same result as LINGO solver and for problem instances of size two (PS2), the percentage of deviation from optimal value is less than $5 \%$ in all cases.

Figure 6-16 shows a comparison of the percentage of deviation from optimal value with average, standard deviation and maximum value of the solution quality of the two heuristic approaches after solving 30 cases. 


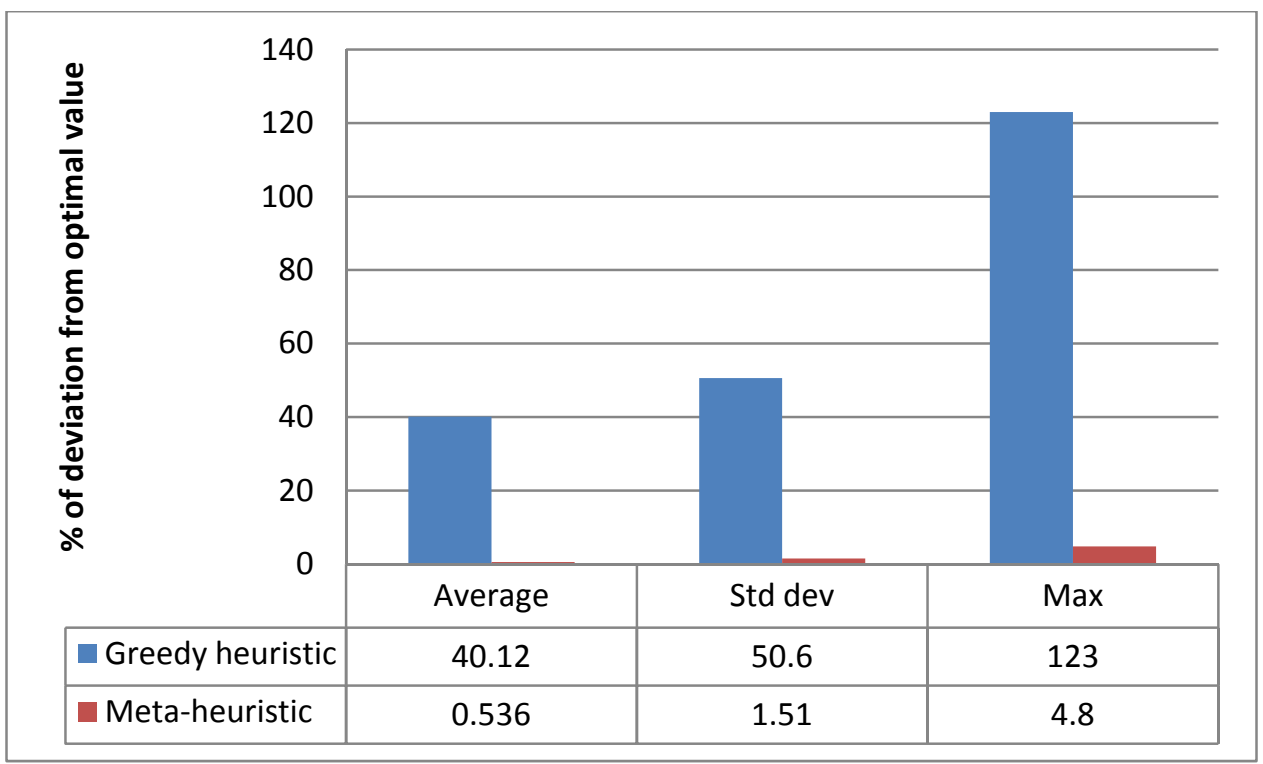

Figure 6-16 Average, std dev and max percentage of solution

As shown in previous results, the proposed meta-heuristic algorithm (based on MetaRaPS) effectively improves the solution quality of the problem under study. The metaheuristic also has the following advantages:

1. The results from this experimentation (Table 6-21) conclude that the metaheuristic is able to introduce randomness and enhance the solution quality of the greedy algorithm.

2. The meta-heuristic generates a feasible route at every iteration; the algorithm can be stopped at any time and a feasible solution is available.

3. The average percentage difference from optimal is consistent with other values found in the literature for meta-heuristic approaches. Therefore, this meta-heuristic is a good method for this combinatorial problem.

4. The proposed solution approach gives a reasonable (good) run time for problems involving up to 700 jobs and 40 groups. 


\section{CONCLUSIONS AND FUTURE WORK}

This chapter discusses the results of this research according to the original questions proposed in the Research Plan (Chapter 3), presents the conclusions, and finally proposes possible future directions for the research.

\subsection{Summary}

There exist abundant reports in literature on the subject of organization theories, organizational structure design, and the span of control problem. This latter alone has attracted voluminous reports in the literature. Most of these efforts are empirical in nature and are all qualitative. Few mathematical models were found in the literature and they were developed taking into account specific parameters for certain types of organizations, such as: relative wage rates between supervisors and subordinates, wage scales and communication time ratios (between and within hierarchies). These studies did not allow their use for general design of an organizational structure. This dissertation aims to study the following issues, and to reduce the research gap in this field:

1. The feasibility of optimal design (or re-design) of the organizational structure based on a quantitative model

2. The impact of organizational decisions on operation costs

3. The customization of the proposed model for different industrial domains of application, with the instruments developed for measuring the parameters in the proposed quantitative model

4. The development of a practical solution approach for large-size industrial problems 
To address these issues, a novel mathematical formulation was developed to model the problem of interest. This model consists of constraints that govern the decision process and allows optimizing the span of control decision, from the allocation of jobs to workers to the management layers of the corporate structure. The proposed model optimizes the entire organizational hierarchy by eliminating unnecessary organizational units, instead of optimizing local spans of control.

The model aims at minimizing the cost of work and supervision by eliminating layers and units of the organization that are not needed based on the allocation of jobs to worker groups and the span of control needed for management. This model assigns jobs to workers, such that the total span of control costs is minimized, helping the decision maker to determine the possible impact on organization costs.

Customization of the organizational structure design model has been made through the analysis of the factors of supervision effort in the context of Information System (IS) companies. Therefore, an implementation of this model was made with a particular group of companies resulting in the selection of a feasible span of control for this type of organizations.

A commercial software system, LINGO, was used to help validate the proposed binary integer model, study its behavior, and explore its computational limits. Extensive experiments were conducted to validate the model with practical problems and evaluate the impact of changing the complexity and compatibility parameters at level 0 and managerial-related parameters for planning, training, execution, and control at the higher 
levels. This experimentation showed the commercial tool (LINGO) was limited to solving small-size problems. The system parameters, including the number of jobs, worker groups, supervisors and managers, all have significant impact on the computational efficiency and the computational time grows exponentially with the number of variables in the system. That is, increasing the number of jobs and groups dramatically increases computational requirements.

A heuristic and meta-heuristic were proposed for solving large-size integer programming problems in a practical computational time. The binary integer model was decomposed into two sub-problems. One assigns jobs to working groups, while the other focuses on the higher levels of managerial hierarchy. The proposed solution approach was based on the concept of greedy algorithms and the Meta-RaPS algorithm. In this research, for each of the decisions, a two phase approach was proposed that first assigns jobs to workers with a heuristic, and then optimizes the results with a meta-heuristic.

For evaluation purposes, two-size problems were tested: problem size one (PS1) with 8 jobs, 4 groups, 3 supervisors and 2 managers, and problem size two (PS2) with 30 jobs, 10 groups, 5 supervisors and 3 managers. An optimal value was required to serve as the benchmark for the heuristic performance evaluation. The solution of the meta-heuristic was compared with the optimal solution solved by LINGO. The measurement was the percentage of deviation from the optimal value found on the solver. The results show that the quality of the solution found using this meta-heuristic was a good choice for this type of problem, and the computational time required was not excessively high when the size of the problem was not more than 300 activities with 40 working groups. Computational 
time for problems with more variables begins to increase dramatically. Test of the heuristic showed that it generates good solutions in an efficient manner for applications of large-size.

\subsection{Future work}

A roadmap for future research is outlined in Figure 7.1. This research could be extended by improving the decision model of its decision factors, job allocations, and supervisory efforts. Coefficient evaluation is needed for application to other industries, such as construction, manufacturing, education, and so on. The proposed solution approach could also be enhanced by improving the meta-heuristic framework.

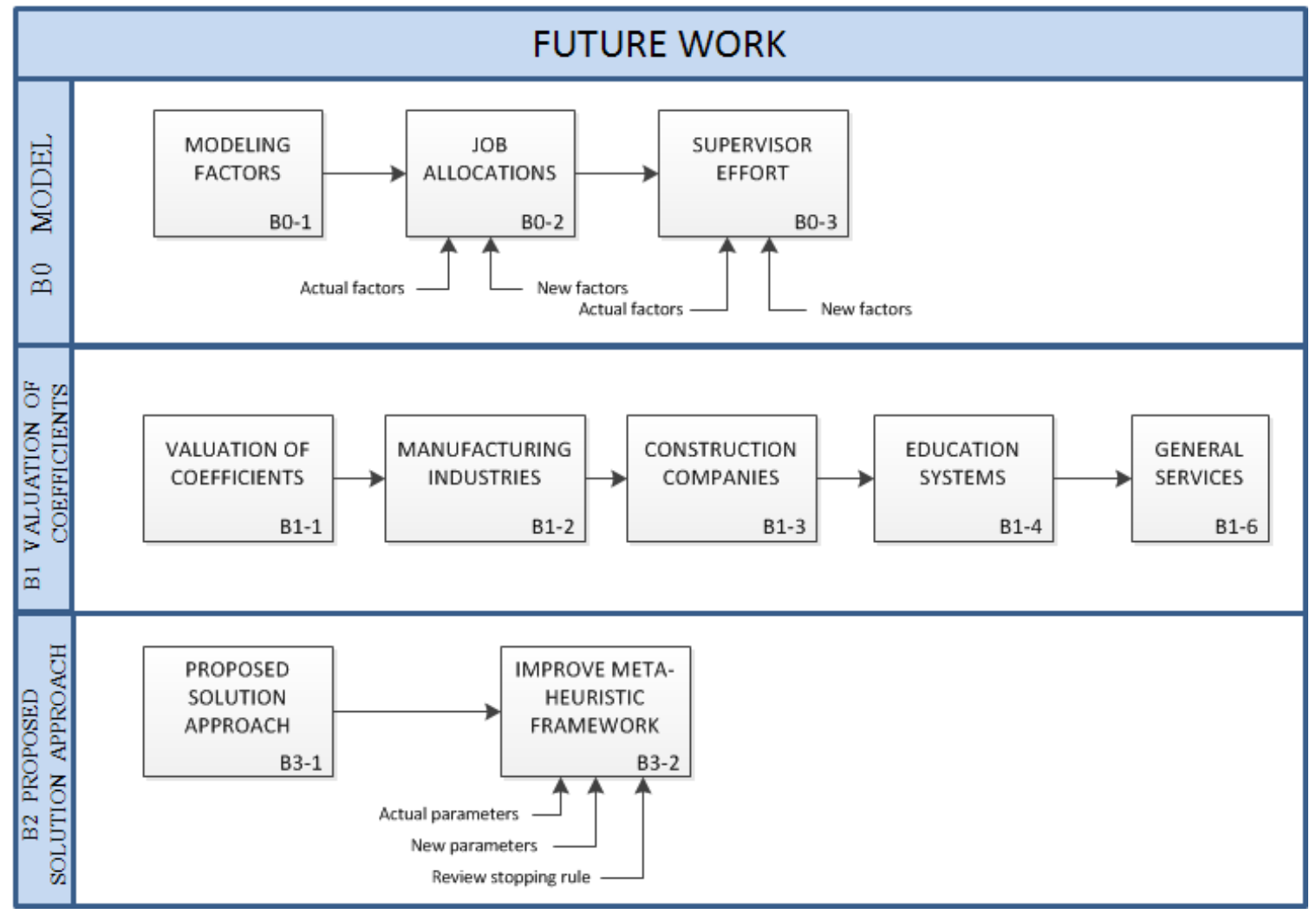

Figure 7-1 Future work

More specifically, this research could be extended to the following three major areas: 
- Exploring additional factors regarding job allocations and supervisory efforts

- Developing evaluation methods to assess supervisor efforts for various industries

- Further improving performance of the proposed solution approach

In the first area, the following questions are relevant: besides complexity and compatibility, are there any other factors regarding the feasibility of job allocations? Are there other factors affecting supervision efforts besides the activities related with planning, control, execution, and training?

In the second area, future research could focus on developing an evaluation method, based on the one proposed in this research, of the factors found for the supervision efforts, to determine their coefficient values in other type of industries, such as manufacturing, construction, education systems or general services. These new developments will allow continuing the customization of the general organizational structure design model proposed in this research.

For the third area, the reason for selecting the method Meta-RaPS above other metaheuristics was due to the results reported in recent research on the solution quality and the ease of implementation for this type of problem. It could be fruitful to continue exploring the structure of the meta-heuristic in order to improve its performance. Relevant questions regarding the meta-heuristic are: is there other stopping rule in order to improve run time? Are there others parameters besides \%ret and \%pry in order to improve the performance of the heuristic? Also it is worth examining other metaheuristics to review the possibility of improving the computation time without affecting the quality of the solution found. 


\section{LIST OF REFERENCES}

[1] Van Fleet, D., and Bedeian, A. "A History of the Span of Management". The Academy of Management Review. Vol. 2, No. 3. (1977): 356-372.

[2] Meier, K., and Bohte, J. "Span of Control and Public Organizations: Implementing Luther Gulick's Research Design". Public Administration Review. Vol. 63, No. 1, Jan/Feb 2003.

[3] Theobald, N. A., and Nicholson-Crotty, S. "The many faces of Span of Control: Organizational Structure Across Multiple Goal". Administration \& Society. 36, 6 (2005): 648-657.

[4] Smith, Adam. The Wealth of Nations. Simon and Brown: Publishers, 2010.

[5] Taylor, F. W. The Principles of scientific management. New York and London: Harper Brothers Publishers, 1911.

[6] Fayol, Henri, et al. General and Industrial Management. Pitman Publishing, 1972.

[7] Blau, P. M., and Scott, W. R. "Formal Organizations: A Corporative Approach". The American Journal of Sociology . Stanford Business Books, 1968.

$\left[8^{]}\right.$Kulik, Brian and Timothy Baker. "Putting the organization back into computational organization theory: a complex Perrowian model of organizational action". Computational and Mathematical Organization Theory. Vol. 14, Iss. 2. Boston, 2008.

[9] Woodward, J. Industrial Organization: Theory and Practice. 2nd Edition. New York: Oxford University Press, 1980.

[10] Choo, C. W. "The knowing organization: how organizations use knowledge to construct meaning". International Journal of Information Management. 16, 5 (1996): 329340 .

[11] Price, Alan. Human Resource Management in a Business Context. Cengage Learning Business Press, 2007.

[12] Burton, R. M. and B. Obel. Strategic Organizational Diagnosis and Design: The Dynamics of Fit. Boston, MA: Kluwer, 2004. 
[13] Lim, M., et al. "Organizational structure for the twenty-first century". The Institute for Operations Research and The Management Sciences. Presented at the annual meeting, Austin, 2010.

[14] Mintzberg, H. Structure in Fives: Designing Effective Organizations. Englewood Cliffs, NJ: Prentice-Hall, 1983.

[15] Pavett, Cynthia M., and Alan W Lau. "Managerial work: The influence of hierarchical level and functional specialty". Academy of Management Journal. 26, 1986.

[16] Davis, J. H. "Group decision and social interaction: Theory of social decision schemes". Psychological Review. 80, (1973): 97-125.

[17] Katz, R., and M. Tushman. "Communication patterns, project performance and task characteristics: An empirical evaluation and integration in an R\&D setting". Organ. Behavior and Human Performance 23 (1979): 139-162.

[18] Entwisle, D., and Walton, J. "Observations on the Span of Control". Administrative Science Quarterly, Vol. 5, No. 4, 1961.

[19] Udell, J.G. "An Empirical Test of Hypotheses Relating to Span of Control". Administrative Science Quarterly, Vol. 12, No. 3. (1967): 420-439.

[20] Bell, G. "Determinants of Span of Control." American Journal of Sociology. Vol. 37, No. 1, July 1967.

[21] Ouchi, W., and Dowling, J. "Defining the Span of Control". Administrative Science Quarterly, Vol. 12, No. 3, 1974.

[22] Meier, K., and Bohte, J. "Ode to Luther Gulick: Span of Control and Organizational Performance," Administration and Society, 32, 2 (2000): 115-137.

[23] Nickols, F. "The Span of Control and the Formulas of V.A. Graicunas". Distance Consulting. 2003. < http://www.nickols.us/graicunas.pdf $>$.

[24] Urwick, L. "The Manager's Span of Control". Harvard Business Review. (1956): 34:39-47.

[25] Mackenzie, K. “Measuring a person's capacity for Interaction in a Problem Solving Group". Organizational Behavior and Human Performance. 12 (1974): 149-169. 
[26] Keren, M., and D Levhari. "The Optimal Span of Control in a Pure Hierarchy". Management Science. Vol. 25, No. 11, (1979): 1162-1172.

[27] Nasrallah, W., and R Levitt. "An Interaction value Perspective on Firms and Differing Size". Computational and mathematical Organizational Theory. 7 (2001): 113144.

[28] Yassine, Ali, et al. "Simple Models of Hierarchical Organizations". IlliGAL Report No. 2005015, University of Illinois at Urbana-Champaign, $2005<$ http://wwwilligal.ge.uiuc.edu>.

[29] Depuy, Gail, et al. "Workforce training schedule for logistic skills". IIE Annual Conference. Proceedings. Norcross: 2006.

[30] LeBlanc, L.J., et al. "Heery International's spreadsheet optimization model for assigning managers to construction projects," Interfaces. 30, 6 (2000): 95-106.

[31] Awad, R.M. and J.W. Chinneck. "Proctor assignment at Carleton University," Interfaces, 28, 2 (1998): 58-71.

[32] Foulds, LR. "The heuristic problem-solving approach". Journal of the Operational Research Society 34 (1983): 927-934.

[33] Il'ev, V. P. "Performance guarantees of greedy algorithms for the problems on hereditary systems". Journal of Applied and Industrial Mathematics. Dordrecht: Vol. 3, Iss. 1; p. 68, 2009.

[34] Mcgovern, S. M., and S. M. Gupta. "Combinatorial optimization analysis of the unary NP-complete disassembly line balancing problem". International Journal of Production Research. Vol. 45, Iss. 18/19; pg. 4485, London, 2007.

[35] Agnihotri, Ameya R. Combinatorial optimization techniques for VLSI placement. State University of New York at Binghamton: 2007.

[36] Angelopoulos, Spyridon. The approximation power of priority algorithms. University of Toronto (Canada): 2006.

[37] Haouari, M. and J. S. Chaouachi. "A probabilistic greedy search algorithm for combinatorial optimisation with application to the set covering problem". The Journal of the Operational Research Society. Vol. 53, Iss. 7. Oxford, 2002. 
[38] Ahuja, Ravindra, et al. "A greedy genetic algorithm for the quadratic assignment problem". Computers and Operations Research. Vol. 27, Iss. 10. New York, 2000.

[39] Thompson, G.M. "Assigning telephone operators to shifts at New Brunswick Telephone Company”. Interfaces. 27, 4 (1997): 1-11.

[40] Glover F, and M. Laguna. Tabu Search. Kluwer Academic Publishers, 1997.

[41] DePuy et al. "Using The Meta-Raps Approach to Solve Combinatorial Problems". Proceedings of the 2002 Industrial Engineering Research Conference, May 19-21, Orlando, Florida, 2002.

[42] DePuy, Gail and G E Whitehouse. "Applying the COMSOAL computer heuristic to the constrained resource allocation problem". Computers \& Industrial Engineering. New York., Vol. 38, Iss. 3, 2000.

[43] DePuy, Gail, et al. "Using The Meta-Raps Approach To Solve Combinatorial Problems". IIE Annual Conference. Proceedings. Norcross: 2002.

[44] Hepdogan, S et al. "A Metaheuristic for the Early/Tardy Single Machine Scheduling Problem”. IIE Annual Conference. Proceedings. Norcross: 2006.

[45] Mora, Rubén D., et al. "Applying Multiple Heuristics to the QAP”. IIE Annual Conference. Proceedings. Norcross: 2006.

[46] Hepdogan, Seyhun, et al. "Solving the 0-1 Multidimensional Knapsack Problem". IIE Annual Conference. Proceedings. Norcross: 2006.

[47] Keith Sinkhorn E., and Xiao Wang. "The Savings Priority Rule in the Meta-RaPS Traveling Salesman Problem Solution". IIE Annual Conference. Proceedings. Norcross: 2006.

[48] Song, J. et al. "A Meta-heuristic for the multi-Vehicle Dial-A-Ride Problem with Time Windows”. IIE Annual Conference. Proceedings. Norcross: 2004.

[49] Moraga, Reinaldo, et al. "A Meta-Heuristic and Oscillation Improvement Strategy for the 0-1 Multidimensional Knapsack Problem". IIE Annual Conference. Proceedings. Norcross: 2004.

[50] Ïyigün, M. "A Decision Support System for R\&D Project Selection and Resource Allocation Under Uncertainty”. Project Management Journal 24, 4, 1993. 
[51] Raisch, S. "Balanced structures: Designing organizations for profitable growth". Long Range Planning 41, 5 (2008):483-508.

[52] Anand, N. and Daft Richard L. "What is the Right Organization Design?". Social

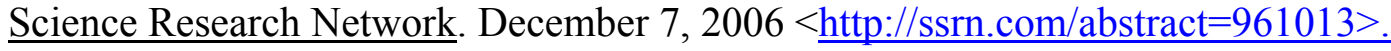

[53] Al-Hindawe, J. "Considerations when constructing a semantic differential scale". La Trobe Papers in Linguistics. La Trobe University, 1996.

[54] Moraga, Reinaldo, et al. "Meta-RaPS approach for the 0-1 Multidimensional Knapsack Problem”. Computers \& Industrial Engineering. New York: Vol. 48, Iss. 1, 2005.

[55] Hales. C.P. "What do managers do? A critical review of the evidence". Journal of Management Studies. (1986): 23: 88-115.

[56] Pugh, D. S., ed. Organization Theory: Selected Readings. Harmondsworth: Penguin, 1990.

[57] Armandi, B.R., and Wills, E.W. "Organizational Size, Structure, and Efficiency: A Test of a Blau-Hage Model". American Journal of Economics and Sociology. Vol. 41, No. 1 (1982): 43-60.

[58] Khaled, El Emam, and Nazim H. Madhavji. "The reliability of measuring organizational maturity". Software Process Improvement and Practice, John Wiley \& Sons, 1995.

[59] Crowley, Martha et al. "Neo-Taylorism at Work: Occupational Change in the PostFordist Era”. Social Problems. Vol. 57, Iss. 3, Berkeley (2010): 421, 27.

[60] Klein, E. "Using information technology to eliminate layers of bureaucracy," The National Public Accountant. Vol. 46, Iss. 4 (2001): 46-56.

[61] Qian, Y. "Incentives and Loss of Control in an Optimal Hierarchy". Review of Economic Studies. 61, 3 (1994): 527-544.

[62] Beckmann, M. Tinbergen Notes on Organization Theory. Berkin: Springer-Verlag, 1988.

[63] Jonker, R. and Volgenant, A. "A Shortest Augmenting Path Algorithm for Dense and Sparse Linear Assignment Problems". Computing, 38, 4 (1987): 325-340. 
[64] Jackson, E, et al. "Logistics Skills Management Heuristics". Proceedings of the 2008 Industrial Engineering Research Conference, J Fowler and S. Mason, eds., 2008.

[65] Tang, Jiafu et al. "Heuristics-Based Integrated Decisions for Logistics Network Systems", Journal of Manufacturing Systems. 23, 1, 2004.

[66] Phelps, Selcen and Murat Koksalan. "An Interactive Evolutionary Metaheuristic for Multiobjective Combinatorial Optimization"; Management Science; 49, 12, 2003.

[67] Gamvros, Ioannis, et al. "The Multilevel Capacitated Minimum Spanning Tree Problem". INFORMS Journal on Computing; Vol 18, No 3 (2006): 348-365.

[68] Silver, EA. "An overview of heuristic solution methods". Journal of the Operational Research Society 55 (2004): 936-956.

[69] French, Alan, and John Wilson. "Heuristic Solution Methods for the Multilevel Generalized Assignment Problem". Journal of Heuristics. 8, 2, 2002.

[70] Glover, F., et al. "Improved Computer-Based Planning Techniques - Part II". Interfaces 9, 4 (1979): 12-20.

[71] Boehm, B. W. Software Engineering Economics. Prentice-Hall, 1981.

[72] Nemetz, P.L. and Fry, L.W. "Flexible Manufacturing Organizations: Implications for Strategy Formulation and Organization Design". The Academy of Management Review. Vol. 13, No. 4. (1988): 627-638.

[73] Hareton, K.N., et al. "Automated support of software quality improvement". The International Journal of Quality \& Reliability Management. Vol. 24, Iss. 3; p. 230. Bradford: 2007.

[74] Humphrey, Watts S. "Using a defined and measured personal software process". IEEE Software. Vol. 13, Iss. 3; p. 77. Los Alamitos: 1996.

[75] Kennington, J. and Z. Wang. "A Shortest Augmenting Path Algorithm for the SemiAssignment Problem”. Operations Research, Vol. 40, No. 1 (1992): 178-187.

[76] Donaldson, L. The Contingency Theory of Organizations, Thousand Oaks, CA: SAGE Publications, 2001.

[77] Claessens, B., et al. "Planning behavior and perceived control of time at work". Journal of Organization Behavior, 93, 2004. 
[78] Cullen, J.B. and Baker, D.D. "Administration size and organization size: an examination of the lag structure". The Academy of Management Journal, Vol. 27 (1984): 644-653.

[79] Garicano, L. "Hierarchies and the organization of knowledge in production". Journal of Political Economy. (2000): 874-904.

[80] Salas, E., et al. "Does Crew Resource Management Training Work? An Update, an Extension, and Some Critical Needs". Journal of Human Factors. (2006): 392-403.

[81] Akella, Devi. "A reflection on critical management studies". Journal of Management and Organization (2008): 100-110.

[82] Carroll, S. J., and D. J. Gillen. "Are classical management functions useful in describing managerial work". Academy of Management Review. (1987): 38-51.

[83] Fournier, V and C. Grey. "At the critical moment: Conditions and prospects for critical management studies". SAGE Journal Human Relations 53, 1 (2000):7-32.

[84] Jinghong Liang, Pierre, et al. "Optimal Team Size and Monitoring in Organizations". The accounting review. Vol. 83, No. 3, (2008): 789-822.

[85] Davison, B. "Management span of control: how wide is too wide?". Journal of Business Strategy. (1993): 24, 22-29.

[86] Hoffer Gittell, Jody. "Supervisory Span, Relational Coordination and Flight Departure Performance: A Reassessment of Post-bureaucracy Theory”. Organization Science. Vol. 12, No. 4, (2001): 468-483.

[87] DePuy, Gail, et al. "Skills Management Assignment Problem Heuristics". IIE Annual Conference. Proceedings. Norcross: 2009. 


\section{APPENDICES}

APPENDIX A: Parameters (data), formulations in LINGO, and results of computational experiments of Chapter 4 .

APPENDIX B: Formats used in the application and validations process of the valuation

of factors of Chapter 5.

APPENDIX C: Complete algorithm scripts in MatLab for the meta-heuristic and heuristic of the proposed solution approach developed for Chapter 6. 


\section{APPENDIX A}

Table A.1 Parameters for data for supervisors (levels $0 \rightarrow 1$ ) of case one

\begin{tabular}{|c|c|c|c|c|}
\hline \multirow{2}{*}{$\begin{array}{l}\text { DATA OF SUPERVISORS } \\
\text { LEVEL } 0 \rightarrow 1\end{array}$} & & \multicolumn{3}{|c|}{ SUPERVISORS } \\
\hline & & S1 & S2 & S3 \\
\hline \multicolumn{2}{|l|}{ CAPACITY (Hrs) } & 3 & 2 & 1 \\
\hline \multicolumn{2}{|l|}{$\operatorname{cosT}(w)$} & $\$ 200$ & $\$ 150$ & $\$ 100$ \\
\hline FACTORS OF & \multicolumn{4}{|c|}{ WORKERS (GROUPS) } \\
\hline SUPERVISION EFFORT & G1 & G2 & G3 & G4 \\
\hline PLANNING $(\rho)$ & 0.02 & 0.03 & 0.1 & 0.11 \\
\hline CONTROL (c) & 0.015 & 0.1 & 0.2 & 0.12 \\
\hline TRAINING $(\mathrm{t})$ & 0.01 & 0.14 & 0.01 & 0.01 \\
\hline EXECUTION (e) & 0.02 & 0.11 & 0.02 & 0.05 \\
\hline
\end{tabular}

Table A.2 Parameters for data for levels $1 \rightarrow 2$ of case one

\begin{tabular}{|c|c|c|c|}
\hline \multirow{2}{*}{$\begin{array}{l}\text { DATA OF MANAGERS } \\
\text { LEVEL } 1 \rightarrow 2\end{array}$} & & \multicolumn{2}{|c|}{ MANAGERS } \\
\hline & & M1 & M2 \\
\hline CAPACITY (Hrs) & & 5 & 1 \\
\hline $\operatorname{COST}(\mathrm{w})$ & & $\$ 450$ & $\$ 500$ \\
\hline FACTORS OF & \multicolumn{3}{|c|}{ SUPERVISORS } \\
\hline MANAGERS EFFORT & S1 & $\mathrm{S} 2$ & S3 \\
\hline PLANNING $(\rho)$ & 0.25 & 0.16 & 0.24 \\
\hline
\end{tabular}




\begin{tabular}{|l|c|c|c|}
\hline CONTROL (c) & 0.2 & 0.17 & 0.25 \\
\hline TRAINING (t) & 0.15 & 0.15 & 0.2 \\
\hline EXECUTION (e) & 0.25 & 0.25 & 0.2 \\
\hline
\end{tabular}

Example of formulation in LINGO Software (Case 1)

$\operatorname{Min}: \sum_{n=1}^{N} \sum_{j=1}^{J} w_{n j} f_{n j} y_{n j p_{n}}$

MIN $2200 \mathrm{Y} 11+1704 \mathrm{Y} 12+3000 \mathrm{Y} 13+2504 \mathrm{Y} 14+3750 \mathrm{Y} 15+2250 \mathrm{Y} 16+5400$

$\mathrm{Y} 17+11500 \mathrm{Y} 21+12000 \mathrm{Y} 22+16000 \mathrm{Y} 23+\mathrm{Y} 01+\mathrm{Y} 02+\mathrm{Y} 03+\mathrm{Y} 04$

Constraints

SUBJECT TO

1) Each job (operation type) is assigned to only one direct labor group

$\sum_{j} z_{i j}=1$

$\mathrm{Z} 11+\mathrm{Z} 12+\mathrm{Z} 13+\mathrm{Z} 14=1$

$\mathrm{Z} 21+\mathrm{Z} 22+\mathrm{Z} 23+\mathrm{Z} 24=1$

$\mathrm{Z} 31+\mathrm{Z} 32+\mathrm{Z} 33+\mathrm{Z} 34=1$

$\mathrm{Z} 41+\mathrm{Z} 42+\mathrm{Z} 43+\mathrm{Z} 44=1$

2) Each direct labor group has a finite capacity, all job assignments are limited by the capacity of each labor group. 


$$
\sum_{i} \beta_{i} \alpha_{i j} \eta_{i j} z_{i j} \leq r_{0 j} y_{0 j p_{0}}
$$

$0.4 \mathrm{Z} 11+1.28 \mathrm{Z} 21+1.6 \mathrm{Z} 31+1.6 \mathrm{Z} 41-1.3 \mathrm{Y} 01<=0$

$0.5 \mathrm{Z} 12+0.4 \mathrm{Z} 22+\mathrm{Z} 32+\mathrm{Z} 42-4.8 \mathrm{Y} 02<=0$

$0.7 \mathrm{Z} 13+1.12 \mathrm{Z} 23+0.7 \mathrm{Z} 33+1.4 \mathrm{Z} 43-4.3 \mathrm{Y} 03<=0$

$0.7 \mathrm{Z} 14+1.12 \mathrm{Z} 24+1.4 \mathrm{Z} 34+0.7 \mathrm{Z} 44-3.8 \mathrm{Y} 04<=0$

3 and 4) The total managerial work requirement of its child units cannot exceed the finite capacity imposed on the parent unit.

$$
\sum_{j} r_{0 j} y_{0 j p_{0}} \alpha_{0 j}\left(\rho_{1 j}+c_{1 j}+t_{1 j}+e_{1 j}\right) / \omega_{0 j} \leq \sum_{j} f_{1 j} y_{1 j p_{1}}
$$

$1.04 \mathrm{Y} 01+1.5 \mathrm{Y} 02+1.505 \mathrm{Y} 03+1.995 \mathrm{Y} 04-11 \mathrm{Y} 11-8 \mathrm{Y} 12-12 \mathrm{Y} 13-8 \mathrm{Y} 14-10$ Y15 - 6 Y $16-12$ Y $17<=0$

$$
\sum_{j} f_{n-1, j} y_{n-1, j p_{n-1}}\left(\rho_{n j}+c_{n j}+t_{n j}+e_{n j}\right) / \omega_{n j} \leq \sum_{j} f_{n j} y_{n j p_{n}}
$$

$11 \mathrm{Y} 11+8 \mathrm{Y} 12+12 \mathrm{Y} 13+8 \mathrm{Y} 14+10 \mathrm{Y} 15+6 \mathrm{Y} 16+12 \mathrm{Y} 17-20 \mathrm{Y} 21-20 \mathrm{Y} 22-25$ $\mathrm{Y} 23<=0$

5 and 6) Each child unit must have a parent unit.

$$
y_{0 j p_{0}} \leq \sum_{p_{1}} y_{1 p_{0} p_{1}}
$$

$$
\begin{aligned}
& \mathrm{Y} 01-\mathrm{Y} 11-\mathrm{Y} 12-\mathrm{Y} 13-\mathrm{Y} 14-\mathrm{Y} 15-\mathrm{Y} 16-\mathrm{Y} 17<=0 \\
& \mathrm{Y} 02-\mathrm{Y} 11-\mathrm{Y} 12-\mathrm{Y} 13-\mathrm{Y} 14-\mathrm{Y} 15-\mathrm{Y} 16-\mathrm{Y} 17<=0 \\
& \mathrm{Y} 03-\mathrm{Y} 11-\mathrm{Y} 12-\mathrm{Y} 13-\mathrm{Y} 14-\mathrm{Y} 15-\mathrm{Y} 16-\mathrm{Y} 17<=0 \\
& \mathrm{Y} 04-\mathrm{Y} 11-\mathrm{Y} 12-\mathrm{Y} 13-\mathrm{Y} 14-\mathrm{Y} 15-\mathrm{Y} 16-\mathrm{Y} 17<=0 \\
& \quad y_{n-1, j p_{n-1}} \leq \sum_{p_{n}} y_{n p_{n-1} p_{n}}
\end{aligned}
$$

$\mathrm{Y} 11-\mathrm{Y} 21-\mathrm{Y} 22-\mathrm{Y} 23<=0$ 
$\mathrm{Y} 12-\mathrm{Y} 21-\mathrm{Y} 22-\mathrm{Y} 23<=0$
$\mathrm{Y} 13-\mathrm{Y} 21-\mathrm{Y} 22-\mathrm{Y} 23<=0$
$\mathrm{Y} 14-\mathrm{Y} 21-\mathrm{Y} 22-\mathrm{Y} 23<=0$
$\mathrm{Y} 15-\mathrm{Y} 21-\mathrm{Y} 22-\mathrm{Y} 23<=0$
$\mathrm{Y} 16-\mathrm{Y} 21-\mathrm{Y} 22-\mathrm{Y} 23<=0$
$\mathrm{Y} 17-\mathrm{Y} 21-\mathrm{Y} 22-\mathrm{Y} 23<=0$

Results from LINGO Software.

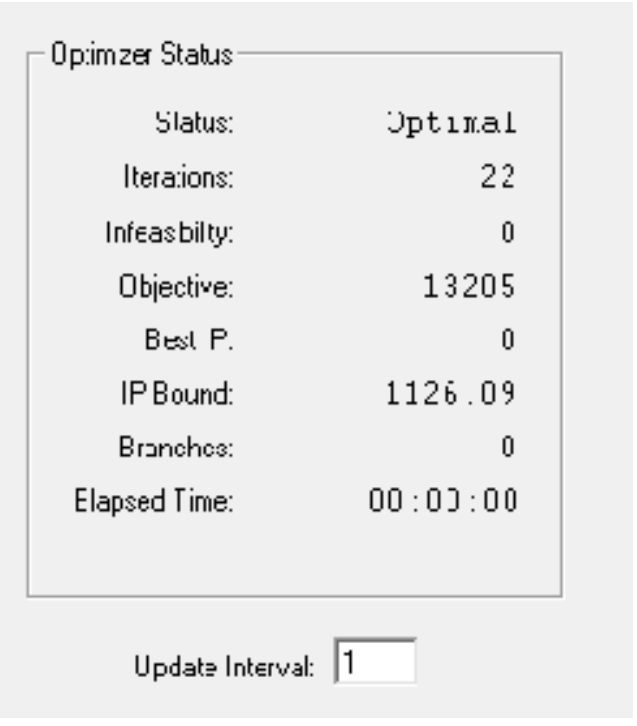

\begin{tabular}{|l|l|l|}
\hline \multicolumn{3}{|c|}{ Results } \\
\hline INT Z11 & INT Z32 & INT Y13 \\
\hline INT Z12 & INT Z33 & INT Y14 \\
\hline INT Z13 & INT Z34 & INT Y21 \\
\hline INT Z14 & INT Z41 & INT Y22 \\
\hline INT Z21 & INT Z42 & INT Y23 \\
\hline INT Z22 & INT Z43 & INT Y01 \\
\hline INT Z23 & INT Z44 & INT Y02 \\
\hline INT Z24 & INT Y11 & INT Y03 \\
\hline INT Z31 & INT Y12 & INT Y04 \\
\hline
\end{tabular}

Example of formulation in LINGO Software (Case 2)

Objective function

Min $\quad \sum_{n=1}^{N} \sum_{j=1}^{J} w_{n j} f_{n j} y_{n j p_{n}}$

Min

$72000 \mathrm{Y} 11+67200 \mathrm{Y} 12+72000 \mathrm{Y} 13+172800 \mathrm{Y} 21+156000 \mathrm{Y} 22+216000 \mathrm{Y} 23+$ $\mathrm{Y} 01+\mathrm{Y} 02+\mathrm{Y} 03+\mathrm{Y} 04$ 
Constraints

1. $\quad \sum_{j} z_{i j}=1 \quad \underline{i \in I}$

$$
\begin{aligned}
& Z 11+Z 12+Z 13+Z 14=1 \\
& Z 21+Z 22+Z 23+Z 24=1 \\
& Z 31+Z 32+Z 33+Z 34=1 \\
& Z 41+Z 42+Z 43+Z 44=1 \\
& Z 51+Z 52+Z 53+Z 54=1 \\
& Z 61+Z 62+Z 63+Z 64=1 \\
& Z 71+Z 72+Z 73+Z 74=1 \\
& Z 81+Z 82+Z 83+Z 84=1
\end{aligned}
$$

2. $\quad \sum_{i} \beta_{i} \alpha_{i j} z_{i j} / \eta_{i j} \leq r_{0 j} y_{0 j p_{0}} \quad j \in J$

$$
\begin{aligned}
& \frac{\beta_{1} \alpha_{11}}{\eta_{11} z_{11}}+\frac{\beta_{2} \alpha_{21}}{\eta_{21} z_{21}}+\frac{\beta_{3} \alpha_{31}}{\eta_{31} z_{31}}+\frac{\beta_{4} \alpha_{41}}{\eta_{41} Z_{41}} \leq r_{01} y_{01} \\
& \frac{\beta_{1} \alpha_{12}}{\eta_{12} z_{12}}+\frac{\beta_{2} \alpha_{22}}{\eta_{22} z_{22}}+\frac{\beta_{3} \alpha_{32}}{\eta_{32} z_{32}}+\frac{\beta_{4} \alpha_{42}}{\eta_{42} Z_{42}} \leq r_{02} y_{02} \\
& \frac{\beta_{1} \alpha_{13}}{\eta_{13} z_{13}}+\frac{\beta_{2} \alpha_{23}}{\eta_{23} z_{23}}+\frac{\beta_{3} \alpha_{33}}{\eta_{33} z_{33}}+\frac{\beta_{4} \alpha_{43}}{\eta_{43} Z_{43}} \leq r_{03} y_{03} \\
& \frac{\beta_{1} \alpha_{14}}{\eta_{14} z_{14}}+\frac{\beta_{2} \alpha_{24}}{\eta_{24} z_{24}}+\frac{\beta_{3} \alpha_{34}}{\eta_{34} z_{34}}+\frac{\beta_{4} \alpha_{44}}{\eta_{44} Z_{44}} \leq r_{04} y_{04}
\end{aligned}
$$

$0.2 \mathrm{Z} 11+0.3 \mathrm{Z} 21+0.5 \mathrm{Z} 31+0.2 \mathrm{Z} 41+0.8 \mathrm{Z} 51+0.75 \mathrm{Z} 61+0.1 \mathrm{Z} 71+0.15 \mathrm{Z} 81-1$ $\mathrm{Y} 01<=0$

$0.16 \mathrm{Z} 12+0.24 \mathrm{Z} 22+40 \mathrm{Z} 32+0.8 \mathrm{Z} 42+0.64 \mathrm{Z} 52+60 \mathrm{Z} 62+0.8 \mathrm{Z} 72+0.12 \mathrm{Z} 82-1$ $\mathrm{Y} 02<=0$

$18 \mathrm{Z} 13+0.27 \mathrm{Z} 23+45 \mathrm{Z} 33+0.9 \mathrm{Z} 43+0.72 \mathrm{Z} 53+0.68 \mathrm{Z} 63+9 \mathrm{Z73}+0.14 \mathrm{Z} 83-1$ $\mathrm{Y} 03<=0$

$0.2 \mathrm{Z} 14+30 \mathrm{Z} 24+0.5 \mathrm{Z} 34+1 \mathrm{Z} 44+0.8 \mathrm{Z} 54+0.75 \mathrm{Z} 64+0.1 \mathrm{Z} 74+0.1 \mathrm{Z} 84-1 \mathrm{Y} 04$ $<=0$

3.

$$
\sum_{j} r_{0 j} \alpha_{i j}\left(\rho_{1 j}+c_{1 j}+t_{1 j}+e_{1 j}\right) y_{0 j p_{0}} / \omega_{0 j} \leq \sum_{j} f_{1 j} y_{1 j p_{1}}
$$




$$
\begin{aligned}
& \frac{r_{01} y_{01} \alpha_{01}\left(\rho_{11}+c_{11}+t_{11}+e_{11}\right)}{\omega_{01}}+\frac{r_{02} y_{02} \alpha_{02}\left(\rho_{12}+c_{12}+t_{12}+e_{12}\right)}{\omega_{02}} \\
& +\frac{r_{03} y_{03} \alpha_{03}\left(\rho_{13}+c_{13}+t_{13}+e_{13}\right)}{\omega_{03}} \\
& +\frac{r_{04} y_{04} \alpha_{04}\left(\rho_{14}+c_{14}+t_{14}+e_{14}\right)}{\omega_{04}} \leq f_{11} y_{11}+f_{12} y_{12}+f_{13} y_{13}
\end{aligned}
$$$$
0.55 \mathrm{Y} 01+8 \mathrm{Y} 02+27 \mathrm{Y} 03+26 \mathrm{Y} 04-360 \mathrm{Y} 11-240 \mathrm{Y} 12-240 \mathrm{Y} 13<=0
$$

$$
\text { 4. } y_{0 j p_{0}} \leq \sum y_{1 p_{0} p_{1}}
$$

$\mathrm{Y} 01-\mathrm{Y} 11-\mathrm{Y} 12-\mathrm{Y} 13<=0$

$\mathrm{Y} 02-\mathrm{Y} 11-\mathrm{Y} 12-\mathrm{Y} 13<=0$

$\mathrm{Y} 03-\mathrm{Y} 11-\mathrm{Y} 12-\mathrm{Y} 13<=0$

Y04 - Y11 - Y12 - Y13<=0

5. $\quad \sum_{j} f_{n-1, j}\left(\rho_{n j}+c_{n j}+t_{n j}+e_{n j}\right) y_{n-1, j p_{n-1}} / \omega_{i j} \leq \sum_{j} f_{n j} y_{n j p_{n}}$

$$
\begin{aligned}
& \frac{f_{11} y_{11}\left(\rho_{21}+c_{21}+t_{21}+e_{21}\right)}{\omega_{21}}+\frac{f_{12} y_{12}\left(\rho_{22}+c_{22}+t_{22}+e_{22}\right)}{\omega_{22}} \\
& \quad+\frac{f_{13} y_{13}\left(\rho_{23}+c_{23}+t_{23}+e_{23}\right)}{\omega_{23}}+\frac{f_{14} y_{14}\left(\rho_{24}+c_{24}+t_{24}+e_{24}\right)}{\omega_{24}} \\
& \quad \leq f_{21} y_{21}+f_{22} y_{22}+f_{23} y_{23}
\end{aligned}
$$

$18 \mathrm{Y} 11+240 \mathrm{Y} 12+540 \mathrm{Y} 13-360 \mathrm{Y} 21-240 \mathrm{Y} 22-240 \mathrm{Y} 23<=0$

6. $\quad y_{n-1, j p_{n-1}} \leq \sum_{p_{n}} y_{n p_{n-1} p_{n}}$

$\mathrm{Y} 11-\mathrm{Y} 21-\mathrm{Y} 22-\mathrm{Y} 23<=0$

$\mathrm{Y} 12-\mathrm{Y} 21-\mathrm{Y} 22-\mathrm{Y} 23<=0$

$\mathrm{Y} 13$ - Y21 - Y22 - Y23<=0 


\section{Data and solution formulated in LINGO for Case two}

Table A.3 Capacity of groups, processing time of jobs, complexity and compability data

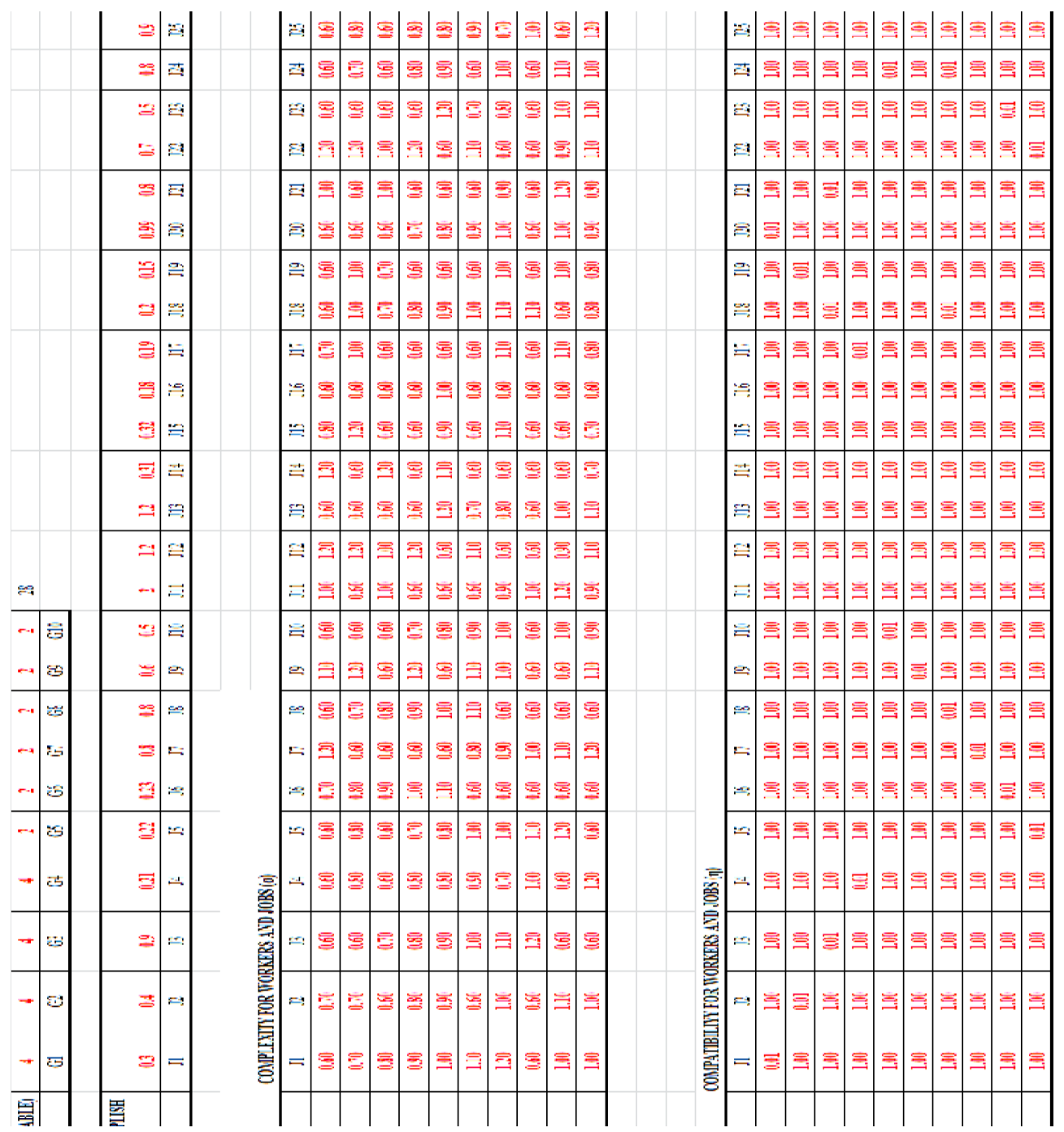

Table A.4 Level 1 (DATA) 


\begin{tabular}{|c|c|c|c|c|c|c|c|c|c|c|}
\hline $\begin{array}{c}\text { CAPACITY (r=HOURS } \\
\text { AVAILABLE) }\end{array}$ & 2.5 & 2.5 & 2.5 & 2.5 & 2.5 & 2.5 & 2.5 & 2.5 & 2.5 & 2.5 \\
\hline GROUPS (j) & $\mathrm{G} 1$ & $\mathrm{G} 2$ & $\mathrm{G} 3$ & $\mathrm{G} 4$ & $\mathrm{G} 5$ & G6 & G7 & G8 & G9 & G10 \\
\hline CAPACITY (f) & & & $\operatorname{cosT}(\mathrm{w})$ & & & & & & & \\
\hline SUPERVISOR & HRS & & SUPERVISOR & $\$$ & & & & & & \\
\hline $\mathrm{S} 1$ & 8 & & $\mathrm{~S} 1$ & 50 & & & & & & \\
\hline $\mathrm{S} 2$ & 8 & & S2 & 100 & & & & & & \\
\hline S3 & 8 & & S3 & 150 & & & & & & \\
\hline S4 & 8 & & S4 & 200 & & & & & & \\
\hline S5 & 8 & & S5 & 250 & & & & & & \\
\hline & & & & & & & & & & \\
\hline & & & & & & & & & & \\
\hline & & & & & & & & & & \\
\hline \multicolumn{11}{|l|}{ COEFFICIENTS } \\
\hline & PLANNING $(\rho)$ & CONTROL (c) & TRAINING (t) & EXECUTION (e) & & & & & & \\
\hline $\mathrm{S}^{*}=\Rightarrow \mathrm{G} 1$ & \begin{tabular}{l|}
0.2 \\
\end{tabular} & 0.25 & \begin{tabular}{l|l}
0.18 \\
\end{tabular} & 0.25 & 0.88 & & & & & \\
\hline $\mathrm{S}^{*}=\Rightarrow \mathrm{G} 2$ & 0.25 & 0.19 & 0.2 & 0.22 & 0.86 & & & & & \\
\hline $\mathrm{S}^{*}=\Rightarrow \mathrm{G} 3$ & 0.19 & 0.22 & 0.23 & 0.18 & 0.82 & & & & & \\
\hline $\mathrm{S}^{*}=\Rightarrow \mathrm{G} 4$ & 0.23 & 0.23 & 0.19 & 0.2 & 0.85 & & & & & \\
\hline $\mathrm{S}^{*}=\Rightarrow \mathrm{G} 5$ & 0.2 & 0.25 & 0.18 & 0.25 & 0.88 & & & & & \\
\hline $\mathrm{S}^{*}=\Rightarrow \mathrm{G} 6$ & 0.25 & 0.19 & 0.2 & 0.22 & 0.86 & & & & & \\
\hline $\mathrm{S}^{*}==>\mathrm{G} 7$ & 0.19 & 0.22 & 0.23 & 0.18 & 0.82 & & & & & \\
\hline $\mathrm{S}^{*}=\Rightarrow \mathrm{G} 8$ & 0.23 & 0.23 & 0.19 & 0.2 & 0.85 & & & & & \\
\hline $\mathrm{S}^{*}=\Rightarrow \mathrm{G} 9$ & 0.2 & 0.25 & 0.18 & 0.25 & 0.88 & & & & & \\
\hline $\mathrm{S}^{*}==>\mathrm{G} 10$ & 0.25 & 0.19 & 0.2 & 0.22 & 0.86 & & & & & \\
\hline & & & & & & & & & & \\
\hline & & & & & & & & & & \\
\hline & & & & & & & & & & \\
\hline$\frac{\text { RESTRICCION 2 }}{\text { roj (poj+coj+toj+ eoj) }}$ & 2.2 & 2.15 & 2.05 & 2.125 & 2.2 & $\begin{array}{l}\text { G6 } \\
2.15\end{array}$ & 2.05 & G8 & G9 & G10 \\
\hline & & & & & & & & & & \\
\hline \multicolumn{11}{|l|}{ FUN OBJETIVO } \\
\hline WnjFnj & 400 & & & & & & & & & \\
\hline WnjFnj & 800 & & & & & & & & & \\
\hline WnjFnj & 1200 & & & & & & & & & \\
\hline WnjFnj & 1600 & & & & & & & & & \\
\hline WnjFnj & 2000 & & & & & & & & & \\
\hline
\end{tabular}

Table A.5 Level 2 (DATA) 


\begin{tabular}{|c|c|c|c|c|c|}
\hline \multicolumn{6}{|l|}{ CAPACITY $(f)$} \\
\hline SUPERVISOR & HRS & & & & \\
\hline $\mathrm{S} 1$ & 8 & & & & \\
\hline S2 & 8 & & & & \\
\hline S3 & 8 & & & & \\
\hline S4 & 8 & & & & \\
\hline S5 & 8 & & & & \\
\hline MANAGER & 2 & & & & \\
\hline CAPACITY & & & $\operatorname{cosT}(w)$ & & \\
\hline MANAGER & HRS & & MANAGER & $S$ & \\
\hline M1 & 10 & & M1 & 100 & \\
\hline M2 & 10 & & M2 & 200 & \\
\hline M3 & 10 & & M3 & 300 & \\
\hline \multicolumn{6}{|c|}{ COEFFICIENTS } \\
\hline & PLANNING $(\rho)$ & CONTROL (c) & TRAINING $(\mathrm{t})$ & EXECUTION (e) & \\
\hline $\mathrm{M}^{*}=\Rightarrow \mathrm{S} 1$ & 0.25 & 0.2 & 0.15 & 0.25 & 0.85 \\
\hline $\mathrm{M}^{*}=\Rightarrow \mathrm{S} 2$ & 0.16 & 0.17 & 0.15 & 0.25 & 0.73 \\
\hline $\mathrm{M}^{*}==\mathrm{S} 3$ & 0.24 & 0.25 & 0.2 & 0.2 & 0.89 \\
\hline$M^{*}==>\mathrm{S} 4$ & 0.21 & 0.26 & 0.22 & 0.18 & 0.863333 \\
\hline $\mathrm{M}^{*}=\Rightarrow \mathrm{S} 5$ & 0.20 & 0.28 & 0.24 & 0.16 & 0.883333 \\
\hline
\end{tabular}

\begin{tabular}{|r|r|}
\hline REST 2 (COEFF) & \\
\hline flj(pij+cij+tij+eij) & 6.8 \\
\hline flj(pij+cij+tij+eij) & 5.84 \\
\hline flj(pij+cij+tij+eij) & 7.12 \\
\hline flj(pij+cij+tij+eij) & 6.906666667 \\
\hline flj(pij+cij+tij+eij) & 7.066666667 \\
\hline & \\
\hline & \\
\hline FUN OBJE & \\
\hline WnjFnj & 1000 \\
\hline WnjFnj & 2000 \\
\hline WnjFnj & 3000 \\
\hline
\end{tabular}

Table A.6 Results from LINGO

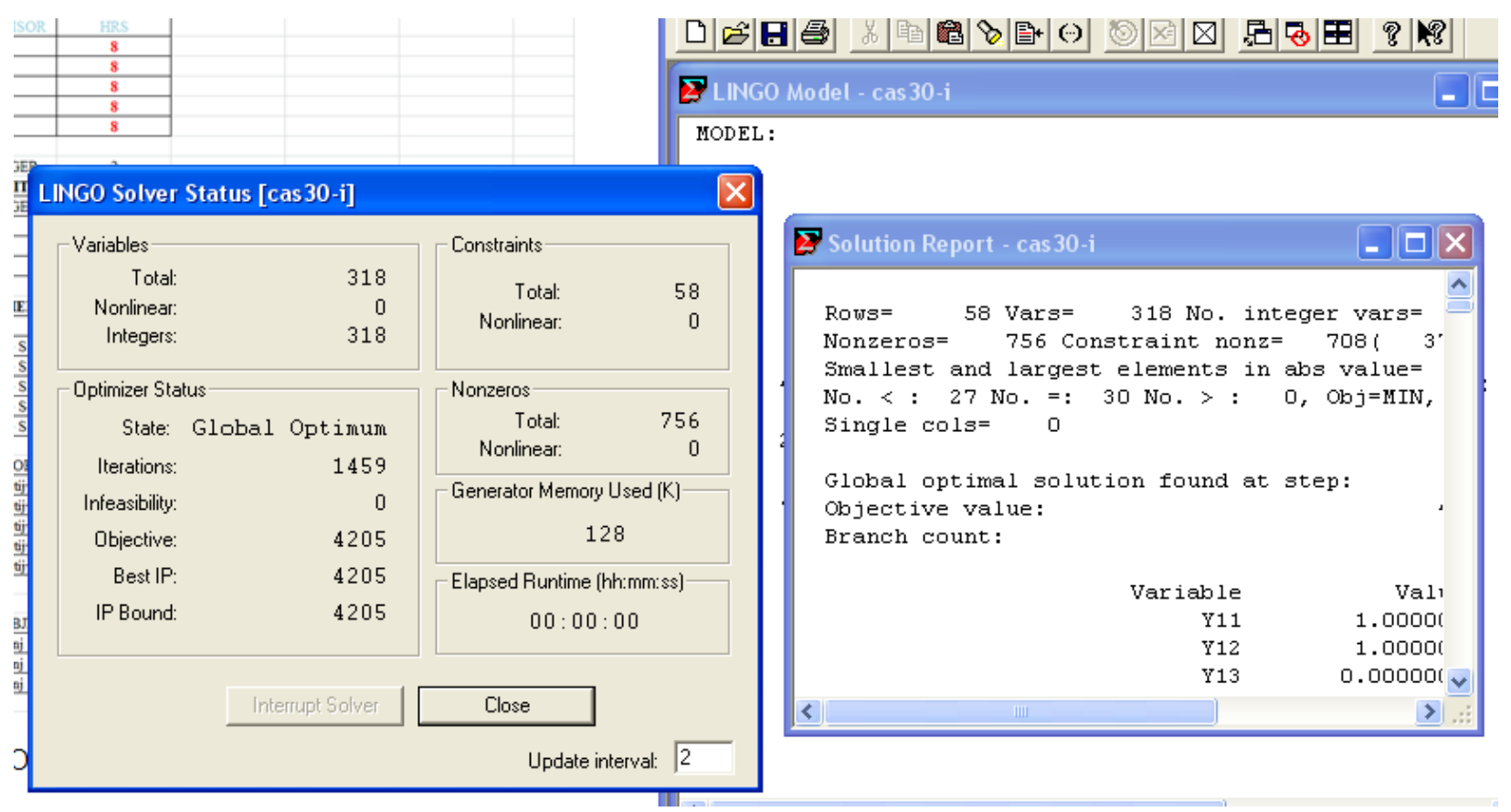




\section{APPENDIX B}

Table B.1 SWOT Matrix format

\begin{tabular}{|l|l|l|}
\hline & Strengths (S) & Weaknesses (W) \\
& 1. & 1. \\
2. & 2. \\
\hline Opportunities (O) & 3. & 3. \\
1. & Strategies(SO) & Strategies(SO) \\
2. & 1. & 1. \\
3. & 2. & 2. \\
\hline Threats & 3 & 3. \\
1. & Strategies(ST) & Strategies(ST) \\
2. & 1. & 1. \\
3. & 2. & 2. \\
\hline
\end{tabular}

Table B.2 Project Action Plan format

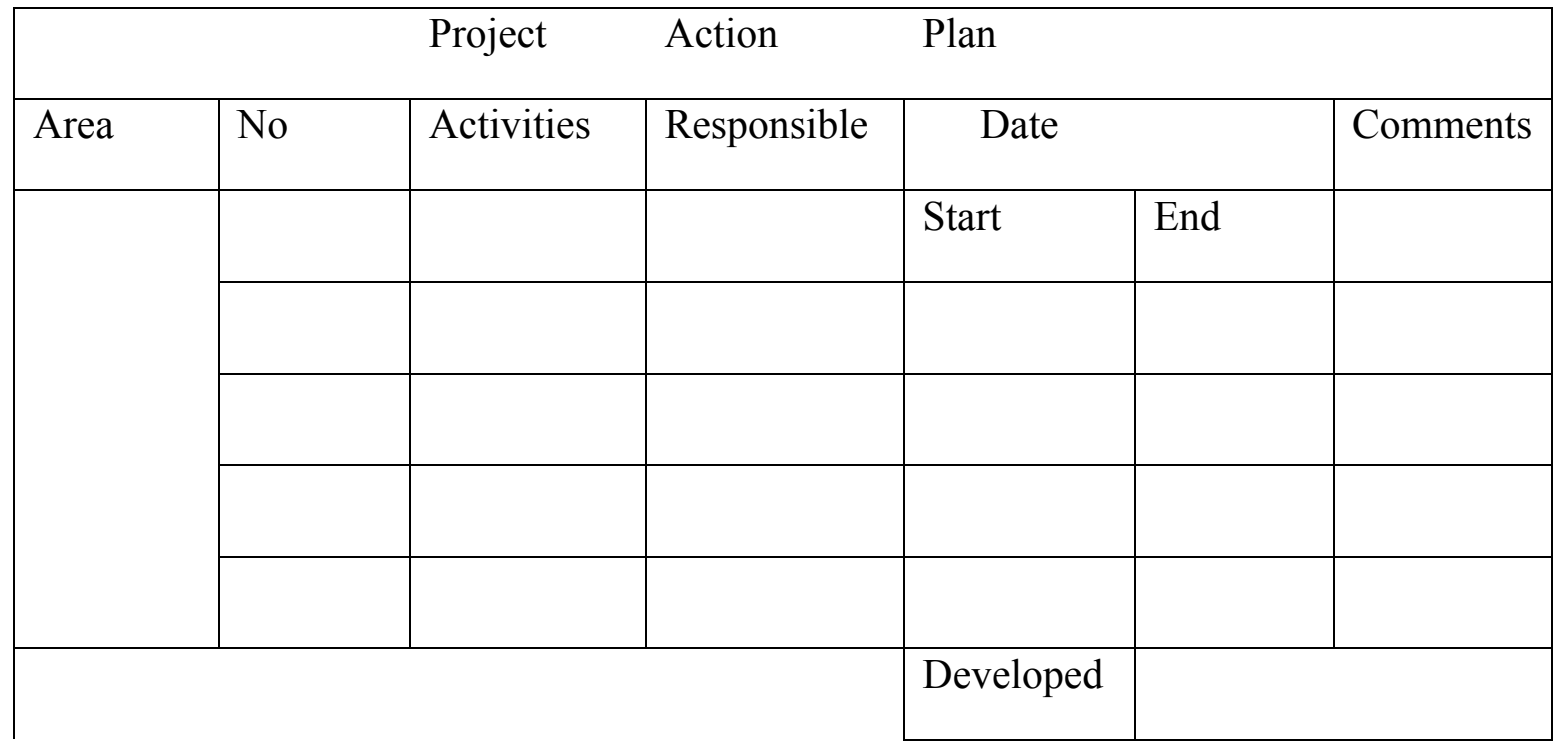




\begin{tabular}{|l|l|l|}
\hline & by & \\
\hline & & \\
\cline { 2 - 4 } & Supervisor & \\
\hline
\end{tabular}

Table B.3 Description of job profile format

\begin{tabular}{|l|l|}
\hline Job & \\
\hline Area & \\
\hline General Description & \\
\hline Specific Description & \\
\hline 1) Daily activities & \\
\hline 2) Periodic activities & \\
& \\
\hline Responsibilities & \\
\hline
\end{tabular}

Table B.4 Performance format

\begin{tabular}{|l|l|l|l|}
\hline $\begin{array}{l}\text { Worker's } \\
\text { name }\end{array}$ & & Job: & \\
& & & \\
\hline
\end{tabular}




\begin{tabular}{|l|l|l|l|l|l|}
\hline $\begin{array}{l}\text { Evaluator's } \\
\text { name }\end{array}$ & \multicolumn{2}{|l|}{ Date: } & \\
\hline $\begin{array}{l}\text { Enowledge } \\
\text { of the job }\end{array}$ & & Very Good & Good & Regular & Bad \\
\hline $\begin{array}{l}\text { Quality of } \\
\text { work }\end{array}$ & & & & & \\
\hline $\begin{array}{l}\text { Quantity of } \\
\text { work }\end{array}$ & & & & & \\
\hline $\begin{array}{l}\text { Working } \\
\text { speed }\end{array}$ & & & & & \\
\hline $\begin{array}{l}\text { Commitment } \\
\text { to work }\end{array}$ & & & & & \\
\hline
\end{tabular}

Table B.5 Analysis of the performance of work format

\begin{tabular}{|l|l|}
\hline Worker's name & \\
\hline Evaluator's & \\
name & \\
\hline Job: & \\
\hline
\end{tabular}




\begin{tabular}{|l|l|}
\hline Date: & \\
\hline Instructions: & \\
Check with YES/NO statements. & \\
\hline 1. Has the ability to respond to an emergency situation & \\
2. Usually offers new ideas & \\
3. Usually proposes and achieves goals & \\
4. Stays calm in difficult situations & \\
\hline Comments: & \\
& \\
\end{tabular}

Table B.6 Performance in relation to work performed format

\begin{tabular}{|l|l|}
\hline Worker's name: & \\
\hline Evaluator's name: & \\
\hline Job: & \\
\hline Date: & \\
\hline Instructions: & \\
Below is a list of statements about job performance. & \\
Please check with an X all that applies. & \\
\hline 1. Efficient use of working area & \\
2. Is very careful about cleaning the equipment & \\
3. Their work is specifically good & \\
4. Working below standards & \\
5. Changes to other activities quickly & \\
\hline Comments: & \\
\hline
\end{tabular}


Table B.7 Questions for supervisor's survey

\begin{tabular}{|c|c|c|c|c|c|c|}
\hline $\begin{array}{l}\text { Question } \\
\text { Type }\end{array}$ & Question & 1 & 2 & 3 & 4 & 5 \\
\hline$p$ & $\begin{array}{l}\text { I need to have my work goals and objectives defined in } \\
\text { advance }\end{array}$ & & & & & \\
\hline$c$ & $\begin{array}{l}\text { It is important to keep all the rules laid down in the } \\
\text { organization }\end{array}$ & & & & & \\
\hline$c$ & $\begin{array}{l}\text { In my work I need to take care of the details of each } \\
\text { activity }\end{array}$ & & & & & \\
\hline$e$ & I need to be part of a team in order to do my work & & & & & \\
\hline$p$ & $\begin{array}{l}\text { I need to analyze different alternatives for the same } \\
\text { scenario }\end{array}$ & & & & & \\
\hline$c$ & $\begin{array}{l}\text { It is very important to continuously check the } \\
\text { appropriate course of activities }\end{array}$ & & & & & \\
\hline$t$ & $\begin{array}{l}\text { It is important to know what other skills the people } \\
\text { have }\end{array}$ & & & & & \\
\hline$e$ & $\begin{array}{l}\text { In order to do my job, I need to follow specific } \\
\text { instructions }\end{array}$ & & & & & \\
\hline e & $\begin{array}{l}\text { It is important to have experience in order to perform } \\
\text { this job properly }\end{array}$ & & & & & \\
\hline c & $\begin{array}{l}\text { I need to make judgments on the activities of the } \\
\text { company }\end{array}$ & & & & & \\
\hline$t$ & $\begin{array}{l}\text { It is important to increase the learning capacity of } \\
\text { people }\end{array}$ & & & & & \\
\hline$p$ & It is important to have flexibly with the working group & & & & & \\
\hline$p$ & $\begin{array}{l}\text { In order to do my work it is necessary to update the } \\
\text { programs continuously }\end{array}$ & & & & & \\
\hline$c$ & I need to evaluate the performance of people who are & & & & & \\
\hline
\end{tabular}




\begin{tabular}{|c|l|l|l|l|l|}
\hline & under my charge & & & & \\
\hline$t$ & It is important for the company to have training & & & & \\
\hline$e$ & $\begin{array}{l}\text { It is important to know the job formats established by } \\
\text { the company }\end{array}$ & & & & \\
\hline$t$ & It is important to learn new ways to perform an activity & & & \\
\hline$p$ & I need to manage the resources of my office & & & \\
\hline$p$ & It is necessary to strengthen the activities of employees & & & \\
\hline$e$ & I need to put into practice new ideas when I do my work & & & & \\
\hline
\end{tabular}




\section{APPENDIX C}

\section{C.1 Meta-Heuristic Procedure}

The meta-heuristic proposed is summarized as follows:

1. Run script MET (MET contains the parameters of the Meta-Heuristic algorithm) (see files in CD attach).

Table C.1 Scrip for MET (parameters)

\begin{tabular}{|l|l|}
\hline Parameters: & Description \\
\hline Itee & $\begin{array}{l}\text { Number of iterations (repeats the modified and original } \\
\text { greedy algorithm for a user-defined number of iterations). }\end{array}$ \\
\hline Itei & $\begin{array}{l}\text { Number of iterations (internal) (select an activity in order to } \\
\text { find the activity that has a minimum value within restriction } \\
\text { ret and retl1). }\end{array}$ \\
\hline pry & $\begin{array}{l}\text { Priority percentage (if p= 10\%, it means that } 10 \% \text { of the } \\
\text { time the greedy algorithm will be used and } 90 \% \text { of the time } \\
\text { the modified algorithm will be used to select the next item) }\end{array}$ \\
\hline ret & $\begin{array}{l}\text { Restriction percentage to reduce the magnitude of the } \\
\text { maximum rate in order to choose the next available } \\
\text { activities (the variable will be picked randomly) at level } 0\end{array}$ \\
\hline retl1 & $\begin{array}{l}\text { Restriction percentage to reduce the magnitude of the } \\
\text { maximum rate in order to choose the next available } \\
\text { activities (the variable will be picked randomly) at level } 1 \text { to } \\
n\end{array}$ \\
\hline
\end{tabular}




\begin{tabular}{|c|c|c|}
\hline Example: & 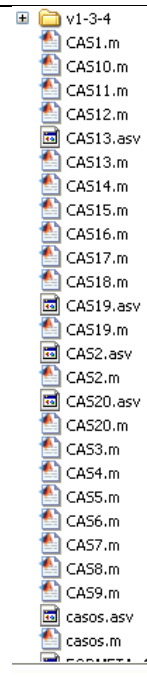 & $\begin{array}{r}\text { P> MET } \\
\text { itee }= \\
10 \\
\text { itei = } \\
10 \\
\text { pry }= \\
10 \\
\text { ret = } \\
1 \\
\text { ret11 = } \\
1\end{array}$ \\
\hline
\end{tabular}

2. Run Script CAS\# (CAS\# contains the data for cas \# n)

Table C.2 Scrip for CAS (data)

\begin{tabular}{|c|c|}
\hline Data & Description \\
\hline aor & $\begin{array}{l}\text { Table of time of each activity with complexity and compatibility factors } \\
\qquad \text { aor }[i, j] \rightarrow \text { i= activity, } \mathrm{j}=\text { group }\end{array}$ \\
\hline $\mathrm{b}$ & Capacity of worker $\mathrm{j}$ \\
\hline $\mathrm{n}$ & Number of groups \\
\hline $\mathrm{m}$ & Number of activities \\
\hline $\mathrm{ns}$ & Number of supervisors \\
\hline $\mathrm{nm}$ & Number of managers \\
\hline ctsor & Cost of supervisor $[1 \ldots \mathrm{ns}]$ \\
\hline cpsor & Capacity of supervisor $[1 \ldots \mathrm{ns}]$ \\
\hline tfac & $\begin{array}{l}\text { Value of factors (planning, execution, training, control) of supervisors for } \\
\text { each worker }[1 \ldots \mathrm{n}]\end{array}$ \\
\hline ctmor & Cost of manager $[1 \ldots \mathrm{nm}]$ \\
\hline
\end{tabular}




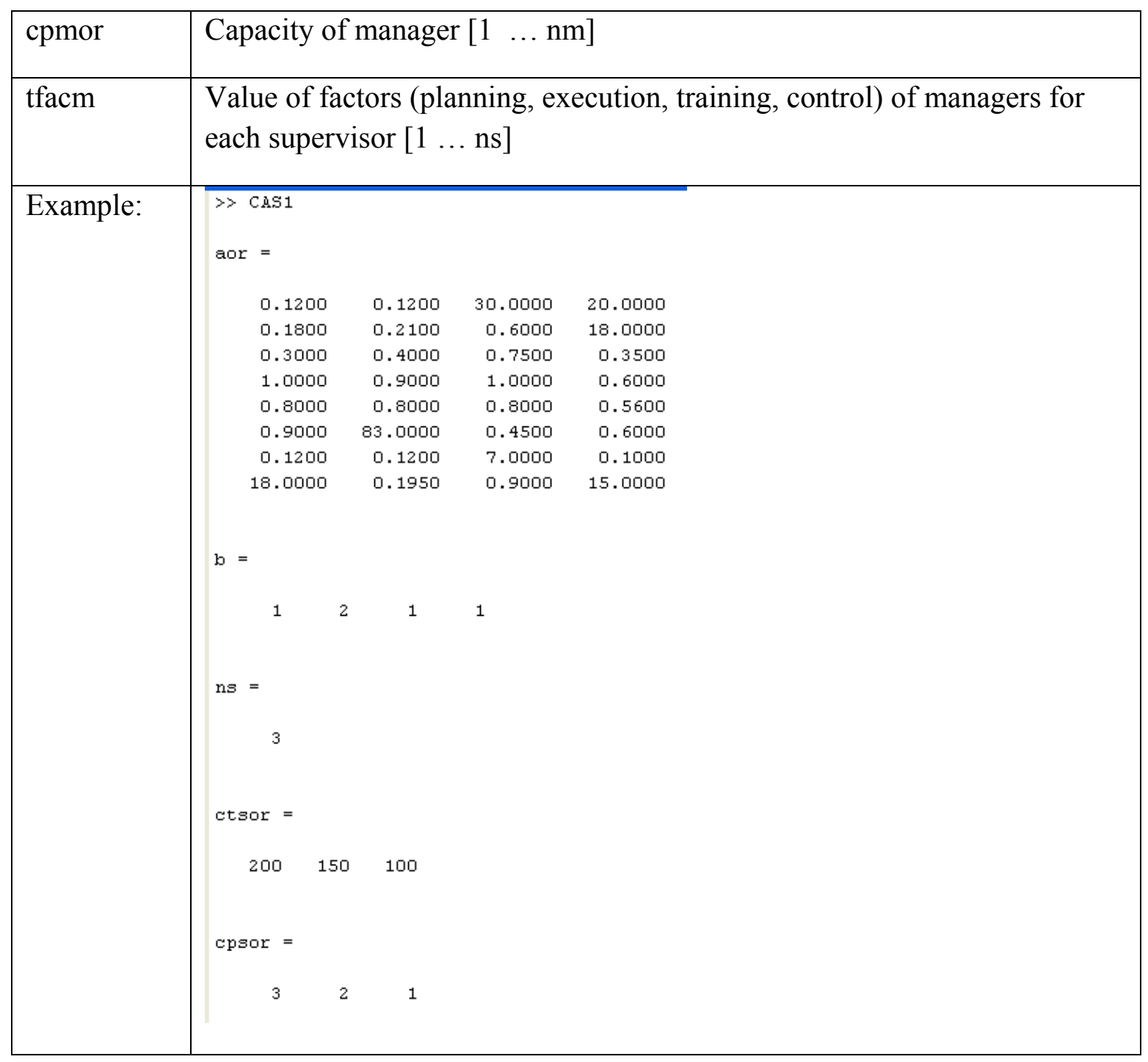

3. Run script L0 (level 0)

Table C.3 Scrip for L0 (level 0)

\begin{tabular}{|l|l|}
\hline Step: & Script: \\
\hline $\begin{array}{l}\text { Reset variables } \\
\text { yopt }(\mathrm{i}, \mathrm{j})=\text { Assign activities (i) to groups } \\
\text { (j) }\end{array}$ & for $\mathrm{j}=1: \mathrm{m}$ \\
$\mathrm{cW}=$ assign time to each group & for $\mathrm{i}=1: \mathrm{n}$ \\
$\begin{array}{l}\text { (y2, u, gopt) : auxiliary variables for the } \\
\text { meta-heuristic }\end{array}$ & \multicolumn{1}{c|}{$\operatorname{yopt}(\mathrm{i}, \mathrm{j})=0 ;$} \\
& end \\
\hline
\end{tabular}




\begin{tabular}{|c|c|}
\hline & end \\
\hline $\begin{array}{l}\text { Set iteration } \mathrm{k} \\
\text { Itee }=\text { number of iterations }\end{array}$ & $\begin{array}{l}\text { for } \mathrm{k}=1 \text { :itee } \\
{[\ldots]} \\
\text { end }\end{array}$ \\
\hline $\begin{array}{l}\text { Find activity with minimum procesing } \\
\text { time }\end{array}$ & $\begin{array}{l}\text { for } i=1: n \\
\qquad \begin{array}{l}\text { if } a(z, j)>a(i, j) \\
\text { else }\end{array} \\
\text { end } \\
\text { end } \\
\text { men }=a(z, j)\end{array}$ \\
\hline Generate a random number between 1-100 & $\mathrm{PR}=\operatorname{randi}(100)$ \\
\hline $\begin{array}{l}\text { If } \mathrm{PR}<=\text { pry, the solution approach will } \\
\text { choose the greedy algorithm from the } \\
\text { available list of activities (this list contains } \\
\text { all activities that can be scheduled for any } \\
\text { group j) }\end{array}$ & $\begin{array}{l}\text { if } \mathrm{PR}<=\text { pry } \\
\% \text { heuristic solution } \\
\mathrm{cw}=\mathrm{cw}+\mathrm{a}(\mathrm{z}, \mathrm{j}) \\
\text { if } \mathrm{cw}<=\mathrm{b}(\mathrm{j}) \\
\mathrm{y} 2(\mathrm{z}, \mathrm{j})=1 \\
\text { for } \mathrm{x}=1: \mathrm{m} \\
\mathrm{a}(\mathrm{z}, \mathrm{x})=\mathrm{tot} \\
\text { end } \\
\text { else } \\
\text { end }\end{array}$ \\
\hline
\end{tabular}




\begin{tabular}{|c|c|}
\hline $\begin{array}{l}\text { Otherwise the solution aproach will } \\
\text { determine the next activity to be scheduled } \\
\text { by selecting an activity at random from the } \\
\text { available list and comparing it to the } \\
\text { minimum value modified by \%r. If the } \\
\text { time is according to this rule, assign the } \\
\text { activities to the group, then assign to the } \\
\text { activities a value = tot (maximum time). } \\
\text { Variable "cw" reduces the number of units } \\
\text { of resource available for group resource j. } \\
\text { This part of the algorithm uses an iteration } \\
\text { "itei" in order to find an activity whose } \\
\text { value is within the minimum value and the } \\
\text { \%rest. }\end{array}$ & $\begin{array}{l}\text { for } \mathrm{f}=1 \text { :itei } \\
\qquad \mathrm{c}=\operatorname{randi}(\mathrm{n}) \text {; } \\
\qquad \mathrm{cw}(\mathrm{c}, \mathrm{j})<=\mathrm{a}(\mathrm{z}, \mathrm{j}) *(1+\mathrm{ret}) \\
\qquad \mathrm{if}(\mathrm{c}, \mathrm{j}) \text {; }<=\mathrm{b}(\mathrm{j}) \\
\qquad \mathrm{y} 2(\mathrm{c}, \mathrm{j})=1 \text {; } \\
\text { selected } \\
\text { assigned value tot if the activity is } \\
\qquad \mathrm{x}=1: \mathrm{c}, \mathrm{x})=\text { tot; } \\
\text { end } \\
\text { else } \\
\text { end }\end{array}$ \\
\hline $\begin{array}{l}\text { Number of activities assigned to each } \\
\text { group (variable "ti") }\end{array}$ & $\begin{array}{l}\% \text { look if the solution is factible with } \\
\text { variable fac } \\
\text { for } j=1: \mathrm{m} \\
\text { for } \mathrm{i}=1: \mathrm{n} \\
\text { fac }(\mathrm{k})=\mathrm{fac}(\mathrm{k})+\mathrm{y} 2(\mathrm{i}, \mathrm{j}) \text {; } \\
\text { end } \\
\text { end }\end{array}$ \\
\hline $\begin{array}{l}\text { Verify if the group has been assigned to } \\
\text { the solution with variable "ta" }\end{array}$ & $\%$ look if the group has one or more \\
\hline
\end{tabular}




\begin{tabular}{|c|c|}
\hline & 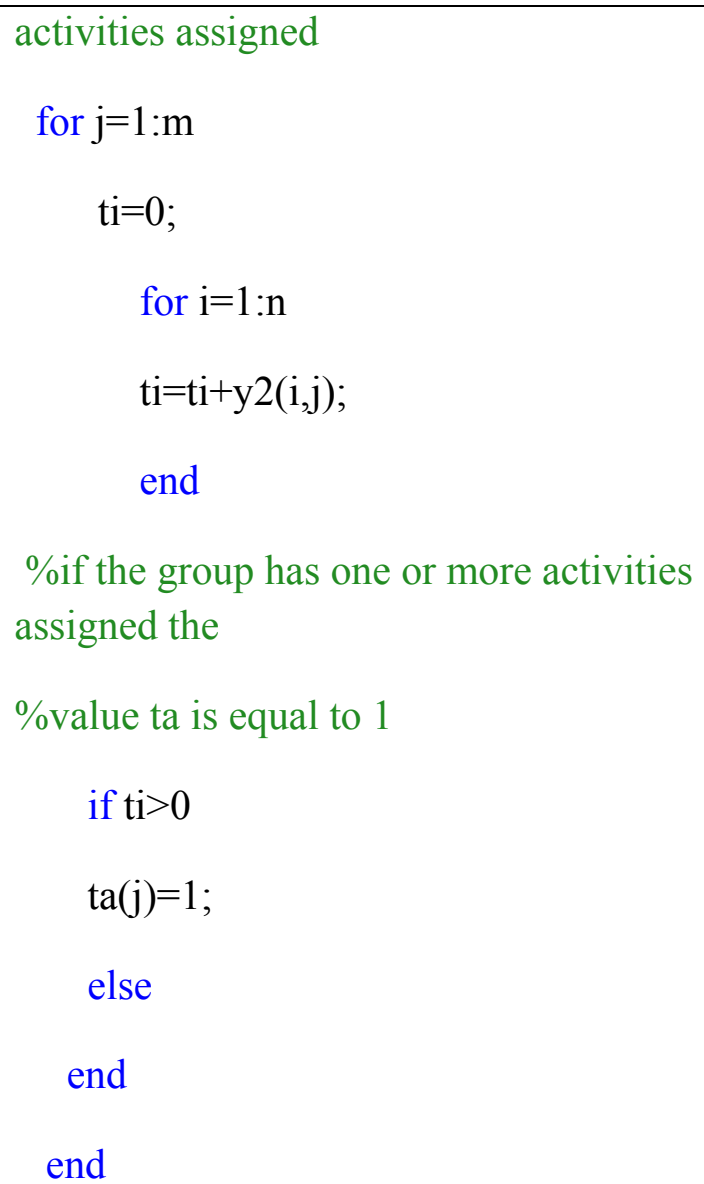 \\
\hline $\begin{array}{l}\text { Compute how many groups were assigned } \\
\text { with variable "opt" }\end{array}$ & $\begin{array}{l}\text { for } \mathrm{j}=1: \mathrm{m} \\
\qquad \operatorname{opt}(\mathrm{k})=\operatorname{opt}(\mathrm{k})+\mathrm{ta}(\mathrm{j}) \\
\text { end }\end{array}$ \\
\hline $\begin{array}{l}\text { If the solution is feasible, variable "yopt" } \\
\text { will have the assigned activities with their } \\
\text { group. } \\
\text { Asign the number of groups selected (if } \\
\text { the solution is feasible) to variable "gopt". } \\
\text { These processes will choose the minimum } \\
\text { groups assigned in order to minimize the } \\
\text { objective function. }\end{array}$ & $\begin{array}{l}\text { \%is solution is feasible, then assign yopt, } \\
\text { gopt in mem }=\mathrm{k} \\
\text { if } \operatorname{fac}(\mathrm{k})==\mathrm{n} \\
\mathrm{u}=\mathrm{u}+1 \text {; } \\
\text { if } \mathrm{u}==1 \\
\quad \mathrm{yopt}=\mathrm{y} 2 \text {; }\end{array}$ \\
\hline
\end{tabular}




\begin{tabular}{|c|c|}
\hline & $\begin{array}{l}\text { gopt }=\text { opt }(\mathrm{k}) \text {; } \\
\text { mem }=\mathrm{k} \text {; } \\
\text { else } \\
\text { if opt }(\mathrm{k})<=\mathrm{opt}(\mathrm{mem}) \\
\text { yopt }=\mathrm{y} 2 \text {; } \\
\text { mept }=\mathrm{opt}(\mathrm{k}) \text {; }=\mathrm{k} ; \\
\text { else } \\
\text { end } \\
\text { end } \\
\text { else } \\
\text { end }\end{array}$ \\
\hline $\begin{array}{l}\text { Variable "tb" has the "best solution" } \\
\text { within the iterations k }\end{array}$ & $\begin{array}{l}\% \text { look for the best solution within the } \\
\text { iterations } \\
\text { for } \mathrm{j}=1: \mathrm{m} \\
\operatorname{tb}(\mathrm{j})=0 \text {; } \\
\text { end } \\
\text { for } \mathrm{j}=1: \mathrm{m} \\
\text { ti2 }=0 \text {; } \\
\quad \text { for } \mathrm{i}=1: \mathrm{n} \\
\text { ti } 2=\operatorname{ti} 2+\operatorname{yopt}(\mathrm{i}, \mathrm{j}) \text {; } \\
\text { end }\end{array}$ \\
\hline
\end{tabular}




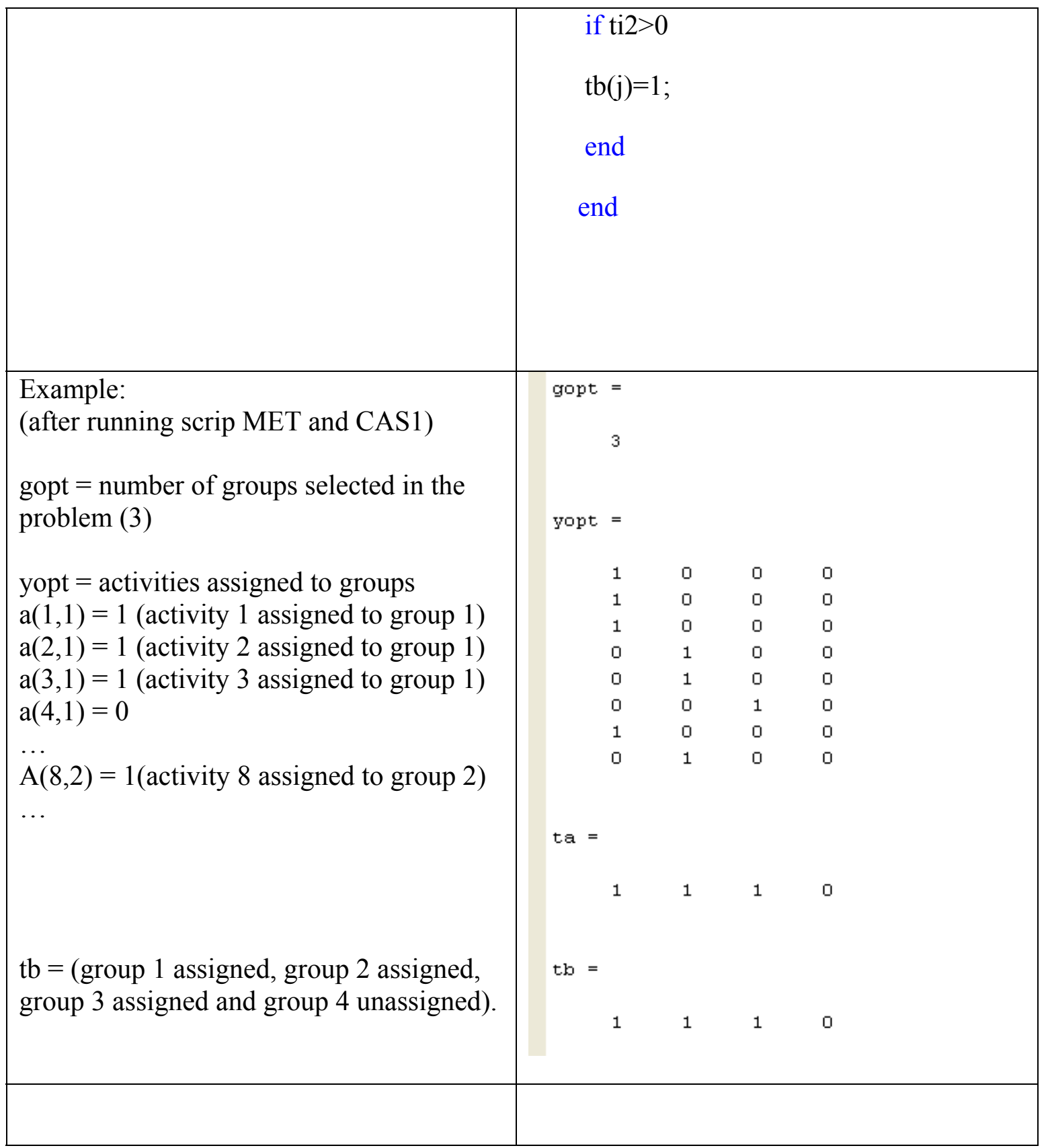

4. Run Script L1 \& L2

Table C.4 Scrip for L1 to Ln (level 1 to $\mathrm{n}$ )

\begin{tabular}{|l|l|}
\hline Step: & Script: \\
\hline Reset variables & \\
\hline
\end{tabular}




\begin{tabular}{|c|c|}
\hline $\begin{array}{l}\text { yopcts }(j)=\text { time assigned to each } \\
\text { supervisor } \\
\text { cws }=\text { assign time to each supervisor } \\
\text { ysptot }(\mathrm{I}, \mathrm{j})=\text { assigned groups to } \\
\text { supervisors }\end{array}$ & $\begin{array}{l}\text { for } \mathrm{j} 0=1: \mathrm{ns} \\
\qquad \operatorname{yopcts}(\mathrm{j} 0)=0 \\
\quad \text { for } \mathrm{i} 0=1: \mathrm{m}\end{array}$ \\
\hline & $\begin{array}{l}\qquad y \operatorname{sptot}(\mathrm{i} 0, \mathrm{j} 0)=0 \\
\text { end } \\
\text { end }\end{array}$ \\
\hline $\begin{array}{l}\text { Set iteration kt } \\
\text { Itee }=\text { number of iterations }\end{array}$ & $\begin{array}{l}\text { for } \mathrm{kt}=1: \text { itee } / 2 \\
{[\ldots]} \\
\text { end }\end{array}$ \\
\hline $\begin{array}{l}\% \text { yspt }=\text { assigning supervisors to } \\
\text { groups } \\
\% \text { calculate rgt and rg } 2 t \\
\% \text { if group is not assigned, then rgt } \\
\text { goes to } 2000 \\
\% \text { assign to each yspt the same value }\end{array}$ & 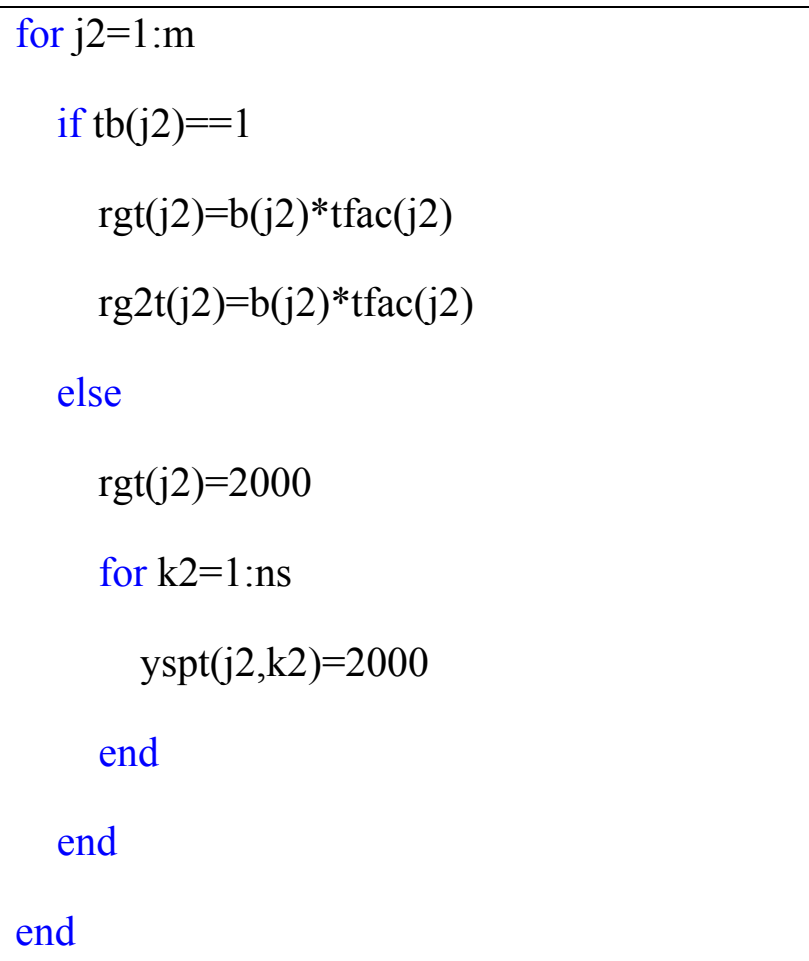 \\
\hline Find supervisor with minimum cost & $\begin{array}{l}\% \text { the algorithm is going to choose between the } \\
\text { assign of }\end{array}$ \\
\hline
\end{tabular}




\begin{tabular}{|c|c|}
\hline & $\begin{array}{l}\% \text { groups based on minimum cost or values } \\
\text { between factor ret } \\
\text { for } \mathrm{d}=1 \text { :ns } \\
\mathrm{wt}=0 \\
\mathrm{cwst}=0 \\
\text { for } \mathrm{j} 3=1 \text { :ns } \\
\text { if } \mathrm{cts}(\mathrm{gs})>\mathrm{cts}(\mathrm{j} 3) \\
\quad \mathrm{gs}=\mathrm{j} 3 \\
\text { end } \\
\text { end } \\
\text { mencts }=\mathrm{cts}(\mathrm{gs})\end{array}$ \\
\hline $\begin{array}{l}\text { Generate a random number between } \\
1-100\end{array}$ & $\mathrm{PRT}=\operatorname{randi}(100)$ \\
\hline $\begin{array}{l}\text { If } \mathrm{PR}<=\text { pry, the solution approach } \\
\text { will choose the greedy algorithm from } \\
\text { the available list of supervisors. } \\
\text { In order to assign groups to } \\
\text { supervisors the greedy algorithm will } \\
\text { look for the minimum processing } \\
\text { time. }\end{array}$ & $\begin{array}{l}\text { if } \mathrm{PRT}<=\text { pry } \\
\text { for } \mathrm{hx}=1: \mathrm{m} \\
\mathrm{gr}=1 \\
\text { for } \mathrm{j} 4=1: \mathrm{m} \\
\text { if } \operatorname{rgt}(\mathrm{gr})>\operatorname{rgt}(\mathrm{j} 4) \\
\quad \mathrm{gr}=\mathrm{j} 4 \\
\text { end } \\
\text { end } \\
\text { menrg }=\operatorname{rgt}(\mathrm{gr})\end{array}$ \\
\hline
\end{tabular}




\begin{tabular}{|c|c|}
\hline & $\begin{array}{l}\% \text { assign group ony if their value is minus than } \\
2000 \\
\% \text { groups with value of } 2000 \text { are alreday } \\
\text { assigned } \\
\text { cwst }=\text { cwst }+\operatorname{rgt}(\mathrm{gr}) \\
\text { if cwst }<=\operatorname{cps}(\mathrm{gs}) \\
\quad \mathrm{yspt}(\mathrm{gr}, \mathrm{gs})=1 \\
\quad \operatorname{rgt}(\mathrm{gr})=2000 \\
\text { else } \\
\text { cts }(\mathrm{gs})=100000 \\
\text { end } \\
\text { end } \\
{\left[\begin{array}{l}\text {... }\end{array}\right.}\end{array}$ \\
\hline $\begin{array}{l}\text { Otherwise the solution approach will } \\
\text { determine the next supervisor to be } \\
\text { scheduled by selecting a supervisor at } \\
\text { random from the available list and } \\
\text { compare with the minimum value } \\
\text { modified by \%r1. If the cost is } \\
\text { according to this rule assign the group } \\
\text { to supervisor, then assign to the group } \\
\text { a value = } 2000 \text { (maximum time). } \\
\text { Variable "cw" reduces the number of } \\
\text { units of resource available for group } \\
\text { resource j. } \\
\text { This part of the algorithm uses an } \\
\text { iteration "itei" in order to find a } \\
\text { supervisor whose value is within the } \\
\text { minimum value and the \%rest } 1\end{array}$ & $\begin{array}{l}\text { Else } \\
\text { ff }=\mathrm{gs} \\
\mathrm{ct}=\mathrm{kc}=1: \mathrm{itei} / 2 \\
\text { if } \mathrm{cts}(\mathrm{ct})<=\mathrm{cts}(\mathrm{gs}) *(1+\mathrm{ret} 11) \\
\mathrm{cf}=\mathrm{ct} \\
\text { end } \\
\text { end } \mathrm{hx}=1: \mathrm{m} \\
\mathrm{gr}=1 \\
\quad \text { for } \mathrm{j} 5=1: \mathrm{m} \\
\quad \text { if } \operatorname{rgt}(\mathrm{gr})>\operatorname{rgt}(\mathrm{j} 5)\end{array}$ \\
\hline
\end{tabular}




\begin{tabular}{|c|c|}
\hline & 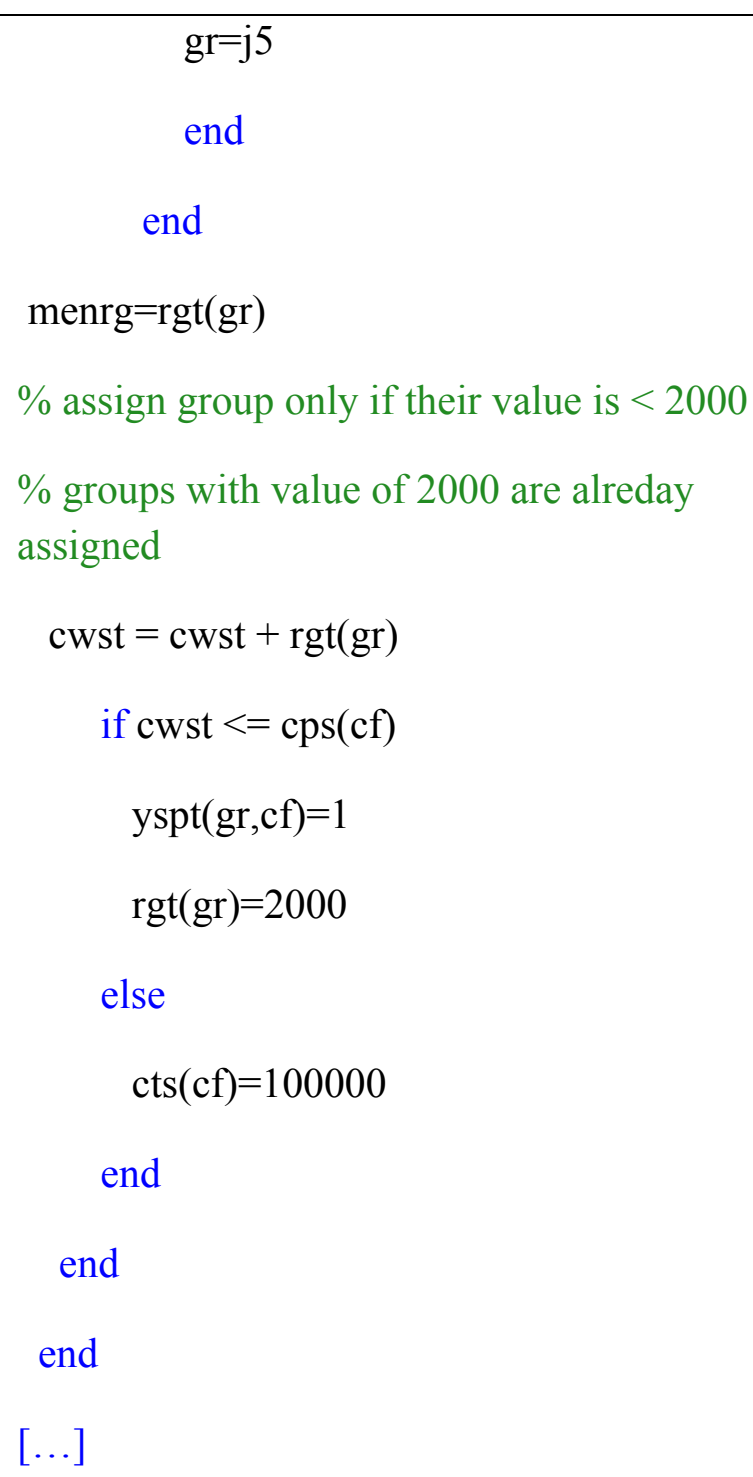 \\
\hline $\begin{array}{l}\text { Compute the time needed of } \\
\text { supervision for each group (variable } \\
\text { "yhrt") }\end{array}$ & $\begin{array}{l}\text { calculate the time needed of supervision } \\
\text { for } \mathrm{j} 11=1: \mathrm{ns} \\
\text { for } \mathrm{j} 21=1: \mathrm{m} \\
\quad \text { if } \operatorname{yspt}(\mathrm{j} 21, \mathrm{j} 11)==1 \\
\operatorname{yhrt}(\mathrm{j} 11)=\operatorname{yhrt}(\mathrm{j} 11)+\operatorname{rg} 2 \mathrm{t}(\mathrm{j} 21) \text {; } \\
\quad \text { end } \\
\text { end } \\
\text { end }\end{array}$ \\
\hline
\end{tabular}




\begin{tabular}{|c|c|}
\hline & $\begin{array}{l}\% \text { calculate the cost related to the supervisors } \\
\text { assigned } \\
\text { costt }=0 \text {; } \\
\text { for } \mathrm{jhr}=1: \mathrm{ns} \\
\quad \text { if } y \text { hrt }(\mathrm{jhr})>0 \\
\quad \text { end } \mathrm{tt}=\operatorname{costt}+\left(\operatorname{cpsor}(\mathrm{jhr})^{*} \operatorname{ctsor}(\mathrm{jhr})\right) \text {; } \\
\text { end }\end{array}$ \\
\hline $\begin{array}{l}\text { Verify feasibility of the solution at } \\
\text { this level (variable "rgtot") }\end{array}$ & $\begin{array}{l}\% \text { if the solution is not feasible assigned a high } \\
\text { cost } \\
\text { rgtot }=0 \\
\text { for } \mathrm{j} 6=1: \mathrm{m} \\
\text { rgtot }=\text { rgtot }+\operatorname{rgt}(\mathrm{j} 6) \\
\text { end } \\
\text { if rgtot }==2000^{*} \mathrm{~m} \\
\quad \text { solf }=\text { 'FACTIBLE LEVEL' } \\
\quad \mathrm{wt}=0 \\
\text { else } \\
\text { solf }=\text { 'NO FACTIBLE LEVEL1' } \\
\mathrm{wt}=1 \\
\text { costt }=100000 \\
\text { end }\end{array}$ \\
\hline
\end{tabular}




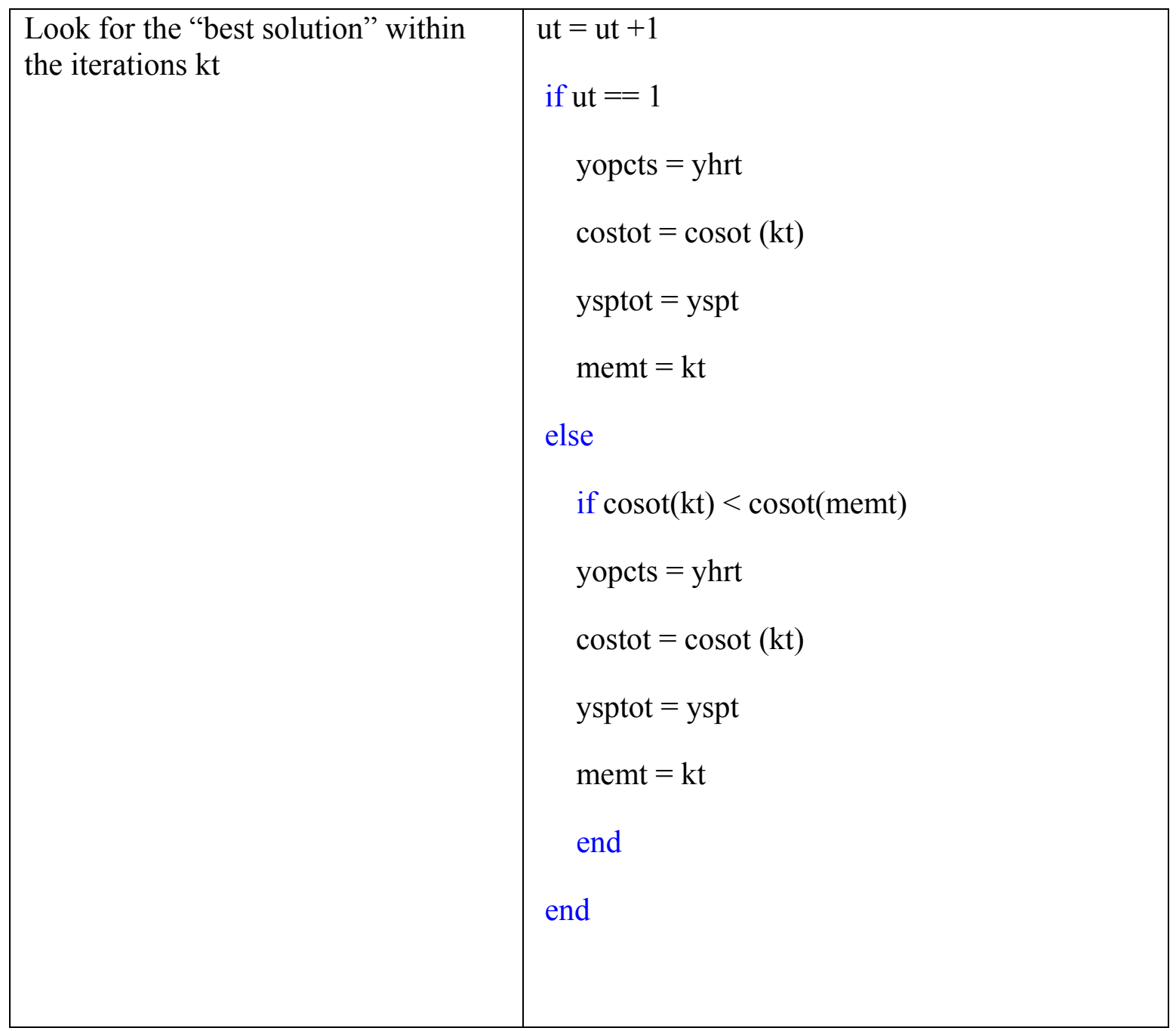




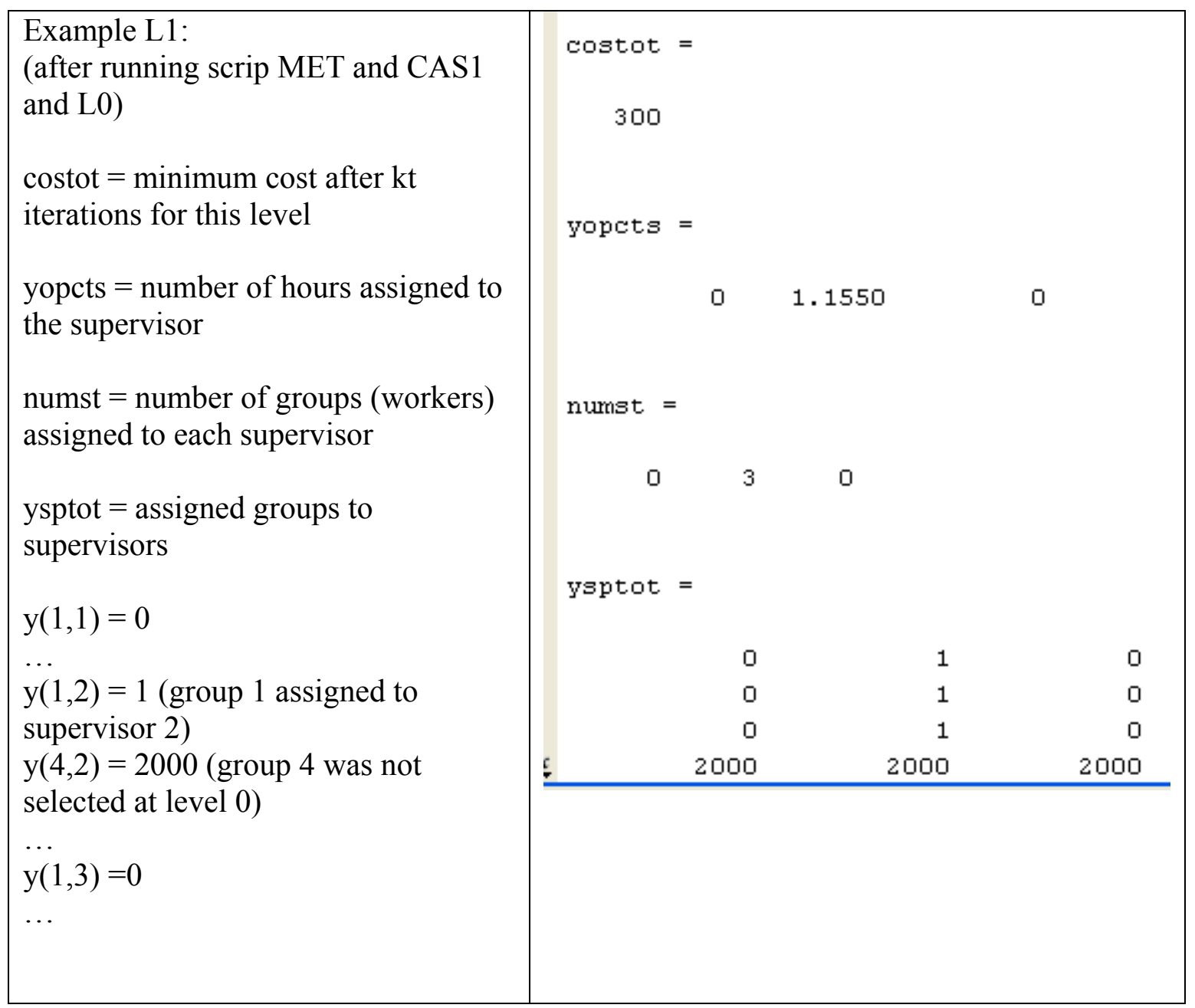




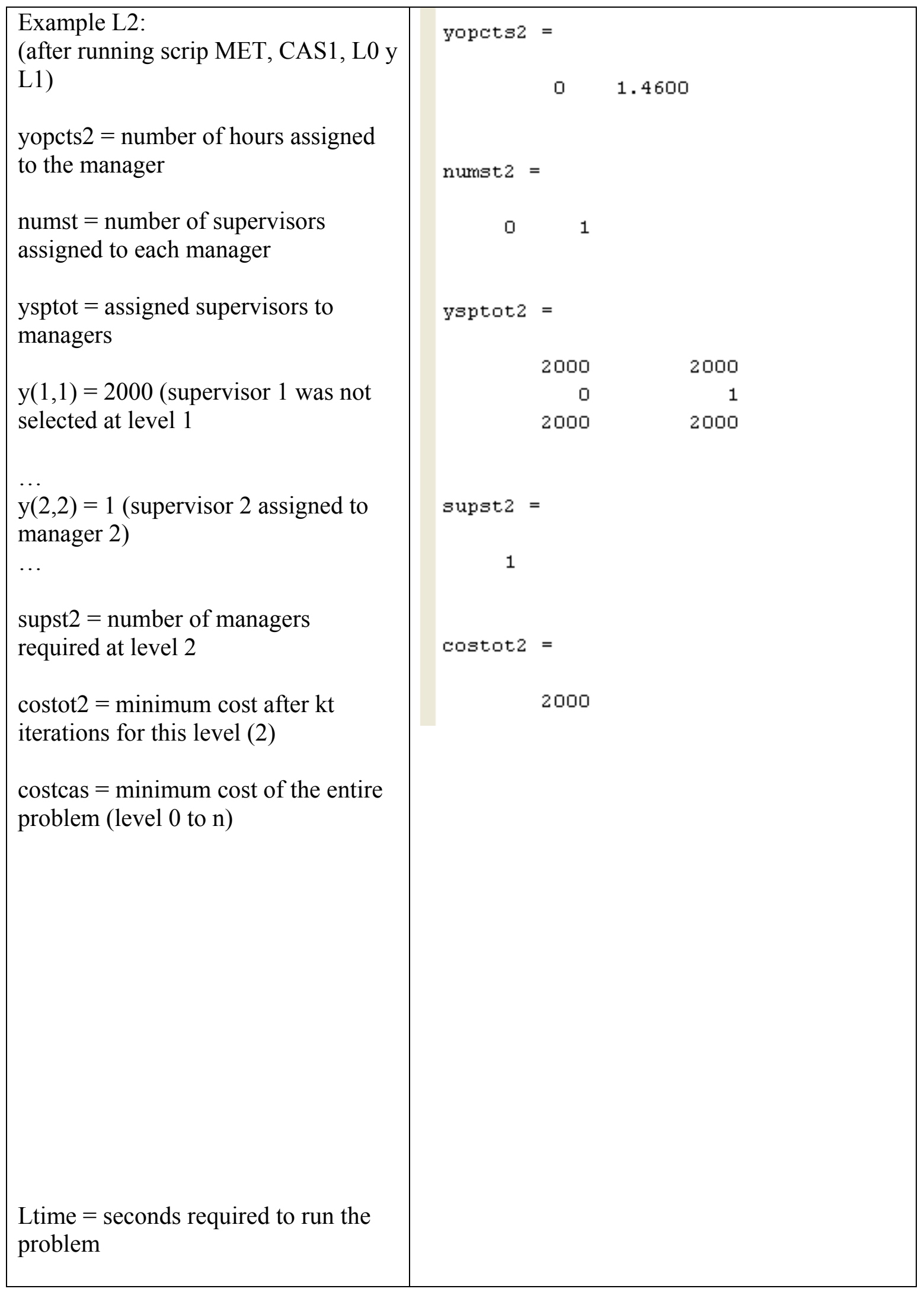




$\left|\begin{array}{c|c|}\text { costcas }= \\ 2303 \\ \text { Elapsed time is } 0.309355 \text { seconds. } \\ \text { L2tim }= \\ 0 \\ \text { L2tim }= \\ 0.3094 \\ \text { Ltime }= \\ 0.9231 \\ 0\end{array}\right|$


C.2 Script (matlab) for heuristic (greedy algorithm) at level 0

Let $J$ be the set of workstations, and let $a_{i j}$ be the modified procesing time of task $i$ with respect to workstation $j$ (including complexity and compatibility factors).

Let $n, m$ be the number of tasks and the number of workstations.

Let tot be the maximum processing time for $a_{i j}$ once the task is assigned to a workstation.

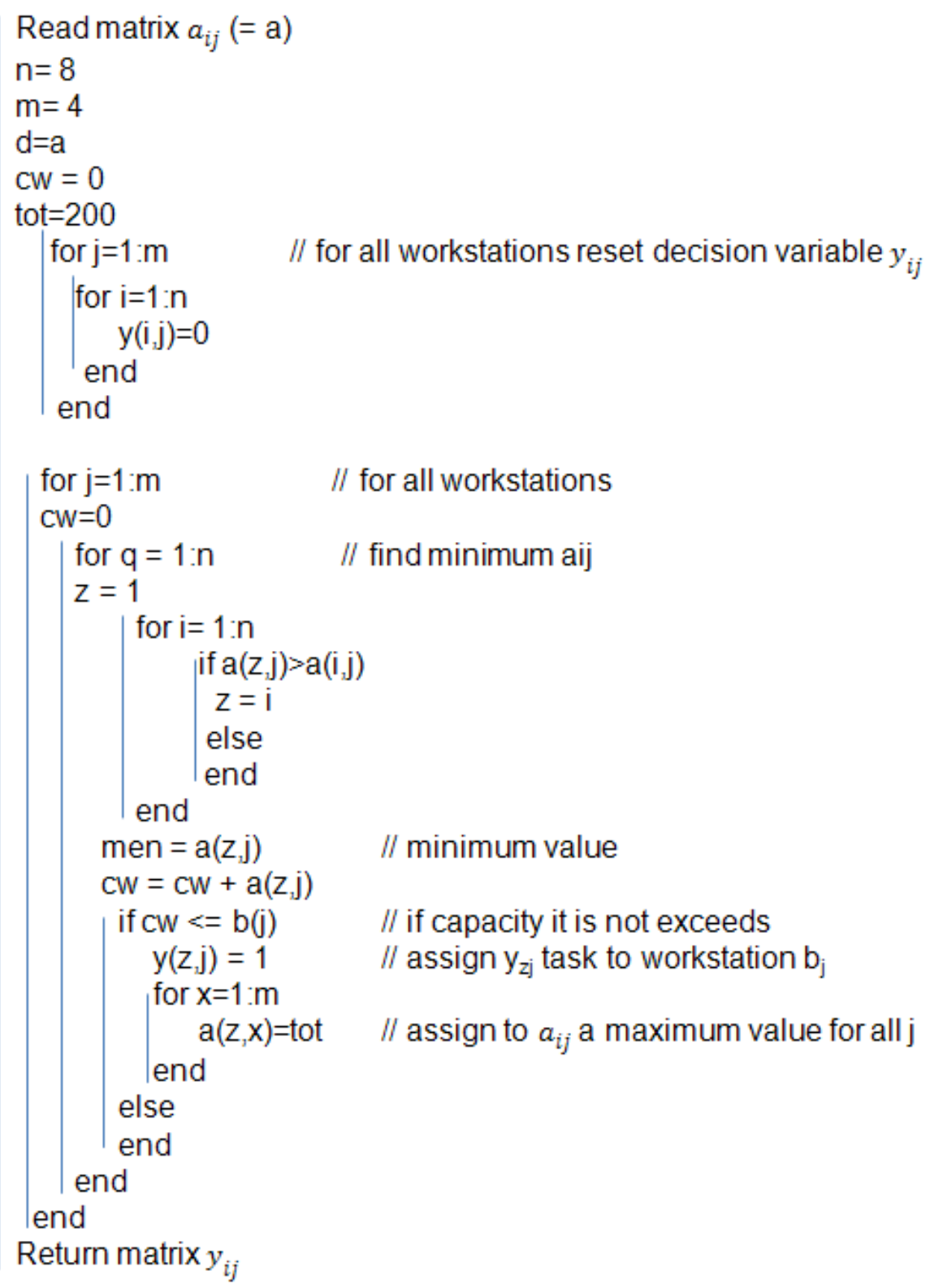


C.3 Script (matlab) for heuristic (greedy algorithm) at level 1 to $\mathrm{n}$

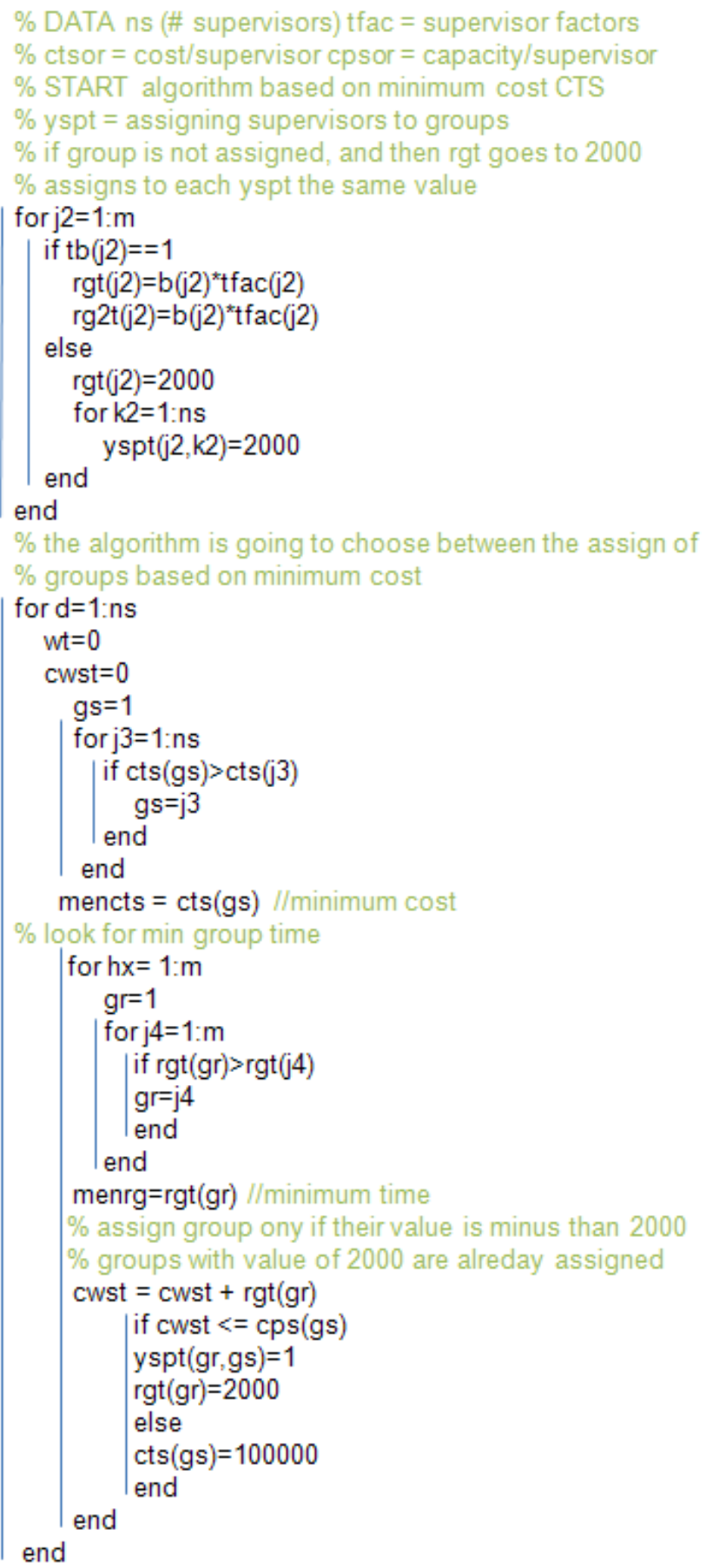




\section{JESÚS A. MENA}

Born, Chihuahua, Chih, México

1984-1988

B.A., Industrial Engineering Chihuahua Institute of Technology

Chihuahua, Chih, México

1989-1990

M.S., Manufacturing Systems

Monterrey Institute of Technology

Monterrey, NL, México

1991-2011

Full Time Professor

Monterrey Institute of Technology

Campus Chihuahua

Chihuahua, Chih, México

2005-2007

Teaching Assistant

Florida International University

Miami, Florida

Doctoral Candidate in Industrial and Systems Engineering Florida International University Miami, Florida 